\title{
Aplicação de Marcadores Orgânicos Moleculares em Estudos Oceanográficos e Paleoceanográficos: \\ Estudo de Caso na Margem Continental Superior do Sudeste do Brasil
}

Tese apresentada ao Instituto Oceanográfico da Universidade de São Paulo, como parte dos requisitos para a obtenção do Título de Doutor em Ciências, área de Oceanografia Química e Geológica.

\section{Orientadora:}

Profa. Dra. Márcia Caruso Bícego

Co-orientador

Prof. Dr. Michel Michaelovitch de Mahiques

\section{São Paulo}


Universidade de São Paulo

Instituto Oceanográfico

Aplicação de Marcadores Orgânicos Moleculares

em Estudos Oceanográficos e Paleoceanográficos:

Estudo de Caso na Margem Continental Superior

do Sudeste do Brasil

\section{Rafael André Lourenço}

Tese apresentada ao Instituto Oceanográfico da Universidade de São Paulo, como parte dos requisitos para a obtenção do Título de Doutor em Ciências, área de Oceanografia Química e Geológica.

Aprovada em 1

$\operatorname{Prof}(a)$. Dr(a).

$\operatorname{Prof}(a) \cdot \operatorname{Dr}(a)$.

Prof(a). Dr(a).

Prof(a). Dr(a).

Prof(a). Dr(a). 
As long as you live in this universe, and have a modest talent for science, sooner or later you'll find it. It's already here. It's inside everything. You don't have to leave your planet to find it. In the fabric of space and in the nature of matter, as in a great work of art, there is, written small, the artist's signature.

Sagan, C. - Contact 


\section{Agradecimentos}

Já que essa é a primeira coisa que as pessoas lêem quando pegam uma tese, vamos lá....

Antes de qualquer um, agradeço a minha orientadora, Márcia Caruso Bícego, não só pela orientação nesse trabalho, mas pelas inúmeras oportunidades, viagens, consultorias, embarques e saídas a campo que me proporcionou, por todas as portas que mostrou, por toda a confiança depositada durante esses seis anos de convivência e amizade no LabQom. Eu acho que sou a única pessoa que diz que fazer doutorado foi divertido. Foi mesmo. A Márcia é a pessoa que mais "culpa" tem nisso. Muito Obrigado.

Outra pessoa que merece minha atenção é o Michel Michaelovitch de Mahiques, meu co-orientador, que sempre se mostrou interessado, empolgado e ansioso com os resultados do meu trabalho, sempre dando idéias para melhorar o projeto e a tese.

No puedo olvidarme de agradecer al Antoni Rosell-Melé, mi orientador en el Institut de Ciència i Tecnologia Ambientals de la Universitat Autònoma de Barcelona, por la recepción sin interés, por la disponibilización del laboratorio, por la confiabilidad y ayuda en mi proyecto de doctorat durante los siete "impagables" meses en que estuve por allá. Seguro que el proyecto ha salido de la UAB mejor que ha llegado. i Muchas gracias!

Tem também a Rosalinda Carmela Montone, que tantas oportunidades me proporcionou desde que entrei no IO e que muito faz pela Área de Oceanografia Química e Geológica e pelo LabQom, além de sempre dar o suporte necessário aos alunos habitantes do "cantinho da vadiagem". 
A Satie Taniguchi, ao Lourival Pereira, ao Silvio Sassaki e a Vera Lucia, a equipe que mantém o LabQom em funcionamento, seja conseguindo padrões, mantendo o laboratório em condições de uso, mantendo os cilindros de gases cheios ou conseguindo ratoeiras e vassouras para espantar alguns incautos visitantes de um lugar em que não se pode usar inseticidas, raticidas e nem "gaticidas".

A Ilana Elazari K. C. Wainer pelos dados de TSM e discussão desses dados. (vai que ela aparece na minha banca ... é melhor puxar um pouco o saco!!).

Ao Rolf Roland Weber, coordenador do laboratório e parceiro nas experiências de destilação alcoólica.

Um "salve" para o César de Castro Martins, pela parceria no LabQom, nas consultorias, nas Operações Antárticas, nas corridas de rua, na fila do bandex $e$, principalmente, por me convencer a manter o lema do Keep Walking, de que valia a pena!

Outro "salve" para o Mauricio Antonio C. Coimbra, e para o Denis Albuquerque M. da Silva, pela divulgação mundo afora do que fazemos no LabQom. Os contatos de vocês me deram um ânimo extra na reta final.

A Ju e ao Silvio por estarem sempre dispostos a encarar a fila do bandex e sempre botarem pilha nos impagáveis papos preconceituosos.

Agora chegou à hora da cambada que eleva meu humor no LabQom e no IO ainda que eu as vezes me esforce para diminuir o humor de alguns: Caio "bonitão", Caio "feio", Juliana Aureliano, Juliana Leonel, Aninha, Carolzão, Fernanda, Hiléia, Josilinha da motoquinha (porque se eu escrever Josilão do motocão eu apanho), Fernanda, Bia (vira casaca), Edgar (matadô), Mariana, Mauro e Sandrinha.

Muchas gracias a los becarios del ICTA: Nuria Moraleda, Marina Pascual, Natalia Nuñes, Alfredo Martinez y Saioa Elordui, por la ayuda en el 
laboratorio, con los equipos y por las peleas con los gasis y líquidos para que estuviesen siempre listos.

A Lu, meu "pé de coelho", pela paciência nesses meses finais do trabalho.

Ao povo ainda não citado sem o qual a vida seria menos divertida: Felipe, Zuzo, Nara, Gui, Gi, Cláudio, Dani, Massari, Revi, Liz, Pé, Vanessão, Mari, Rodrigo, Ilaria, Giorgia, Renatinha, Alê, Ana, Bruna, Brasil, Camila, Mark, Daniella, Sabrina, Nathália, Tati, Edu, e todos os outros que, por um apagão cerebral, eu não citei.

Aos meus pais, e aos familiares, por todo o apoio, por tudo.

E claro, se não tiver dinheiro a gente não levanta nem da cama.

A CAPES, pelo apoio financeiro (ainda que seja a merreca que é a bolsa !!)

Ao Proantar, por garantir o "décimo terceiro"

A Márcia e ao César, por todas as consultorias que me passaram! 


\section{Resumo}

Eventos climáticos ocorridos no planeta deixam registros no ambiente, com os quais é possível realizar reconstruções das condições ambientais. No oceano, o destino de grande parte da matéria orgânica é o sedimento; assim o estudo de colunas sedimentares preservadas, testemunhos, fornece um registro de informações sobre os processos biológicos, geológicos e químicos ocorridos no passado e de como esses processos responderam às mudanças ambientais. No presente trabalho foram analisados sedimentos superficiais marinhos ao longo da margem continental superior do Sudeste do Brasil de forma a validar a utilização de marcadores geoquímicos orgânicos na região e foi analisado um testemunho cuja base aponta para 35.000 anos e que engloba importantes eventos climáticos ocorridos no planeta: eventos Heinrich 3, 2 e 1, o Último Máximo Glacial e o evento Younger Dryas, de forma a realizar uma reconstrução paleoceanográfica desse período. Os resultados dos marcadores orgânicos moleculares nas amostras superficiais, quando comparados com outros trabalhos realizados na região, mostraram que os marcadores respondem corretamente aos processos sedimentares na margem continental do Sudeste do Brasil e que a utilização de alquenonas como indicadores de temperatura superficial marinha na região é válida. A análise do testemunho permitiu correlacionar as variações de temperatura da água superficial do mar e variações do nível do mar com o fluxo de material terrígeno para o meio marinho nos últimos 35.000 anos, além de identificar os eventos climáticos citados e verificar a influência desses eventos para a região da margem continental superior do Sudeste do Brasil. Os resultados mostraram uma variação de temperatura superficial marinha de até $4^{\circ} \mathrm{C}$ entre o Último Máximo Glacial e o Holoceno e mostraram que, para a região, não ocorreu a anti-fase térmica entre o Atlântico Norte e o Atlântico Sul citada em diversos trabalhos realizados no Atlântico Sul, durante os eventos climáticos citados.

Palavras Chaves: Marcadores Orgânicos Moleculares, Calibração TSM- $U_{37}^{k^{\prime}}$, Paleoceanografia, Margem continental superior do Sudeste do Brasil. 


\begin{abstract}
Climatic changes produce environmental signatures with which it is possible to reconstruct past environmental conditions. In the ocean, the fate of most of the organic matter is the marine sediment. Sediment core analyses reveal a unique reservoir of biological, chemical and geological information about past processes and how they responded to the environmental changes. In the present work, marine surface sediments from the Southeastern Brazilian Continental Margin were analyzed to verify the efficiency of organic geochemical markers in this area. Sediment core from the Southeastern Brazilian upper slope were also analyzed to carry out a paleoceanographic reconstruction. The core covers a time period of 35,000 years, where important climatic changes occurred, such as the Heinrich events 3, 2 and 1, the LGM, and the Younger Dryas events. Surface sediment results for geochemical markers were comparable with other works developed in the area, efficiently describing the processes that occur there. The alkenone based SST was also comparable with observations from multinational programs, being valid for this area. The core analyses showed correlations between SST and sea level variations with changes in terrestrial organic matter flow to the ocean over the last 35,000 years, allowed the identification of previously mentioned climatic events and the verification of the influence of these events on the Southeastern Brazilian Continental Shelf. Results showed that the SST varied up to $4.5^{\circ} \mathrm{C}$ between the LGM and the Holocene indicating that at this region a thermal antiphasing between southern and northern Atlantic Ocean SST during the last 35,000 years did not occur.
\end{abstract}

Key Words: Molecular Organic Markers, TSM- $U_{37}^{k^{\prime}}$ calibration, Paleoceanography, Southeastern Brazilian Continental Margin. 


\section{Sumário}

Agradecimentos

Resumo

Abstract $\quad$ V

Lista de Tabelas $\quad$ IX

Lista de Figuras $\quad X$

Lista de Equações

Lista de Anexos $\quad$ XII

Lista de Abreviações $\quad$ XIII

Capítulo 1 - Introdução

1.1- Considerações Iniciais

1.2- Marcadores Orgânicos Moleculares como indicadores paleoambientais do Quaternário 2

1.2.1- Alquenonas 4

1.2.2- n-Alcanos 9

1.2.3- Ácidos Graxos 13

1.2.4- Álcoois Graxos 15

1.2.5- Pigmentos - Clorinas 16

1.2.6- Outros Marcadores 18

Capítulo 2-Objetivos 22

2.1- Objetivos Gerais 22

2.2- Objetivos Específicos 22

Capítulo 3 - Área de Estudo 23

3.1- Localização 23

3.2- Aspectos geomorfológicos $\quad 24$ 
3.3- Sedimentação Quaternária 25

3.4- Aspectos oceanográficos 26

$\begin{array}{ll}\text { Capítulo 4 - Materiais e Métodos } & 28\end{array}$

4.1- Coleta das amostras 28

4.2- Preparação das amostras 29

4.3- Metodologia empregada no LabQom - IO USP 30

4.3.1- Equipamentos usados $\quad 30$

4.3.2- Limpeza de vidraria $\quad 30$

4.3.3- Reagentes e padrões $\quad 30$

4.3.4- Tratamento das amostras 31

4.3.5- Condições Cromatográficas para análise dos compostos 33

4.3.5.1- GC-FID Agilent - Primeira fração: Hcs Alifáticos e Alquenonas 33

4.3.5.2- GC-MS Agilent - Segunda fração: Álcoois e Ácidos Graxos 34

4.3.6- Identificação e Quantificação de HCs Alifáticos e Alquenonas 34

4.3.7- Identificação e Quantificação de Álcoois e Ácidos Graxos 35

4.4- Metodologia empregada no ICTA - UAB 36

4.4.1- Equipamentos usados $\quad 36$

4.4.2- Limpeza da vidraria $\quad 37$

4.4.3- Reagentes e padrões $\quad 37$

4.4.4- Tratamento das amostras $\quad 37$

4.4.5- Análise das clorinas 38

4.4.5- Análise das alquenonas $\quad 39$

4.4.7- Identificação e quantificação das alquenonas $\quad 40$

4.5- Controle de qualidade do método 40

4.5.1- Limite de detecção $\quad 40$

4.5.2- Verificação da qualidade do método $\quad 42$

Capítulo 5-Resultados e Discussões $\quad 43$

5.1- Amostras de sedimentos de superfície 43

5.1.1- Temperatura superficial marinho 43

5.1.2- Marcadores de material terrígeno 48

5.1.3- Marcadores de produtividade 54 
5.1.4- Análise estatística dos resultados

5.1.5- Discussão dos resultados das amostras de sedimento de superfície

5.2- Amostras de sedimento do testemunho

64

5.2.1- Datação do testemunho e taxa de sedimentação

64

5.2.2- Temperatura superficial marinha e marcadores terrígenos 65

$\begin{array}{ll}\text { 5.2.3- Marcadores de produtividade } & 71\end{array}$

5.2.4- Marcador de potencial de redução $\quad 75$

5.2.5- Análise estatística dos resultados 76

5.2.5.1- Estágio Isotópico Marinho $3 \quad 80$

5.2.5.2- Estágio Isotópico Marinho 2

5.2.5.3- Estágio Isotópico Marinho 1

Capítulo 6 - Identificação de Eventos Climáticos nos Estágios Isotópicos Marinhos e Ciclicidade da TSM

6.1- No Estágio Isotópico Marinho $3 \quad 91$

6.1.1- Evento Heinrich $3 \quad 91$

6.2- No Estágio Isotópico Marinho 2

6.2.1- Evento Heinrich 2 e Último Máximo Glacial 91

6.2.2- Evento Heinrich $1 \quad 91$

6.2.3- Evento Younger Dryas 92

6.3- No Estágio Isotópico Marinho 1 - Holoceno 92

6.4- Ciclicidade da variação da temperatura 92

6.4- Discussão dos resultados das amostras de sedimento do testemunho 94

$\begin{array}{ll}\text { Capítulo } 7 \text {-Conclusões } & 100\end{array}$

$\begin{array}{ll}\text { Capítulo 8-Bibliografia } & 103\end{array}$ 


\section{Lista de Tabelas}

Tabela 1: Alquenonas e alquenoatos de cadeia longa.

Tabela 2: Fontes características de n-alcanos de origem biológica.

Tabela 3: Interpretação da distribuição de n-alcanos no sedimento.

Tabela 4: Principais ácidos graxos encontrados em plantas superiores.

Tabela 5: Localização de descrição das amostras superficiais.

Tabela 6: Rampa de temperatura do forno para separação de alcanos e alquenonas.

Tabela 7: Rampa de temperatura do forno para separação de álcoois, ácidos e esteróis.

Tabela 8: Relação massa/carga do compostos analisados pelo GC-MS.

Tabela 9: Rampa de temperatura do forno para separação de alquenonas.

Tabela 10: Resultados da extração da amostra de sedimento marinho para cálculo do limite de detecção para hidrocarbonetos alifáticos, alquenonas, esteróis, álcoois e ácidos graxos.

Tabela 11: Resultados dos marcadores orgânicos moleculares e metais no sedimento superficial no Embaiamento de São Paulo.

Tabela 12: Análise estatística dos marcadores geoquímicos nas amostras de superfície ao longo da Plataforma Continental Superior Sudeste do Brasil.

Tabela 13: Datação do Testemunho.

Tabela 14: Correlação estatística de Pearson para o testemunho, da base ao topo.

Tabela 15: Correlação estatística de Pearson para o Estágio Isotópico Marinho 3.

Tabela 16: Correlação estatística de Pearson para o Estágio Isotópico Marinho 2.

Tabela 17: Correlação estatística de Pearson para o Estágio Isotópico Marinho 1. 


\section{Lista de Figuras}

Figura 1: Linearidade entre o índice $U_{37}^{k^{\prime}}$ e a TSM (Prahl e Wakehan, 1987).

Figura 2: Calibração do índice $U_{37}^{k^{\prime}}$ com a média anual de TSM

Figura 3: Biossíntese de alcanos por plantas superiores partindo de ácidos carboxílicos, através de descarboxilação.

Figura 4: Sumário da degradação do fitol e produção de pristano e fitano.

Figura 5: Exemplo de biossíntese de ácidos graxos saturados em plantas superiores.

Figura 6: Biossíntese de álcoois a partir de ácidos graxos. 15

Figura 7: Diagênese da clorofila a. 16

Figura 8: Mapa da Área de estudo. 23

Figura 9: Reação de esterificação de ácidos graxos 32

Figura 10: Esquema de derivatização de álcoois graxos.

Figura 11: Esquema para preparação de diazometano.

Figura 12: Reação de preparação do diazometano.

Figura 13: Variação da TSM $U_{37}^{k^{\prime}}$ ao longo da margem continental superior do

Sudeste do Brasil.

Figura 14: TSM média histórica para a região nos diferentes programas. 46

Figura 15: Relações entre os valores de $U_{37}^{k^{\prime}}$ obtidos a partir das análises das alquenonas e TSM obtidas dos programas multinacionais.

Figura 16: Comparação dos valores de TSM calculados a partir do índice $U_{37}^{k^{\prime}} \mathrm{e}$ os valores de TSM extraídos dos programas multinacionais.

Figura 17: Distribuição do TAR ao longo da margem continental superior do Sudeste do Brasil.

Figura 18: Distribuição do IPC ao longo da margem continental superior do Sudeste do Brasil.

Figura 19: Distribuição de ácidos pesados ao longo da margem continental superior do Sudeste do Brasil.

Figura 20: Distribuição de álcoois pesados ao longo da margem continental superior do Sudeste do Brasil. 
Figura 21: Distribuição da razão $\mathrm{Fe} / \mathrm{Ca}$ ao longo da margem continental 53 superior do Sudeste do Brasil.

Figura 22: Distribuição da razão Ti/Ca ao longo da margem continental superior do Sudeste do Brasil.

Figura 23: Distribuição da somatória de alquenonas ao longo da margem 54 continental superior do Sudeste do Brasil.

Figura 24: Distribuição da concentração de clorinas ao longo da margem continental superior do Sudeste do Brasil.

Figura 25: Distribuição da razão Ba/Al ao longo da margem continental superior 56 do Sudeste do Brasil.

Figura 26: Distribuição da razão $\mathrm{Ba} / \mathrm{Ti}$ ao longo da margem continental superior 56 do Sudeste do Brasil.

Figura 27: Distribuição da razão Ba/Ca ao longo da margem continental superior do Sudeste do Brasil.

Figura 28: Distribuição da razão Al/Ti ao longo da margem continental superior do Sudeste do Brasil.

Figura 29: Distribuição da razão Sr/Ca ao longo da margem continental superior do Sudeste do Brasil.

Figura 30: Dispersão Alumínio x Titânio nas amostras de superfície.

Figura 31: Concentração estimada de clorofila na superfície $\left(\mathrm{mg} \cdot \mathrm{m}^{-3}\right)$ usando o algoritmo OC2v4 Sea WIFS.

Figura 32: Variação da taxa de sedimentação.

Figura 33: Perfil da temperatura superficial marinha e dos marcadores de 67 material terrígeno ao longo do testemunho.

Figura 34: Gráfico de dispersão entre $\mathrm{C}_{\text {org }}$ e $\mathrm{N}_{\text {tot }}$.

Figura 35: Perfil dos marcadores de produtividade ao longo do testemunho.

Figura 36: Dispersão Alumínio x Titânio nas amostras ao longo da coluna 75 sedimentar.

Figura 37: Variação da relação pristano/fitano ao longo do testemunho.

Figura 38: Valores médios dos marcadores geoquímicos orgânicos durante os eventos climáticos

Figura 39: Periodograma. 
Figura 40: Ajuste senoidal da variação da TSM para 3.300 anos.

Figura 41: Curvas de variação relativa do nível do mar (extraída de Klein, 95 2006).

Figura 42: Modelo esquemático para a posição da Corrente do Brasil em 97 diferentes condições climáticas: (A) Presente e MIS 3; (B) MIS 2.

\section{Lista de Equações}

Equação 1: índice $U_{37}^{k}$

Equação 2: índice $U_{37}^{k^{\prime}}$

Equação 3: Relação entre TSM e $U_{37}^{k^{\prime}}$ 7

Equação 4: IPC

Equação 5: TAR

Equação 5: Limite de detecção

\section{Lista de Anexos}

Anexo 1: Espectros de Massa para identificação dos álcoois e ácidos graxos. 126 


\section{Lista de Abreviações}

Corg Carbono orgânico

CB Corrente do Brasil

$\mathrm{C}_{\mathrm{n}} \quad$ Cadeia carbônica contendo $\mathrm{n}$ átomos de cabono

C/N Razão entre quantidade de carbono orgânico e nitrogênio total

DP Desvio padrão

Et Etilado

GC-FID Cromatógrafo a gás - detector por ionização em chama

GC-MS Cromatógrafo a gás -espectrômetro de massa

H1 Evento Heinrich 1

H2 Evento Heinrich 2

H3 Evento Heinrich 3

ICTA-UAB Instituto de Ciências Ambientais - Univ. Autônoma de Barcelona

IPC Índice Preferêncial de Carbono (Carbon Preferential Index)

LabQom Laboratório de Química Orgânica Marinha

LD Limite de Detecção

MCSE Margem Continental Sudeste

Me Metilado

MIS Estágio Isotópico Marinho (Marine Isotopic Stage)

NADW Água de Fundo do Atlântico Norte (Norh Atlantic Deep Water)

Norg Nitrogênio Orgânico

$\mathrm{N}_{\text {tot }} \quad$ Nitrogênio Total

TAR Relação Terrígeno/Aquático entre n-alcanos (Terrigenos/Aquatic Ratio)

TSM Temperatura Superficial Marinha

UMG (LGM) Último Máximo Glacial (Last Glacial Maximum)

YD Younger Dryas 


\section{Capítulo 1}

\section{Introdução}

\subsection{Considerações Iniciais}

O Quaternário é o período geológico mais recente, iniciado há cerca de 2,6 milhões de anos e se extende até o presente. O Quaternário se divide em duas épocas, Pleistoceno e Holoceno, sendo que o Holoceno teve início com o final do evento Younger Dryas há 11,6 mil anos (Grooters et al., 1993). O Holoceno representa o período quente mais recente na escala climática do Quaternário, escala essa que compreende desde períodos frios (glaciais) durante os quais as capas de gelo alcançaram a máxima extensão - até períodos quentes (inter-glaciais) - quando as capas de gelo retrocederam com clima médio semelhante ou pouco mais quente que o período atual. A alta freqüência e amplitude das oscilações climáticas durante o Quaternário fazem dele um período geologicamente distinto. O Quaternário representa um período de grandes e pequenas variações climáticas (variações de até $15^{\circ} \mathrm{C}$ durante a transição glacial - interglacial e variações de $2^{\circ} \mathrm{C}$ no intra-Holoceno). Essas variações deixaram registros no ambiente, com os quais é possível realizar reconstruções das condições ambientais.

Existem várias técnicas para identificar as variações climáticas do passado. As técnicas diferem na sensibilidade, resolução e quão completo são os registros que elas revelam, como por exemplo:

- Evidências Geomorfológicas:

Preservação de linhas de costas, estrias, dunas fosseis, levantamento de linhas de costa, calhas de rios.

- Evidências Biológicas:

Identificação de espécies: pólen, diatomáceas, insetos, moluscos, ostracodes, foraminíferos, radiolários, cocolitoforídeos, corais, vertebrados.

- Evidências Litológicas: 
Distribuição do tamanho das partículas, descrição do sedimento, carbono orgânico, quantificação de isótopos estáveis, marcadores orgânicos moleculares e marcadores inorgânicos.

O presente estudo propõe a análise de marcadores orgânicos moleculares em sedimentos superficiais ao longo da margem continental superior do Sudeste do Brasil, de forma a verificar a validade da aplicação desses marcadores na região. $O$ trabalho visa também verificar as variações ambientais, como variações da temperatura superficial do mar, variações no fluxo de material terrígeno para o meio marinho, variações na linha de costa e identificação de eventos climáticos ocorridos desde o final do Pleistoceno até o presente, através da análise dos marcadores orgânicos moleculares em um testemunho de $204 \mathrm{~cm}$ obtido no talude superior ao norte do Estado de São Paulo, a $374 \mathrm{~m}$ de profundidade.

\subsection{Marcadores Orgânicos Moleculares como indicadores paleoambientais do Quaternário}

Compostos orgânicos de carbono são componentes ubíquos nos oceanos, lagos e rochas sedimentares (Summons, 1993). Direta ou indiretamente esses compostos abastecem todos os processos biogeoquímicos. Diversos tipos de material orgânico, na forma de lipídeos, são encontrados em sedimentos (Brassell, 1993; Cranwell et al., 1987; Hedges e Oades, 1997; Meyers, 1997; Meyers e Ishiwatari, 1993b, Simoneit, 2002; Volkman et al., 1998). A distribuição de compostos lipídicos tem recebido atenção especial porque eles são facilmente extraídos do sedimento e facilmente analisados por métodos cromatográficos e espectrofotométricos corriqueiros (Hedges e Oades, 1997). Muitos lipídios têm fonte orgânica específica e refletem o controle enzimático dos organismos que os produzem. Estudos têm mostrado que muitos organismos têm a capacidade de regular a biossíntese de seus constituintes lipídicos de acordo com as condições ambientais em que estão sujeitos como, por exemplo, variações da temperatura, salinidade e luz (Harwood e Russel, 1984). 
Esse trabalho tem como alvo principal a distribuição espacial e temporal dos marcadores orgânicos moleculares, que são moléculas orgânicas encontradas no ambiente e que podem ser, inequivocadamente, associadas com seus precursores biológicos. Essas moléculas, após biossintetizadas, podem ser incorporadas ao sedimento e preservadas durante os períodos geológicos na forma alterada ou inalterada. Para o presente estudo, serão considerados os marcadores orgânicos moleculares presentes na fração lipídica e que apresentam as características de marcador ideal conforme descrito nos seguintes trabalhos: Brassell (1993); Marlowe (1984); Poynter e Eglinton (1991).

- Marcadores cujos dados possam ser interpretados e relacionados com variações paleoambientais, por exemplo, Temperatura Superficial Marinha TSM.

- Compostos de origem biológica específica, preferencialmente de organismos com nicho ecológico bem definido.

- Derivados de organismos com funções biológicas conhecidas.

- Estáveis à diagênese.

- Com mecanismo de transporte definido, desde a sua produção até seu soterramento no sedimento.

- Compostos que existem largamente distribuídos no espaço e no tempo, para fornecerem informações que possam ser aplicadas de forma geral em diferentes bacias sedimentares e preferencialmente estendidos durante todo um período geológico.

- Os registros dos sinais que os compostos geram devem ser aplicáveis em técnicas quantitativas e de calibração, preferencialmente por técnicas analíticas rotineiras.

Algumas classes de compostos têm potencial ou já são comumentemente aplicados como indicadores ambientais, por exemplo: $n$ alcanos, ácidos carboxílicos, n-alcanols, alquenonas (e alquil alquenoatos correlacionados), alcenos, esteróis, hopanóides, clorinas, tetra-éteres, entre outros. As suas abundâncias e distribuição podem fornecer diferentes tipos de informações, as quais podem ser usadas para resolver ou contribuir com a reconstrução de um regime climático. 
Nessa tese foram analisados os seguintes marcadores orgânicos moleculares: alquenonas, n-alcanos, clorinas, álcoois e ácidos graxos. Outros marcadores como $\delta^{13} \mathrm{C}$ da matéria orgânica total, razão $\mathrm{C} / \mathrm{N}$, suscetibilidade magnética e metais ( $\mathrm{Ba}, \mathrm{Ca}, \mathrm{Sr}, \mathrm{Fe}, \mathrm{Al}, \mathrm{Ti}$ ) foram analisados de forma a complementar os resultados.

\subsubsection{Alquenonas}

Os requerimentos bioquímicos para que os organismos possam sobreviver a uma variação termal e manter uma fluidez constante nas suas membranas celulares têm fornecido muitas respostas para a geoquímica orgânica na determinação de paleotemperaturas. Indicadores geoquímicos de paleotemperaturas podem se basear em propriedades químicas genéricas como, por exemplo, o ponto de fusão de determinadas moléculas orgânicas, nas quais o ponto de fusão é inversamente proporcional ao número de suas insaturações (Meyers, 1997). Como resultado, observa-se que os peixes que vivem em águas mais frias têm uma proporção maior de ácidos graxos poliinsaturados em seu teor total de lipídeos do que os peixes que vivem em águas mais quentes (Farkas \& Csengeri, 1976). Esse fenômeno de aumento do número de insaturações lipídicas com o decréscimo da temperatura, como forma de manter a fluidez nas membranas, é chamado de adaptação homeoviscosa. Contudo, a composição lipídica dos peixes representa normalmente uma soma de ambientes pelos quais os peixes migram e são parcialmente afetados pela dieta. Para que indicadores de temperatura, baseados na bioquímica dos organismos, possam ser úteis para reconstruções paleoceanográficas, eles devem ser baseados em organismos que representem um ambiente conhecido, limitado e que seja relativamente pouco ou nada afetado pela dinâmica da cadeia alimentar. Compostos biossintetizados, indicadores de temperatura, que respondem a essas exigências são conhecidos como alquenonas.

Alquenonas são cetonas com longas cadeias de carbono $\left(\mathrm{C}_{37}, \mathrm{C}_{38}, \mathrm{C}_{39} \mathrm{e}\right.$ $\mathrm{C}_{40}$ ) contendo de 2 a 4 insaturações. As alquenonas são compostos presentes em quase todos os sedimentos oceânicos do planeta, assim como os alquenoatos de alquila. As estruturas das alquenonas, bem como dos 
alquenoatos de alquila são mostrados na Tabela 1, juntamente com a sua nomenclatura segundo a IUPAC. Conhecidas por serem sintetizadas por um número limitado de microalgas haptofitas (ordem das Isochrysidales) podem, em termos orgânicos e geoquímicos, serem consideradas como biomarcadores (Conte et al., 1995; Conte et al.; 1994b; de Leeuw et al., 1980; Marlowe et al., 1984, Volkman et al., 1995, Volkman et al., 1980a). As suas fontes biológicas mais comum nos oceanos e sedimentos contemporâneos são os abundantes e cosmopolitas cocolitoforídeos Emiliania huxleyi (Volkman et al., 1980a; Volkman et al. 1980b). Em baixas latitudes os cocolitoforídeos Gephyrocapsa oceanica podem também ser um contribuidor importante (Volkman et al., 1995). No registro marinho fóssil, E. huxleyi apareceu inicialmente há 270 mil anos, sendo a haptofita marinha dominante há cerca de 70 a 50 mil anos (Flores et al., 1997; Thierstein et. Al. 1977). Contudo, a ocorrência de alquenonas no registro geológico precede o surgimento da E. Huxleyi, como demonstra sua identificação em sedimentos do Eoceno (45 milhões de anos) (de Leeuw et al., 1980; Marlowe, 1984; Volkman et al., 1980b), além de existir um registro seu no Cretáceo datado de 100 milhões de anos (Farrimond et al., 1986). O produtor de alquenonas no período anterior há 270 mil anos não é conhecido, porém, baseado na co-ocorrência de cocolitos e alquenonas, Marlowe (1990) especula que uma espécie de Reticulofenestra possa ser o organismo fonte.

Tabela 1: Alquenonas e alquenoatos de cadeia longa (Me=Metilado, Et=Etilado).

\begin{tabular}{|c|c|c|}
\hline Designação & Nome IUPAC & Notação \\
\hline Alquenonas & & \\
\hline A & heptatriaconta-8E,15E,22E,29E-tetraen-2-ona & $\mathrm{C}_{37: 4}$ \\
\hline B & heptatriaconta-8E,15E,22E-trien-2-ona & $\mathrm{C}_{37: 3}$ \\
\hline C & heptatriaconta-15E,22E-dien-2-ona & $\mathrm{C}_{37: 2}$ \\
\hline D & octatriaconta-9E,16E,23E,30E-tetraen-3-ona & $\mathrm{C}_{38: 4} \mathrm{Et}$ \\
\hline E & octatriaconta-9E,16E,23E,30E-tetraen-2-ona & $\mathrm{C}_{38: 4} \mathrm{Me}$ \\
\hline F & octatriaconta-9E,16E,23E-trien-3-ona & $\mathrm{C}_{38: 3} \mathrm{Et}$ \\
\hline G & octatriaconta-9E,16E,23E-trien-2-ona & $\mathrm{C}_{38: 3} \mathrm{Me}$ \\
\hline H & Octatriaconta-16E,23E-dien-3-ona & $\mathrm{C}_{38: 2} \mathrm{Et}$ \\
\hline I & Octatriaconta-16E,23E-dien-2-ona & $\mathrm{C}_{38: 2} \mathrm{Me}$ \\
\hline
\end{tabular}




\begin{tabular}{|c|c|c|}
\hline $\mathrm{J}$ & nonatriaconta-10E,17E,24E,31E-tetraen-ona & $\mathrm{C}_{39: 4}$ \\
\hline $\mathrm{K}$ & nonatriaconta-10E,17E,24E-trien-ona & $\mathrm{C}_{39: 3}$ \\
\hline $\mathrm{L}$ & nonatriaconta-17E,24E-dien-ona & $\mathrm{C}_{39: 2}$ \\
\hline $\begin{array}{c}\text { Alquenoatos de } \\
\text { Alquila }\end{array}$ & & \\
\hline $\mathrm{M}$ & metil heptatriaconta-7E,14E,21E-trienonato & $\mathrm{C}_{36: 3} \mathrm{OMe}$ \\
\hline $\mathrm{N}$ & metil heptatriaconta-14E,21E-dienonato & $\mathrm{C}_{36: 2} \mathrm{OMe}$ \\
\hline $\mathrm{O}$ & etil heptatriaconta-14E,21E-dienonato & $\mathrm{C}_{36: 2} \mathrm{OEt}$ \\
\hline
\end{tabular}

Desde que foi demonstrado, pela primeira vez, que a abundância dos diferentes tipos de alquenonas varia de maneira sistemática com as variações de temperatura do meio em que foram biossintetizadas (Brassell et al., 1986a; Brassel et al 1986b; Marlowe, 1984), diversos estudos foram realizados para confirmar e calibrar a relação entre as alquenonas e a temperatura. A dependência das alquenonas C37:2 e C37:3 com a temperatura foi confirmada em estudos com cultura de algas, estudos em sedimentos superficiais e em material orgânico particulado na coluna de água (Brassel, 1993; Muller et al., 1998; Prahl et al., 2000; Prahl et al., 1988; Prahl e Wakeham, 1987; RosellMelé et al., 1995a; Sikes e Volkman, 1993; Sikes et al., 1997; Ternois et al., 1997).

$O$ índice $U_{37}^{k}$ (Equação 1) foi inicialmente usado para calcular a porcentagem de alquenonas $C_{37: 2}$ (Brassell et al., 1986b). Estudos subseqüentes com material do Pacífico N.E. e com culturas de algas mostraram uma linearidade ente $U_{37}^{k}$ e a TSM, porém o $C_{37: 4}$ alterava a linearidade da equação de calibração de $U_{37}^{k}$ com a TSM em temperaturas inferiores a $15^{\circ} \mathrm{C}$ (Prahl e Wakehan, 1987).

$$
U_{37}^{K}=\frac{C_{37: 2}}{C_{37: 2}+C_{37: 3}+C_{37: 4}} \quad(\text { Equação 1) }
$$

Uma melhor regressão foi alcançada usando um índice $U_{37}^{k^{\prime}}$ (Equação 2), uma simplificação que não incorpora o $C_{37: 4}$ (Prahl e Wakehan, 1987). Além disso $\circ \mathrm{C}_{37: 4}$ é praticamente inquantificável em sedimentos oceânicos em 
médias e baixas latitudes. Dessa forma, o índice $U_{37}^{k^{\prime}}$ é mais usado, exceto em alguns poucos casos (Bard et al., 2000; Madureira et al., 1997; Rosell-Melé, 1998; Rosell-Melé et al., 1997).

$$
U_{37}^{K^{\prime}}=\frac{C_{37: 2}}{C_{37: 2}+C_{37: 3}} \quad \text { Equação 2) }
$$

A equação de correlação entre o $U_{37}^{k^{\prime}}$ e a TSM (Equação 3) mostrou uma excelente correlação entre 8 e $25^{\circ} \mathrm{C}$, com precisão menor que $0,5^{\circ} \mathrm{C}$ (Fig. 1) (Prahl e Wakehan, 1987).

$$
T S M=30,3 U_{37}^{K^{\prime}}-1,3 \quad \text { (Equação 3) }
$$

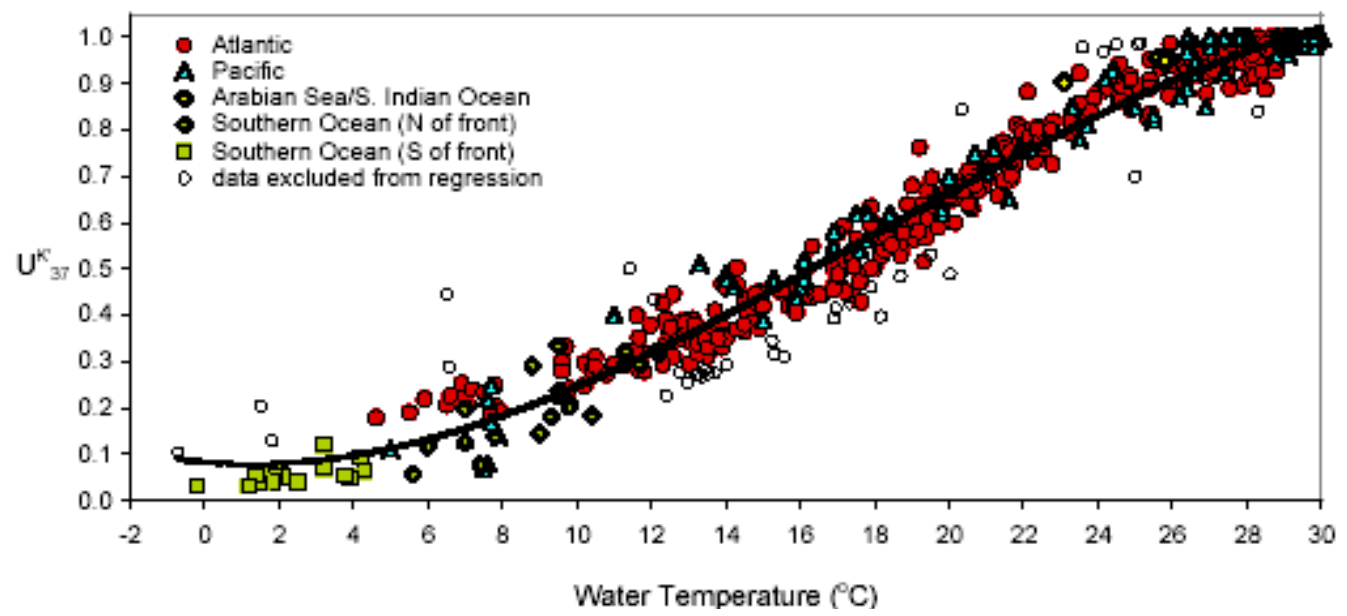

Figura 1: Linearidade entre o índice $U_{37}^{k^{\prime}}$ e a TSM (Prahl e Wakehan, 1987).

Estudos comprovam que os valores de $U_{37}^{k^{\prime}}$ não são significativamente alterados pelos processos de degradação sedimentar (Conte et al., 1992; Freeman e Wakehan, 1991; Madureira et al., 1995; Prahl e Muelhausen, 1989; Teece et al., 1998). O sinal das alquenonas, incorporada ao sedimento, reflete de maneira direta a temperatura da água superficial onde viveu o organismo precursor da alquenona (Prahl et al., 2000).

Rosell-Melé et al., 2001 demonstrou que a análise do índice $U_{37}^{k^{\prime}}$ em amostras padronizadas analisadas por 24 laboratórios gerou resultados 
intercomparáveis dentro dos limites de confiança. Isso sugere que o índice $U_{37}^{k^{\prime}}$ calculado por diferentes grupos científicos é comparável.

Apesar dos resultados positivos citados, os índices das alquenonas não são isentos de incertezas. A calibração inicial de $U_{37}^{k^{\prime}}-$ TSM, resultante da cultura de E. huxleyi (Prahl e Wakeham, 1987), mostrou uma clara linearidade na escala entre 8 e $25^{\circ} \mathrm{C}$. Alguns autores citam a não linearidade da relação entre alquenonas e TSM em temperaturas inferiores a $8^{\circ} \mathrm{C}$ e superiores a $25^{\circ} \mathrm{C}$. (Conte et al., 2001; Pelejero e Calvo, 2003; Rosell-Melé, 1998). Porém tanto a calibração proposta por Prahl e Wakehan (1997) (Figura 1), como a proposta por Muller et al 1998 (Figura 2), mostraram que a linearidade se estende até cerca de $30^{\circ} \mathrm{C}$, e que, próximo a essa temperatura, a calibração é mais precisa que em temperaturas inferiores.

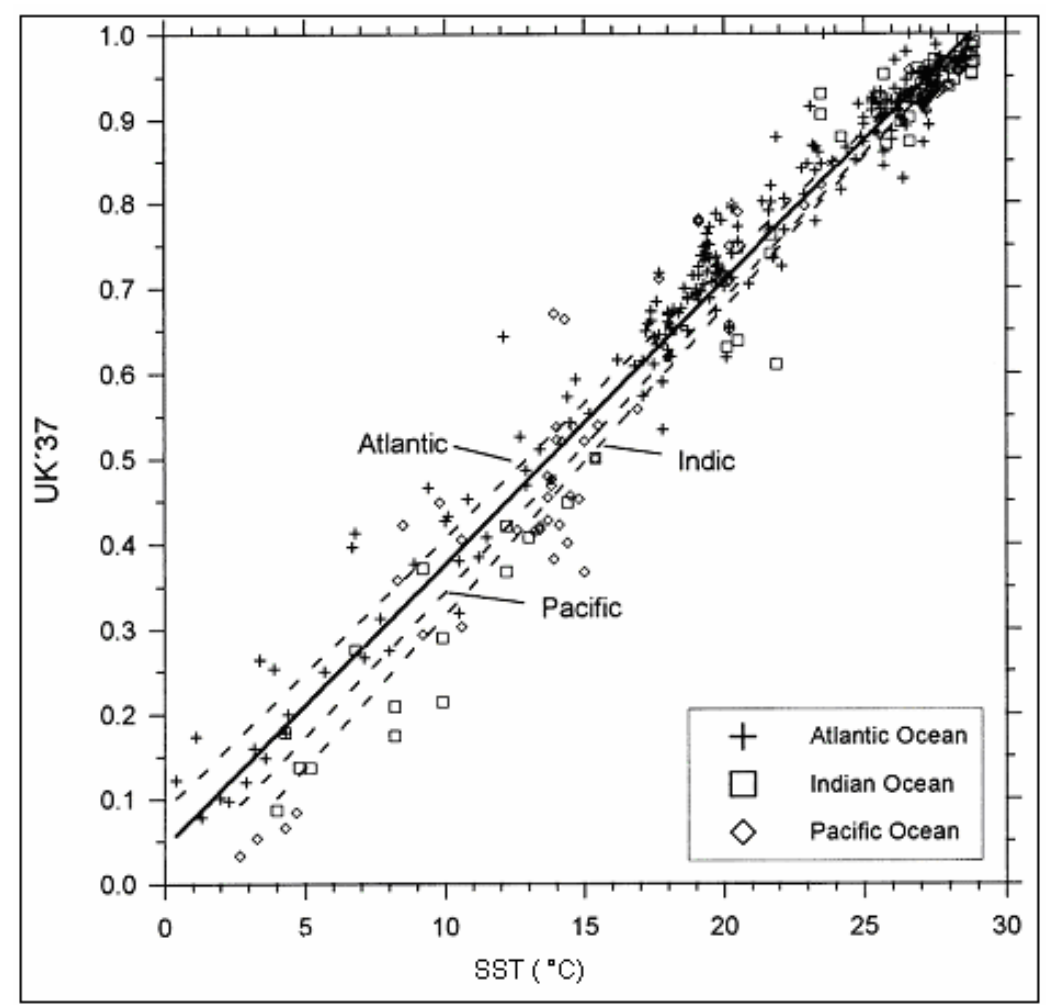

Figura 2: Calibração do índice $U_{37}^{k^{\prime}}$ com a média anual de TSM (Muller et al, 1998).

Estudos utilizando culturas de E. huxleyi e G. oceanica extraídas de diferentes regiões têm produzido diferentes rampas de calibração entre $U_{37}^{k^{\prime}} \mathrm{e}$ 
TSM (Herbert, 2001). Há ainda uma diferença sistemática na calibração usando material particulado da coluna de água (Conte e Eglinton, 1993; Harada et al., 2003, Sicre et al., 2002; Sikes e Sicre, 2002; Sike e Volkman, 1993; Ternois et al., 1998; Ternois et al., 1997; Muller et al., 1998), material obtido da cultura de algas (Prahl e Wakeham, 1987) e sedimentos superficiais (Muller et al., 1998), de forma que os resultados obtidos através de estudos em material particulado fornecem uma temperatura acima da real, particularmente na faixa entre 5 e $15^{\circ} \mathrm{C}$.

Além dos problemas relacionados à não linearidade da equação em temperaturas extremas, algumas regiões também apresentam um desafio na aplicação das equações relacionando alquenonas e TSM, são elas: mares internos (Schulz et al., 2000), áreas costeiras (Conte et al., 1994a) e lagos (Li et al., 1996; Thiel et al., 1997). Além dessas, regiões com altas taxas de sedimentação ou baixa produtividade podem dificultar a utilização de alquenonas como indicadores de TSM, uma vez que a concentração das alquenonas pode se tornar baixa o suficiente para que a quantificação não seja confiável (< 10 ng/área do pico cromatográfico) (Grimalt et al. , 2001).

\subsection{2 n-Alcanos}

n-Alcanos são compostos orgânicos constituídos apenas por carbono e hidrogênio, em cadeia linear e saturados. São encontrados em praticamente todos os sedimentos que contém matéria orgânica, e são os compostos saturados dominantes (Miles, 1994). n-Alcanos são sintetizados por praticamente todos os organismos vivos (Tissot e Welte, 1978).

A distribuição característica de $\mathrm{n}$-alcanos provenientes de algas e plantas superiores difere significativamente. Os n-alcanos sintetizados pelas algas mostram predominância de cadeias com número ímpar de carbono, em geral entre 15 e 17 átomos de carbono (Brassell, 1993; Brassell et al., 1978; Clark e Blumer, 1967; Goutx e Saliot, 1980; Kennicut II e Comet, 1992). Em contraste, n-alcanos sintetizados por plantas terrestres mostram uma forte predominância de cadeias com número ímpar de carbonos em geral entre $23 \mathrm{e}$ 35 átomos de carbono. A predominância de n-alcanos com cadeias carbônicas 
contendo número ímpar de átomos de carbono deriva da biossíntese dos $\mathrm{n}$ alcanos a partir dos ácidos graxos, que têm, predominantemente, número par de átomos de carbono, através de uma descarboxilação enzimática (Fig. 3) (Killops e Killops, 2005).

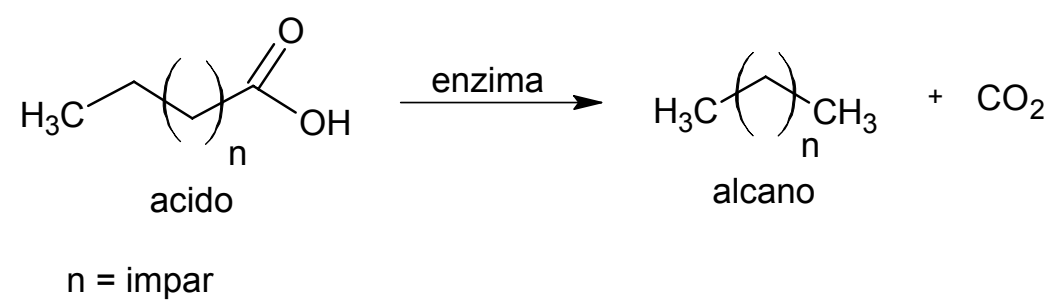

Figura 3: Biossíntese de alcanos por plantas superiores partindo de ácidos carboxílicos, através de descarboxilação.

A predominância relativa entre $n$-alcanos ímpares e pares pode ser expressa numericamente pelo índice preferencial de carbono (IPC):

$$
I P C=\frac{1}{2}\left\langle\frac{C_{25}+C_{27}+C_{29}+C_{31}+C_{33}}{C_{24}+C_{26}+C_{28}+C_{30}+C_{32}}+\frac{C_{25}+C_{27}+C_{29}+C_{31}+C_{33}}{C_{26}+C_{28}+C_{30}+C_{32}+C_{34}}\right\rangle \text { (Equação 4) }
$$

A razão para essa diferenciação é que todas as plantas sintetizam predominantemente $n$-alcanos com cadeias carbônicas ímpares, porém as plantas superiores sintetizam ceras epicuticulares com $\mathrm{n}$-alcanos longos, $\mathrm{C}_{25}$ a $\mathrm{C}_{35}$ para preservar o conteúdo de água nas folhas. As algas sintetizam nalcanos de cadeia curta, $\mathrm{C}_{15}$ a $\mathrm{C}_{21}$ (Hunt, 1979). Bactérias sintetizam n-alcanos de $\mathrm{C}_{10}$ a $\mathrm{C}_{29}$ em quantidades pequenas quando comparadas com outras classes de compostos como os hopanos e isoprenóides (Comet e Eglinton, 1987), porém o sinal dos n-alcanos produzido pelas bactérias é sempre insignificante quando comparado com o sinal das algas ou plantas superiores.

As fontes de n-alcanos, algas ou plantas superiores, podem ser estimadas pela razão TAR (Equação 5); que é a razão entre n-alcanos de cadeias longas e curtas. Contudo os n-alcanos de baixa massa molecular são mais facilmente degradados do que os de alta massa molecular, e a quantificação dessa razão pode ser errônea devido à maior degradação desses n-alcanos mais leves (Cranwell, 1976; Kawamura et al., 1987). 


$$
T A R=\left\langle\frac{C_{27}+C_{29}+C_{31}}{C_{15}+C_{17}+C_{19}}\right\rangle(\text { Equação 5) }
$$

A Tabela 2 resume a distribuição típica de $n$-alcanos nas diferentes fontes biológicas. A Tabela 3 exemplifica como pode ser interpretada a distribuição de $n$-alcanos no sedimento.

Tabela 2: Fontes características de n-alcanos de origem biológica.

\begin{tabular}{|l|l|l|l|l|l|}
\hline Organismo & Ambiente & $\mathbf{N}^{\circ} \mathbf{C}$ Dominante & IPC * & $\begin{array}{l}\mathbf{N}^{\circ} \\
\text { Carbonos }\end{array}$ & Ex de Referência \\
\hline $\begin{array}{l}\text { Bactéria } \\
\text { Fotossintética }\end{array}$ & $\begin{array}{l}\text { Aquático } \\
\text { (pelágico) }\end{array}$ & $\mathrm{C}_{17}$ e $\mathrm{C}_{26}$ & Baixo & $14-29$ & Crawell et al., 1987 \\
\hline $\begin{array}{l}\text { Bactéria não } \\
\text { fotossintética }\end{array}$ & $\begin{array}{l}\text { Aquático } \\
\text { (bentônico) }\end{array}$ & $\mathrm{C}_{17}$ a $\mathrm{C}_{20}$ & $\begin{array}{l}\text { baixo } \\
\text { baixo }\end{array}$ & $\begin{array}{l}15-28 \\
15-29\end{array}$ & Han e Calvin, 1970 \\
\hline Fungo & Aq/Terr & $\mathrm{C}_{29}$ & - & $25-29$ & Yen, 1975 \\
\hline $\begin{array}{l}\text { Algas verdes e } \\
\text { azuis }\end{array}$ & $\begin{array}{l}\text { Aquático } \\
\text { (pelágico) }\end{array}$ & $\mathrm{C}_{17}$ & Alto & $14-19$ & Blumer et al., 1971 \\
\hline Alga & $\begin{array}{l}\text { Aquático } \\
\text { (pelágico) }\end{array}$ & $\mathrm{C}_{17}$ & Alto & $15-21$ & Gelpi et al., 1970 \\
\hline Alga Marrom & $\begin{array}{l}\text { Aquático } \\
\text { (bêntônico) }\end{array}$ & $\mathrm{C}_{15}$ & Baixo & $15-26$ & $\begin{array}{l}\text { Youngblood e } \\
\text { Blumer, 1973 }\end{array}$ \\
\hline Alga Vermelha & $\begin{array}{l}\text { Aquático } \\
\text { (bêntônico) }\end{array}$ & $\mathrm{C}_{17}$ & Baixo & $15-24$ & $\begin{array}{l}\text { Youngblood et al., } \\
1971\end{array}$ \\
\hline Zooplâncton & $\begin{array}{l}\text { Aquático } \\
\text { (pelágico) }\end{array}$ & $\mathrm{C}_{17}, \mathrm{C}_{18}$ e $\mathrm{C}_{24}$ & Baixo & $\begin{array}{l}18-54 \text { ou } \\
20 \text { a } 28\end{array}$ & Crawell et al., 1987 \\
\hline $\begin{array}{l}\text { Plantas } \\
\text { superiores }\end{array}$ & Terrestre & $\mathrm{C}_{27}, \mathrm{C}_{29}$ e $\mathrm{C}_{31}$ & Alto & $15-57$ & Caldicott, 1973 \\
\hline Insetos & Terrestre & $\mathrm{C}_{27}, \mathrm{C}_{29}$ e $\mathrm{C}_{31}$ & Alto & $21-55$ & $\begin{array}{l}\text { Jackson e } \\
\text { Blomquist, 1976 }\end{array}$ \\
\hline
\end{tabular}

Tabela 3: Interpretação da distribuição de n-alcanos no sedimento.

\begin{tabular}{|l|l|l|}
\hline Parâmetro de alcano & Característica & Razão \\
\hline \multirow{4}{*}{$\sum$ n-alcanos } & $\begin{array}{l}\text { Alta abundância } \\
\text { relativa }\end{array}$ & $\begin{array}{l}\text { Fontes abundantes de produtores de n- } \\
\text { alcanos / degradação preferencial de material } \\
\text { mais lábil que n-alcanos }\end{array}$ \\
\cline { 2 - 3 } & $\begin{array}{l}\text { Baixa } \\
\text { abundância } \\
\text { relativa }\end{array}$ & $\begin{array}{l}\text { Poucas fontes de produtores de n-alcanos / } \\
\text { degradação preferencial de n-alcanos }\end{array}$ \\
\hline \multirow{2}{*}{ IPC } & Alto & Predominância de plantas superiores \\
\cline { 2 - 3 } & Baixo & $\begin{array}{l}\text { Poucas plantas superiores, predominância de } \\
\text { algas }\end{array}$ \\
\hline \multirow{2}{*}{ TAR } & Alto & $\begin{array}{l}\text { Plantas superiores relativamente contribuindo } \\
\text { mais ou degradação dos curtos }\end{array}$ \\
\hline \multirow{2}{*}{ Maior abundância de Cn } & Baixo & Algas relativamente contribuindo mais \\
\hline Pristano / Fitano & $\mathrm{C}_{15}$ ou $\mathrm{C}_{17}$ & Dominância de algas \\
\cline { 2 - 3 } & $\mathrm{C}_{27}, \mathrm{C}_{29}, \mathrm{C}_{31}$ & Dominância de planta superiores \\
\hline & Alto & Ambiente oxidante \\
\cline { 2 - 3 } & Baixo & Ambiente Redutor \\
\hline
\end{tabular}


n-Alcanos têm sido extensivamente utilizados como indicadores de fontes de material terrestre ou material marinho no ambiente (Huang et al., 2000; Ikehara et al., 2000; Kawamura, 1995; Ohkouchi et al., 1997; Philip, 1985; Zhao et al., 2003), além disso, eles têm sido usados em ambientes lacustres para verificar alterações nas fontes de matéria orgânica proveniente de algas (incluindo eutrofização) e de efluentes terrestres (Cranwell, 1973; Cranwell et al., 1987; Kawamura et al., 1987; Meyers e Benson, 1988; Meyers e Ishiwatari, 1993b).

Além dos n-alcanos, há uma outra classe de alcanos que merece atenção em estudos oceanográficos, os alcanos isoprenóides. Alcanos isoprenóides são hidrocarbonetos de cadeia ramificada com estruturas molecular comuns, derivados do isopreno $\left(\mathrm{C}_{5} \mathrm{H}_{8}\right)$, um alceno ramificado com cinco átomos de carbono que constitui um dos blocos de construção de cadeias carbônicas favoritos da natureza (Morrison \& Boyd, 1995)

O pristano $(1,6,10,14$ - tetrametil-pentadecano) e o fitano $(2,6,10,14$ tetrametil-hexadecano) são isoprenóides muito utilizados em estudos sobre origem de hidrocarbonetos no meio marinho (Cripps, 1989; Cripps 1992; Green et al. 1992; Bícego et al. 1996). Esses hidrocarbonetos são produzidos a partir da degradação do fitol $\left(\mathrm{C}_{20} \mathrm{H}_{40} \mathrm{O}\right)$ (Figura 4), um álcool abundante na natureza, constituinte da clorofila-a, e a formação de um ou de outro está associada a condições oxidantes (pristano) ou redutoras (fitano), sendo que o pristano é geralmente encontrado em concentrações superiores ao fitano no meio marinho (Cripps, 1989).

Em épocas de ótimo climático, em função do menor gradiente de temperatura entre o equador e os pólos, a circulação termohalina é menos intensa, resultando em menor oxigenação das águas profundas e portanto favorecendo a formação do fitano. Já em épocas frias, o maior gradiente de temperatura entre o equador e os pólos resulta em circulação termohalina mais intensa e maior oxigenação de águas profundas, favorecendo a formação do pristano.

Assim a relação entre eles, pristano/fitano, pode ser um indicativo de variações climáticas e ou de condições oxidantes ou redutoras do meio. 
<smiles>CC(=CCO)CCCC(C)CCCC(C)CCCC(C)C</smiles>

Fitol

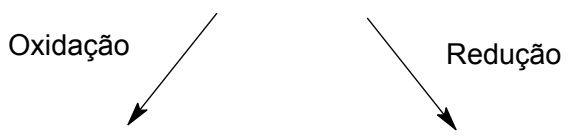<smiles>[R]CC(C)CC(=O)O</smiles><smiles>[R]CC([R])CCCO</smiles><smiles>[R]CC(=C)CCCCCCCCCC(C)CCCC(C)CCCC(C)C</smiles>

Figura 4: Sumário da degradação do fitol e produção de pristano e fitano.

A razão pristano/fitano $<0,6$ indica a degradação do fitol em condições anóxicas, a razão > 3 indica degradação do fitol em condições oxidantes. Além disso a razão pristano/fitano é afetada também pela maturidade do sedimento (Peters e Moldowan, 1993).

\subsection{3 Ácidos Graxos}

Ácidos graxos são compostos amplamente distribuídos em organismos e cumprem diversos papéis, como por exemplo constituintes da membrana celular (fosfolipídios), estoque energético (triglicerídios) e capas protetoras (ceras cuticulares), e são encontrados principalmente na forma esterificada. Mais de 500 ácidos graxos são encontrados em plantas e microorganismos, porém apenas alguns deles de forma abundante, sendo o ácido palmítico $\left(C_{16: 0}\right)$ o mais abundante (Killops e Killops, 2005). Em plantas superiores, sete 


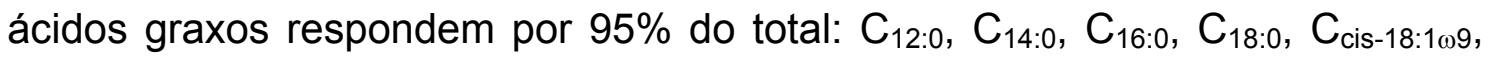

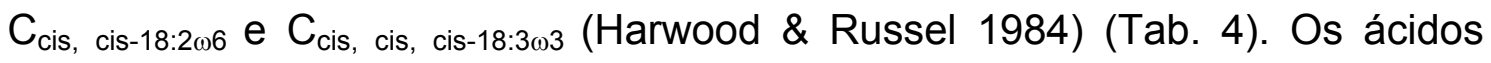
graxos encontrados em algas multicelulares geralmente são similares aos encontrados em plantas superiores. Os 3 ácidos $C_{18}$ insaturados também são freqüentes em algas unicelulares, junto com $C_{16: 4 \omega 3}$ (Johns et al. 1979). Juntamente com os ácidos graxos citados, plantas superiores apresentam ainda ácidos graxos de cadeia longa, entre 24 e 36 átomos de carbono. A biossíntese dos ácidos graxos têm como estrutura de partida o acetil (cadeia de 2 átomos de carbono), que deriva da glucose, na presença de enzimas e coenzimas (Fig. 5). Dessa forma a cadeia carbônica é aumentada de 2 em 2 átomos de carbono, resultando em uma predominância de cadeias contendo número par de átomos de carbono (Harwood \& Russel 1984). Assim, a relação entre ácidos de cadeia carbônica longa e ácidos de cadeia carbônica curta pode ser útil para a determinação da fonte de matéria orgânica para o oceano.

Tabela 4 : Principais ácidos graxos encontrados em plantas superiores.

\begin{tabular}{|l|l|l|}
\hline Nome Comum & Nome IUPAC & Estrutura \\
\hline Ácido Láurico & Ácido Dodecanóico & $\mathrm{CH}_{3}\left(\mathrm{CH}_{2}\right)_{10} \mathrm{COOH}$ \\
\hline Ácido Mistírico & Ácido Tetradecanóico & $\mathrm{CH}_{3}\left(\mathrm{CH}_{2}\right)_{12} \mathrm{COOH}$ \\
\hline Ácido Palmítico & Ácido Hexadecanóico & $\mathrm{CH}_{3}\left(\mathrm{CH}_{2}\right)_{14} \mathrm{COOH}$ \\
\hline Ácido Esteárico & Ácido Octadecanóico & $\mathrm{CH}_{3}\left(\mathrm{CH}_{2}\right)_{16} \mathrm{COOH}$ \\
\hline Ácido Araquídico & Ácido Eicosanóico & $\mathrm{CH}_{3}\left(\mathrm{CH}_{2}\right)_{18} \mathrm{COOH}$ \\
\hline Ácido Oléico & Ácido Octadec-9-enóico & $\mathrm{CH}_{3}\left(\mathrm{CH}_{2}\right)_{7} \mathrm{CH}=\mathrm{CH}\left(\mathrm{CH}_{2}\right)_{7} \mathrm{COOH}$ \\
\hline Ácido Linolêico & Ácido Octadec-9,12-dienóico & $\mathrm{CH}_{3}\left(\mathrm{CH}_{2}\right)_{4} \mathrm{CH}=\mathrm{CHCH}_{2} \mathrm{CH}=\mathrm{CH}(\mathrm{CH})_{7} \mathrm{COOH}$ \\
\hline Ácido Linolênico & Ácido Octadec-9,12,15-trienóico & $\mathrm{CH}_{3} \mathrm{CH}{ }_{2} \mathrm{CH}=\mathrm{CHCH}{ }_{2} \mathrm{CH}=\mathrm{CHCH}{ }_{2} \mathrm{CH}=\mathrm{CH}\left(\mathrm{CH}_{2}\right)_{7} \mathrm{COOH}$ \\
\hline
\end{tabular}




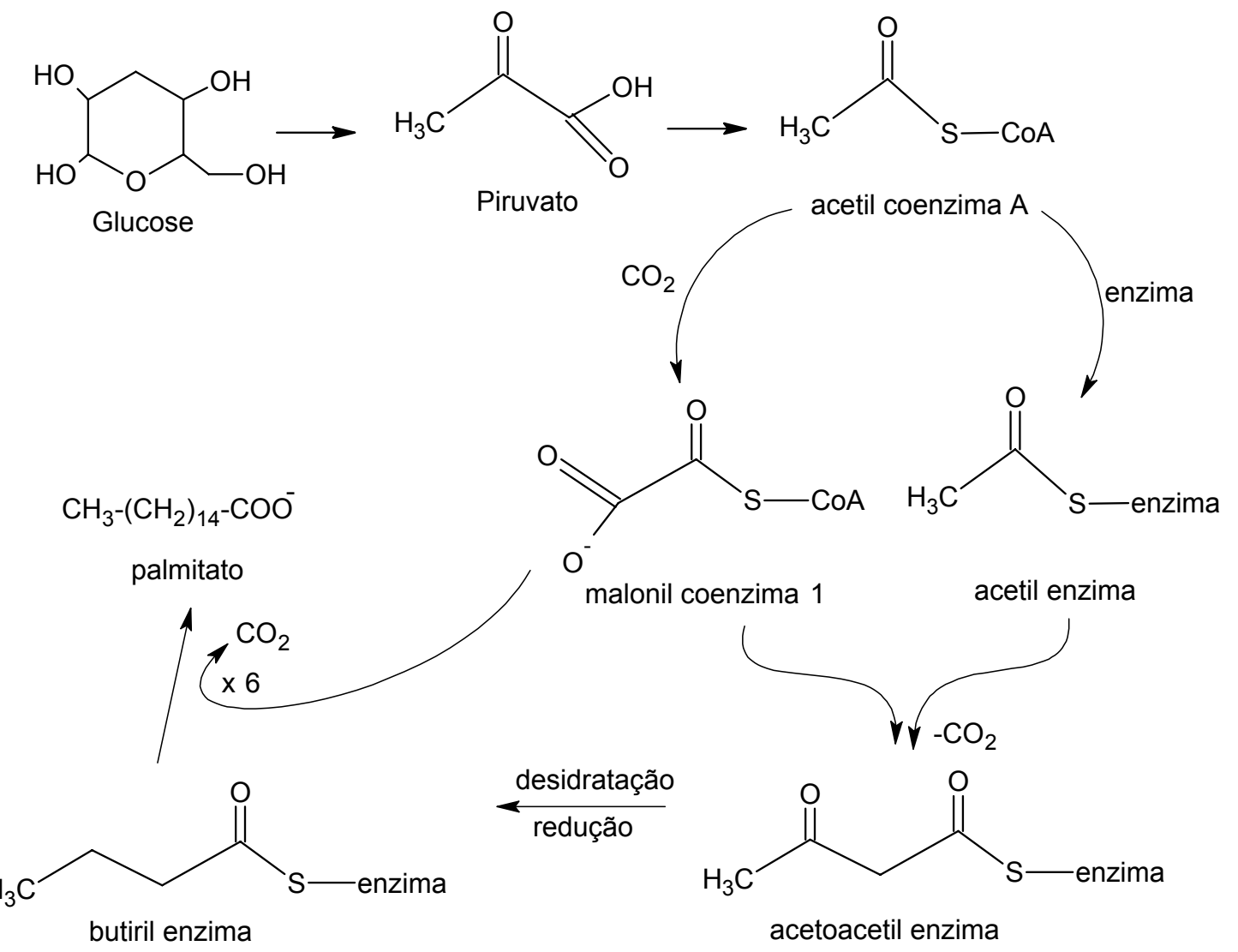

Figura 5: Exemplo de biossíntese de ácidos graxos saturados em plantas superiores.

\subsection{4 Álcoois Graxos}

Os álcoois graxos possuem praticamente as mesmas funções dos ácidos nos organismos, e possuem cadeias carbônicas longas, sendo que plantas superiores sintetizam principalmente entre $\mathrm{C}_{24}$ e $\mathrm{C}_{28}$. Plantas superiores biossintetizam os álcoois a partir dos ácidos graxos, através de redução enzimática (Fig. 6). Nesse processo são geradas também quantidades menores de cetonas, alcanos e aldeídos.

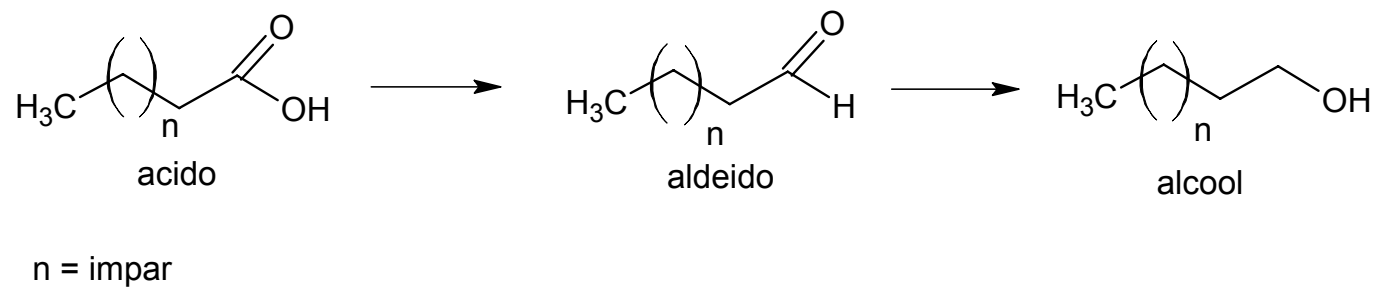

Figura 6: Biossíntese de álcoois a partir de ácidos graxos.

Uma vez que no processo de redução não ocorre perda ou ganho de átomos de carbono na cadeia, os álcoois apresentam a mesma característica 
dos ácidos de predominância de cadeias carbônicas com número par de átomos de carbono (Killops e Killops, 2005).

\subsubsection{Pigmentos - Clorinas}

Plantas superiores e algas sintetizam uma variedade de compostos orgânicos pigmentados, usados principalmente para 0 processo de fotossíntese. O principal pigmento fotossintético utilizado pelas plantas e maioria de classes de algas são as clorofilas, das quais a clorofila-a (Chl-a) é a mais comum (Jeffrey e Vesk, 1995). Pigmentos de clorofila contém grupos cromóforos, tipicamente ligações $\mathrm{C}=\mathrm{C}$ conjugadas, os quais absorvem parte da luz visível e conferem à molécula sua cor característica. Além disso, contém oxigênio nos grupos funcionais. A dupla ligação e os grupos funcionais contendo oxigênio proporcionam sítios para o ataque microbiano (Meyers, 1997). Experimentos de incubação com sedimento de ocorrência natural mostram que a concentração de Chl-a, de forma geral, exibe uma degradação exponencial (Sun et al., 1993). Vários estudos têm mostrado que a série de processos de transformação, incluindo a desmetalação do quelato de magnésio, descarbometoxilação (piro-formação) e a hidrólise dos ésteres ocorrem tanto na coluna de água quanto na interface água sedimento, formando os feopigmentos, chamados de clorinas (Baker e Palmer, 1979; Baker et al., 1978; Keely e Maxwell, 1991; Louda et al., 1980; Louda et al., 2002; Spooner et al., 1994) (Fig. 7)

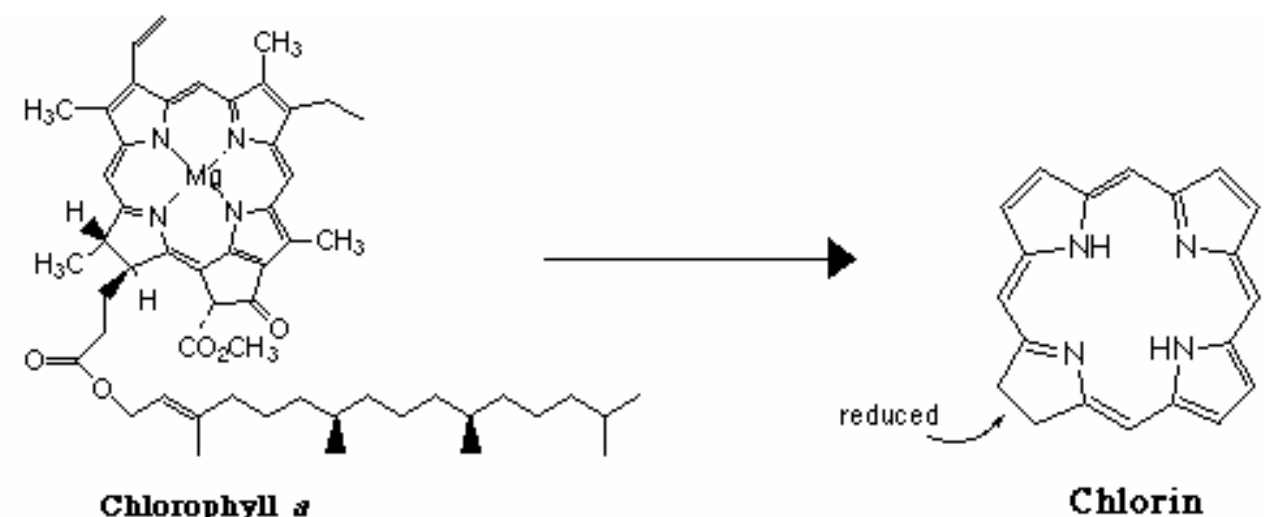

Figura 7: Diagênese da clorofila a.

Contudo, apesar da fácil degradação dos pigmentos clorofílicos na coluna de água e na superfície do sedimento, uma pequena porém significante 
fração é preservada sob forma de clorinas. A quantificação dessas clorinas pode ser feita por espectrofotometria em UV/vis usando comprimento de onda de absorção de 410 nm (Higginson, 1999).

No Oceano Atlântico as variações estratigráficas de clorinas no sedimento marinho têm sido relacionadas à paleoprodutividade em locais de alta produtividade como áreas de ressurgência na costa africana (Brassel et al., 1986b; Harris et al., 1996; Summerhayes et al., 1995) e também no Atlântico Norte e mares do Norte (Rosell-Melé e Koç, 1997; Rosell-Melé et al., 1997).

A abundância de clorinas ao longo do testemunho depende, assim como toda a matéria orgânica, de variações na produtividade e na diagênese, sendo que a diagênese é influenciada por fatores como quantidade de $\mathrm{O}_{2}$ na coluna de água e água de fundo, tempo de residência na coluna de água e na interface sedimento-água após deposição, reatividade molecular, formação de complexos pigmentados, adsorção e bioturbação (Higginson, 1999).

A classificação dos pigmentos pode ser também realizada utilizando razões de absorbância em certos comprimentos de onda. Rosel-Melé et al. (1997) empregaram espectrofotometria de UV/vis para detectar e distinguir clorinas e porfirinas em testemunho no Atlântico Norte. Porfirinas (tetrapirroles aromáticos de cor vermelha) são produtos do último estágio da diagênese das clorinas (Rosel-Melé et al., 1997).

Altas taxas de clorinas encontradas em testemunhos foram usadas para esclarecer os efeitos e a origem abrupta dos Eventos Heinrich no Atlântico Norte. Mudanças abruptas e bem definidas de pigmentos de Chl-a e derivados nas frações sedimentares entre os Eventos Heinrich foram atribuídas às condições oceânicas produzidas pela deriva dos icebergs. Em particular, clorinas foram encontradas com IRD (Ice-rafted debris), porém estavam ausentes quando o nível de IRD voltava aos níveis normais. Os autores concluíram que a abundância de água doce aumentava a preservação de clorinas durante as deposições das frações sedimentares nos Heinrichs devido à diminuição da formação de água de fundo e concomitante redução de oxigênio na água (Rosell-Melé et al., 1997). 


\subsubsection{Outros Marcadores}

\section{Isótopos Estáveis de Carbono}

As razões de isótopos estáveis de carbono podem ser usadas para distinguir entre fontes marinhas e terrígenas de carbono orgânico nos sedimentos e para identificar a matéria orgânica de diferentes plantas terrestres. A composição dos isótopos estáveis de carbono na matéria orgânica reflete a composição isotópica da fonte de carbono bem como a discriminação entre ${ }^{12} \mathrm{C}$ e ${ }^{13} \mathrm{C}$ durante o processo de fotossíntese.

A maioria das plantas, incluindo o fitoplâncton, incorpora o carbono na sua biomassa utilizando a forma Calvin $\left(\mathrm{C}_{3}\right)$, ou seja, fazendo a discriminação do ${ }^{13} \mathrm{C}$, de forma a produzir uma mudança nos valores de $\delta^{13} \mathrm{C}$, em relação ao padrão do PDB, de cerca de $-20 \%$ na sua razão isotópica de carbono, em relação à fonte inorgânica de carbono.

Algumas plantas usam o caminho Hatch-Slack $\left(\mathrm{C}_{4}\right)$, o qual proporciona uma alteração de cerca de $-7 \%$. Há ainda plantas que utilizam o CAM (Crassulacean Acid Metabolism) como caminho, que é como uma mescla entre os caminhos $\mathrm{C}_{3}$ e $\circ \mathrm{C}_{4}$ e produzem variações no $\delta^{13} \mathrm{C}$ que dependem da dinâmica de crescimento das plantas (Hayes, 1993).

A matéria orgânica produzida a partir do $\mathrm{CO}_{2}$ atmosférico $\left(\delta^{13} \mathrm{C}_{\mathrm{PDB}} \approx\right.$ $7 \%$ ) pelas plantas terrestres usando o caminho $\mathrm{C}_{3}$ (o que inclui quase todas as árvores e a maioria dos arbustos) apresenta em média valores de $\delta^{13} \mathrm{C}_{\mathrm{PDB}}$ próximos a $-27 \%$. Já as plantas que utilizam o caminho $\mathrm{C}_{4}$ (gramíneas) apresentam em média valores de $\delta^{13} C_{\text {PDB }}$ próximos a $-14 \%$. Algas marinhas usam bicarbonato dissolvido como fonte de $\mathrm{CO}_{2}$, o qual contém valores de $\delta^{13} C_{\mathrm{PDB}}$ próximos a $\% \%$. Como conseqüência, a matéria orgânica marinha apresenta valores típicos de $\delta^{13} C_{\mathrm{PDB}}$ variando entre $-20 \%$ e $-22 \%$. $\mathrm{O}$ fracionamento isotópico também é dependente da temperatura, por exemplo, em águas de regiões polares os valores de carbono isotópicos na matéria orgânica são menores ou iguais a -26\% (Rau et al., 1991).

A diferença típica no $\delta^{13} \mathrm{C}_{\mathrm{PDB}}$ de cerca de $7 \%$ entre a matéria orgânica produzida pelos produtores primários marinhos e as plantas terrestres tem sido extensivamente usada para traçar a fonte e a distribuição da matéria orgânica 
nos sedimentos costeiros oceânicos (Westerhausen et al. 1993, Prahl et al, 1994).

A disponibilidade de $\mathrm{CO}_{2}$ dissolvido na água também influencia na composição isotópica de carbono da matéria orgânica produzida pelas algas, uma vez que a discriminação isotópica em relação ao ${ }^{12} \mathrm{C}$ aumenta proporcionalmente com a pressão parcial de $\mathrm{CO}_{2}\left(\mathrm{pCO}_{2}\right)$.

Assim os valores de $\delta^{13} C_{P D B}$ na matéria orgânica podem ser usados como indicadores tanto de origem da matéria orgânica como de alterações nas condições paleoambientais tanto em escala curta quanto longa de tempo (Schulz e Zabel, 2000).

\section{Suscetibilidade Magnética}

Materiais magnéticos encontrados em sedimentos marinhos derivam principalmente de material terrígeno, minerais com propriedades diamagnéticos magnéticas, carregado para 0 meio marinho. Assim 0 aumento da suscetibilidade magnética é associado ao aumento do aporte continental para o oceano (Kornilova, 2005).

\section{Razão Carbono/Nitrogênio}

A razão $\mathrm{C} / \mathrm{N}$ é baseada no fato de que diferentes grupos de organismos produzem matéria orgânica contendo diferentes conteúdos de C e N (Stein, 1991).

A razão carbono/nitrogênio tanto para fito quanto para zooplâncton fornece em média um valor em torno de 6 enquanto que essa razão para material terrígeno fornece valores para a razão $\mathrm{C} / \mathrm{N}$ em torno de 20 ou mais (Meyers, 1997). Essa diferença ocorre devido à ausência de celulose em algas (menor quantidade de C) e a sua abundância em plantas vasculares, e devido à abundância de proteínas em algas (maior quantidade de nitrogênio).

A degradação seletiva dos componentes da matéria orgânica durante a primeira diagênese tem a tendência de modificar, geralmente aumentar, os valores de $\mathrm{C} / \mathrm{N}$ já na coluna de água, porém em bacias sedimentares a razão é bem preservada e fornece alguma indicação da contribuição da matéria orgânica terrígena (Prahl et al, 1994). Já em oceanos profundos, com baixa quantidade de carbono orgânico, o nitrogênio inorgânico (amônia) é adsorvido 
pela matriz mineral, especialmente argila, e depositado junto ao sedimento. Essa adição de nitrogênio faz com que a razão $\mathrm{C} / \mathrm{N}$ adquira valores abaixo do normal (Meyers, 1997).

A razão $C / N$ é alta em sedimentos fluviais, pois esses sedimentos costumam ser dominados por matéria orgânica de origem terrestre. A razão $\mathrm{C}_{\text {org }} / \mathrm{N}_{\text {org }}$ é maior do que a razão $\mathrm{C}_{\text {org }} / \mathrm{N}_{\text {tot }}$ indicando que o $\mathrm{N}_{\text {inorg }}$ permanece depois da remoção do carbonato. A proporção de $\mathrm{N}_{\text {inorg }}$ torna-se dominante no sedimento fluvial pobre em $\mathrm{C}_{\text {org }}$ e resulta em uma falsa assinatura de origem C/N (Meyers, 1997).

A natureza do nitrogênio (orgânico ou inorgânico) pode ser verificada através da plotagem dos teores de $\mathrm{C}_{\text {org }}$ contra os teores de $\mathrm{N}_{\text {tot. }}$ Uma forte correlação linear positiva $\left(r^{2}>0,85\right.$, com correlação de Pearson significativa e $p<0,05)$ confirma a natureza orgânica do nitrogênio e valida a utilização da razão $\mathrm{C} / \mathrm{N}$ para avaliar a fonte da matéria orgânica sedimentar (continental/marinha). No caso de uma correlação linear fraca, os valores da razão $\mathrm{C} / \mathrm{N}$ podem ser subestimados, em função do $N_{\text {tot }}$ não ser de origem essencialmente orgânica.

\section{Metais}

Assim como para os marcadores derivados de organismos, os metais se diferenciam entre os de natureza terrestre e os de natureza marinha. Porém também não são isentos de erros.

Metais como ferro, alumínio e titânio têm natureza predominantemente terrígena. Alumínio e titânio são considerados metais não reativos no meio marinho, assim as suas variações acompanham, em geral, o fluxo de material terrígeno para o meio marinho (Murray et al., 2000; Schroeder et al, 1997) e são portanto indicadores de material terrígeno. Em relação ao alumínio, algumas incertezas sobre a sua origem persistem, por exemplo, Murray (1996) cita algumas anomalias na razão Al/Ti em amostras do Pacífico Equatorial relacionadas a características não terrígenas do alumínio. Assim o uso do alumínio como elemento "normalizante" pode ser errôneo.

Metais como bário, estrôncio e cálcio estão envolvidos em processos biológicos. O bário é um dos indicadores mais utilizados para estimar a paleoprodutividade (Dymond et al., 1992; Paytan et al., 1996). A sua presença 
no sedimento marinho ocorre na forma de silicato, proveniente do continente e na forma de barita, associada ao material orgânico. Sedimentos em áreas de alta produtividade são enriquecidos em bário, o motivo disso não é totalmente conhecido, e sua alta preservação no sedimento o torna um bom indicador de produtividade. Porém, de forma a estimar a paleoprodutividade a partir do bário presente no sedimento, é necessário estimar a quantidade de bário biogênico (excesso de $\mathrm{Ba}, \mathrm{Ba}_{\mathrm{ex}}$ ) e distinguí-lo da sua fonte não biogênica. (Pattan et al., 2003). Contudo nem sempre é possível estimar esse valor e, para algumas regiões, não são conhecidos valores médios de $\mathrm{Ba}_{\mathrm{ex}}$, o que torna a estimativa da paleoprodutividade a partir do bário ineficiente.

Averyt e Paytan(2004) indicam discrepância nos resultados obtidos com diferentes parâmetros relacionados com o conteúdo de Ba bem como com a taxa de acumulação de Al e razão Al/Ti. Anderson e Winckler (2005) criticam a utilização das razões $\mathrm{Ba} / \mathrm{Ti}$ e $\mathrm{Al} / \mathrm{Ti}$ pois podem ser influenciadas por variações espaciais e temporais do fluxo de Ti. De acordo com os autores, a dissolução do $\mathrm{CaCO}_{3}$ durante o Holoceno pode ter causado aumento na concentração de barita bem como excesso de alumínio, o que pode gerar dificuldades na utilização desses indicadores para estimar a paleoprodutividade. Pattan et al. (2003), estudando variações glacial-interglacial no mar da Arábia, indica que a razão $\mathrm{Al} / \mathrm{Ti}$ não pode ser utilizada como um indicador de paleoprodutividade confiável.

De forma a amenizar as incertezas geradas pelos problemas associados à utilização dos metais, algumas relações podem ser úteis. A dispersão Al-Ti pode ser utilizada para verificar a validade do alumínio como elemento normalizante já que o titânio é não reativo em meio marinho, e verificar a influência da variação do fluxo do Ti. As razões $\mathrm{Fe} / \mathrm{Ca}$ e Ti/Ca podem também ser utilizadas como indicadores de aporte terrígeno. 


\section{Capítulo 2}

\section{Objetivos}

\subsection{Objetivos Gerais}

+ Verificar a validade da aplicação de marcadores orgânicos moleculares como indicares da fonte da matéria orgânica, indicadores de produtividade e indicadores de TSM na margem continental superior do Sudeste do Brasil e promover uma reconstrução paleoceanográfica dessa região, de forma a compreender as variações ambientais ocorridas ao longo dos anos procurando identificar os ciclos climáticos naturais existentes.

\subsection{Objetivos Específicos}

Quantificar os marcadores orgânicos moleculares em sedimentos superficiais coletados ao longo da margem continental superior do Sudeste do Brasil e em todas as frações de um testemunho coletado no talude superior ao Norte do estado de São Paulo.

Marcadores Orgânicos Moleculares de Interesse:
$\checkmark$ Alquenonas
$\checkmark$ Álcoois Graxos
$\checkmark$ n-alcanos
$\checkmark$ Clorinas
$\checkmark$ Ácidos Graxos

Identificar as variações no tipo de matéria orgânica depositada ao longo da margem continental superior do Sudeste do Brasil e validar a metodologia analítica e os resultados obtidos

Analisar $\delta^{13} \mathrm{C}$ da matéria orgânica total, razão $\mathrm{C} / \mathrm{N}$, suscetibilidade magnética e metais ( $\mathrm{Ba}, \mathrm{Ca}, \mathrm{Sr}, \mathrm{Fe}, \mathrm{Al}, \mathrm{Ti})$ em todas as amostras de forma a complementar os resultados.

Correlacionar os marcadores analisados no testemunho e verificar as variações ambientais desde o final do Pleistoceno até o presente.

Identificar os ciclos climáticos naturais e as magnitudes das suas influências na margem continental superior do Sudeste do Brasil. 


\section{Capítulo 3}

\section{Área de Estudo}

\subsection{Localização}

A área de estudo corresponde ao setor da margem continental brasileira, entre as cidades de Cabo Frio, estado do Rio de Janeiro e Itajaí, Santa Catarina, sendo a área delimitada entre as latitudes $22^{\circ} 55^{\prime}$ e $27^{\circ} 22^{\prime} \mathrm{S}$ e longitudes $41^{\circ} 58^{\prime}$ e $48^{\circ} 40^{\prime}$ W (Fig. 8)

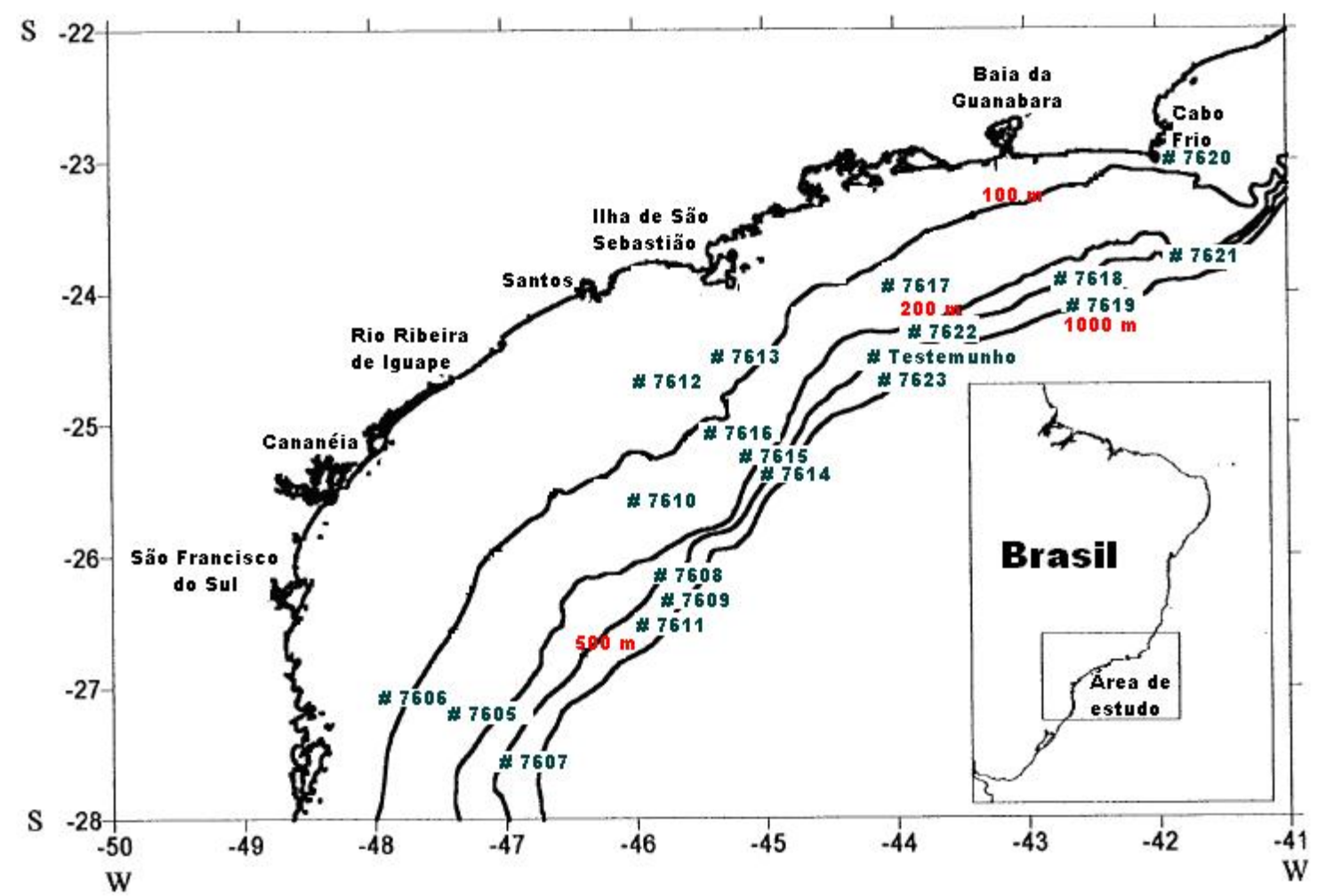

Figura 8: Mapa da Área de estudo com os números das estações onde foram coletados os sedimentos superficiais e o testemunho. 


\subsection{Aspectos Geomorfológicos}

A fisiografia da margem continental brasileira reflete fenômenos geológicos pretéritos e atuais, originados por agentes internos (estratigráficos e tectônicos), normalmente conjugados com agentes externos (subaéreos e oceanográficos) (Zembruscki, 1979).

A Margem Continental Sul, que abrange a região estudada, representa a zona de transição entre continente e oceano (Martins et al., 1972), possuindo largura e relevo regulares. No seu setor localizado mais a norte encontra-se o Embaiamento de São Paulo, situado entre o Cabo Frio e Cabo de Santa Marta (SC) (Zembruscki, et al., 1972).

A plataforma continental é definida como sendo a área que bordeja todos os continentes, estendendo-se da linha de maré mais baixa até a quebra da plataforma. A sua largura relaciona-se ao grau de subsidência marginal subseqüente ao rifte inicial e ao suprimento de sedimento do continente adjacente (Heezen et al. 1959).

A plataforma continental possui uma largura média de $130 \mathrm{~km}$ na faixa do Embaiamento de São Paulo. Seu declive se diferencia em 3 desníveis, sendo genericamente suave e monótono (Zembruscki, 1979). É enquadrada como pertencente ao tipo Atlântico, divergente e autóctone. Numa plataforma autóctone os sedimentos depositados resultam do retrabalhamento de sedimentos mais antigos, tendo sua origem na própria plataforma. Sua forma relaciona-se com a tendência do rifteamento inicial, que foi modificado por subsidência, erosão e deposição. Sua orientação aproximada é E-W sendo que, abaixo de Paranaguá passa a ser N-S.

Toda a plataforma nesse setor é cortada por canais estreitos, rasos, longos e perpendiculares ao declive que, em geral, alcançam a quebra da plataforma, por vezes ultrapassando-a. Esses canais facilitam o transporte de sedimentos para as regiões mais profundas. Os mais evidentes são os canais de Cabo Frio, Rio de Janeiro, Ilha Grande, Cananéia e Itajaí (Zembruscki, 1979).

Na região costeira do litoral norte do Estado de São Paulo, os esporões da Serra do Mar e os pequenos maciços e morros litorâneos atingem 
diretamente as águas oceânicas, individualizando pequenas planícies costeiras. A maior extensão desse trecho ocorre entre Santos e Cananéia onde são distinguíveis as baixadas de Santos, Itanhaém e Ribeira do Iguape (IPT, 1981).

O rio de maior importância no aporte de água doce é o Rio Ribeira de Iguape, que desemboca nas proximidades da cidade de lguape, ao sul do Estado de São Paulo. A maioria dos outros rios, de menor importância, drena as vertentes atlânticas na região da Serra do Mar e têm suas desembocaduras localizadas em baias, sistemas estuarinos ou lagunares. Exceções a esse padrão são verificadas nos rios Juqueriquerê, Itanhaém e Una, localizados no Estado de São Paulo (Lima, 2000).

\subsection{Sedimentação Quaternária}

Após o Terciário, os grandes ciclos climáticos, caracterizados por glaciações e seus períodos interglaciais, responsáveis pelas retrações e avanços do nível do mar, passaram a constituir o principal motivo causador da impressão do relevo (Zembruscki, 1979). No Pleistoceno Superior e Holoceno, a plataforma continental sul-sudeste brasileira foi palco de um forte ciclo glacioeustático, marcado por uma regressão, responsável pela exposição de quase toda a superfície, seguido por uma transgressão, quando os processos marinhos modelaram o relevo da plataforma e afogaram a drenagem continental, estabelecendo a configuração atual da costa (Zembruscki, 1979).

Shepard (1960) e Emery (1968), enfatizaram a existência e importância de sedimentos relíquias, oriundos da sedimentação presente durante os períodos de nível do mar mais baixo. No trecho da plataforma continental externa entre Cabo Frio (RJ) e a llha de São Sebastião (SP) ocorrem construções biogênicas, com alinhamento SE-NW que gradam, progressivamente para biodetritos e, posteriormente, para areias terrígenas, desaparecendo na altura de Paranaguá (PR) (Francisconi et al, 1974). Essas faixas de areia ortoquartzíticas, contíguas aos calcáreos, sugerem antigos níveis de praias (Francisconi et al, 1974) existentes em períodos de estabilização do nível do mar à profundidade de 30 e 60 metros, sendo que esta última possui uma idade estimada em torno de 11.000 anos (Francisconi 
et al, 1974). A faixa de lama terrígena, que ocorre na plataforma média de São Paulo, progradando sobre biodetritos e areias ortoquartzíticas biodetríticas de plataforma externa, tem o limite interno acompanhando aproximadamente a isóbata de 80 metros tendo provável origem associada ao nível de praia de 60 metros (Francisconi et al, 1974). Ocorre um aumento dessa lama de plataforma na direção Sul.

As areias ortoquartzíticas retrabalhadas formam um terceiro nível de praia, ocorrendo na plataforma externa, desde São Paulo até o extremo sul do Brasil, relacionando-se ao nível do mar de - 110 metros, ocorrido há aproximadamente 19.000 anos (Francisconi et al, 1974).

\subsection{Aspectos Oceanográficos}

Do ponto de visto hidrodinâmico, a região está inserida na Margem Continental Sudeste (MCSE), que se estende de Cabo Frio (RJ) ao Cabo de Santa Marta (SC). Sua parte mais larga, com $230 \mathrm{~km}$, localiza-se em frente a Santos e sua parte mais estreita está na proximidade de Cabo Frio, com 50 km. A profundidade de quebra da plataforma continental varia entre 120 e 180 metros. (Castro Filho, 1996).

Os movimentos oceânicos, na maior parte da MCSE, são forçados em diferentes escalas de tempo, pelos ventos, pela Corrente do Brasil e pelas marés. As correntes deslocam-se, normalmente, paralelas às isóbatas, para que se mantenha o balanço geofísico na direção normal à topografia. Dependendo de uma combinação entre a largura e a topografia continental, e a intensidade, a direção e a persistência da tensão de cisalhamento do vento, essas correntes podem ser mais enérgicas na MCSE (Castro Filho, 1996). Sob condições atmosféricas normais, as correntes de superfície apresentam velocidades junto ao fundo menores que $20 \mathrm{~cm} / \mathrm{s}$ podendo chegar até $50 \mathrm{~cm} / \mathrm{s}$ quando da passagem de frentes frias (Mahiques, 1992).

A Corrente do Brasil (CB), presente na parte mais externa da MCSE, forma-se a partir do ramos mais setentrional da Corrente Sul Equatorial, próximo a $10^{\circ} \mathrm{S}$. A CB flui para sudoeste, acompanha a linha de quebra da plataforma continental, junto ao talude superior, como uma corrente superficial rasa (Castro Filho, 1996). 
As massas de água presentes na MCSE, conforme descrito por Miranda (1982, apud Castro, 1996) são resultantes da mistura entre:

- Água Tropical (AT), quente e salina $\left(T>20^{\circ} \mathrm{C}\right.$ e $\left.\mathrm{S}>36,4\right)$ e é transportada para sul-sudoeste na camada superficial $(0-200 \mathrm{~m})$ da Corrente do Brasil (CB), sobre o talude continental, nas proximidades da quebra da plataforma continental;

- Água Central do Atlântico Sul (ACAS), relativamente fria $\left(T<20^{\circ} \mathrm{C}\right.$ e $S<36,4$ ), e é transportada também para o sul-sudoeste ao longo do talude continental na camada inferior da CB (200-500 m), próximo à quebra da plataforma continental.

- Água Costeira (AC), resultante da mistura da descarga continental de água doce com as águas da plataforma continental, tendo a menor salinidade das águas da PCSE devido principalmente ao efeito combinado dos muito pequenos e médios rios existentes na região

A parte mais interna da margem continental é ocupada principalmente pela AC. Ao longo da MCSE, observa-se a presença de águas com influência da AT próxima à superfície, e da ACAS próxima ao fundo, principalmente no entorno da quebra da plataforma continental. Durante o verão a ACAS desloca-se em direção à costa, muitas vezes atingindo a parte mais interna da plataforma continental e, devido aos ventos de NE mais freqüentes nesse período, ocorre o transporte de águas superficiais da costa para o mar aberto, e em sentido contrário na camada de fundo. Durante o inverno, a ACAS afasta-se em direção ao talude, aumentando a largura da faixa costeira onde a AC é predominante e devido aos ventos provenientes de SW ocorre o transporte de água do mar aberto para a costa na camada superior. 


\section{Capítulo 4}

\section{Materiais e Métodos}

\subsection{Coleta das amostras}

\section{Amostras Superficiais}

As amostras de superfície foram coletada ao longo da margem continental superior do Sudeste do Brasil com auxílio do Navio Oceanográfico Prof. W. Besnard utilizando uma caixa amostradora (do inglês box-core). Os pontos amostrados são mostrados na Figura 8. A Tabela 5 mostra a Latitude e Longitude de cada ponto e a descrição visual do sedimento. Os dois primeiros centímetros de sedimento superficial de cada ponto amostrado foram armazenados em bandejas de alumínio e congelados.

Tabela 5: Localização de descrição das amostras superficiais.

\begin{tabular}{|ccccc|}
\hline Amostra & Latitude & Longitude & Profundidade (m) & Descrição \\
\hline 7605 & $-27,104$ & $-47,804$ & 93 & Lama \\
7606 & $-26,988$ & $-48,076$ & 60 & Lama \\
7607 & $-27,369$ & $-47,140$ & 287 & Areia fina com lama \\
7608 & $-25,940$ & $-46,137$ & 179 & Areia fina biodetrítica \\
7609 & $-26,020$ & $-46,044$ & 308 & Areia fina biodetrítica com lama \\
7610 & $-25,508$ & $-46,635$ & 89 & Lama maciça \\
7611 & $-25,664$ & $-46,450$ & 127 & Lama arenosa biodetrítica \\
7612 & $-24,620$ & $-46,188$ & 57 & Areia lamosa biodetrítica \\
7613 & $-24,969$ & $-45,798$ & 88 & Lama \\
7614 & $-25,562$ & $-45,114$ & 217 & Areia média \\
7615 & $-25,274$ & $-45,447$ & 117 & Lama \\
7616 & $-25,098$ & $-45,644$ & 100 & Lama maciça \\
7617 & $-24,059$ & $-44,562$ & 121 & Lama arenosa \\
7618 & $-23,848$ & $-42,867$ & 231 & Lama arenosa biodetrítica \\
7619 & $-23,935$ & $-42,817$ & 511 & Lama arenosa biodetrítica \\
7620 & $-22,942$ & $-41,980$ & 44 & Lama arenosa \\
7621 & $-23,708$ & $-41,998$ & 413 & Areia Fina \\
7622 & $-24,314$ & $-43,752$ & 430 & Areia lamosa \\
7623 & $-24,489$ & $-44,241$ & 458 & Areia lamosa \\
\hline
\end{tabular}




\section{Testemunho}

Com auxílio do Navio Oceanográfico Professor W. Besnard, na Latitude 24,6575 S e Longitude $44,4372 \mathrm{~W}$, utilizando um testemunhador de pistão (do inglês piston core), foi coletado, a $374 \mathrm{~m}$ de profundidade, um testemunho de $203 \mathrm{~cm}$ (Fig. 8). Após a coleta, o testemunho foi submetido a análise de suscetibilidade magnética usando o sensor Bartington MSC2 e logo em seguida fracionado continuamente em intervalos de $2 \mathrm{~cm}$. Testas de foraminíferos (Globigerinoides ruber) encontradas ao longo do testemunho foram submetidas à datação radiométrica pela técnica $\mathrm{AMS}{ }^{14} \mathrm{C}$ (10 testas no total). As frações foram armazenadas em bandejas de alumínio e congeladas.

\subsection{Preparação das amostras}

Todas as amostras de sedimento, tanto as superficiais quanto as do testemunho, foram secas em liofilizador e uma fração de cada amostra foi submetida a análise granulométrica e CNS no Laboratório de Sedimentologia do Instituto Oceanográfico da USP através de um analisador Malvern 2000 e LECO CNS-2000 analyzer respectivamente.

Nas amostras do testemunho, foram realizadas análises de isótopos de carbono $\left(\delta^{13} \mathrm{C}\right)$ na matéria orgânica contida nos sedimento, pela técnica de espectrometria de massa. Essas análises foram realizadas no Laboratório de Ciências Costeiras (Austin, TX, EUA). A calibração do isótopo de carbono foi feita utilizando óleo padrão NBS 22 (definido como $-29,60 \%$ em relação ao PDB).

Todas as amostras foram então maceradas e estocadas em frascos de vidro.

Para a análise dos metais uma fração de cada amostra foi enviada ao CorpLab Brasil, onde, para a digestão da amostra, foi utilizada a metodologia US EPA 3050 (http://www.epa.gov/sw-846/pdfs/3050b.pdf). Para a determinação de metais por ICP-AES foi utilizada a metodologia US EPA 6010B (http://www.epa.gov/sw-846/pdfs/6010b.pdf). 
Parte das análises dos marcadores geoquímicos orgânicos foi realizada no Laboratório de Química Orgânica Marinha do Instituto Oceanográfico da Universidade de São Paulo e parte foi realizada no Instituto de Ciência e Tecnologia Ambiental da Universidade Autônoma de Barcelona.

\subsection{Metodologia empregada no Laboratório de Química Orgânica Marinha do Instituto Oceanográfico da Universidade de São Paulo (LabQom-USP)}

\subsubsection{Equipamentos usados}

- Banho ultra sônico Thorton T50.

- Evaporador rotativo a vácuo.

- Centrífuga Excelsa II, 206 BL - Fanem.

- Cromatógrafo a gás Agilent 6890 com injetor automático Agilent 7683, acoplado a um detector por ionização em chama (GC-FID).

- Cromatógrafo a gás Agilent 6890 com injetor automático Agilent 7683, acoplado a um detector de massa (GC-MS).

\subsubsection{Limpeza da vidraria}

Toda a vidraria e objetos utilizados foram deixados em banho de Extran alcalino (Merck) por 8 horas. O material foi então enxaguado em água corrente e por fim em água destilada. A vidraria, com exceção do material volumétrico, foi seca em estufa e posteriormente queimada em mufla por 4 horas a $400^{\circ} \mathrm{C}$ para eliminação de qualquer resíduo orgânico, e devidamente armazenada para o uso. O material volumétrico, pinças e espátulas foram secas à temperatura ambiente e no momento da utilização lavadas 3 vezes com mistura de n-hexano-diclorometano grau resíduo (1:1).

\subsubsection{Reagentes e padrões}

Utilizou-se apenas solventes "grau resíduo"; n-hexano, diclorometano e metanol, adquiridos da Merck Alemanha. Os padrões de hidrocarbonetos 
alifáticos foram adquiridos da Supelco, EUA, e ácidos graxos da Carlo Erba, Itália.

A sílica, a alumina e o sulfato de sódio foram queimados em mufla por 4 horas a $400^{\circ} \mathrm{C}$, armazenados em frascos de vidro e estocados em dessecador. A sílica e alumina, antes de serem utilizadas foram aquecidas em estufa a $120^{\circ} \mathrm{C}$, resfriadas em dessecador e parcialmente desativadas com $5 \%$ de água. Para a desativação utilizou-se água deionizada (sistema Milli-Q - Millipore) extraída com n-hexano ( $3 \times 15 \mathrm{~mL}$ de hexano/litro de água).

\subsubsection{Tratamento das amostras no LabQom}

As amostras do testemunho e de superfície receberam o seguinte tratamento:

Três gramas de sedimento foram colocados em um frasco de vidro, no qual foram adicionados os padrões internos n-hexadeceno, n-eicoseno e nhexatriacontano. O sedimento foi então extraído 3 vezes em banho ultra-sônico utilizando diclorometano $(3 \times 15 \mathrm{~mL})$. Cada uma das frações foi centrifugada sendo o solvente transferido para um balão de $125 \mathrm{~mL}$. As 3 frações da extração foram unidas no mesmo balão.

O extrato final foi então concentrado em evaporador rotativo a vácuo até cerca de $1 \mathrm{~mL}$. $\mathrm{O}$ extrato foi fracionado em 2 frações em coluna cromatográfica contendo $2 \mathrm{~g}$ de sílica e $1 \mathrm{~g}$ de alumina, sendo a eluição da primeira fração feita com de $8 \mathrm{~mL}$ de hexano seguido de $6 \mathrm{~mL}$ de diclorometano-n-hexano 8:2 (hidrocarbonetos alifáticos e alquenonas) e a segunda fração com $15 \mathrm{~mL}$ de metanol (álcoois e ácidos graxos).

A primeira fração foi concentrada em evaporador rotativo a vácuo até cerca de $1 \mathrm{~mL}$ e posteriormente até cerca de $100 \mu \mathrm{L}$ em fluxo de $\mathrm{N}_{2}$, adicionada de padrão interno cromatográfico tetradeceno e concentrada a $200 \mu \mathrm{L}$.

A segunda fração foi concentrada a cerca de $1 \mathrm{~mL}$ em evaporador rotativo a vácuo e posteriormente até secura em fluxo de $\mathrm{N}_{2}$. Devido à baixa volatilidade dos compostos presentes nessa fração, para melhorar a resolução cromatográfica utilizou-se $200 \mu \mathrm{L}$ de diazometano em diclorometano (2 horas 
em temperatura ambiente) para esterificar os ácidos graxos (Fig. 9), seguido de adição de 40 $\mu \mathrm{L}$ N,O-bis(trimetil-silil-trifluor-acetamida)/trimetil-cloro-silano (9:1) (BSTFA/TCMS) (1 hora em banho maria a $65^{\circ} \mathrm{C}$ ) para converter álcoois em trimetil-silil éteres (Fig. 10).

O diazometano foi preparado seguindo o procedimento proposto por Lombardi (1990) (Fig. 11), através da reação de diazald (N-metil-N-nitroso-ptoluenesulfonamida) com hidróxido de potássio (solução saturada) (Fig. 12).<smiles>[R]C(=O)O[14CH2][14CH2][14CH2][14C](=O)OC</smiles>

Figura 9: Reação de esterificação de ácidos graxos.

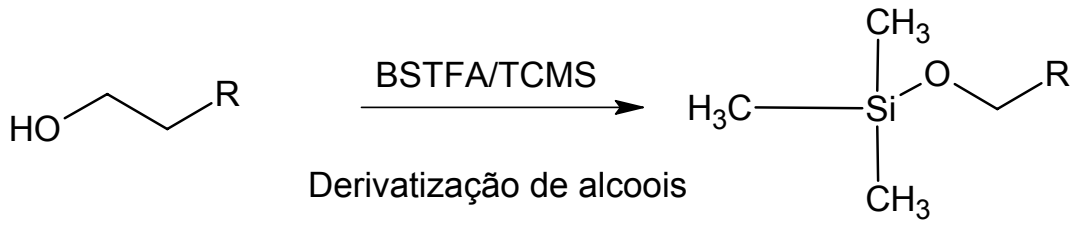

Figura 10: Esquema de derivatização de álcoois graxos.

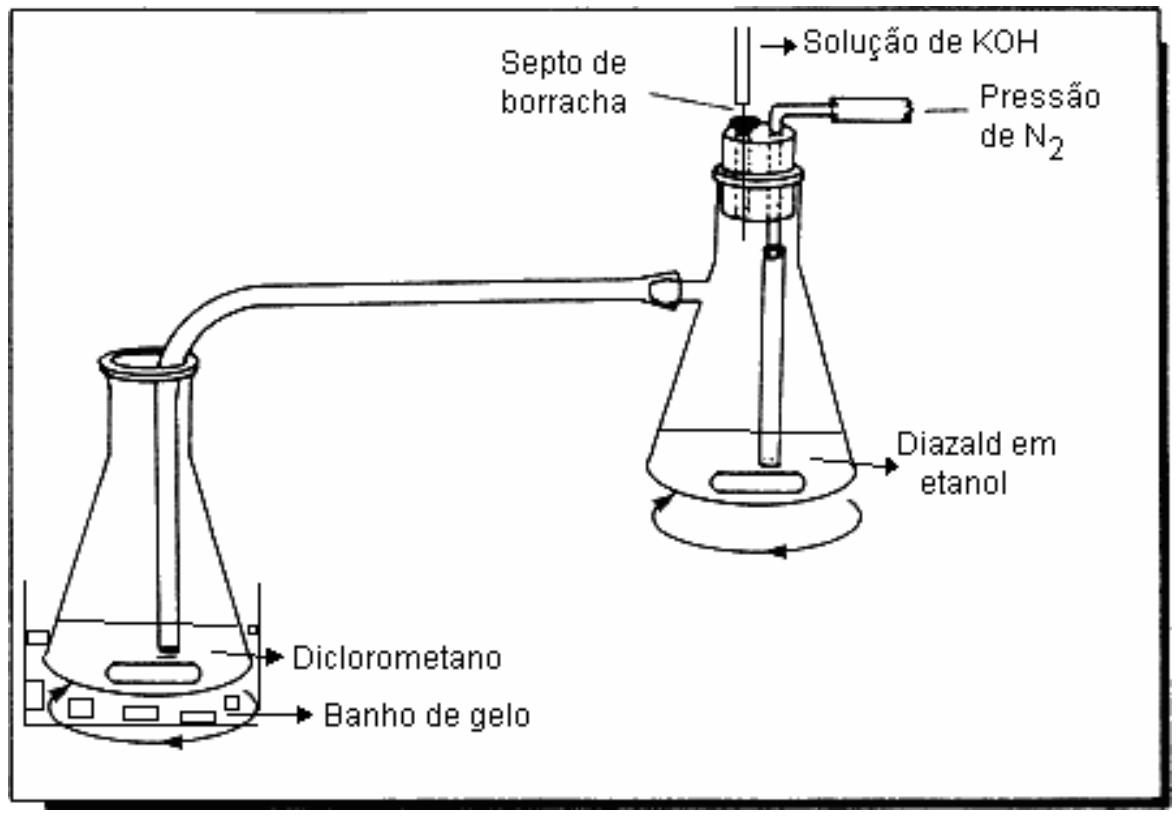


Figura 11: Esquema para preparação de diazometano.<smiles>Cc1ccc(S(=O)(=O)N(C)[N+](=O)[O-])cc1</smiles>

Diazald

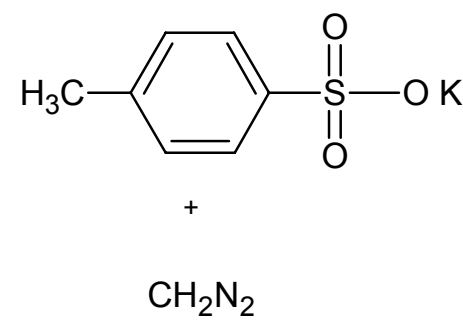

Diazometano

Figura 12: Reação de preparação do diazometano.

\subsubsection{Condições cromatográficas para análise dos compostos}

\subsubsection{GC-FID Agilent - Primeira fração:}

\section{hidrocarbonetos alifáticos e alquenonas}

Foi utilizada uma coluna cromatográfica ( $\mathrm{HP} 5$ ) com as seguintes dimensões: $50 \mathrm{~m}$ de comprimento $\times 0,32 \mathrm{~mm}$ de diâmetro interno $\times 0,17 \mu \mathrm{m}$ de espessura do filme, sendo a fase estacionária composta por $5 \%$ difenil e $95 \%$ dimetilpolisiloxano. O gás de arraste utilizado foi o $\mathrm{H}_{2}$ (pureza $>99,999 \%$ ), com pressão constante de 7,24 psi no injetor. A temperatura no injetor foi programada constante em $280^{\circ} \mathrm{C}$. As injeções foram feitas em modo splitless, com o detector mantido a $325^{\circ} \mathrm{C}$, recebendo fluxo de ar de $350 \mathrm{ml} \cdot \mathrm{min}^{-1}$, um fluxo de $\mathrm{H}_{2}$ de $30 \mathrm{ml} \cdot \mathrm{min}^{-1}$ e make up de $\mathrm{N}_{2}$ de $30 \mathrm{ml} \cdot \mathrm{min}^{-1}$. A rampa de temperatura do forno do GC-FID foi programada conforme a Tabela 6.

Tabela 6 : Rampa de temperatura do forno para separação de alcanos e alquenonas.

\begin{tabular}{|c|c|c|c|}
\cline { 2 - 4 } \multicolumn{1}{c|}{} & $\begin{array}{c}\text { Taxa } \\
\left({ }^{\circ} \mathrm{C}_{\mathrm{min}}{ }^{-1}\right)\end{array}$ & $\begin{array}{c}\text { Temperatura } \\
\left({ }^{\circ} \mathrm{C}\right)\end{array}$ & $\begin{array}{c}\text { Tempo } \\
(\mathrm{min})\end{array}$ \\
\hline Inicio & & 40 & 0 \\
\hline Rampa 1 & 20 & 60 & 0 \\
\hline Rampa 2 & 5 & 250 & 0 \\
\hline Rampa 3 & 20 & 300 & 0 \\
\hline Rampa 4 & 6 & 320 & 20 \\
\hline
\end{tabular}




\subsubsection{GC-MS Agilent - Segunda fração: álcoois e ácidos graxos}

Foi utilizada uma coluna cromatográfica (HP 5) com as seguintes dimensões: $30 \mathrm{~m}$ de comprimento $\times 0,25 \mathrm{~mm}$ de diâmetro interno $\times 0,25 \mu \mathrm{m}$ de espessura do filme, sendo a fase estacionária composta por $5 \%$ difenil e $95 \%$ dimetilpolisiloxano. O gás de arraste utilizado foi o He (pureza $>99,999 \%$ ), com pressão constante de 10 psi no injetor. O potencial de ionização eletrônica foi programado para $70 \mathrm{eV}$. O injetor foi programado com temperatura constante de $280^{\circ} \mathrm{C}$. As injeções foram feitas em modo splitless, com o detector de massa mantido a $325^{\circ} \mathrm{C}$, modo SCAN (faixa 40 a 550 u.m.a)

A rampa de temperatura do forno para separação dos álcoois, ácidos graxos é dada na tabela abaixo (Tab. 7).

Tabela 7 : Rampa de temperatura do forno para separação de álcoois, ácidos e esteróis.

\begin{tabular}{|c|c|c|c|}
\cline { 2 - 4 } \multicolumn{1}{c|}{} & $\begin{array}{c}\text { Taxa } \\
\left({ }^{\circ} \mathrm{C} \cdot \mathrm{min}^{-1}\right)\end{array}$ & $\begin{array}{c}\text { Temperatura } \\
\left({ }^{\circ} \mathrm{C}\right)\end{array}$ & $\begin{array}{c}\text { Tempo } \\
(\mathrm{min})\end{array}$ \\
\hline Inicio & & 60 & 0 \\
\hline Rampa 1 & 6 & 300 & 20 \\
\hline
\end{tabular}

\subsubsection{Identificação e quantificação de hidrocarbonetos alifáticos e alquenonas por GC-FID no LabQom}

A identificação dos compostos por cromatografia - FID é baseada no tempo de eluição de cada composto comparado com um composto de referência, que pode ser um padrão interno, um padrão injetado junto com a amostra ou ainda uma solução contendo os compostos de interesse injetada separadamente nas mesmo condições da amostra.

Os hidrocarbonetos alifáticos geram uma assinatura clássica de uma série homóloga. Nesse trabalho foram identificados os $\mathrm{n}$-alcanos com cadeias carbônicas entre 12 a 34 carbonos, além do pristano e do fitano. Os seus tempos de retenção foram obtidos a partir da injeção de uma solução padronizada contendo esses compostos. Para a quantificação foram feitas 
curvas de calibração para todos os n-alcanos entre 12 e 34 átomos de carbono, além do pristano e fitano e foram utilizados 2 padrões internos, o nhexadeceno, para quantificar os n-alcanos com cadeia carbônica entre 12 e 19 átomos de carbono; e o n-eicoseno, para quantificar os n-alcanos com cadeia carbônica entre 20 e 34 átomos de carbono. Para o cálculo da recuperação dos compostos utilizou-se o padrão interno cromatográfico n-tetradeceno.

Assim como os hidrocarbonetos alifáticos, as alquenonas também geram uma assinatura característica no cromatograma facilmente identificável. Para sua identificação foi injetada um solução contendo alquenonas obtida a partir da extração de uma amostra de sedimento padrão fornecida por Antoni RosellMelé do ICTA-UAB. Para a quantificação foi utilizada uma relação direta entre a área dos picos cromatográficos gerados pelas alquenonas e a área gerada pelo padrão interno n-hexatriacontano.

\subsubsection{Identificação e quantificação de álcoois e ácidos graxos por GC-MS no LabQom}

A identificação dos compostos polares presentes na segunda fração foi feita utilizando as razões massa/carga $(\mathrm{m} / \mathrm{z})$ dos compostos (Tab. 8) e os espectros de massa dos compostos obtidos através de padrões dos compostos ou com auxílio do software Wiley 138 standard library (Anexo 1)

Para os álcoois e ácidos graxos foi feita apenas uma quantificação relativa entre os compostos leves, $\mathrm{C}_{14}, \mathrm{C}_{16}, \mathrm{C}_{18}$ e $\mathrm{C}_{20}$ (tanto ácidos quanto álcoois) e pesados, $\mathrm{C}_{24}, \mathrm{C}_{26}, \mathrm{C}_{28}$ e $\mathrm{C}_{30}$ para álcoois e $\mathrm{C}_{22}, \mathrm{C}_{24}, \mathrm{C}_{26}$ e $\mathrm{C}_{28}$ para ácidos, utilizando as áreas dos picos cromatográficos normalizada em função da área do pico do padrão interno ( $5 \alpha$ androstanol).

Tabela 8: Relação massa/carga do compostos analisados pelo GC-MS.

\begin{tabular}{|l|c|}
\hline Composto & $\mathbf{~ m / z}$ \\
\hline Ácido dodecanóico & $74 / 214$ \\
\hline Dodecanol (Padrão Interno)) & $75 / 243$ \\
\hline Ácido tetradecanóico & $74 / 242$ \\
\hline Tetradecanol & $75 / 271$ \\
\hline Ácido pentadecanóico & $74 / 256$ \\
\hline Pentadecanol & $75 / 285$ \\
\hline Ácido tetradecanóico, trimethylsilyl ether & $117 / 285 / 300$ \\
\hline Ácido hexadecanóico & $74 / 270$ \\
\hline
\end{tabular}




\begin{tabular}{|l|c|}
\hline Hexadecanol & $75 / 299$ \\
\hline Ácido hexadecanóico, trimethylsilyl ether & $117 / 313 / 328$ \\
\hline Ácido heptadecanóico & $74 / 284$ \\
\hline Heptadecanol & $75 / 313$ \\
\hline Ácido octadecanóico & $74 / 298$ \\
\hline Octadecanol & $75 / 327$ \\
\hline Ácido octadecanoico, trimethylsilyl ether & $117 / 341 / 356$ \\
\hline Ácido eicosanóico & $74 / 326$ \\
\hline Eicosanol & $75 / 355$ \\
\hline Ácido heneicosanóico & $74 / 340$ \\
\hline Ácido docosanóico & $74 / 354$ \\
\hline Docosanol & $75 / 383$ \\
\hline Ácido tricosanóico & $74 / 368$ \\
\hline Ácido eicosanóico, trimethylsilyl ether & $117 / 369 / 384$ \\
\hline Ácido tetracosanóico & $74 / 382$ \\
\hline Tetracosanol & $75 / 411$ \\
\hline Ácido pentacosanóico & $74 / 396$ \\
\hline Ácido hexacosanóico & $74 / 410$ \\
\hline Hexacosanol & $75 / 439$ \\
\hline Ácido octacosanóico & $74 / 438$ \\
\hline Octacosanol & $75 / 467$ \\
\hline Ácido triacontanóico & $74 / 466$ \\
\hline Triacontanol & $75 / 495$ \\
\hline
\end{tabular}

\subsection{Metodologia no Laboratório do Instituto de Ciências e Tecnologias Ambientais da Universidade Autônoma de Barcelona (ICTA-UAB)}

\subsubsection{Equipamentos usados}

- Sistema acelerador de reações por microondas MARS 5 equipado com tubos de teflon de $100 \mathrm{ml}$ com tampa.

- Concentrador Labconco Centrivap acoplado a uma bomba de vácuo (KNF Laboport) e um trap frio (Labconco Corporation).

- Centrífuga Rotofix 32, Hettich.

- Sistema de Cromatografia Liquida de Alto Desempenho (HPLC) Surveyor, Thermo Finnigan, acoplado a um detector PDA (Photodiode Array Detector) do mesmo fabricante.

- Cromatógrafo de gases Trace GC Ultra, Thermo Finnigan com injetor automático Thermo AS3000, acoplado a um detector de ionização de chama (GC-FID). 


\subsubsection{Limpeza da vidraria}

Toda a vidraria e objetos utilizados foram deixados em banho de Extran alcalino (Merck) por 6 horas e posteriormente em solução de ácido nítrico $2 \%$ por 6 horas. $O$ material foi então enxaguado em água corrente e por fim em água destilada. A vidraria, com exceção do material volumétrico, foi seca em estufa e posteriormente queimada em mufla por 4 horas a $400^{\circ} \mathrm{C}$ para eliminação de qualquer resíduo orgânico, e devidamente armazenada para o uso. O material volumétrico, pinças e espátulas foram secas à temperatura ambiente e no momento da utilização lavadas 3 vezes com mistura de nhexano-diclorometano grau resíduo (1:1).

\subsubsection{Reagentes e padrões}

Foram utilizados apenas solventes "grau resíduo", acetona, diclorometano e metanol, adquiridos da Merck. Os padrões da Sigma, EUA.

O sulfato de sódio foi queimado em mufla por 4 horas a $400^{\circ} \mathrm{C}$, armazenado em frasco de vidro e estocado em dessecador. A lã de vidro foi extraída em soxhlet durante 6 horas utilizando mistura de diclorometanometanol (1:1)e posteriormente estocada em frasco de vidro e em dessecador.

\subsubsection{Tratamento das amostras no ICTA-UAB}

No laboratório do ICTA-UAB as amostras receberam o seguinte tratamento:

Um grama de sedimento seco em liofilizador foi colocado em um tubo de teflon para o microondas, no qual foi adicionado padrão interno, $n-C_{32}$ e $10 \mathrm{ml}$ de mistura de diclorometano - metanol (3:1). Para cada bateria de extrações foram realizadas extrações de 12 frações do testemunho, 1 branco e 1 amostra de sedimento padronizado.

As extrações foram realizadas pelo sistema acelerador de reações por microondas MARS 5 , programado para aquecer até $70^{\circ} \mathrm{C}$ em 3 minutos e manter a temperatura de $70^{\circ} \mathrm{C}$ durante 5 minutos. 
Após a extração a mistura solvente/sedimento foi transferida para tubos de ensaio de cerca de $15 \mathrm{~mL}$ e centrifugados durante 5 minutos a $2000 \mathrm{rpm}$. $\mathrm{O}$ solvente sobrenadante, contendo o extrato lipídico, foi então decantado em outro tubo de ensaio. Para garantir a recuperação, adicionou-se $3 \mathrm{~mL}$ de mistura diclorometano-metanol (3:1) ao tubo de ensaio contendo o sedimento extraído, agitou-se mecanicamente o tubo, procedeu-se mais uma centrifugação, nas mesmas condições e o sobrenadante foi adicionado ao primeiro tubo.

O extrato combinado foi concentrado até secura utilizando 0 concentrador da marca Labconco Centrivap.

Para remover água residual e ou vestígios de sedimento, o extrato seco foi redissolvido em cerca de $1,5 \mathrm{ml}$ de diclorometano $(3 \times 0,5 \mathrm{ml})$ e eluído através de uma pipeta de vidro contendo lã de vidro e sulfato de sódio anidro.

$\mathrm{O}$ extrato foi novamente levado à secura utilizando fluxo de $\mathrm{N}_{2}$ e estocado a $-20^{\circ} \mathrm{C}$ até o momento da análise de clorinas.

\subsubsection{Análise das clorinas}

Para a análise de pigmentos totais, o extrato orgânico obtido foi redissolvido em $50 \mu \mathrm{L}$ de acetona e agitado mecanicamente. Uma alíquota da solução $(10 \mu \mathrm{L})$ foi analisada por espectrofotometria, usando um sistema de HPLC, constituído por uma bomba Dionex P 580 acoplado a um PDA-100 (photodiode array detector). O sistema foi operado sem utilizar coluna e com um restritor de fluxo, de forma a aumentar a pressão do sistema, com fluxo isocrático de acetona (1 $\mathrm{ml} / \mathrm{min})$. Foi gerado um espectro de absorbância com comprimento de onda na faixa do visível $(\lambda=380 \mathrm{~nm}$ a $800 \mathrm{~nm})$, e quantificada a absorbância em 410nm e 662nm. A aquisição e integração dos dados foi feita pelo software ChromQuest 4.1, Thermo Electron 2003. O procedimento visou quantificar o total de pigmentos na amostra e não os pigmentos individualmente. Assim, uma vez que a clorofila e seus derivados e alguns carotenóides tem absorção máxima similar, a quantificação de absorbância fixada em $410 \mathrm{~nm}$ e em $662 \mathrm{~nm}$ é aproximadamente representativa para a absorção total de pigmentos (Rosell-Melé, 1994). Uma vez que se visa apenas verificar as variações de produtividade, as áreas dos picos de absorbância 
gerados nesses dois comprimentos de onda são suficientes para verificar a produtividade relativa, não sendo necessário o cálculo de concentração absoluta de pigmentos, o que demandaria uma curva de calibração para os pigmentos.

Visto que a análise de clorinas por PDA não é uma técnica destrutiva da amostra, após a análise das clorinas, a amostra foi recuperada e adicionada ao extrato restante, que foi novamente levado à secura através de fluxo de $\mathrm{N}_{2}$ para a análise de alquenonas.

\subsubsection{Análise das Alquenonas}

Após secos, os extratos utilizados para análise de clorinas foi redissolvido em $40 \mu \mathrm{L}$ de solução de padrão interno $\mathrm{n}-\mathrm{C}_{36}$.

As análises foram realizadas no GC-FID Thermo. Foi utilizada uma coluna cromatográfica (HP 1 ) com as seguintes dimensões: $30 \mathrm{~m}$ de comprimento $\times 0,25 \mathrm{~mm}$ de diâmetro interno $\times 0,25 \mu \mathrm{m}$ de espessura do filme, sendo a fase estacionária composta por $5 \%$ difenil e $95 \%$ dimetilpolisiloxano. $\mathrm{O}$ gás de arraste utilizado foi o $\mathrm{H}_{2}$ (pureza $>99,999 \%$ ), com fluxo constante de $20 \mathrm{ml} \cdot \mathrm{min}^{-1}$ no injetor. A temperatura no injetor foi mantida constante em $300^{\circ}$ C. As injeções foram feitas em modo splitless, com o detector mantido a $300^{\circ}$ C, recebendo um fluxo de ar de $350 \mathrm{ml} \cdot \mathrm{min}^{-1}$, um fluxo de $\mathrm{H}_{2}$ de $35 \mathrm{ml} \cdot \mathrm{min}^{-1} \mathrm{e}$ make up de $\mathrm{N}_{2}$ de $30 \mathrm{ml} \cdot \mathrm{min}^{-1}$. A rampa de temperatura do forno para separação das alquenonas é dada na tabela abaixo (Tab. 9).

Tabela 9 : Rampa de temperatura do forno para separação de alquenonas.

\begin{tabular}{|c|c|c|c|}
\cline { 2 - 4 } \multicolumn{1}{c|}{} & $\begin{array}{c}\text { Taxa } \\
\left({ }^{\circ} \mathrm{C} \cdot \mathrm{min}^{-1}\right)\end{array}$ & $\begin{array}{c}\text { Temperatura } \\
\left({ }^{\circ} \mathrm{C}\right)\end{array}$ & $\begin{array}{c}\text { Tempo } \\
(\mathrm{min})\end{array}$ \\
\hline Inicio & & 80 & 1 \\
\hline Rampa 1 & 20 & 200 & 0 \\
\hline Rampa 2 & 10 & 290 & 0 \\
\hline Rampa 3 & 20 & 310 & 18 \\
\hline
\end{tabular}




\subsubsection{Identificação e Quantificação das alquenonas por GC-FID no ICTA-UAB}

A identificação e quantificação das alquenonas no ICTA foi realizada da mesma forma que foi realizada no LabQom, ou seja, a identificaçã foi feita através do tempo de retenção, obtido a partir de extração de amostra padronizada contendo alquenonas,. E a quantificação foi baseada no n-alcano n-hexatriacontano.

\subsection{Controle de Qualidade do Método}

\subsubsection{Limite de Detecção}

O limite de detecção de um método (LD) é definido como a concentração mínima de uma substância que pode ser medida com $99 \%$ de confiança e que pode ser determinada em uma matriz contendo o analíto (Wade \& Cantillo, 1994). Uma das formas de se calcular o limite de detecção é através do desvio padrão (DP) de, no mínimo, 5 replicatas da mesma amostra. O limite de detecção do método é dado então pela equação:

$$
\text { LD }=3 \times \text { DP (Equação 6) }
$$

Como se deseja trabalhar com amostras de sedimentos marinhos, foi tomada uma amostra de sedimento e feita a análise de cinco replicatas dessa amostra. Os analítos de interesse foram quantificados e foi calculado o desvio padrão e o limite de detecção para cada um dos compostos.

Alguns dos compostos que se desejava analisar não foram identificados na amostra de sedimento. Para esses compostos foi considerado o limite de detecção como sendo igual ao limite de detecção de um composto quimicamente semelhante, encontrado na amostra.

Sericano (1998) propôs que o branco deve conter no máximo dois compostos com concentração maior que três vezes o limite de detecção do método.

$\mathrm{Na}$ Tabela 10 são apresentados os limites de detecção obtidos pelos resultados das extrações de 5 replicatas da amostra. 
Em nenhuma das classes de marcadores foram encontrados no branco compostos com concentração superior a três vezes o limite de detecção.

Tabela 10: Resultados da extração da amostra de sedimento marinho para cálculo do limite de detecção para hidrocarbonetos alifáticos, alquenonas, esteróis, álcoois e ácidos graxos sendo D.P. o desvio padrão, L.D. o limite de detecção do método.

\begin{tabular}{|c|c|c|c|c|c|c|c|c|c|}
\hline HCs Alifaticos (ug/g) & Branco & R1 & R2 & R3 & R4 & R5 & Média & D.P. & L.D \\
\hline $\mathrm{n}-\mathrm{C} 12$ & 0,001 & 0,026 & 0,031 & 0,028 & 0,028 & 0,028 & 0,029 & 0,002 & 0,005 \\
\hline $\mathrm{n}-\mathrm{C} 13$ & 0,001 & 0,014 & 0,015 & 0,013 & 0,014 & 0,013 & 0,014 & 0,001 & 0,002 \\
\hline $\mathrm{n}-\mathrm{C} 14$ & 0,002 & 0,035 & 0,033 & 0,031 & 0,031 & 0,031 & 0,032 & 0,002 & 0,005 \\
\hline $\mathrm{n}-\mathrm{C} 15$ & 0,003 & 0,033 & 0,031 & 0,030 & 0,030 & 0,030 & 0,031 & 0,002 & 0,005 \\
\hline$n-C 16$ & 0,006 & 0,038 & 0,036 & 0,036 & 0,040 & 0,035 & 0,038 & 0,003 & 0,010 \\
\hline$n-C 17$ & 0,002 & 0,046 & 0,046 & 0,045 & 0,046 & 0,046 & 0,046 & 0,001 & 0,002 \\
\hline Pristano & 0,004 & 0,041 & 0,039 & 0,039 & 0,040 & 0,040 & 0,040 & 0,002 & 0,005 \\
\hline$n-C 18$ & 0,002 & 0,027 & 0,027 & 0,026 & 0,027 & 0,027 & 0,027 & 0,001 & 0,002 \\
\hline Fitano & 0,002 & 0,012 & 0,010 & 0,009 & 0,010 & 0,010 & 0,010 & 0,001 & 0,004 \\
\hline$n-C 19$ & 0,001 & 0,020 & 0,020 & 0,020 & 0,019 & 0,020 & 0,020 & 0,001 & 0,003 \\
\hline $\mathrm{n}-\mathrm{C2O}$ & 0,001 & 0,015 & 0,015 & 0,015 & 0,015 & 0,015 & 0,015 & 0,001 & 0,002 \\
\hline $\mathrm{n}-\mathrm{C21}$ & 0,001 & 0,033 & 0,033 & 0,032 & 0,032 & 0,031 & 0,033 & 0,002 & 0,005 \\
\hline $\mathrm{n}-\mathrm{C22}$ & 0,003 & 0,020 & 0,022 & 0,021 & 0,020 & 0,020 & 0,019 & 0,004 & 0,011 \\
\hline $\mathrm{n}-\mathrm{C23}$ & 0,002 & 0,024 & 0,025 & 0,023 & 0,024 & 0,024 & 0,025 & 0,002 & 0,007 \\
\hline $\mathrm{n}-\mathrm{C24}$ & 0,002 & 0,013 & 0,013 & 0,012 & 0,012 & 0,012 & 0,012 & 0,001 & 0,002 \\
\hline $\mathrm{n}-\mathrm{C25}$ & 0,004 & 0,031 & 0,035 & 0,032 & 0,033 & 0,032 & 0,033 & 0,001 & 0,004 \\
\hline $\mathrm{n}-\mathrm{C} 26$ & 0,004 & 0,022 & 0,021 & 0,021 & 0,022 & 0,020 & 0,021 & 0,001 & 0,004 \\
\hline $\mathrm{n}-\mathrm{C27}$ & 0,012 & 0,037 & 0,037 & 0,033 & 0,037 & 0,035 & 0,037 & 0,004 & 0,013 \\
\hline $\mathrm{n}-\mathrm{C28}$ & 0,023 & 0,048 & 0,044 & 0,035 & 0,039 & 0,037 & 0,038 & 0,008 & 0,023 \\
\hline $\mathrm{n}-\mathrm{C29}$ & 0,012 & 0,174 & 0,160 & 0,158 & 0,148 & 0,141 & 0,156 & 0,011 & 0,032 \\
\hline $\mathrm{n}-\mathrm{C} 30$ & 0,013 & 0,057 & 0,043 & 0,039 & 0,043 & 0,037 & 0,042 & 0,007 & 0,020 \\
\hline $\mathrm{n}-\mathrm{C} 31$ & 0,022 & 0,106 & 0,095 & 0,087 & 0,092 & 0,086 & 0,092 & 0,007 & 0,022 \\
\hline $\mathrm{n}-\mathrm{C} 32$ & 0,017 & 0,048 & 0,035 & 0,027 & 0,030 & 0,027 & 0,033 & 0,007 & 0,021 \\
\hline $\mathrm{n}-\mathrm{C} 33$ & 0,014 & 0,063 & 0,057 & 0,050 & 0,054 & 0,051 & 0,050 & 0,010 & 0,029 \\
\hline $\mathrm{n}-\mathrm{C} 34$ & 0,016 & 0,038 & 0,037 & 0,027 & 0,028 & 0,030 & 0,029 & 0,006 & 0,017 \\
\hline $\mathrm{n}-\mathrm{C} 35$ & 0,008 & 0,039 & 0,046 & 0,028 & 0,037 & 0,044 & 0,037 & 0,007 & 0,022 \\
\hline Alquenonas (ng/g) & Branco & R1 & R2 & R3 & R4 & R5 & Média & D.P. & L.D \\
\hline Alq C37:3 & n.d. & 65,21 & 69,38 & 57,13 & 65,19 & 64,95 & 64,372 & 4,45 & 13,35 \\
\hline Alq C37:2 & n.d. & 320,58 & 352,79 & 324,73 & 330,42 & 331,74 & 332,052 & 12,43 & 37,29 \\
\hline Ácidos (ng.g) & Branco & R1 & R2 & R3 & R4 & R5 & Média & D.P. & L.D \\
\hline Ácido C12 & n.d. & 0,073 & 0,059 & 0,098 & 0,072 & 0,057 & 0,072 & 0,016 & 0,049 \\
\hline Ácido C14 & 0,630 & 0,383 & 0,189 & 0,338 & 0,376 & 0,191 & 0,295 & 0,098 & 0,293 \\
\hline Ácido C16 & 0,176 & 2,513 & 2,149 & 2,732 & 2,471 & 2,164 & 2,006 & 0,082 & 0,245 \\
\hline Ácido C18 & 0,111 & 1,030 & 1,000 & 1,013 & 1,013 & 0,999 & 1,011 & 0,013 & 0,038 \\
\hline Ácido C20 & n.d. & 0,069 & 0,040 & 0,099 & 0,079 & 0,060 & 0,077 & 0,020 & 0,060 \\
\hline Ácido C22 & n.d. & 0,030 & 0,032 & 0,041 & 0,032 & 0,032 & 0,036 & 0,009 & 0,026 \\
\hline Ácido C24 & n.d. & 0,063 & 0,076 & 0,081 & 0,072 & 0,086 & 0,068 & 0,023 & 0,068 \\
\hline Ácido C26 & n.d. & 0,041 & 0,038 & 0,057 & 0,040 & 0,038 & 0,039 & 0,012 & 0,036 \\
\hline Ácido C28 & n.d. & 0,045 & 0,048 & 0,068 & 0,044 & 0,049 & 0,043 & 0,014 & 0,042 \\
\hline
\end{tabular}




\begin{tabular}{|l|rrrrrrrr|r|}
\multicolumn{1}{|c}{} & \multicolumn{1}{c}{ Branco } & $\mathbf{R 1}$ & $\mathbf{R 2}$ & $\mathbf{R 3}$ & $\mathbf{R 4}$ & $\mathbf{R 5}$ & Média & D.P. & L.D \\
\hline Alcoois (ng.g) & n.d. & 1,422 & 1,828 & 1,715 & 1,398 & 1,852 & 1,643 & 0,219 & 0,657 \\
Alcool C14 & n.d. & 0,566 & 0,580 & 0,916 & 0,557 & 0,586 & 0,601 & 0,180 & 0,541 \\
Alcool C18 & n.d. & 0,388 & 0,378 & 0,571 & 0,382 & 0,371 & 0,376 & 0,123 & 0,370 \\
Alcool C20 & n.d. & 0,756 & 0,766 & 0,600 & 0,743 & 0,776 & 0,728 & 0,073 & 0,218 \\
Alcool C24 & n.d. & 1,046 & 1,053 & 1,516 & 1,029 & 1,067 & 1,142 & 0,210 & 0,629 \\
Alcool C26 & n.d. & 1,585 & 1,716 & 2,544 & 1,559 & 1,739 & 1,829 & 0,408 & 1,223 \\
Alcool C28 & n.d. & 1,496 & 2,192 & 2,357 & 1,471 & 2,221 & 1,948 & 0,428 & 1,285 \\
Alcool C30 & n.d. & 1,923 & 1,985 & 2,902 & 1,891 & 2,012 & 2,143 & 0,427 & 1,282 \\
\hline
\end{tabular}

\subsubsection{Verificação da Qualidade do Método}

O controle de qualidade do método foi realizado com resultados obtidos da extração de um branco (sulfato de sódio), um branco adicionado de padrões externos (branco spike), uma matriz e uma matriz adicionada de padrões externos.

Segundo Sericano (1998) os critérios para o controle de qualidade de uma metodologia são:

- O branco adicionado deve conter $80 \%$ dos analítos com recuperação entre 40 e $130 \%$

- A matriz adicionada deve conter $80 \%$ dos analítos com recuperação entre 40 e $130 \%$, sendo que nesse cálculo entram apenas os compostos originalmente presentes na amostra em quantidade igual ou superior à adicionada.

- Os padrões internos devem ser recuperados entre 70 e $120 \%$ em todas as amostras analisadas.

Para os hidrocarbonetos alifáticos a recuperação individual dos compostos no branco adicionado ficou entre 60 e $91 \%$ e na matriz adicionada a recuperação ficou entre 60 e 83\%. Para os ácidos a recuperação individual dos compostos no branco ficou entre 80 e $95 \%$ e na matriz adicionada, entre 76 e $86 \%$.

A recuperação do padrão interno para todas as classes de compostos ficou dentro do limite estabelecido e não foram encontradas nas amostras compostos em quantidade igual ou superior a adicionada. 


\section{Capítulo 5}

\section{Resultados e Discussões}

\subsection{Amostras de Sedimentos de Superfície Resultados das Amostras Superficiais}

Os resultados das análises das amostras superficiais são mostrados na Tabela 11.

\subsubsection{Temperatura Superficial Marinha}

$\mathrm{Na}$ região do Embaiamento de São Paulo a temperatura superficial marinha calculada a partir do índice $U_{37}^{k^{\prime}}$ variou entre 22,9 e $26,06^{\circ} \mathrm{C}$. O gradiente de variação espacial da $U_{37}^{k^{\prime}}$ TSM (Figura 13) mostra que a temperatura superficial do mar na plataforma continental superior do Sudeste do Brasil aumenta em direção ao norte, com águas superficiais mais frias ao sul e águas mais quentes ao norte da llha de São Sebastião.

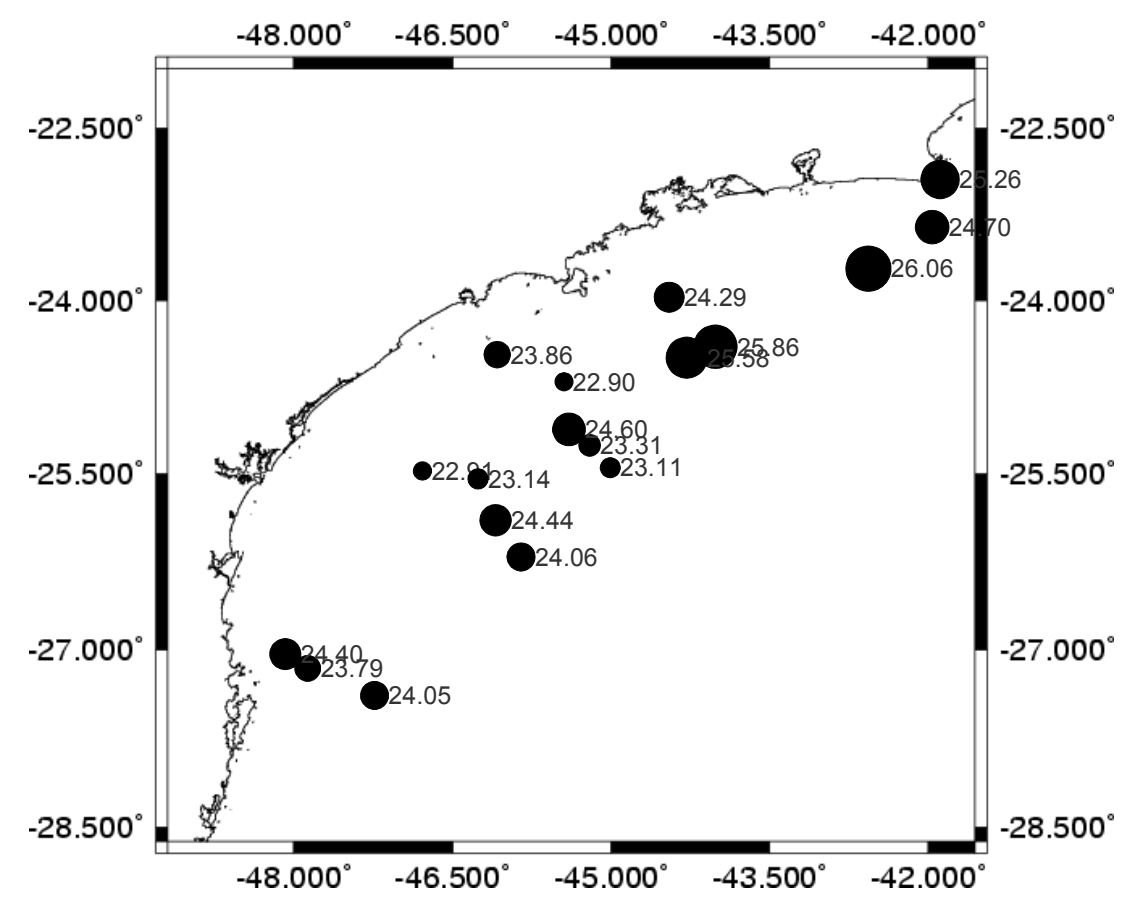

Figura 13: Variação da TSM calculada a partir do índice $U_{37}^{k^{\prime}}$ ao longo da margem continental superior do Sudeste do Brasil. 
Tabela 11: Resultados dos marcadores orgânicos moleculares e metais no sedimento superficial no Embaiamento de São Paulo.

\begin{tabular}{|c|c|c|c|c|c|c|c|c|c|c|c|c|c|c|c|c|c|c|c|c|c|c|c|}
\hline Est. & $\begin{array}{l}\sum \mathbf{n} \text {-alc. } \\
\left(\mu \mathbf{g} \cdot \mathbf{g}^{-1}\right)\end{array}$ & IPC & Pri/Fit & TAR & $\begin{array}{c}\text { TSM UK37 } \\
\left({ }^{\circ} \mathrm{C}\right)\end{array}$ & $\begin{array}{c}\text { Alq. } \\
\text { (ng.g-1) }\end{array}$ & $\begin{array}{c}\text { Clorinas } \\
\times 10^{\circ}\end{array}$ & $\begin{array}{c}\text { Álcoois } \\
\text { P/L }\end{array}$ & $\begin{array}{c}\text { Ácidos } \\
\text { P/L }\end{array}$ & (Al) & (Ba) & $\begin{array}{c}\text { (Ca) } \\
\left(\mu \mathbf{g} \cdot \mathbf{g}^{-1}\right)\end{array}$ & $(\mathrm{Sr})$ & $(\mathrm{Fe})$ & (Ti) & $\begin{array}{l}\mathrm{Ba} / \mathrm{Al} \\
\mathrm{x} 10-3\end{array}$ & $\begin{array}{l}\mathrm{Ba} / \mathrm{Ti} \\
\mathrm{x} 10-2\end{array}$ & $\begin{array}{l}\mathrm{Ba} / \mathrm{Ca} \\
\times 10-4\end{array}$ & $\overline{A l} / \mathrm{Ti}$ & $\mathrm{Sr} / \mathrm{Ti}$ & $\begin{array}{l}\mathrm{Sr} / \mathrm{Ca} \\
\mathrm{x} 10-3\end{array}$ & $\mathrm{Fe} / \mathrm{Ca}$ & $\begin{array}{l}\mathrm{Ti} / \mathrm{Ca} \\
\times 10-2\end{array}$ \\
\hline 7605 & 2,79 & 2,55 & 1,68 & 5,06 & 23,79 & 1641,4 & 10,60 & 1,02 & 0,22 & 17740 & 21,40 & 13180 & 86,6 & 22258 & 225 & 1,21 & 9,51 & 16,24 & 78,84 & 0,38 & 6,57 & 1,69 & 1,71 \\
\hline 7606 & 3,30 & 2,31 & 1,58 & 14,07 & 24,40 & 1979,2 & 12,19 & 1,09 & 0,20 & 15904 & 20,70 & 10857 & 77 & 20607 & 233 & 1,30 & 8,88 & 19,07 & 68,26 & 0,33 & 7,09 & 1,90 & 2,15 \\
\hline 7607 & 1,43 & 1,97 & 3,36 & 8,29 & 24,05 & 409,4 & 3 & 1,67 & 0,15 & 7941 & 14,60 & 86190 & 556 & 22185 & 238 & 1,84 & 6,13 & 1,69 & 33,37 & 2,34 & 6,45 & 0,26 & 0,28 \\
\hline 7608 & 2,02 & 1,27 & 2,29 & 4,95 & 24,44 & 777,3 & 46 & 0,60 & 15 & 6872 & 17,10 & 309375 & 1278 & 14812 & 200 & 2,49 & 8,55 & 0,55 & 34,36 & 6,39 & 4,13 & 0,05 & 0,06 \\
\hline 7609 & 1,74 & 1,81 & 2,28 & 7,63 & 1,06 & 951,9 &, 21 & 0,91 & 25 & 7802 & 18,80 & 79555 & 442 & 10071 & 177 & 2,41 & 10,62 & 2,36 & 44,08 & 2,50 & 5,56 & 0,13 & 0,22 \\
\hline 7610 & 2,82 & 2,00 & 2,13 & 11,29 & 22,91 & 3545,3 & 12,63 & 0,93 & 0,20 & 17546 & 23,40 & 18631 & 130 & 21691 & 244 & 1,33 & 9,59 & 12,56 & 71,91 & 0,53 & 6,98 & 1,16 & 1,31 \\
\hline 7611 & 2,99 & 1,57 & 2,05 & 7,35 & 14 & 2020,9 & 83 & 0,92 & 9 & 8915 & 15,10 & 57615 & 405 & 13379 & 202 & 1,69 & 7,48 & 2,62 & 44,13 & 2,00 & 7,03 & 0,23 & 0,35 \\
\hline 12 & 1,89 & 2,19 & 2,47 & 11,30 & 86 & 61,4 & 26 & 38 & 4 & 2912 & 6,50 & 76675 & 401 & 4554 & 108 & 2,23 & 6,02 & 0,85 & 26,96 & 3,71 & 5,23 & ,06 & 0,14 \\
\hline 7613 & 1,55 & 1,18 & 3,28 & 4,32 & 22,90 & 1349,7 & 10,67 & 1,16 & 0,25 & 13852 & 18,80 & 37537 & 181 & 20331 & 213 & 1,36 & 8,83 & 5,01 & 65,03 & 0,85 & 4,82 & 0,54 & 0,57 \\
\hline 7615 & 2,91 & 1,72 & 2,53 & 6,41 & 23,11 & 3980,3 & 30 & 1,37 & 0,19 & 12628 & 19,40 & 61535 & 383 & 17274 & 221 & 1,54 & 8,78 & 3,15 & 57,14 & 1,73 & 6,22 & 0,28 & 0,36 \\
\hline 516 & 9,28 & 2,07 & 1,64 & 19,09 & , 31 & 4168,0 & 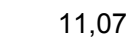 & 1,30 & 0,30 & 13675 & 19,70 & 29286 & 170 & 18775 & 199 & 1,44 & 9,90 & 6,73 & 68,72 & 0,85 & 5,80 & 0,64 & 0,68 \\
\hline 7617 & 2,05 & 1,44 & 2,57 & 7,05 & 24,60 & 2362,3 & 10,51 & 1,37 &, 21 & 8589 & 14,60 & 79235 & 439 & 11568 & 187 & 1,70 & 7,81 & 1,84 & 45,93 & 2,35 & 5,54 & 0,15 & 0,24 \\
\hline 7618 & 2,18 & 2,18 & 3,05 & 7,91 & 24,29 & 1417,3 & 5,87 & 4,10 & 0,15 & 10283 & 19,70 & 52495 & 377 & 17126 & 274 & 1,92 & 7,19 & 3,75 & 37,53 & 1,38 & 7,18 & 0,33 & 0,52 \\
\hline 7619 & 2,42 & 1,14 & 2,49 & 3,21 & 26,06 & 746,6 & 4,89 & 0,92 & 0,10 & 10167 & 49,00 & 119390 & 708 & 14105 & 240 & 4,82 & 20,42 & 4,10 & 42,36 & 2,95 & 5,93 & 0,12 & 0,20 \\
\hline 7620 & 3,75 & 2,35 & 3,17 & 3,81 & 25,26 & 2889,6 & 8,38 & 3,36 & 0,22 & 13780 & 23,70 & 93270 & 812 & 20089 & 398 & 1,72 & 5,95 & 2,54 & 34,62 & 2,04 & 8,71 & 0,22 & 0,43 \\
\hline 7621 & 1,90 & 0,97 & 2,32 & 6,53 & 24,70 & 757,3 & 4,23 & 1,05 & 0,11 & 6554 & 21,10 & 99885 & 772 & 9545 & 174 & 3,22 & 12,13 & 2,11 & 37,67 & 4,44 & 7,73 & 0,10 & 0,17 \\
\hline 7622 & 1,83 & 1,44 & 2,34 & 7,65 & 25,86 & 2411,0 & 9,66 & 1,96 & 0,12 & 12279 & 47,80 & 106025 & 616 & 16373 & 238 & 3,89 & 20,08 & 4,51 & 51,59 & 2,59 & 5,81 & 0,15 & 0,22 \\
\hline 7623 & 2,80 & 1,28 & 2,64 & 1,39 & 25,58 & 1175,7 & 5,06 & 1,05 & 0,12 & 12762 & 44,00 & 86545 & 479 & 15098 & 257 & 3,45 & 17,12 & 5,08 & 49,66 & 1,86 & 5,53 & 0,17 & 0,30 \\
\hline
\end{tabular}


A penetração de águas frias na região mais ao sul da plataforma foi inicialmente atribuída à confluência da Corrente do Brasil com a Corrente das Malvinas (Campos et al. 1996). A presença de foraminíferos bióticos (Bucella peruviana e Quinqueloculina seminulum), de foraminíferos planctônicos (Globigerina bulloides) juntamente com ostracodes e micro-bivalves típicos da plataforma do Uruguai e Argentina sugeriram a penetração de águas de uma extensão da Corrente das Malvinas na plataforma Continental Sudeste do Brasil (Stevenson et al.,1998). Mais recentemente Piola et al (2000) mostrou que as águas frias presentes na região mais ao sul do Embaiamento de São Paulo eram associadas à águas provenientes do deságüe do Rio da Prata.

Ao norte da plataforma, os meandramentos da Corrente do Brasil fazem as águas quentes penetrarem na plataforma média e superior (Piola et al. 2000).

Bancos de dados observacionais de TSM para a região da margem continental do Sudeste do Brasil são raros ou inexistentes. Os dados históricos de TSM média para a área (Fig. 14) derivam de programas multinacionais como o COADS, Reynolds, Levitus e o SODA, porém esses programas utilizam pontos observacionais localizados após a quebra da plataforma.

Os registros de TSM desses programas mostram águas mais frias ao sul, mínimo de $22^{\circ} \mathrm{C}$ (COADS, Reynolds e SODA) e águas mais quentes ao norte, máximo de $25^{\circ} \mathrm{C}$ (SODA). As diferenças de TSM fornecidas por esses programas derivam da metodologia de coleta de dados de cada um deles.

No COADS os dados provêm de relatórios de navios, bóias e outros tipos de plataformas, com observações individuais de variáveis meteorológicas e oceanográficas como temperatura da superfície do mar e do ar, vento, pressão, umidade e nebulosidade. No Reynolds além dos dados obtidos in situ, como no COADS, são combinados também os dados dos resultados das imagens de satélite. O programa LEVITUS, assim como o COADS trabalha com dados analisados in situ. No SODA, os perfis reportados são produtos de uma reanálise que combina dados observacionais com modelagem oceânica. 


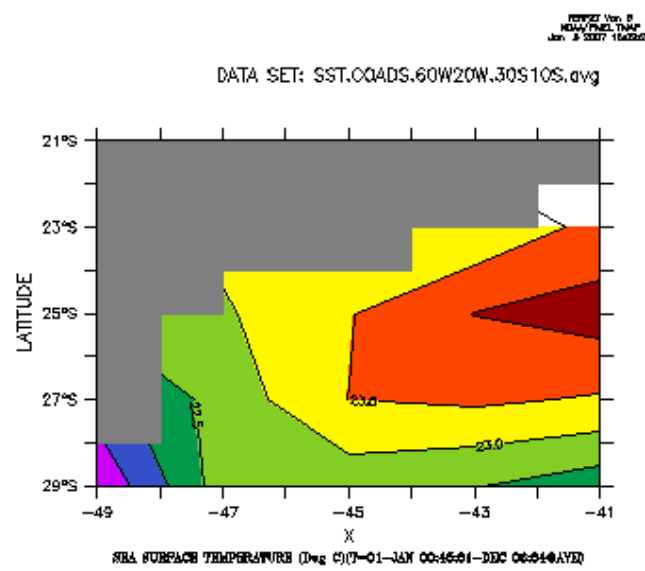

COADS

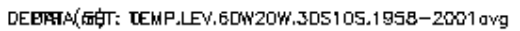

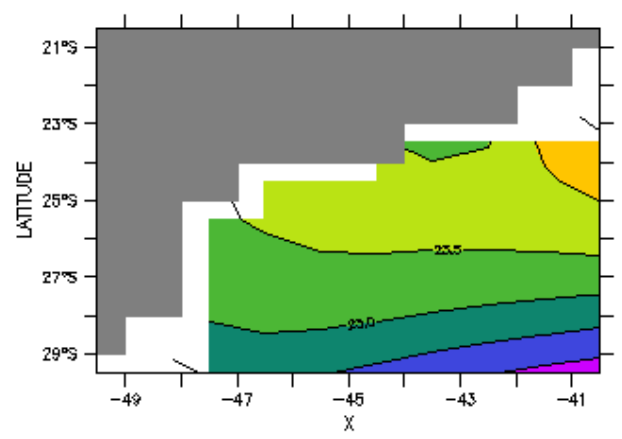

TEMPERATURE (DEG C)

Levitus

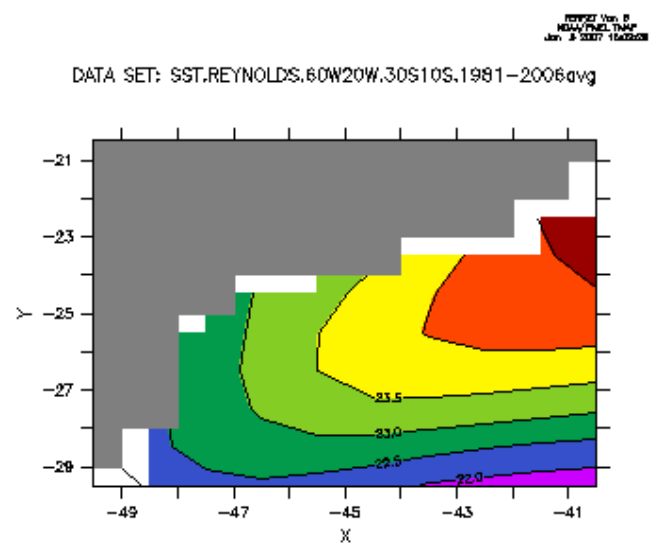

Sea Surface Temperature (Celsius_scale)

Reynolds

ZRAER SET: TEMP.SODA.6CW20W.305105.1958-2001 avg

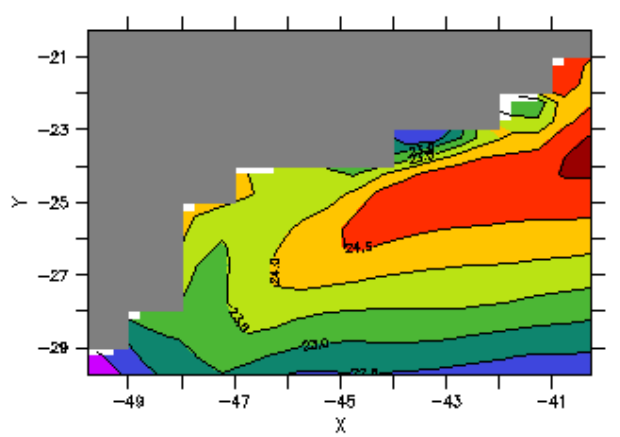

TEMPERATURE (Celsius_scale)

SODA

Figura 14: TSM média histórica para a região nos diferentes programas.

De forma a comparar a semelhança entre os valores de TSM fornecidos pelos programas multinacionais e os dados de TSM obtidos a partir das amostras de superfície, os valores de $U_{37}^{k^{\prime}}$, obtidos a partir da análise das alquenonas nas amostras de superfície, foram plotados contra a TSM fornecida por cada um dos programas multinacionais (Fig.15). A figura mostra que os dados dos programas que mais se aproximam da calibração de Prahl e Wakeham (1987) são os dados dos programas COADS e Reynolds.

Uma característica dos registros (COADS, Reynolds e Soda) é a presença de uma "língua" de água quente a nordeste da região. Apesar da pequena quantidade de amostras superficiais analisadas neste trabalho, 0 gradiente e os valores de TSM $U_{37}^{k^{\prime}}$ são semelhantes aos fornecidos pelos programas citados. 
A Figura 16 apresenta a comparação dos valores de TSM, calculados a partir do índice $U_{37}^{k^{\prime}}$ e os valores de TSM, extraídos dos programas multinacionais, com o desvio padrão entre os resultados dos programas. Observa-se que nas estações 7607, 7608, 7617, 7618, 7619, 7620, 7622 e 7623 os valores de TSM divergem dos resultados dos programas, enquanto que nas estações 7605, 7606, 7609, 7610, 7611, 7612, 7613, 7615, 7616 e 7621 os resultados de TSM coincidem com os valores esperados de TSM dos programas. O maior desvio entre a TSM e os resultados dos programas foi de $1,5^{\circ} \mathrm{C}$, na estação 7622 . Desvios de até $1,6^{\circ} \mathrm{C}$ se encontram dentro de um nível de confiança de 95\% (Rosell-Melé et al., 2001).

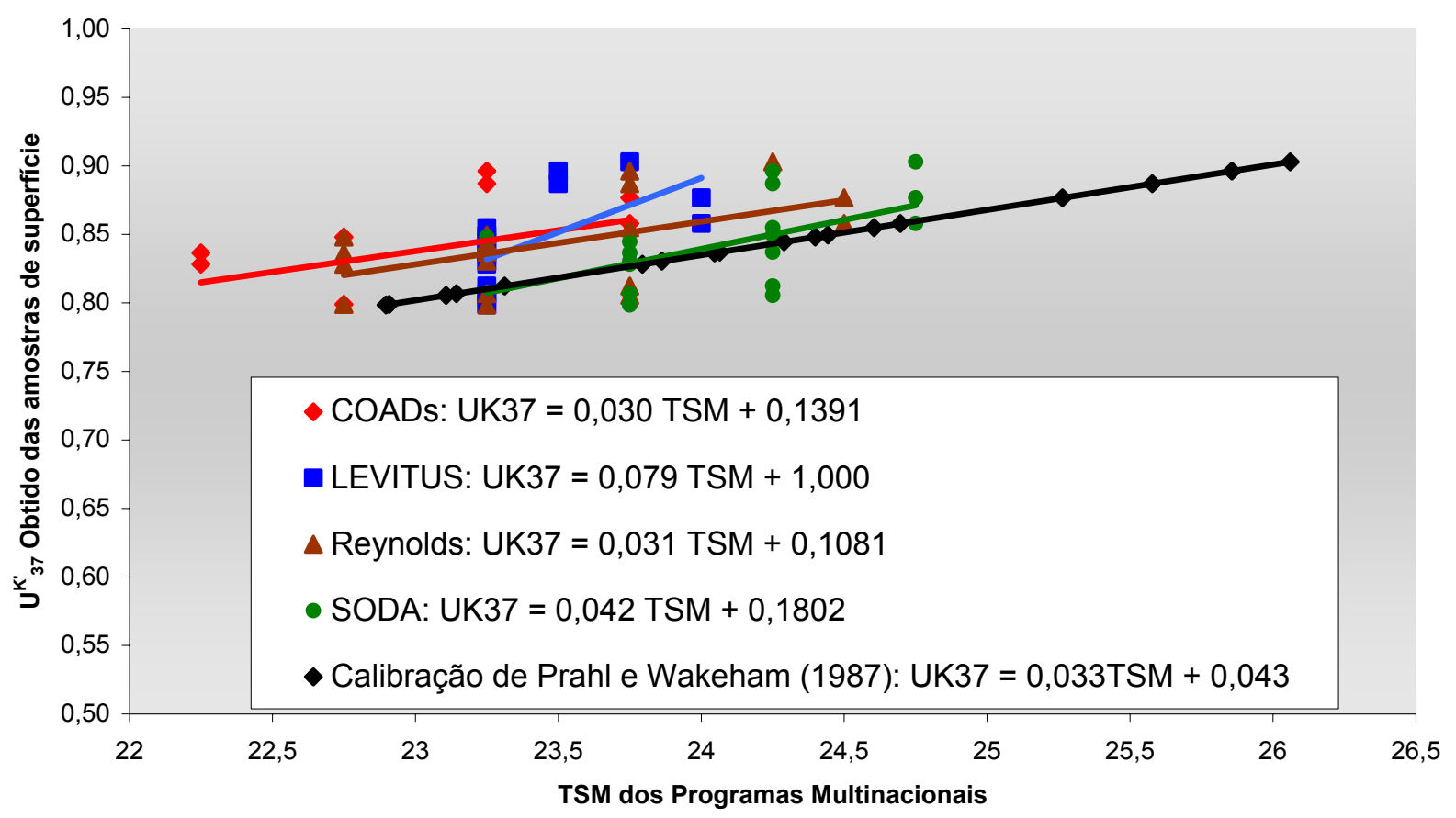

Figura 15: Relações entre os valores de $U_{37}^{k^{\prime}}$ obtidos a partir das análises das alquenonas e TSM obtidas dos programas multinacionais. 


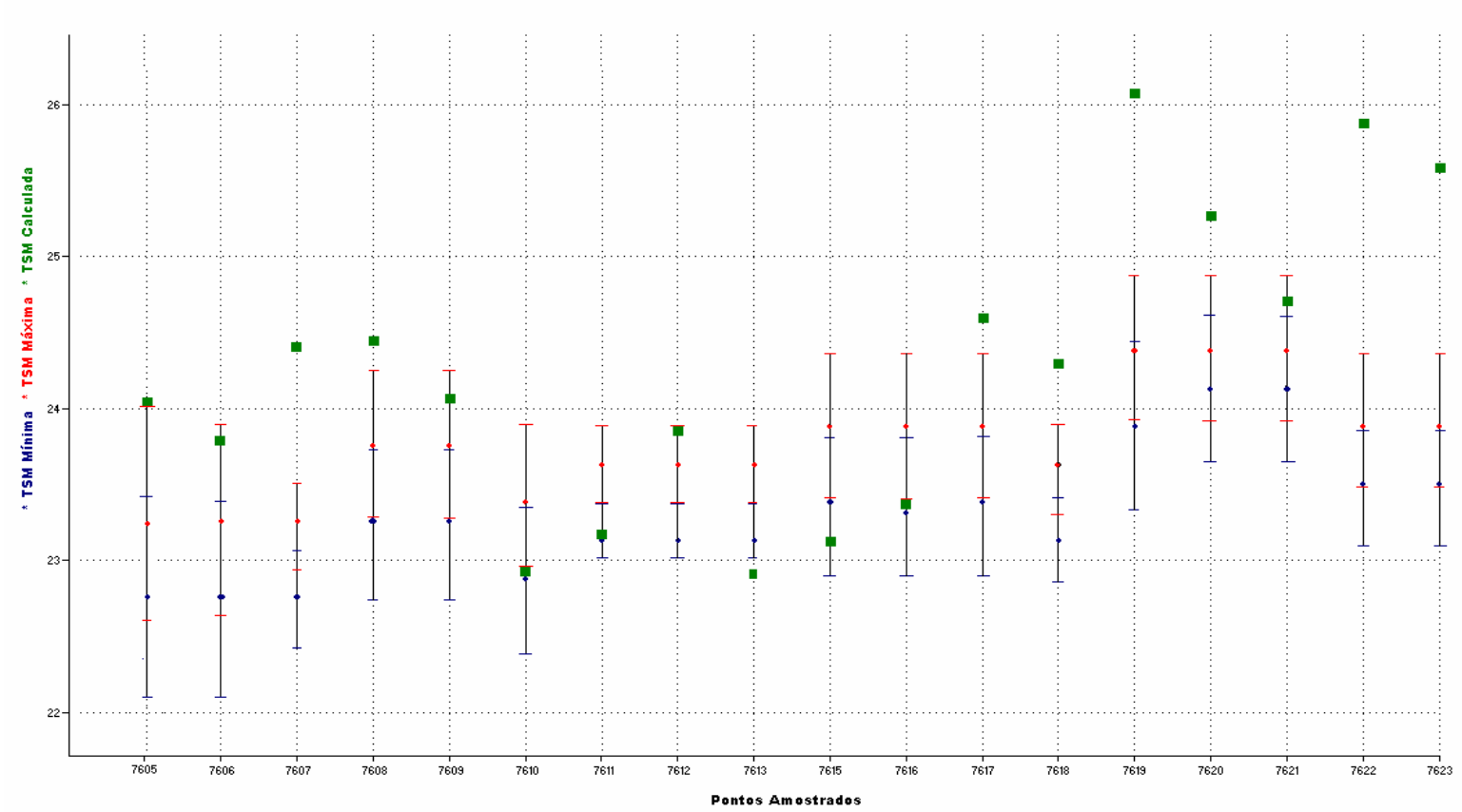

Figura 16: Comparação dos valores de TSM calculados a partir do índice $U_{37}^{k^{\prime}}$ e os valores de TSM extraídos dos programas multinacionais.

Observa-se que, comparando os resultados de TSM, calculados a partir do índice $U_{37}^{k^{\prime}}$ com os resultados de programas, cujos dados são obtidos além da quebra da plataforma continental, obteve-se valores comparáveis e dentro de uma margem de confiança de 95\%. Essa concordância entre os resultados de TSM $U_{37}^{k^{\prime}}$ obtidos e os valores históricos de TSM mostram que a correlação de Prahl e Wakeham (1987), $U_{37}^{k^{\prime}}=0,033 T S M+0,043$, é aplicável na região do Embaiamento de São Paulo.

\subsubsection{Marcadores de Material Terrígeno Marcadores Orgânicos Moleculares TAR}

Os valores mais elevados de TAR ocorrem ao sul da llha de São Sebastião (SP) e próximos à costa (Fig. 17). A parir da llha de São Sebastião, em direção ao norte, os valores de TAR diminuem progressivamente. Essa diferença nos valores de TAR apontam para um menor aporte, ou menor 
acúmulo de material terrígeno ao norte da ilha. Existe ainda um valor alto de TAR na região próxima a $45^{\circ} \mathrm{W}$ e $25,5^{\circ} \mathrm{S}$.

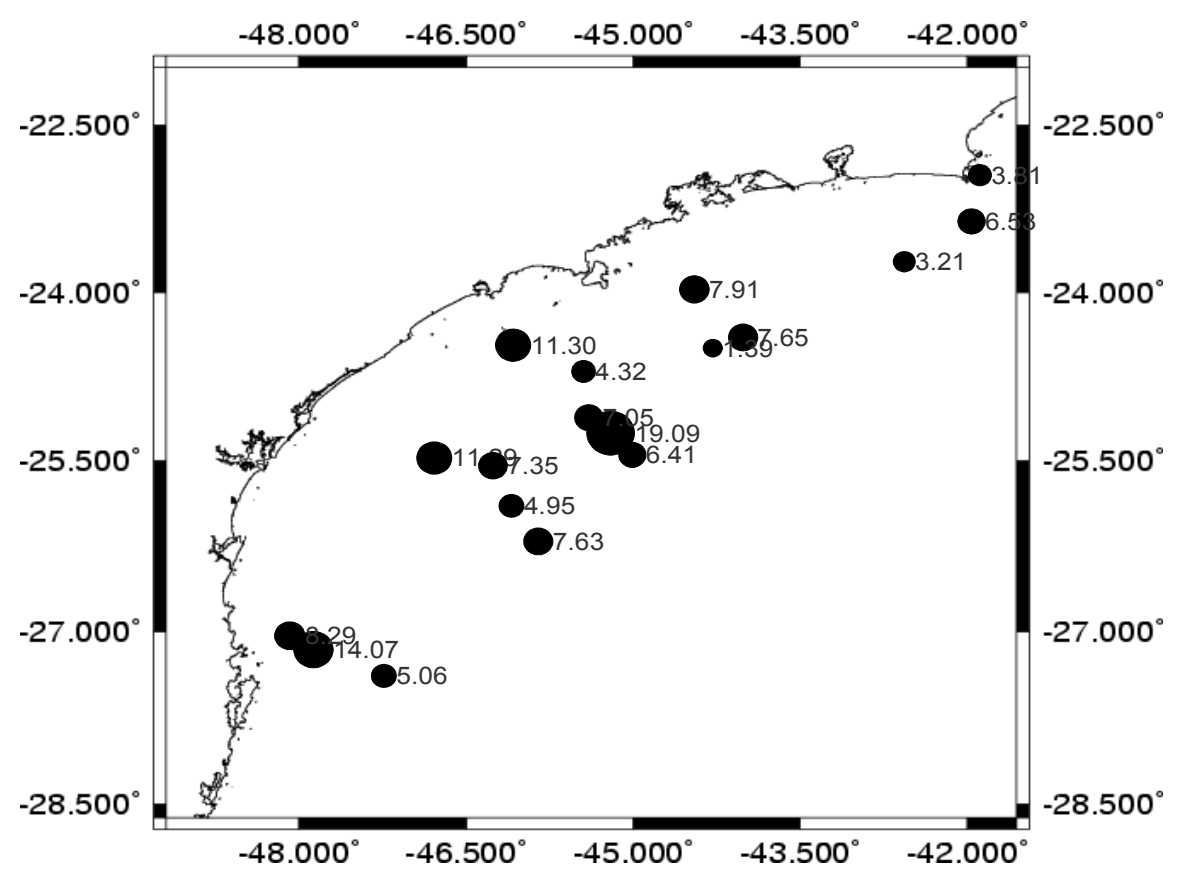

Figura 17: Distribuição do TAR ao longo da margem continental superior do Sudeste do Brasil.

\section{IPC}

Os menores valores de IPC são encontrados ao norte do Embaiamento de São Paulo, próximo à região de Cabo Frio, com exceção da estação 7620 , localizada junto a Cabo Frio (Fig. 18). Nas áreas próximas à costa o valor é praticamente constante, diminuindo gradualmente em direção a plataforma externa. Os menores valores de IPC ao norte da Ilha de São Sebastião refletem o gradiente do TAR, ou seja, menor quantidade de material terrígeno transportada para o meio marinho ao norte da área de estudo 


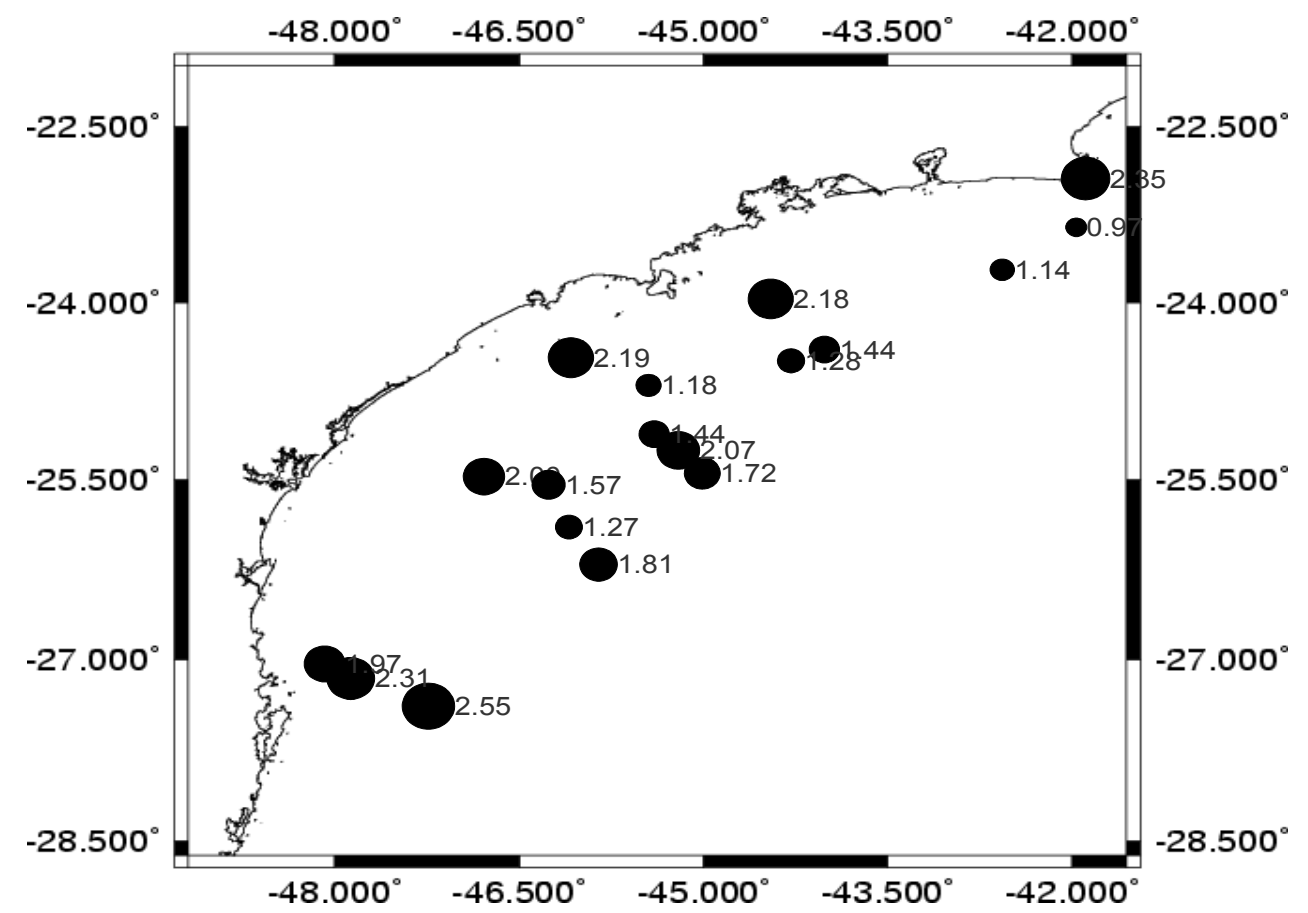

Figura 18: Distribuição do IPC ao longo da margem continental superior do Sudeste do Brasil.

\section{Ácidos Pesados}

As menores concentrações de ácidos pesados são encontradas a nordeste da região estudada, aumentando em direção a sudoeste (Fig. 19). O perfil parece acompanhar o perfil de TSM $U_{37}^{k^{\prime}}$. As menores concentrações de ácidos pesados foram encontradas junto aos menores valores de TAR E IPC, reforçando o fato de que a norte da llha de São Sebastião o aporte ou acúmulo de material terrígeno é menor do que ao sul da ilha. 


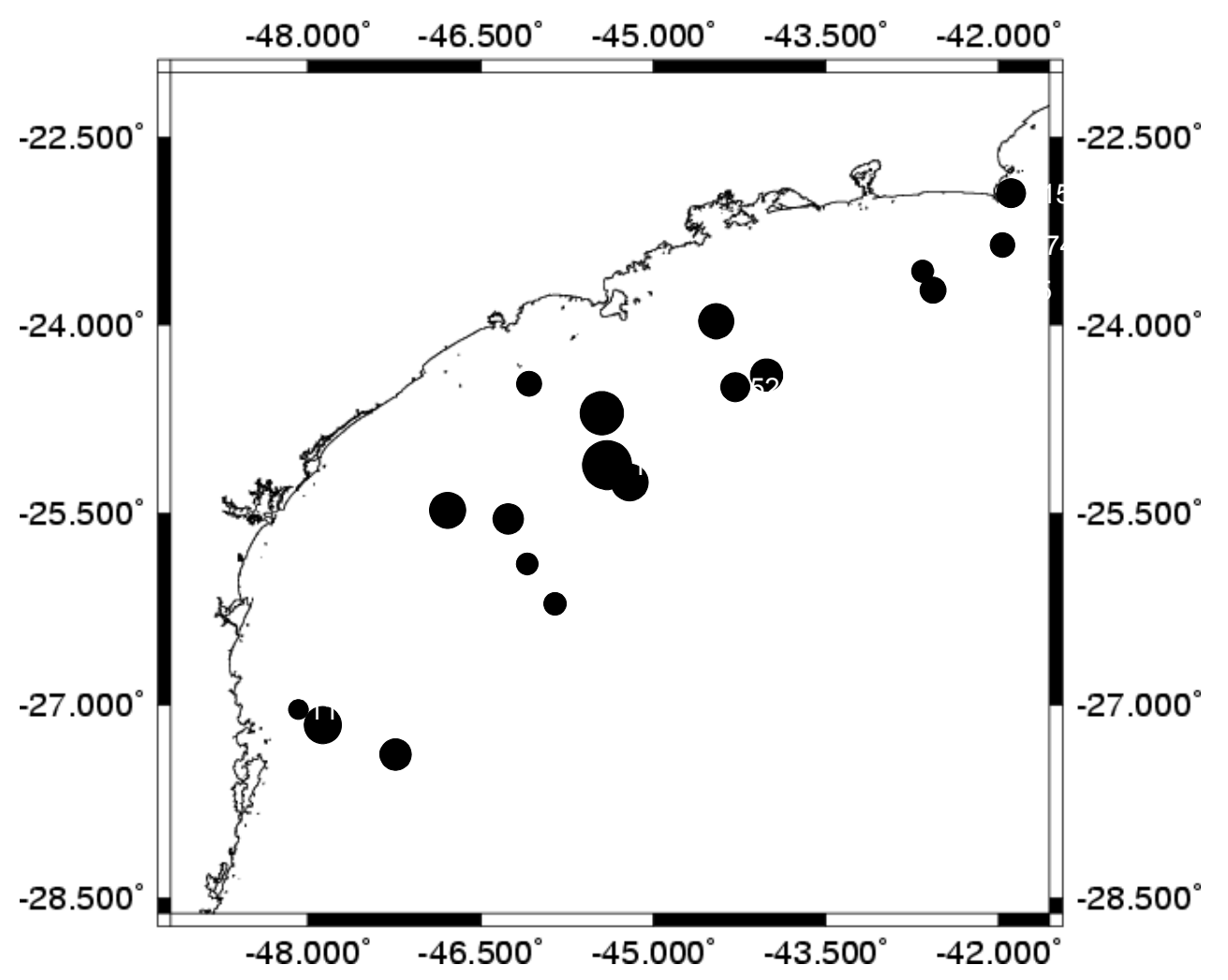

Figura 19: Distribuição de ácidos pesados ao longo da margem continental superior do Sudeste do Brasil.

\section{Álcoois Pesados}

Ao contrário dos outros marcadores de origem terrígena, os álcoois pesados não apresentam as menores concentrações ao norte da llha de São Sebastião (Fig. 20). Apesar de serem compostos derivados de plantas superiores, assim como os ácidos, eles não apresentam distribuição semelhante a dos ácidos e dos outros marcadores terrígenos.

Mahiques (2004) obteve valores de $\delta^{13} C_{\mathrm{PDB}}$ para essa mesma região que mostram que, ao longo da costa, desde Cabo Frio, até Paranaguá, os valores de $\delta^{13} \mathrm{C}_{\mathrm{PDB}}$ são praticamente constantes ao longo das isóbatas.

O motivo para marcadores como os álcoois pesados ou $\delta^{13} \mathrm{C}$ não responderem como os outros marcadores de material terrígeno na região estudada pode estar associado a diferenças na natureza da matéria orgânica que ocorre ao norte e ao sul da llha de São Sebastião. Essa diferenciação da natureza da matéria orgânica pode estar relacionada, por exemplo, ao clima, que passa de tropical para temperado, em direção ao Sul, na altura de 
Cananéia, ao tipo e a preservação da vegetação, floresta ambrófila densa, preservada ao norte de Santos e degradada ao sul, e ao tipo de solo encontrado na costa, cambissolo háplico ao norte da Ilha de São Sebastião e espodossolo ferrocárbico ao Sul da Ilha (IBGE).

Esses resultados indicam que os álcoois pesados podem não ser bons traçadores espaciais de matéria orgânica de origem terrígena nessa região.

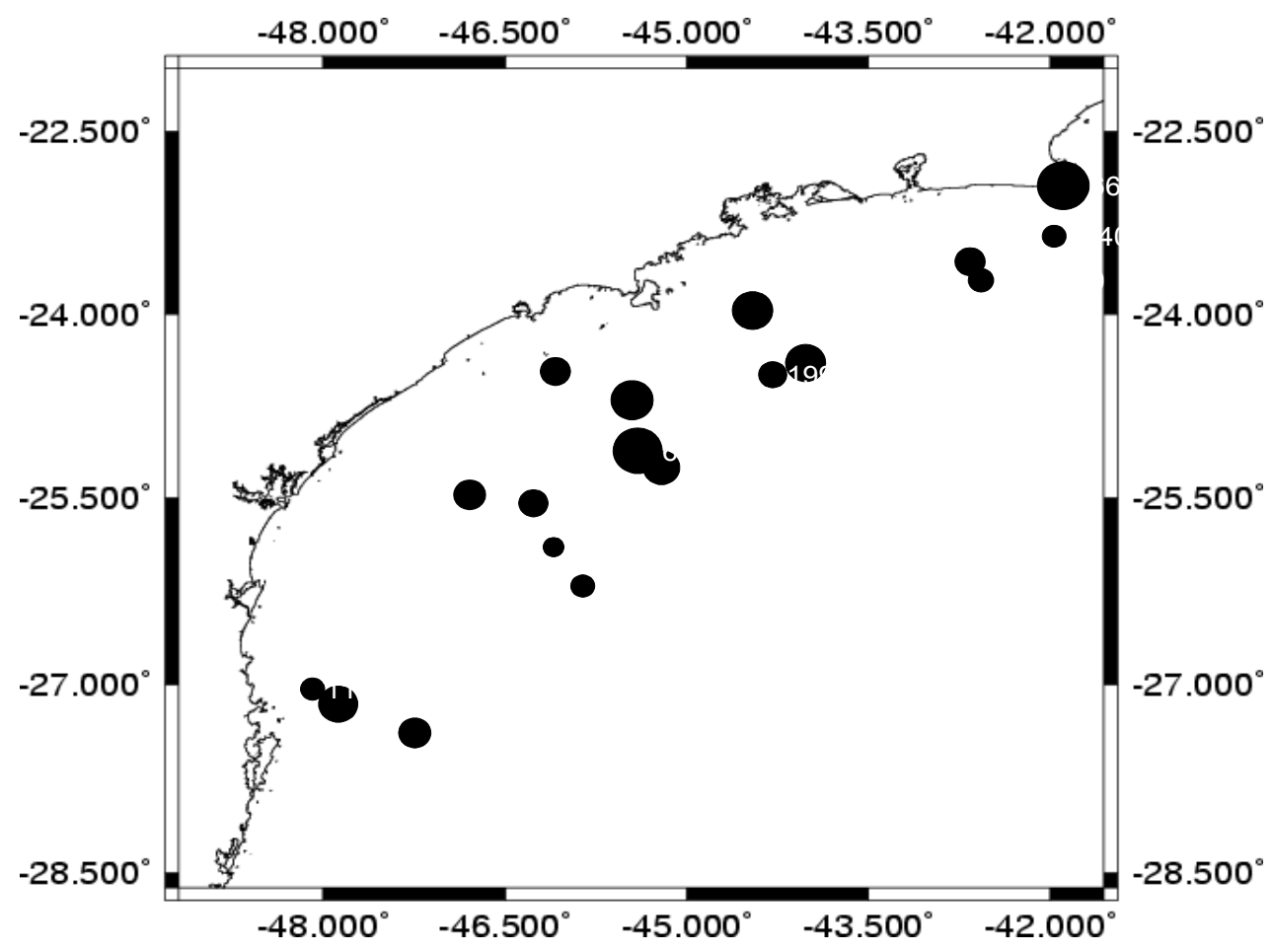

Figura 20: Distribuição de álcoois pesados ao longo da margem continental superior do Sudeste do Brasil.

\section{Outros Marcadores}

\section{Metais}

As razões entre $\mathrm{Fe} / \mathrm{Ca}$ e $\mathrm{Ti} / \mathrm{Ca}$ apresentam os maiores valores na região ao Sul da Ilha de São Sebastião, coincidindo os outros traçadores de material terrígeno, TAR, IPC e ácidos pesados (Fig. 21 e Fig. 22). 


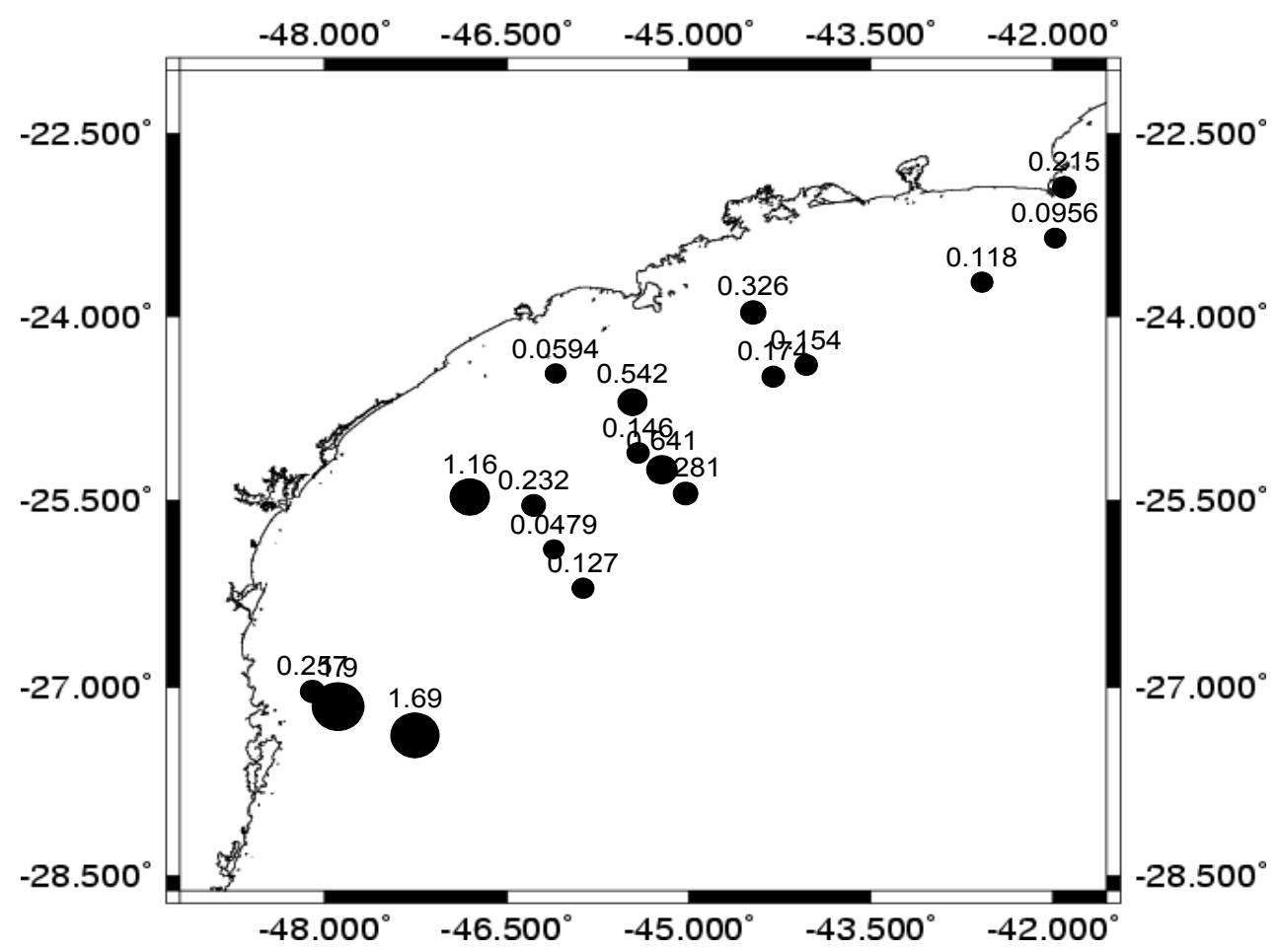

Figura 21: Distribuição da razão $\mathrm{Fe} / \mathrm{Ca}$ ao longo da margem continental superior do Sudeste do Brasil.

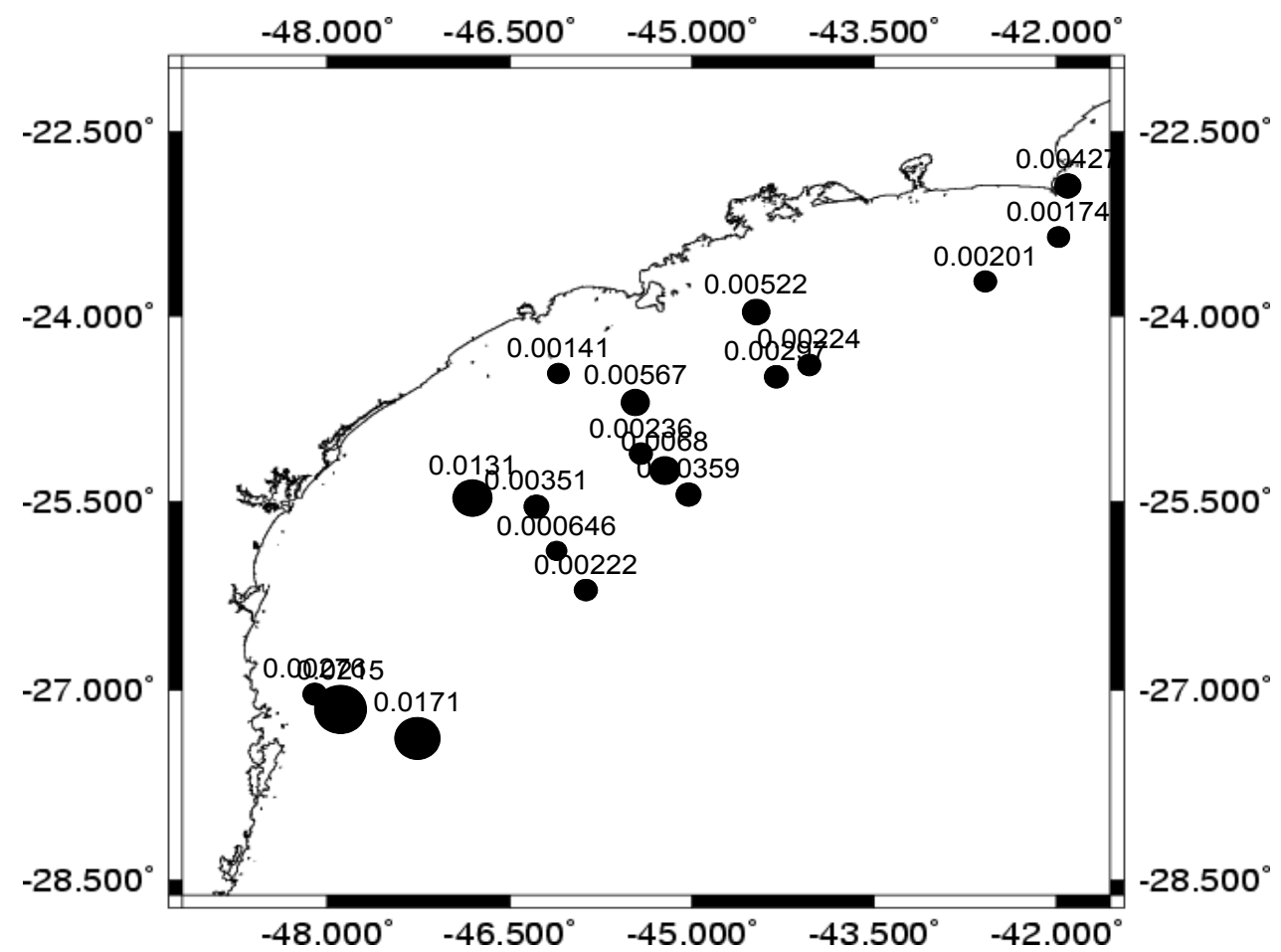

Figura 22: Distribuição da razão Ti/Ca ao longo da margem continental superior do Sudeste do Brasil. 


\subsubsection{Marcadores de Produtividade}

\section{Marcadores Orgânicos Moleculares}

\section{$\Sigma$ Alquenonas}

O gradiente de distribuição espacial das alquenonas (Fig. 23) segue um perfil bastante semelhante ao do TAR, sugerindo que a maior presença de material terrígeno favorece a produtividade primária, já que alquenonas derivam exclusivamente de fitoplâncton. Em torno de $45^{\circ} \mathrm{W}$ e $25,5^{\circ} \mathrm{S}$ foram observados os maiores valores de concentração de alquenonas da região estudada.

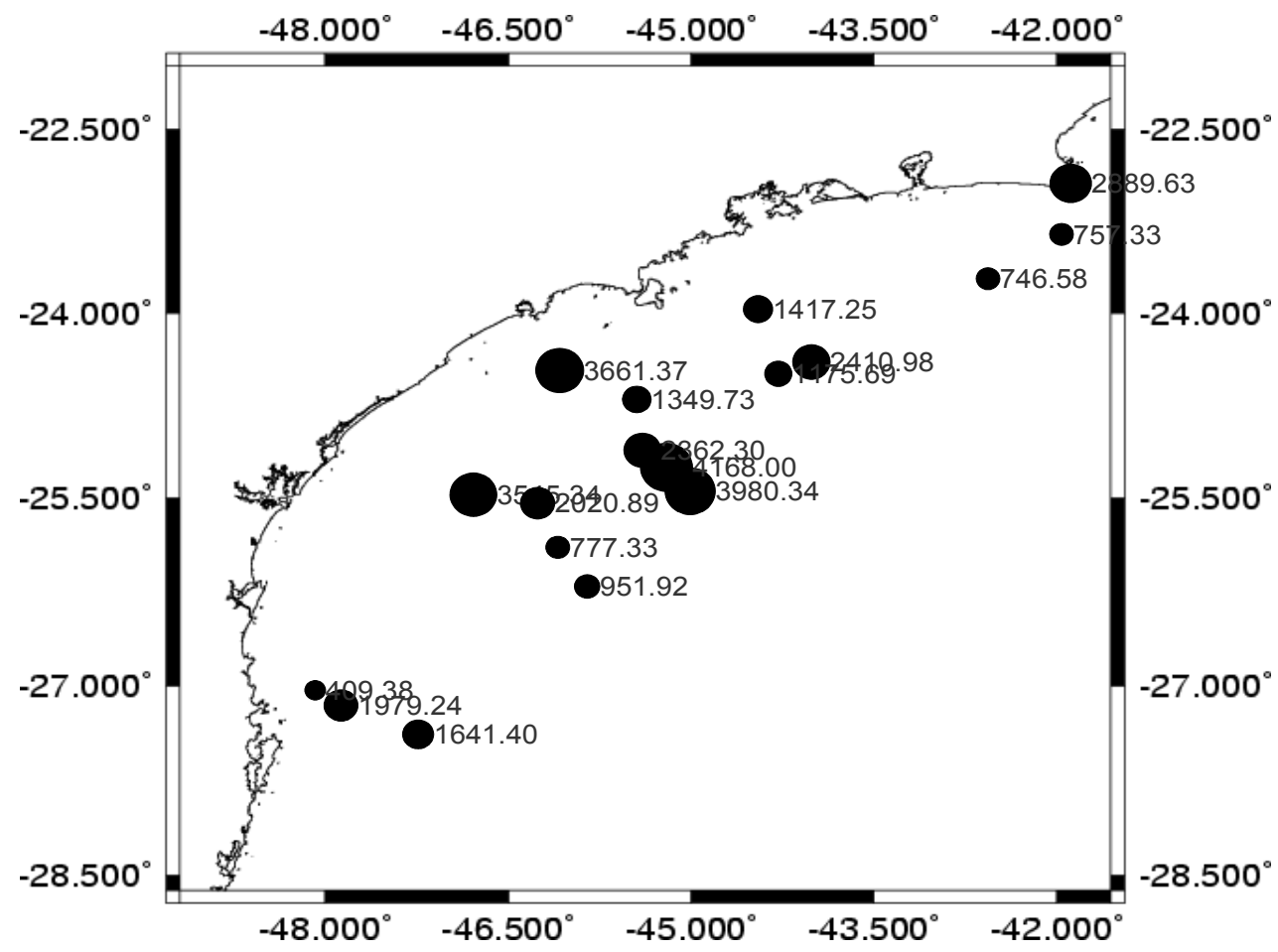

Figura 23: Distribuição da somatória de alquenonas ao longo da margem continental superior do Sudeste do Brasil.

\section{Clorinas}

Os maiores valores de clorinas são encontrados nas mesmas regiões onde foram encontrados os maiores valores de TAR e as maiores concentrações de alquenonas, ou seja, ao sul da Ilha de São Sebastião (SP). Os menores valores foram encontrados nas proximidades de Cabo Frio (RJ).

Valores anômalos de clorofila foram observados também na região próxima a $45^{\circ} \mathrm{W}$ e $25,5^{\circ} \mathrm{S}$ (Fig. 24). 


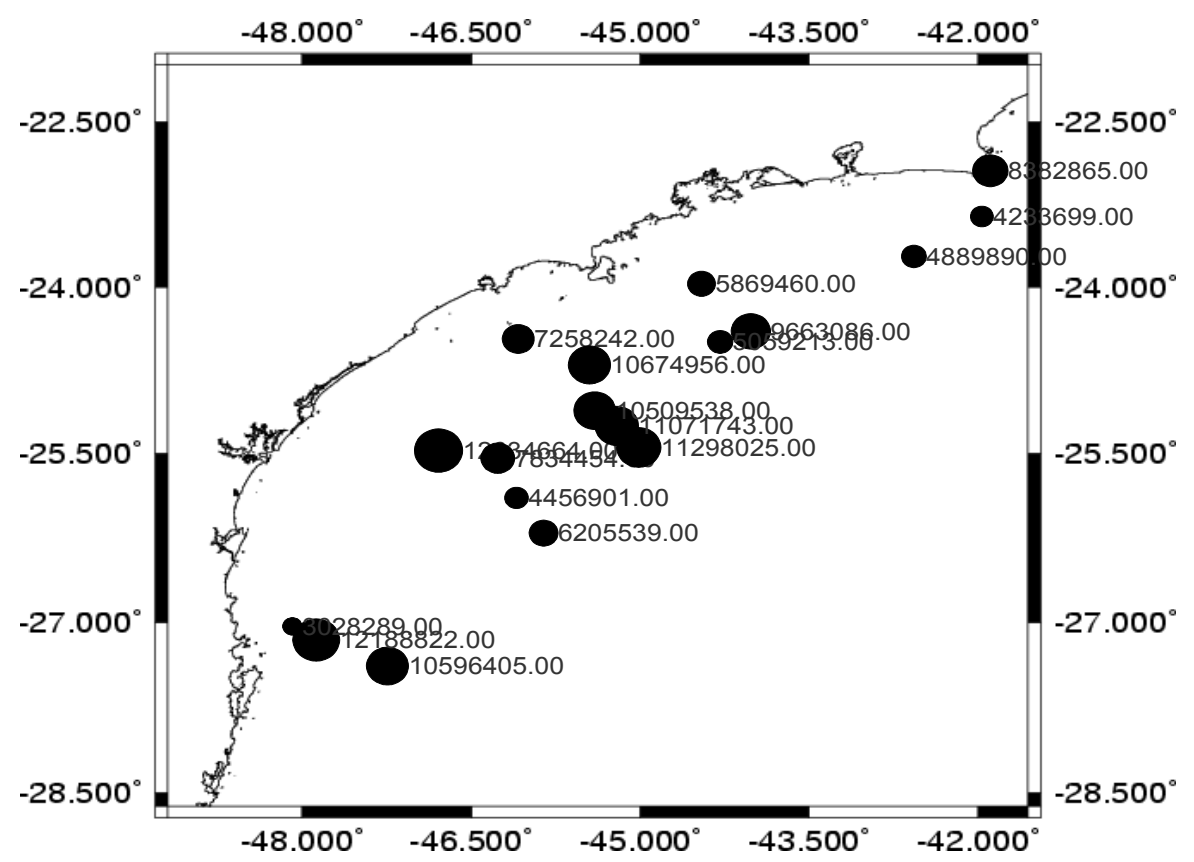

Figura 24: Distribuição da concentração de clorinas ao longo da margem continental superior do Sudeste do Brasil (valores relativos - área do pico cromatográfico).

\section{Outros Marcadores}

\section{Metais}

As relações entre os metais, $\mathrm{Ba} / \mathrm{Al}, \mathrm{Ba} / \mathrm{Ti}, \mathrm{Ba} / \mathrm{Ca}, \mathrm{Al} / \mathrm{Ti}$ e $\mathrm{Sr} / \mathrm{Ca}$, marcadores de produtividade são mostradas nas Figuras 25 a 29.

As figuras mostram que as relações $\mathrm{Ba} / \mathrm{Al}$ e $\mathrm{Ba} / \mathrm{Ti}$ apresentam maiores valores na região a nordeste da área de estudo, enquanto que as relações $\mathrm{Ba} / \mathrm{Ca}$ e $\mathrm{Al} / \mathrm{Ti}$ apresentam os maiores valores a sudoeste da área estudada. $\mathrm{A}$ relação Sr/Ca não mostra nenhuma tendência.

Para as concentrações de bário encontradas na região não há como distinguir a contribuição terrígena da contribuição biogênica. Assim os valores das razões apresentadas envolvendo bário podem estar superestimados para a avaliação de produtividade.

Ao contrário dos marcadores orgânicos moleculares, os metais apresentaram resultados divergentes para a avaliação da produtividade na área, as relações $\mathrm{Ba} / \mathrm{Al}$ e $\mathrm{Ba} / \mathrm{Ti}$ indicam maior produtividade a nordeste enquanto que as relações $\mathrm{Ba} / \mathrm{Ca}$ e $\mathrm{Al} / \mathrm{Ti}$ apontam maior produtividade a sudoeste, coincidindo com a resposta dos marcadores orgânicos moleculares. 


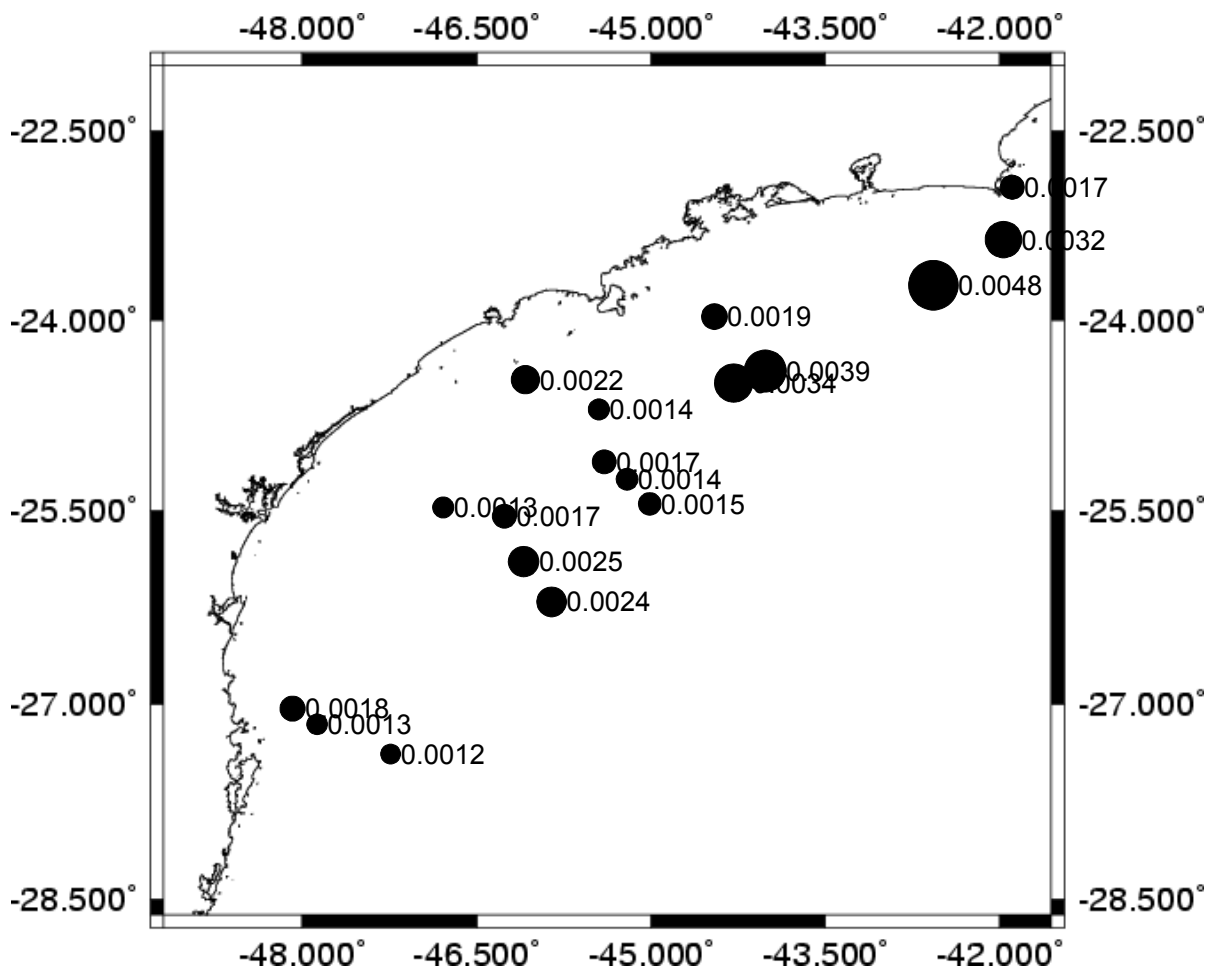

Figura 25: Distribuição da razão Ba/Al ao longo da margem continental superior do Sudeste do Brasil.

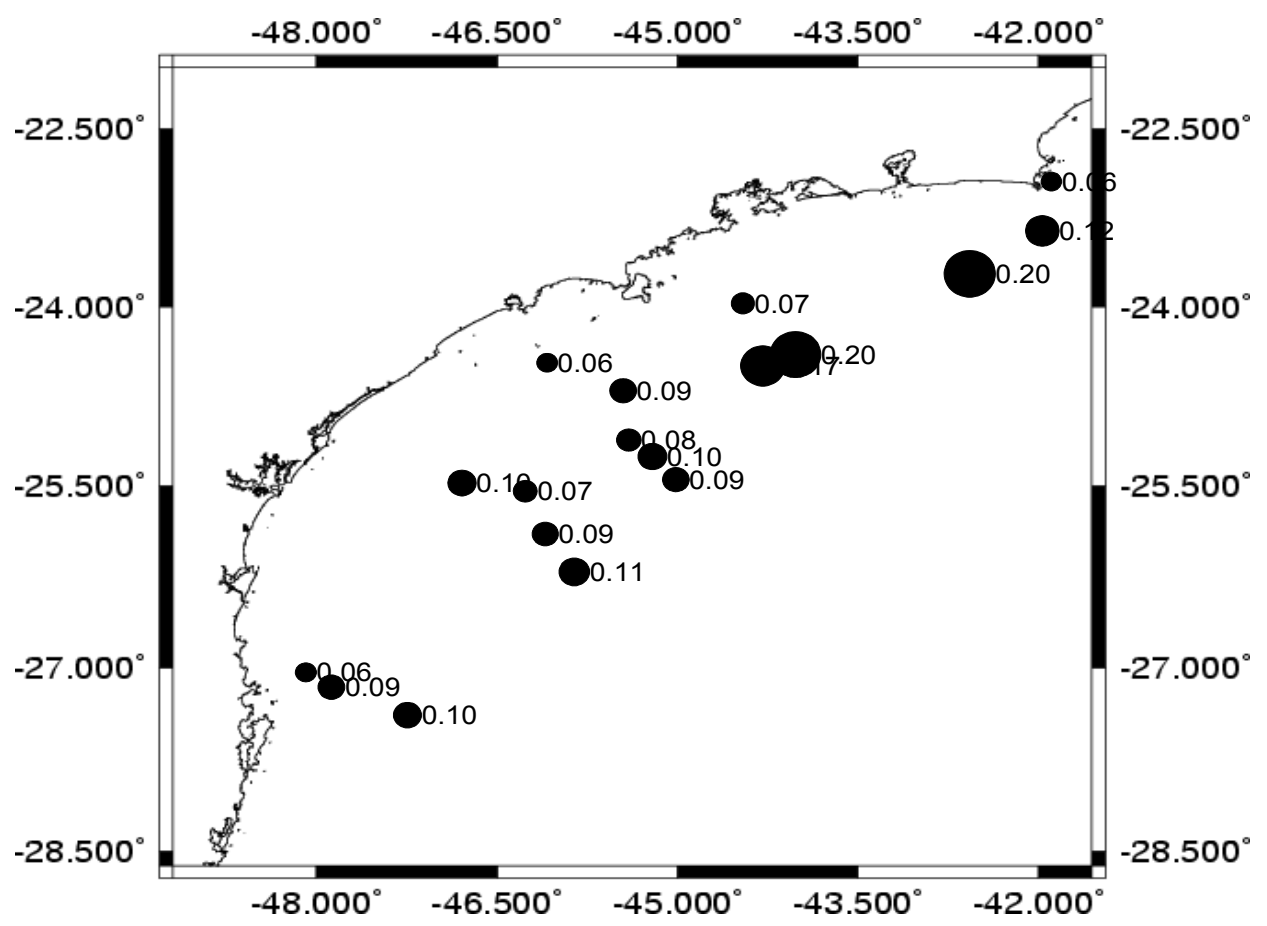

Figura 26: Distribuição da razão Ba/Ti ao longo da margem continental superior do Sudeste do Brasil. 


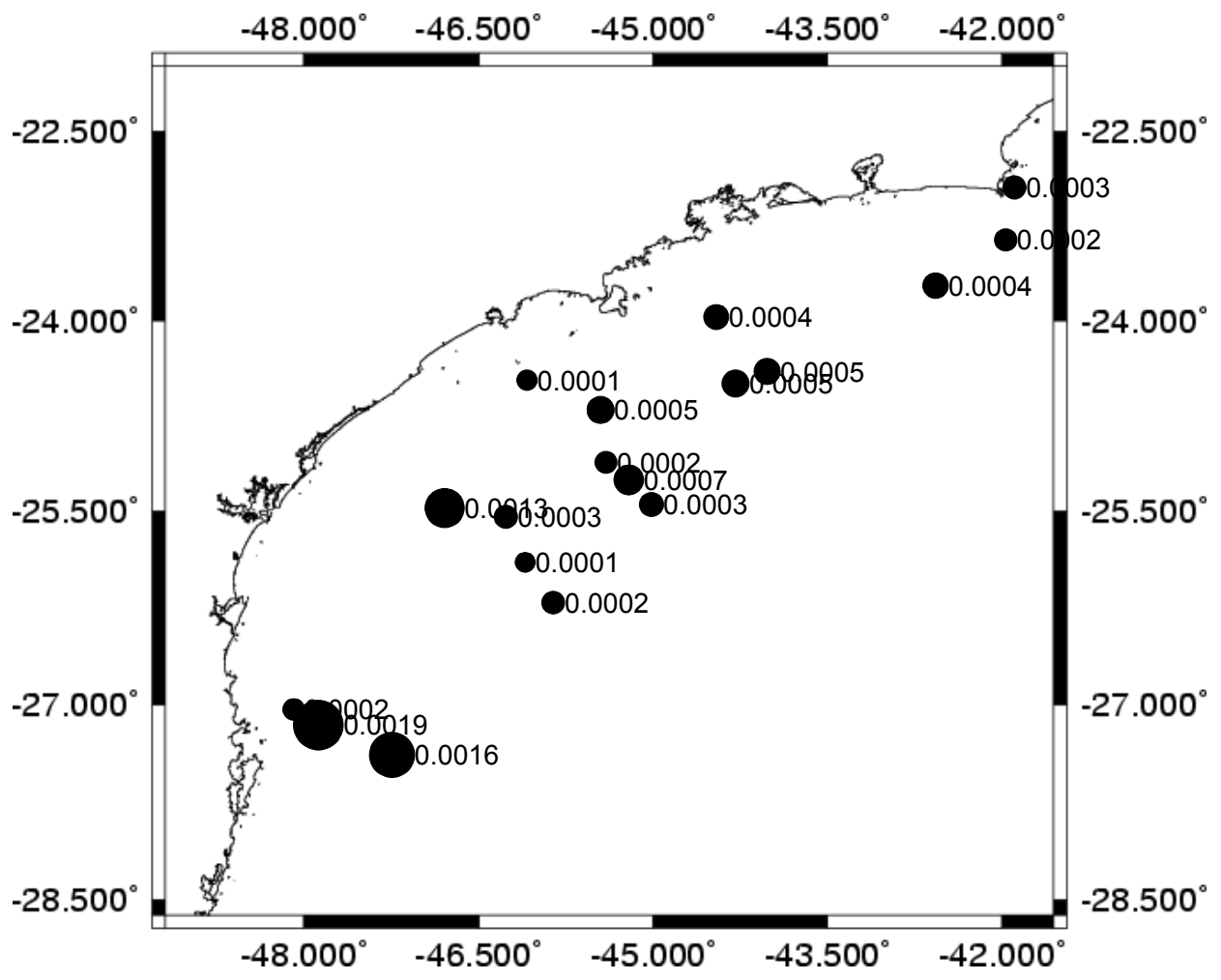

Figura 27: Distribuição da razão $\mathrm{Ba} / \mathrm{Ca}$ ao longo da margem continental superior do Sudeste do Brasil.

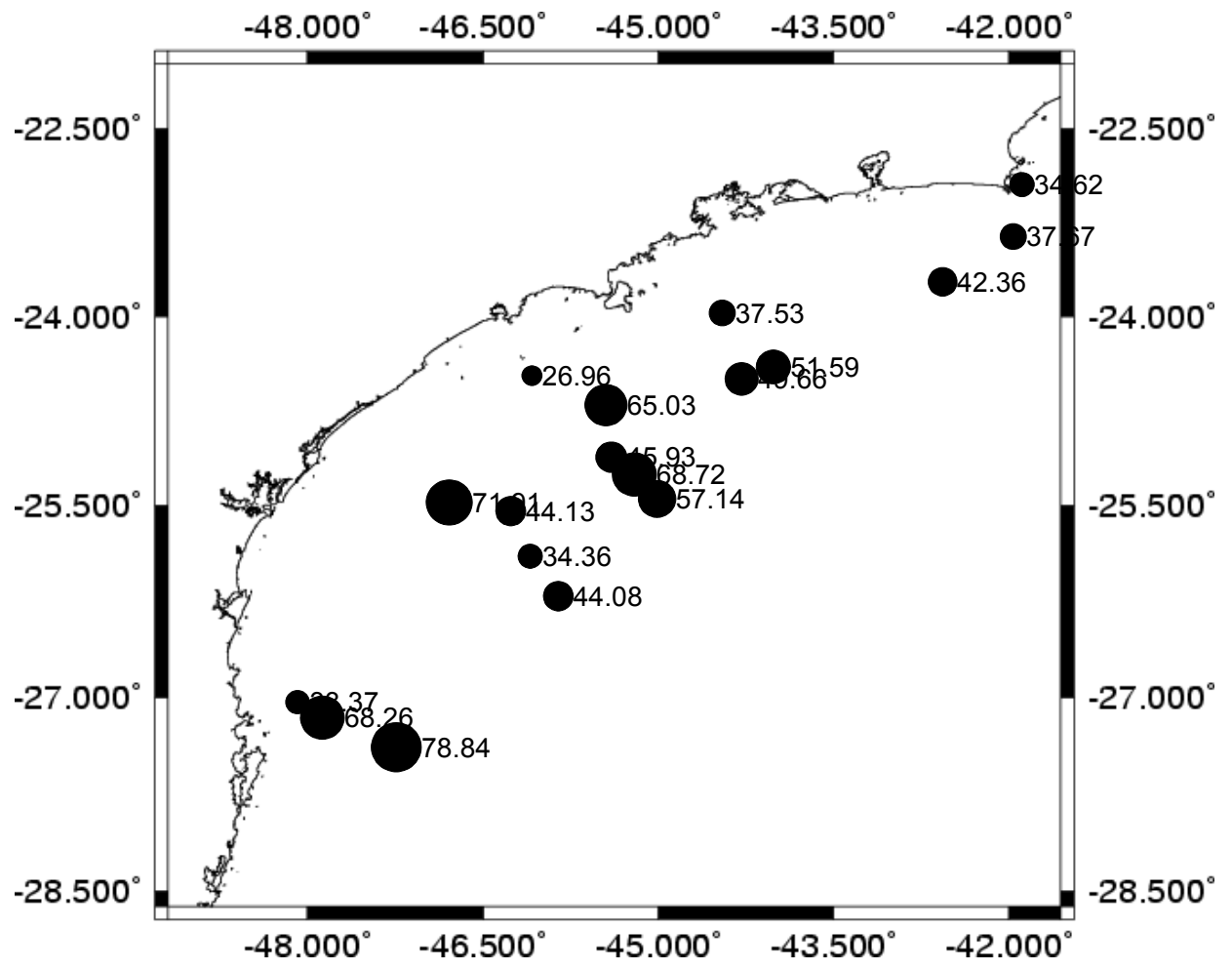

Figura 28: Distribuição da razão $\mathrm{Al} / \mathrm{Ti}$ ao longo da margem continental superior do Sudeste do Brasil. 


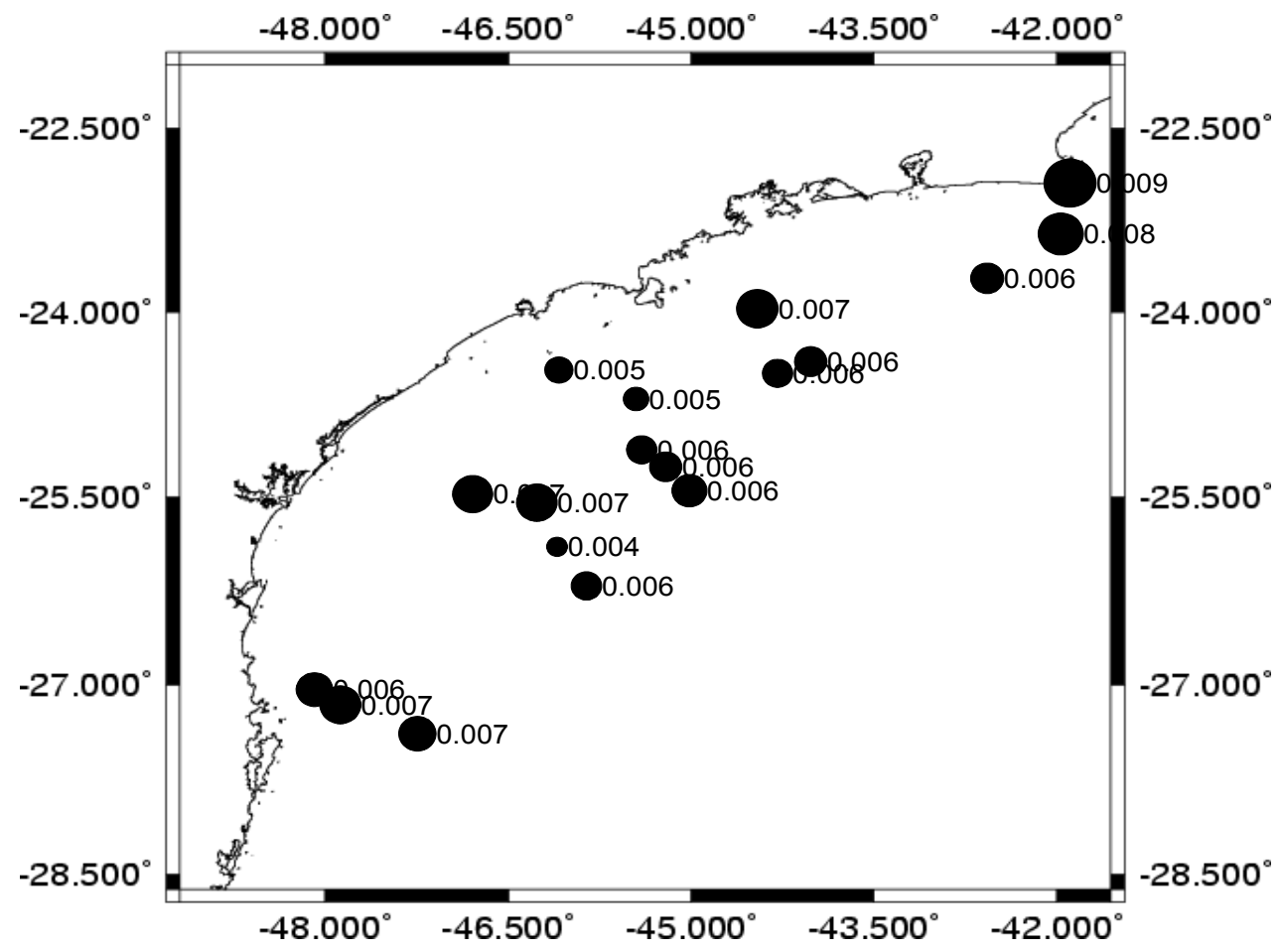

Figura 29: Distribuição da razão $\mathrm{Sr} / \mathrm{Ca}$ ao longo da margem continental superior do Sudeste do Brasil.

Além dos problemas envolvendo a avaliação da produtividade através do bário nesse trabalho, a dispersão Al x Ti na área forneceu um $R^{2}=0,2818$ (Fig. 30), sugerindo que o Al pode estar relacionado à características não terrígenas e não pode ser utilizado como elemento normalizante para os outros metais.

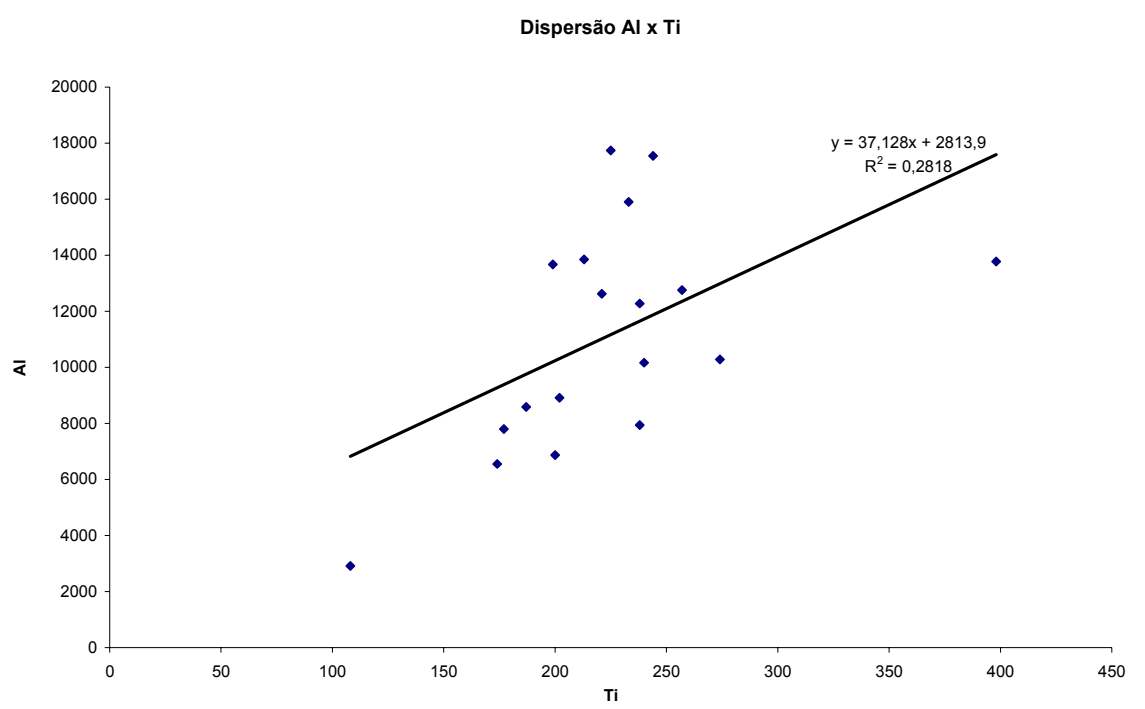

Figura 30: Dispersão Alumínio x Titânio nas amostras de superfície. 
Comparando os dados de produtividade da região com as imagens de concentração estimada de clorofila, extraídas do SeaWIFS (Fig. 31) (apud Mahiques, 2004), vemos que as concentrações de clorofila são menores ao norte da llha de São Sebastião.
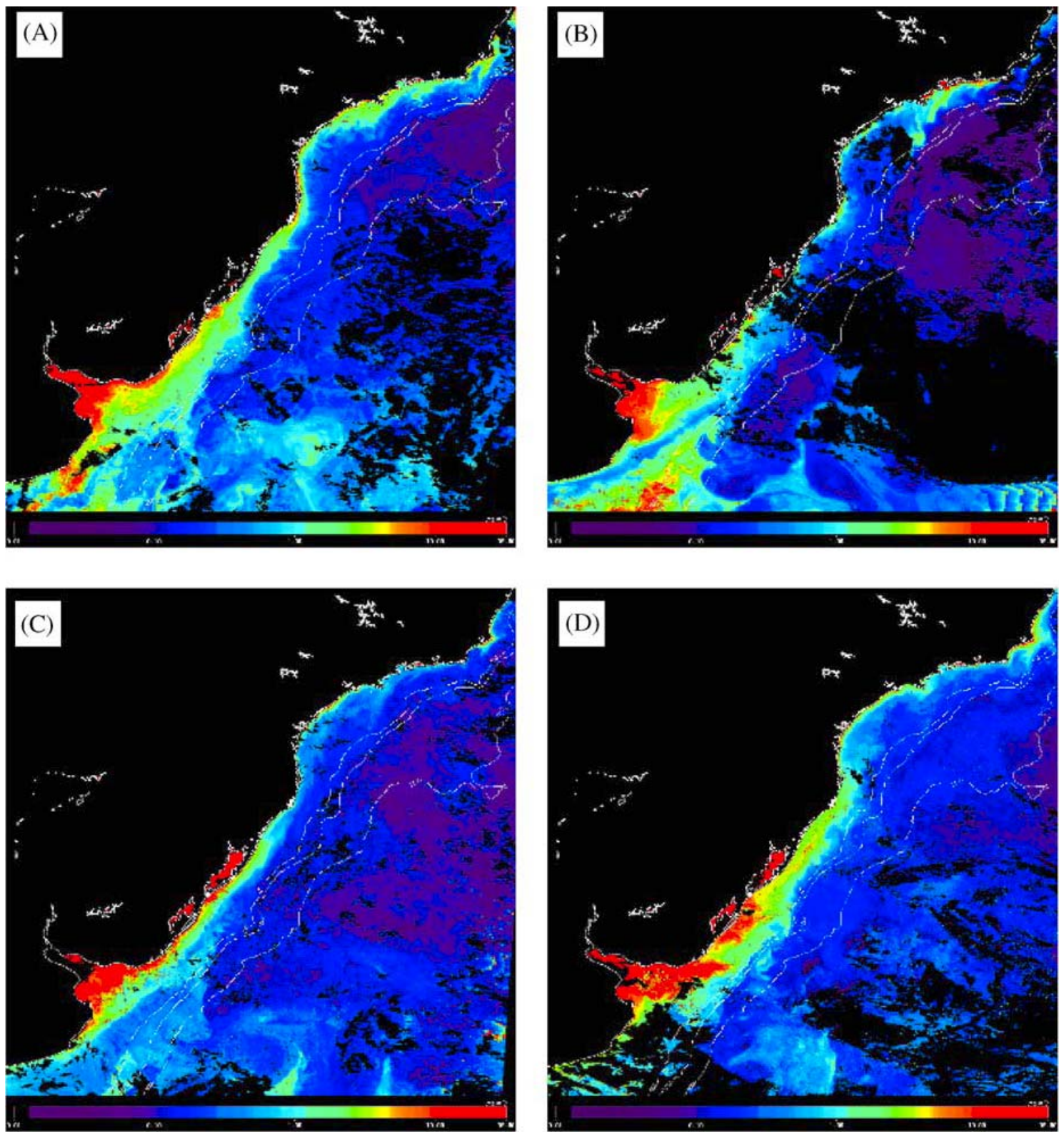

Figura 31: Concentração estimada de clorofila na superfície (mg. $\left.\mathrm{m}^{-3}\right)$ usando o algoritmo OC2v4 Sea WIFS. Figuras de alta resolução $(1 \mathrm{~km})$ compostas entre 4 e 7 dias representando (A) Primavera, (B) Verão, (C) Outono e (D) Inverno de 2001. 


\subsubsection{Análise estatística dos resultados}

De forma a verificar a interdependência dos marcadores, todos os parâmetros estudados foram correlacionados através do coeficiente de Pearson. Na Tabela 12 são apresentados apenas os valores de correlação com probabilidade de erro $<5 \%(\rho<0,05$, ) e são destacados os valores cuja correlação é forte, ou seja, maior que 0,5.

A análise estatística confirma a distribuição dos parâmetros acima descritos. A análise mostra que os maiores valores de n-alcanos coincidem com os maiores valores de TAR, alquenonas e ácidos pesados, e que quanto maior o IPC maior é também a quantidade de metais de origem terrestre, expressos na forma de $\mathrm{Fe} / \mathrm{Ca}$, Ti/Ca. A concentração das alquenonas é também relacionada ao TAR e às clorinas. Uma vez que as clorinas são derivadas da clorofila, a sua presença nos locais de maior concentração de material terrestre pode ser atribuída tanto à clorofila produzida por fitoplâncton quanto por clorofila produzida por plantas terrestre, mas a relação positiva entre clorinas e alquenonas, essa última produzida exclusivamente por fitoplâncton, mostra que a presença do material terrígeno favorece a produtividade primária e portanto a produção de clorinas de origem marinha. 
Tabela 12: Análise estatística dos marcadores geoquímicos nas amostras de superfície ao longo da Plataforma Continental Superior Sudeste do Brasil.

\begin{tabular}{|c|c|c|c|c|c|c|c|c|c|c|c|c|c|c|c|c|c|c|c|c|c|c|c|}
\hline & $\sum$ n-alcanos & IPC & Pri/Fit & TAR & TSM & Alq. & Clorinas & $\begin{array}{c}\mathrm{R}-\mathrm{COH} \\
(\mathrm{P})\end{array}$ & $\begin{array}{c}\mathrm{R}-\mathrm{COOH} \\
\text { (P) }\end{array}$ & $\overline{(\mathrm{Al})}$ & (Ba) & (Ca) & $(\mathrm{Sr})$ & $\overline{(\mathrm{Fe})}$ & (Ti) & $\mathrm{Ba} / \mathrm{Al}$ & $\mathrm{Ba} / \mathrm{Ti}$ & $\mathrm{Ba} / \mathrm{Ca}$ & $\mathrm{Al} / \mathrm{Ti}$ & $\mathrm{Sr} / \mathrm{Ti}$ & $\mathrm{Sr} / \mathrm{Ca}$ & $\mathrm{Fe} / \mathrm{Ca}$ & $\mathrm{Ti} / \mathrm{Ca}$ \\
\hline$\sum$ n-alc. & $* * *$ & - & - & 0,63 & - & 0,56 & - & - & 0,55 & - & - & - & - & - & - & - & - & - & - & - & - & - & - \\
\hline IPC & $x x x$ & *** & - & - & - & - & - & - & - & - & - & $-0,48$ & $-0,48$ & - & - & $-0,62$ & $-0,53$ & 0,49 & - & $-0,52$ & - & 0,57 & 0,59 \\
\hline Pri/fitano & $x x x$ & $x x x$ & $* * *$ & $-0,52$ & - & - & - & 0,52 & - & - & - & - & - & - & - & - & - & $-0,59$ & $-0,54$ & - & - & $-0,55$ & $-0,54$ \\
\hline TAR & $x x x$ & $x x x$ & $x x x$ & $* * *$ & - & 0,55 & - & - & - & - & - & - & $-0,47$ & - & - & - & - & - & - & - & - & - & - \\
\hline TSM & $x x x$ & $x x x$ & $x x x$ & $x x x$ & $* * *$ & - & - & - & $-0,61$ & - & 0,72 & - & 0,54 & - & - & 0,80 & 0,66 & - & - & - & - & - & - \\
\hline Alq. & $x x x$ & $x x x$ & $x x x$ & $x x x$ & $x x x$ & $* * *$ & 0,71 & - & - & - & - & - & - & - & - & - & - & - & - & - & - & - & - \\
\hline Clorinas & $x x x$ & $x x x$ & $x x x$ & $x x x$ & $x x x$ & $x x x$ & $* * *$ & - & 0,60 & 0,69 & - & $-0,59$ & $-0,68$ & - & - & $-0,57$ & - & 0,61 & 0,78 & $-0,67$ & - & 0,63 & 0,63 \\
\hline R-COH P & $x x x$ & $x x x$ & $x x x$ & $x x x$ & $x x x$ & $x x x$ & $x x x$ & $* * *$ & - & - & - & - & - & - & 0,61 & - & - & - & - & - & 0,50 & - & - \\
\hline R-COOH P & $x x x$ & $x x x$ & $x x x$ & $x x x$ & $x x x$ & $x x x$ & $x x x$ & $x x x$ & $* * *$ & - & - & - & $-0,51$ & - & - & $-0,73$ & $-0,47$ & - & 0,54 & $-0,53$ & - & - & - \\
\hline (AI) & $x x x$ & $x x x$ & $x x x$ & $x x x$ & $x x x$ & $x x x$ & $x x x$ & $x x x$ & $x x x$ & $* * *$ & - & $-0,53$ & $-0,56$ & 0,82 & 0,53 & - & - & 0,79 & 0,86 & $-0,78$ & - & 0,75 & 0,75 \\
\hline (Ba) & $x x x$ & $x x x$ & $x x x$ & $x x x$ & $x x x$ & $x x x$ & $x x x$ & $x x x$ & $x x x$ & $x x x$ & *** & - & - & - & - & 0,76 & 0,93 & - & - & - & - & - & - \\
\hline (Ca) & $x x x$ & $x x x$ & $x x x$ & $x x x$ & $x x x$ & $x x x$ & $x x x$ & $x x x$ & $x x x$ & $x x x$ & $x x x$ & $* * *$ & 0,93 & - & - & - & - & $-0,56$ & $-0,58$ & 0,90 & - & $-0,56$ & $-0,58$ \\
\hline (Sr) & $x x x$ & $x x x$ & $x x x$ & $x x x$ & $x x x$ & $x x x$ & $x x x$ & $x x x$ & $x x x$ & $x x x$ & $x x x$ & $x x x$ & *** & - & - & 0,54 & - & $-0,66$ & $-0,73$ & 0,89 & - & $-0,67$ & $-0,67$ \\
\hline$(\mathrm{Fe})$ & $x x x$ & $x x x$ & $x x x$ & $x x x$ & $x x x$ & $x x x$ & $x x x$ & $x x x$ & $x x x$ & $x x x$ & $x x x$ & $x x x$ & $x x x$ & *** & 0,62 & - & - & 0,58 & 0,60 & $-0,62$ & - & 0,61 & 0,60 \\
\hline$(\mathrm{Ti})$ & $x x x$ & $x x x$ & $x x x$ & $x x x$ & $x x x$ & $x x x$ & $x x x$ & $x x x$ & $x x x$ & $x x x$ & $x x x$ & $x x x$ & $x x x$ & $x x x$ & $\star * \star *$ & - & - & - & - & - & 0,58 & - & - \\
\hline $\mathrm{Ba} / \mathrm{Al}$ & $x x x$ & $x x x$ & $x x x$ & $x x x$ & $x x x$ & $x x x$ & $x x x$ & $x x x$ & $x x x$ & $x x x$ & $x x x$ & $x x x$ & $x x x$ & $x x x$ & $x x x$ & $* * *$ & 0,84 & - & - & 0,51 & - & $-0,52$ & $-0,52$ \\
\hline $\mathrm{Ba} / \mathrm{Ti}$ & $x x x$ & $x x x$ & $x x x$ & $x x x$ & $x x x$ & $x x x$ & $x x x$ & $x x x$ & $x x x$ & $x x x$ & $x x x$ & $x x x$ & $x x x$ & $x x x$ & $x x x$ & $x x x$ & $* * *$ & - & - & - & - & - & - \\
\hline $\mathrm{Ba} / \mathrm{Ca}$ & $x x x$ & $x x x$ & $x x x$ & $x x x$ & $x x x$ & $x x x$ & $x x x$ & $x x x$ & $x x x$ & $x x x$ & $x x x$ & $x x x$ & $x x x$ & $x x x$ & $x x x$ & $x x x$ & $x x x$ & $* * *$ & 0,82 & $-0,67$ & - & 0,98 & 0,98 \\
\hline $\mathrm{Al} / \mathrm{Ti}$ & $x x x$ & $x x x$ & $x x x$ & $x x x$ & $x x x$ & $x x x$ & $x x x$ & $x x x$ & $x x x$ & $x x x$ & $x x x$ & $x x x$ & $x x x$ & $x x x$ & $x x x$ & $x x x$ & $x x x$ & $x x x$ & $* \star *$ & $-0,74$ & - & 0,80 & 0,76 \\
\hline $\mathrm{Sr} / \mathrm{Ti}$ & $x x x$ & $x x x$ & $x x x$ & $x x x$ & $x x x$ & $x x x$ & $x x x$ & $x x x$ & $x x x$ & $x x x$ & $x x x$ & $x x x$ & $x x x$ & $x x x$ & $x x x$ & $x x x$ & $x x x$ & $x x x$ & $x x x$ & $* * *$ & - & $-0,67$ & $-0,69$ \\
\hline $\mathrm{Sr} / \mathrm{Ca}$ & $x x x$ & $x x x$ & $x x x$ & $x x x$ & $x x x$ & $x x x$ & $x x x$ & $x x x$ & $x x x$ & $x x x$ & $x x x$ & $x x x$ & $x x x$ & $x x x$ & $x x x$ & $x x x$ & $x x x$ & $x x x$ & $x x x$ & $x x x$ & $* * *$ & - & - \\
\hline $\mathrm{Fe} / \mathrm{Ca}$ & $x x x$ & $x x x$ & $x x x$ & $x x x$ & $x x x$ & $x x x$ & $x x x$ & $x x x$ & $x x x$ & $x x x$ & $x x x$ & $x x x$ & $x x x$ & $x x x$ & $x x x$ & $x x x$ & $x x x$ & $x x x$ & $x x x$ & $x x x$ & $x x x$ & $\star \star \star *$ & 0,99 \\
\hline $\mathrm{Ti} / \mathrm{Ca}$ & $x x x$ & $x x x$ & $x x x$ & $x x x$ & $x x x$ & $x x x$ & $x x x$ & $x x x$ & $x x x$ & $x x x$ & $x x x$ & $x x x$ & $x x x$ & $x x x$ & $x x x$ & $x x x$ & $x x x$ & $x x x$ & $x x x$ & $x x x$ & $x x x$ & $x x x$ & $\star * * *$ \\
\hline
\end{tabular}




\subsubsection{Discussão dos Resultados das Amostras de Superfície}

A determinação de temperaturas a partir das alquenonas é utilizada principalmente em regiões de mar profundo. Os trabalhos que relatam a utilização de alquenonas para determinação de TSM próximas à costa são raros e no caso da costa brasileira, até a realização desse trabalho, pouco se sabia sobre a validade da utilização da equação de Prahl e Wakehan (1987) para a determinação de TSM na margem continental superior do Sudeste do Brasil.

A validade da equação de Prahl e Wakehan (1987) para determinação da TSM a partir do índice $U_{37}^{k^{\prime}}$ na região ao sul do Embaiamento de São Paulo já havia sido aferida por Benthien e Muller (1999). No presente trabalho, a similaridade do perfil de TSM- $U_{37}^{k^{\prime}}$ para toda a região do Embaiamento de São Paulo com os perfis de TSM obtidos a partir de programas multinacionais, e a semelhança entre a calibração das TSMs, extraídas dos programas, e os índices $U_{37}^{k^{\prime}}$, obtidos dos sedimentos, com a calibração da TSM- $U_{37}^{k^{\prime}}$ realizada nos oceanos, mostrou que a equação de Prahl e Wakehan (1987) para a determinação da TSM a partir do registro das alquenonas fornece resultados confiáveis para toda a região do Embaiamento de São Paulo.

Dessa forma os resultados obtidos nesse trabalho mostraram perspectivas promissoras para a utilização de alquenonas para determinação de TSM em toda a região da margem continental superior do Sudeste do Brasil.

De forma geral, o Embaiamento de São Paulo parece se dividir em duas zonas distintas no que diz respeito à presença de marcadores orgânicos moleculares, metais e temperatura superficial marinha; um compartimento ao norte da llha de São Sebastião, marcado por maiores valores de TSM, recebendo menor contribuição de material terrígeno e de menor produtividade primária; e um compartimento ao sul da Ilha de São Sebastião, marcado por menores valores de TSM, recebendo maior quantidade de material de origem terrígena e de maior produtividade primária. 
A maior TSM e a menor produtividade na região ao norte da llha de São Sebastião pode ser atribuída à penetração de águas da Corrente do Brasil, que são águas tipicamente quentes e oligotróficas.

Ao sul, as menores TSM e a maior produção primária se devem tanto à penetração de águas provenientes do deságüe do Rio da Prata, que são águas mais frias e mais ricas em nutrientes, com sua interação com os meandramentos da Corrente do Brasil, quanto à morfologia da plataforma, que favorece o estabelecimento de regiões de alta produtividade.

Diversos trabalhos apontam para essa divisão na margem continental do Sudeste do Brasil. Segundo Mahiques et al. (2002, 2004), na região ao sul da Ilha de São Sebastião, os processos deposicionais estão associados com a penetração sazonal de plumas com salinidade e temperatura baixa, provenientes do deságüe do Rio da Prata com os meandramentos da Corrente do Brasil, bem como com a morfologia da plataforma, favorecendo o estabelecimento de regiões de alta produtividade, além da presença de sedimentos alóctones. Na região ao norte da llha, a heterogeneidade do sedimento indica processos hidrodinâmicos mais complexos, especialmente na plataforma média e interna, sendo a distribuição do sedimento controlada por meandramentos da Corrente do Brasil na região, apresentando mistura da fração terrígena com a pelágica. Rocha et al. (1975) aponta ainda diferença na mineralogia do sedimento, com predominância de montmorilonita ao Sul e mistura de caolinita - ilita - montmorilonita ao Norte. Figueira et al. (2005), mostra que a distribuição de radionuclídeos artificiais na plataforma se divide em dois compartimentos, um ao norte e outro ao sul da llha de São Sebastião, com valores de ${ }^{137} \mathrm{Cs} \mathrm{e}{ }^{238} \mathrm{Pu}$ maiores ao sul da llha e valores menores ao norte.

Existe ainda na região próxima a $45^{\circ} \mathrm{W}$ e $25,5^{\circ} \mathrm{S}$, próximo à isóbata de $200 \mathrm{~m}$, uma área com comportamento anômalo no recebimento, ou acúmulo, de material de origem terrígena e de produtividade primária. Nessa região, localizada ao sul da llha de São Sebastião, são observados valores de TAR elevados e concentrações elevadas de n-alcanos, alquenonas, clorinas e ácidos pesados. Existe nessa região a ocorrência de vórtices ciclônicos das águas da Corrente do Brasil (Calado; 2001, Camargo; 2006). Apesar dos 
estudos realizados não serem conclusivos, essa anomalia na deposição de marcadores geoquímicos pode estar associada à ocorrência desses vórtices.

A concordância entre os resultados obtidos com os marcadores geoquímicos e com os diversos trabalhos publicados sobre a região mostram que os marcadores apresentados fornecem resultados confiáveis para a determinação do tipo de material orgânico depositado na margem continental superior do Sudeste do Brasil.

\subsection{Amostras de Sedimento do Testemunho Resultados das Amostras do Testemunho}

Os resultados das análises do testemunho, tantos os obtidos no IO-USP quanto no ICTA na UAB, são mostrados no Anexo 2.

\subsubsection{Datação do Testemunho e Taxa de Sedimentação}

$\mathrm{O}$ modelo de idade do testemunho foi obtido através da datação por ${ }^{14} \mathrm{C}$ em testas de foraminíferos (Globigerinoides ruber) obtidos em 10 frações distintas do testemunho, conforme a Tabela 13. Nenhuma inversão de idade foi observada pela datação por radiocarbono.

Tabela 13: Datação do Testemunho.

\begin{tabular}{|c|c|c|}
\hline $\begin{array}{r}\text { Depth } \\
(\mathrm{cm})\end{array}$ & BETA Number & $\begin{array}{r}\text { Conventional } \\
\text { Radiocarbon Age } \\
(\mathrm{yr} \text { A.P..) }\end{array}$ \\
\hline 1 & 189509 & $3020+-40$ \\
\hline 11 & 189510 & $7420+-40$ \\
\hline 21 & 189511 & $14230+-90$ \\
\hline 31 & 185176 & $17240+-90$ \\
\hline 51 & 185177 & $18070+-160$ \\
\hline 77 & 185178 & $18560+-140$ \\
\hline 127 & 185179 & $19700+-250$ \\
\hline 151 & 185180 & $21750+-160$ \\
\hline 171 & 185181 & $24860+-270$ \\
\hline 201 & 185182 & $34800+-400$ \\
\hline
\end{tabular}


O testemunho cobre cerca de 34.800 anos. Sedimentos do Holoceno, Estágio Isotópico Marinho 1, correspondem apenas aos primeiros $19 \mathrm{~cm}$ da coluna sedimentar (13.000 anos A.P. até o tempo presente), com a taxa de sedimentação variando de 0,0014 para $0,0026 \mathrm{~cm} \cdot a^{-1}$. A maior parte da coluna sedimentar (de $19 \mathrm{~cm}$ a $160 \mathrm{~cm}$, aproximadamente) consiste de sedimentos do Estágio Isotópico Marinho 2 (23.000 anos A.P. a 13.000 anos A.P.), e as maiores taxas de sedimentação, cerca de $0,4300 \mathrm{~cm} \cdot a n o^{-1}$, são observadas no período entre 18.800 e 18.700 anos A.P. Durante o Estágio Isotópico Marinho 3 (tempo anterior a 23.000 anos A.P.), de 160 a $203 \mathrm{~cm}$, as taxas de sedimentação permaneceram praticamente constantes, entre 0,0030 e $0,0050 \mathrm{~cm}^{\text {ano }}{ }^{-1}$ (Fig. 32).

Uma vez que o testemunho possui na base idade em torno de 34.800 anos e a calibração das idades de radiocarbono para idades de calendário são bem definidas apenas para os últimos 20.000 anos e fornecem incertezas para idades mais antigas do que isso (Bard et al. 1993, Kitagawa e van de Plicht, 1998), optou-se por não corrigir as idades do testemunho para idades de calendário.

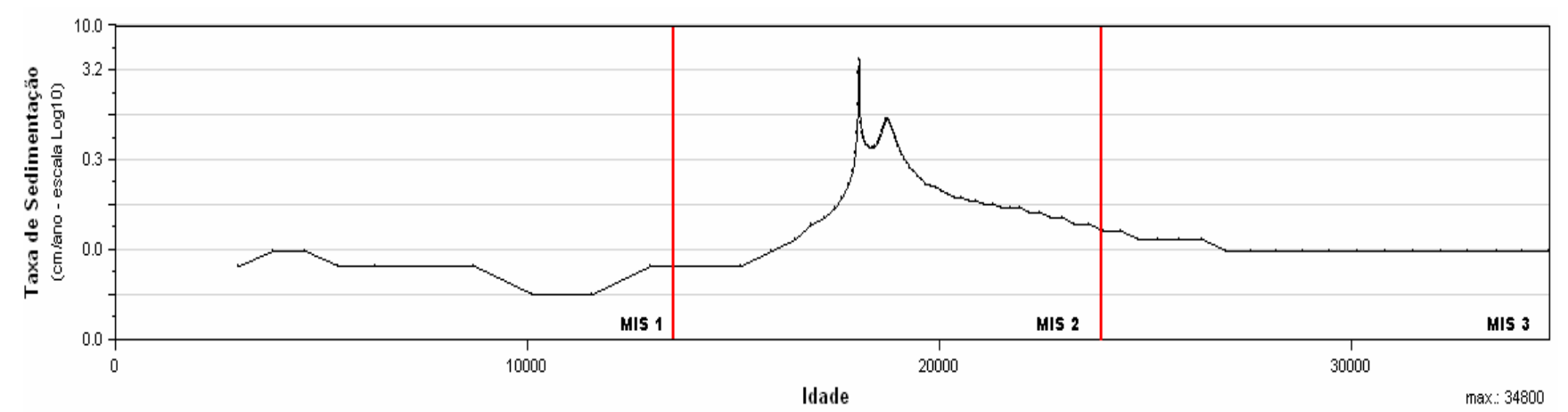

Figura 32: Variação da taxa de sedimentação -escala logarítmica).

\subsubsection{Temperatura Superficial Marinha e Marcadores de Material Terrígeno}

Na Figura 33 são mostrados os perfis da temperatura superficial marinha e dos marcadores de material terrígeno ao longo do testemunho. 
Figura 33: Perfil da temperatura superficial marinha e dos marcadores de material terrígeno ao longo do testemunho.

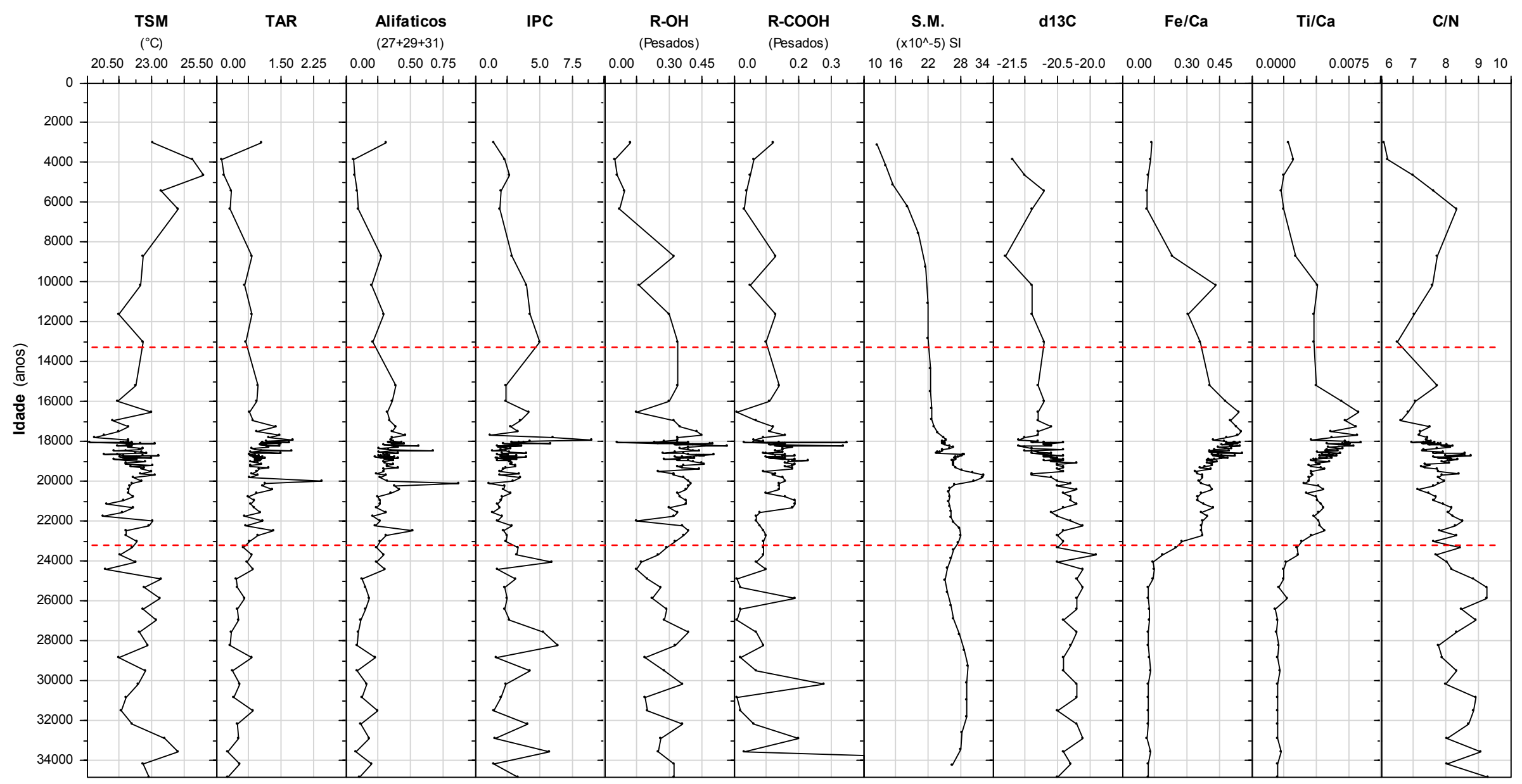

max.: 34800 anos 


\section{Marcadores Orgânicos Moleculares}

\section{Temperatura Superficial Marinha}

Os valores de TSM $U_{37}^{k^{\prime}}$ obtidos no LabQom do IO USP e os valores de TSM $U_{37}^{k^{\prime}}$ obtidos no ICTA da UAB são praticamente os mesmos, e se encontram dentro do desvio de reprodutibilidade sugerido por Rosell-Melé (2001). Essa reprodutibilidade e repetibilidade dos resultados validam as metodologia de análise das alquenonas e, portanto, de TSM $U_{37}^{k^{\prime}}$. A referência aos valores de TSM $U_{37}^{k^{\prime}}$ será feita em relação aos resultados obtidos no LabQom do IO USP.

A temperatura da superfície oceânica, obtida através das alquenonas ao longo do testemunho, varia entre $20,59^{\circ} \mathrm{C}$ e $24,99^{\circ} \mathrm{C}$, variação entre a mínima e a máxima de $4,4^{\circ} \mathrm{C}$ (Fig. 33). A menor temperatura foi registrada há cerca de 18 mil anos e a maior há 4,5 mil anos. Em média a TSM oscila entre 21 e $23^{\circ}$ $\mathrm{C}$, sendo poucos o períodos que apresentam temperatura fora dessa faixa. Observa-se uma tendência de diminuição na TSM durante o Estágio Isotópico Marinho 3, nenhuma tendência de variação durante o Estágio Isotópico Marinho 2 e um aumento na TSM durante o Holoceno.

\section{TAR e Hidrocarbonetos Alifáticos Pesados}

O valor médio de TAR ao longo do testemunho é 0,91 , valor que indica predominância de matéria orgânica de origem marinha, sendo os maiores valores coincidentes com os maiores valores de S.M., ou seja, em 29 mil anos A.P., com S.M. $=29,4$ e TAR $=0,84$, em 22,5 mil anos A.P., com S.M. $=28$ e $\mathrm{TAR}=1,34$, e em 20 mil anos A.P., com S.M. = 30,5 e TAR = 2,46, parâmetros que apontam para maior quantidade de fontes terrígenas para o meio marinho nos períodos citados. Um outro valor alto de $\operatorname{TAR}(1,46)$, não correlacionado com aumento no valor de S.M., ocorre em torno e 18 mil anos A.P. (Fig. 33).

Durante os Estágios Isotópicos Marinhos 3 e 2 há uma tendência de aumento no valor de TAR, que se reverte no Estágio Isotópico Marinho 1. O TAR aponta, para uma mudança no tipo de material orgânico sedimentado na região a partir do início do Holoceno. 
A variação na somatória de hidrocarbonetos alifáticos pesados $\left(n-C_{27}+n-C_{29}+n-C_{31}\right)$ reflete os valores do TAR (Fig. 33). Assim, os hidrocarbonetos pesados apontam para os mesmas conclusões do TAR.

\section{Índice de Preferência do Carbono}

O IPC não apresenta tendência de queda ou de aumento no seu valor ao longo do testemunho, com valores em torno de 2,8, valores típicos de matéria orgânica de origem marinha, com alguns saltos que se destacam (Fig. 33). O primeiro (IPC $=6,4)$ em cerca de 28 mil anos A.P., o segundo (IPC= $5,92)$ em cerca de 24 mil anos A.P. e o último (IPC= 8,99) em cerca de $18 \mathrm{mil}$ anos A.P. Os dois primeiro picos de IPC não apresentam correlação direta com os parâmetros físicos descritos, porém o salto do IPC em 18 mil anos A.P. corresponde a maior taxa de sedimentação, um dos valores mais negativos de $\delta^{13} \mathrm{C}_{\mathrm{PDB}}$ e maiores concentrações de alquenonas. Assim, o valor alto de IPC há 18.000 anos fornece mais um indicativo do aumento no aporte de matéria orgânica de origem terrestre no período do Estágio Isotópico Marinho 2.

\section{Álcoois Pesados}

A somatória dos álcoois pesados, $\mathrm{nC}_{24}+\mathrm{nC}_{26}+\mathrm{nC}_{2} 8+\mathrm{nC}_{30}$ não mostra nenhuma tendência de aumento ou diminuição durante o Estágio Isotópico Marinho 3 e um leve aumento durante o Estágio Isotópico Marinho 2. Durante o Estágio Isotópico Marinho 1, a somatória apresenta uma tendência de queda (Fig. 33). Os maiores valores da somatória das concentrações desses álcoois ocorrem durante o Estágio Isotópico Marinho 2. Esses valores elevados durante esse período refletem o aumento de fontes terrígenas de matéria orgânica para o meio nesse período. A diminuição dos valores durante o Estágio Isotópico Marinho 1 mostra que as fontes de matéria orgânica marinha para a região diminuem em direção ao presente. Essas variações condizem com as variações dos demais marcadores orgânicos moleculares já citados. 
Ao contrário do observado na análise espacial, na análise temporal os álcoois pesados parecem responder em coerência com os demais marcadores.

\section{Ácidos Pesados}

A somatória dos ácidos pesados $\left(\mathrm{nC}_{22}+\mathrm{nC}_{24}+\mathrm{nC}_{26}+\mathrm{nC}_{28}\right)$ apresenta, em geral, valores baixos durante o Estágio Isotópico Marinho 3, com alguns saltos nesses valores. Durante o Estágio Isotópico Marinho 2 há uma tendência de aumento no valor da somatória, que se reverte no Holoceno (Fig. 33). Os resultados dos ácidos estão de acordo com os resultados dos demais marcadores orgânicos moleculares.

\section{Outros Marcadores}

\section{Susceptibilidade Magnética}

Há uma visível mudança na suscetibilidade magnética entre os Estágios Isotópicos Marinhos 3 e 2 e entre os sedimentos mais recentes do testemunho (Fig. 33). Valores maiores que $23 \times 10^{-5} \mathrm{~S}$.I. foram encontrados apenas em sedimentos mais antigos que 18.000 anos A.P., revelando uma considerável mudança no fluxo de material orgânico terrígeno para a área de estudo. Do Último Máximo Glacial até o presente há um decréscimo gradual nos valores de suscetibilidade magnética. No Estágio Isotópico Marinho 3 os valores de suscetibilidade magnética são semelhantes aos valores do Estágio Isotópico Marinho 2, sugerindo que nesses períodos o fluxo de matéria orgânica terrígena para a área se manteve praticamente constante.

\section{Isótopos Estáveis de Carbono $-\delta^{13} \mathrm{C}_{\mathrm{PDB}}$}

As análises de $\delta^{13} \mathrm{C}_{\mathrm{PDB}}$ mostraram que todas as frações do testemunho apresentam valores de $\delta^{13} \mathrm{C}_{\mathrm{PDB}}$ variando entre $-22 \%$ e $-20 \%$, valores típicos de matéria orgânica de origem marinha. A Figura 33 mostra oscilações nos valores de $\delta^{13} \mathrm{C}_{\mathrm{PDB}}$ ao longo de todo testemunho, porém com uma tendência de queda do valor em direção ao tempo presente, especialmente a partir do Estágio Isotópico Marinho 2. Diminuições nos valores de $\delta^{13} C_{P D B}$ são indicativos de aumento de fontes terrígenas de matéria orgânica, porém, 
mesmos os valores mais negativos de $\delta^{13} \mathrm{C}_{\mathrm{PDB}}$ encontrados no testemunho são valores indicativos de predominância de matéria orgânica com fonte marinha. $O$ valor menos negativo de $\delta^{13} \mathrm{C}_{\mathrm{PDB}}$ foi constatado em torno de 23,5 mil anos A.P. $(-19,9 \%)$ e o mais negativo em torno de 8,5 mil anos A.P. (-21,3\%o). No período compreendido entre 21 e 17 mil anos B.P., período de maior taxa de sedimentação, as oscilações que se destacam ocorrem em 19,5 mil anos A.P., oscilação que coincide com o valor máximo de S.M., e em 18 mil anos A.P., oscilação que coincide com a maior taxa de sedimentação. Essas diminuições nos valor de $\delta^{13} \mathrm{C}_{\mathrm{PDB}}$ (mais negativo) juntamente com maiores valores de taxa de sedimentação e maiores valores de SM sugerem um aumento nas contribuições de matéria orgânica de fonte terrígena no período.

\section{Metais}

A avaliação do fluxo de material terrígeno para o mar, pelo uso das razões de $\mathrm{Fe} / \mathrm{Ca}$ e $\mathrm{Ti} / \mathrm{Ca}$, mostra que há um aumento na quantidade de material terrígeno sendo depositado na região durante o MIS 3, essa quantidade atinge o auge no MIS 2 e volta a diminuir no Holoceno (Fig. 33).

A resposta do metais concorda com a resposta fornecida pelos marcadores orgânico moleculares, que também indicam um aumento no fluxo de material terrígeno para o meio marinho, na região do testemunho, até o final do MIS 2 e uma diminuição no fluxo de material terrestre para o mar com o início do Holoceno.

\section{Razão C/N}

A dispersão entre $C_{o r g}$ e $N_{\text {tot }}$ é mostrada na Figura 34. O coeficiente angular mostra uma correlação forte $\left(R^{2}=0,82, p<0,05\right.$ e $\left.r=0,90\right)$. Assim a utilização da razão $\mathrm{C} / \mathrm{N}$, no caso em estudo, gera resultados confiáveis.

O valor da razão $\mathrm{C} / \mathrm{N}$ apresenta uma tendência de queda em direção ao tempo presente desde o Estágio Isotópico Marinho 3 até cerca de 6.300 anos A.P., quando a tendência se inverte (Fig. 33). Menores valores da razão $\mathrm{C} / \mathrm{N}$ indicam maiores contribuições marinhas. O maior valor da razão foi encontrado há 34.800 anos A.P. $(9,38)$ e o menor valor no topo o testemunho, 6,10. Os 
valores da razão $\mathrm{C} / \mathrm{N}$ ao longo de todo o testemunho fornecem valores típicos de contribuição de algas e fitoplâncton, longe do valor ao redor de 20, característico de contribuições de plantas superiores.

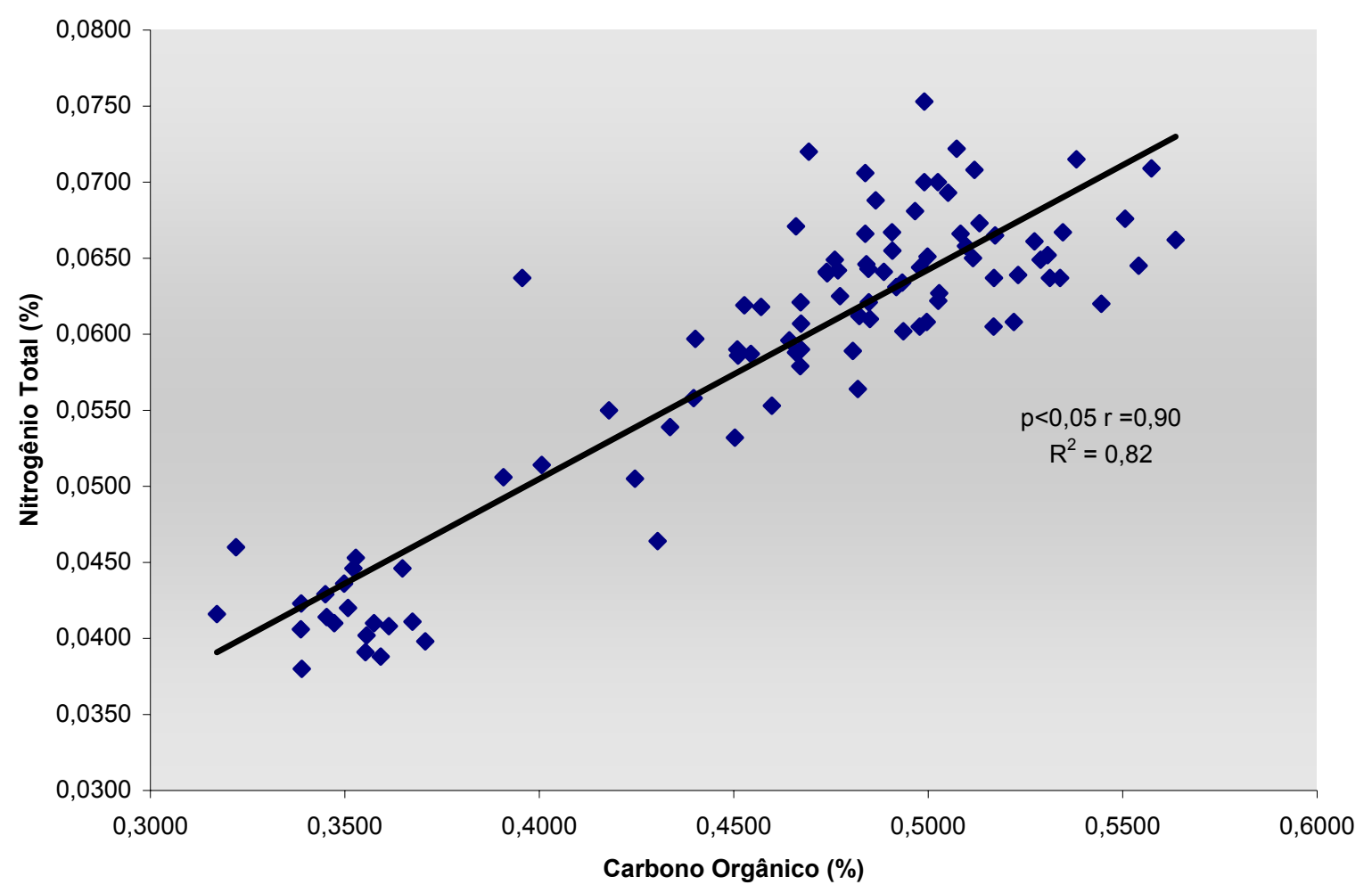

Figura 34 - Gráfico de dispersão entre $\mathrm{C}_{\text {org }}$ e $\mathrm{N}_{\text {tot }}$.

A tendência da razão $\mathrm{C} / \mathrm{N}$ é aparentemente contraditória ao comportamento do $\delta^{13} \mathrm{C}_{\mathrm{PDB}}$ ao longo do testemunho. Essa aparente contradição pode estar relacionada à degradação parcial da matéria orgânica algal, diminuindo a quantidade de material protéico e aumentando os valores de $\mathrm{C} / \mathrm{N}$ em sedimentos mais antigos.

\subsubsection{Marcadores de Produtividade}

Na Figura 35 são mostrados os perfis dos marcadores de produtividade ao longo do testemunho. 
Figura 35: Perfil dos marcadores de produtividade ao longo do testemunho.

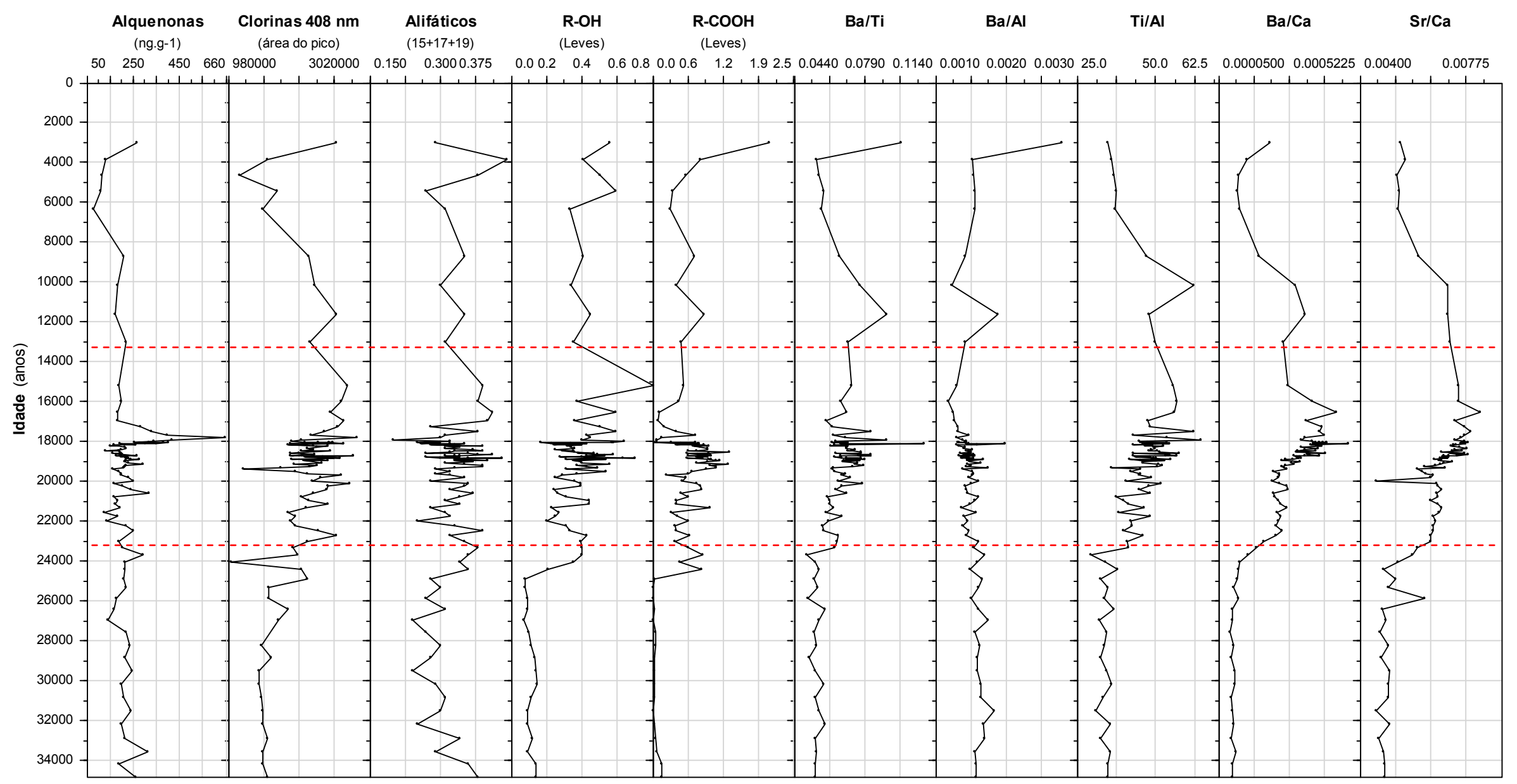

max.: 34800 anos 


\section{Marcadores Orgânicos Moleculares}

\section{Alquenonas}

As alquenonas totais $\left(\mathrm{C}_{37: 2}+\mathrm{C}_{37: 3}+\mathrm{C}_{38: 2}+\mathrm{C}_{38: 3}\right)$ aparecem no testemunho com valor praticamente constante, ao redor de $200 \mathrm{ng}^{-1} \mathrm{~g}^{-1}$ de sedimento, com exceção do período compreendido entre 18 e 17 mil anos A.P. quando ocorre um salto na concentração de alquenonas, atingindo o valor $600 \mathrm{ng}^{-1} \mathrm{~g}^{-1}$ (Fig. 35). O período em torno de $18 \mathrm{mil}$ ano A.P. corresponde também ao período de maior sedimentação. Considerando que as alquenonas são derivadas de organismos planctônicos, um aumento na taxa de sedimentação que não fosse seguida por um aumento na produtividade primária resultaria uma queda na concentração das alquenonas. Ocorre porém que a concentração das alquenonas aumentou cerca de 3 vezes nesse período, indicando que o aumento na sedimentação foi seguido por um aumento ainda maior na produtividade primária. Tanto o aumento na concentração de alquenonas nesse período, quanto 0 aumento da taxa de sedimentação, são acompanhados também por valores mais negativos de $\delta^{13} C_{\text {PDB }}$, ou seja, mais fontes terrígenas contribuindo com matéria orgânica para o meio, o que indica também mais material terrígeno sendo transportado para o local nesse período.

\section{Clorinas}

As análise das concentrações relativas das clorinas mostrou que ambos os comprimentos de onda utilizados, 408 ou $662 \mathrm{~nm}$ geram gráficos de variações de concentração similares. Assim, serão apresentados os valores das áreas dos picos cromatográficos das clorinas obtidas pelo comprimento de onda de 408nm.

A concentração de clorinas apresenta uma tendência de aumento durante os Estágios Isotópicos Marinhos 3 e 2, tendência que se inverte durante o Holoceno, até cerca de 6.300 anos A.P., quando volta a aumentar (Fig. 35). Esse aumento durante os Estágios Isotópicos Marinhos 3 e 2 pode ser devido tanto ao aumento na produtividade primária na região durante esses períodos quanto ao aumento no fluxo de matéria orgânico de origem terrígena para o mar, já que clorinas podem derivar também da clorofila produzida por plantas terrígenas. 


\section{Hidrocarbonetos Alifáticos Leves}

A somatória das concentrações dos hidrocarbonetos alifáticos leves, $n$ $\mathrm{C}_{15}+\mathrm{n}-\mathrm{C}_{17}+\mathrm{n}-\mathrm{C}_{19}$, apresenta uma tendência de queda durante o Estágio Isotópico Marinho 3, aumenta no Estágio Isotópico Marinho 2 e volta a diminuir no Holoceno (Fig. 35). O aumento no valor da somatória no Estágio Isotópico Marinho 2 é mais um indicativo de aumento na produtividade nesse período.

\section{Álcoois Leves}

A somatória das concentrações do álcoois leves, $n-C_{14}+n-C_{16}+n-C_{18}+n-$ $\mathrm{C}_{20}$ são constantes ao longo do MIS 3 , aumentam no MIS $2 \mathrm{e}$, com valor ligeiramente abaixo do MIS 2, se mantém constante no Holoceno. O pefil parece acompanhar o perfil do hidrocarbonetos alifáticos leves (Fig. 35).

\section{Ácidos Leves}

$O$ perfil da somatória das concentrações do ácidos leves, $n-C_{14}+n-C_{16}+n-$ $\mathrm{C}_{18}+\mathrm{n}-\mathrm{C}_{20}$ é bastante semelhante ao perfil dos álcoois leves (Fig. 35). Ambos os parâmetros indicam um aumento na produtividade primária durante o MIS 2.

\section{Outros Marcadores}

\section{Metais}

A dispersão Al $\times$ Ti para as amostras do testemunho forneceu um $\mathrm{R}^{2}=$ 0,6551 (Fig. 36). Isso sugere que o alumínio tem características terrígenas e pode ser usado como elemento normalizante para os demais.

A Figura 35 mostra que durante o Estágio Isotópico Marinho 3 aparecem os menores valores para as relações $\mathrm{Ba} / \mathrm{Ti}, \mathrm{Ti} / \mathrm{Al}, \mathrm{Ba} / \mathrm{Ca}$ e $\mathrm{Sr} / \mathrm{Ca}$. Os valores dessas relações aumentam em direção ao MIS 2 e, com exceção da relação $\mathrm{Ba} / \mathrm{Ti}$, voltam a diminuir no Holoceno.

Assim como nas amostras de sedimento superficial, não se conhece a contribuição terrígena do Ba na região, então as relações envolvendo bário podem estar superestimadas. De qualquer forma verifica-se que os metais indicam um aumento na produtividade primária durante o MIS 2 . 
Dispersão Al x Ti

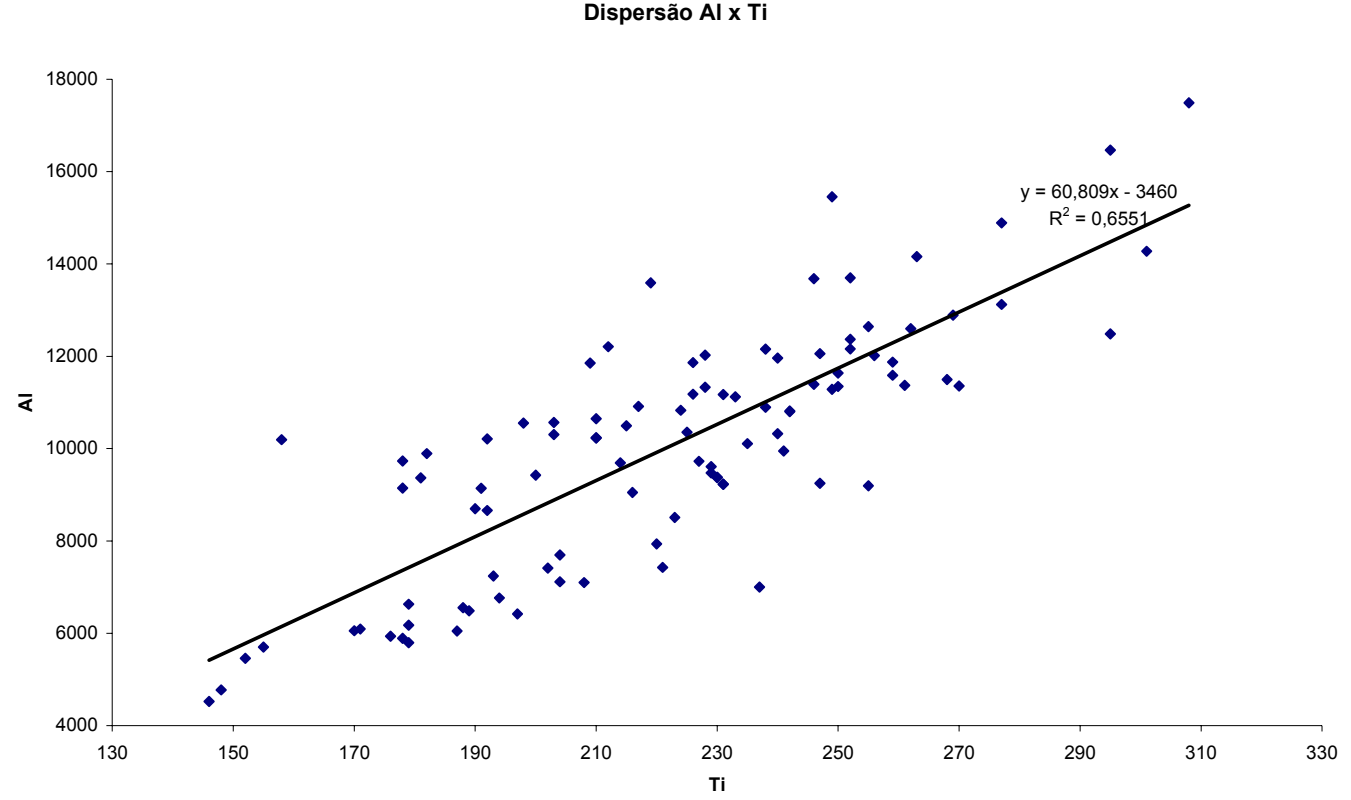

Figura 36: Dispersão Alumínio x Titânio nas amostras ao longo da coluna sedimentar.

\subsubsection{Marcador de Potencial de Redução \\ Pristano/Fitano}

Os valores da relação pristano/fitano não apresentam grandes variações, oscilando em torno de 1,9 (Fig. 37). O menor valor foi registrado há 18.200 anos A.P. $(0,53)$ e o maior 2,55 há 99.100 anos A.P. O valor da relação pristano/fitano observado a 18.200 anos ocorre junto com a maior taxa de sedimentação e maior valor de IPC. Essa maior quantidade de material terrígeno alcançando o meio marinho favoreceria a produção do fitano em relação ao pristano, já que a produção de um ou de outro, a partir do fitol, depende do potencial de redução do meio (Eh), então, uma maior quantidade de material orgânico no meio, consumiria o oxigênio durante processo de degradação, aumentando o potencial de redução. 


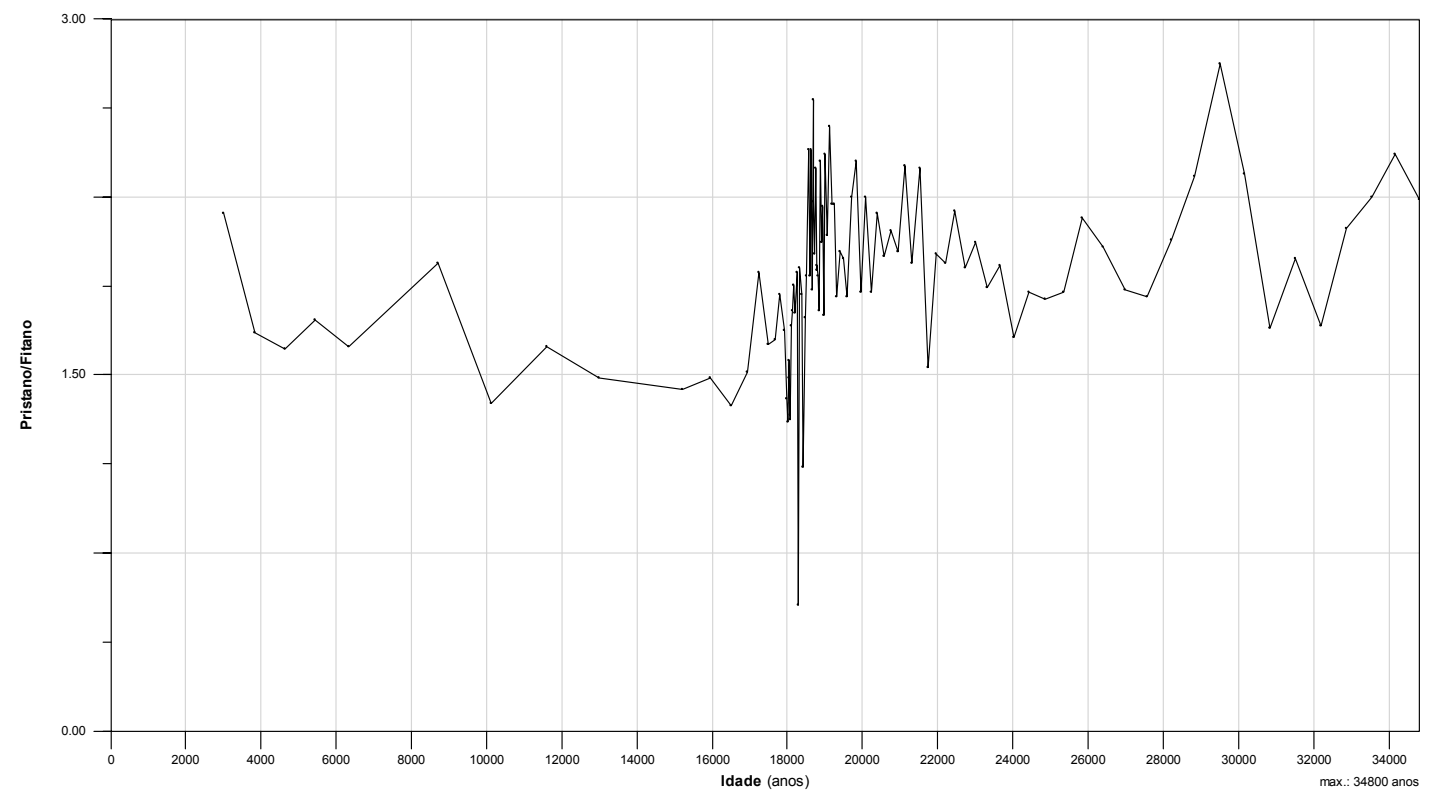

Figura 37: Variação da relação pristano/fitano ao longo do testemunho.

\subsubsection{Análise Estatística dos Resultados}

A Tabela 14 correlaciona os resultados de todas os parâmetros físicos e químicos realizadas no testemunho, de 34,8 mil anos A.P. até o presente, através do coeficiente de Pearson, de forma a verificar o grau de dependência entre esses parâmetros. Na Tabela 14 são apresentados apenas os valores de correlação com probabilidade de erro $<5 \%(\rho<0,05$, $)$ e são destacados os valores cuja correlação é forte, ou seja, maior que 0,50.

As correlações entre os resultados mostram uma relação diretamente proporcional entre a S.M. e a taxa de sedimentação $(R=0,50)$. Essa relação confirma que o aumento de material terrígeno para o oceano promove 0 aumento na taxa de sedimentação, uma vez que materiais com propriedades magnéticas provém quase que exclusivamente do continente. Outro fator que aponta para essa conclusão é a relação entre a susceptibilidade magnética e a relação dos álcoois $P / L(R=0,69)$ pois o aumento na relação pesados/leves é um indicativo no aumento de fontes terrígenas, uma vez que os pesados são sintetizados apenas por plantas superiores.

O IPC se relaciona de forma diretamente proporcional com as alquenonas $(R=0,50)$, o que poderia indicar que aumento em fontes terrígenas 
podem produzir aumentos na produtividade primária, contudo nem o IPC, nem as alquenonas parecem mostrar boa correlação com o outro indicador de produtividade primária, as clorinas. Por outro lado, as clorinas podem ser produto de degradação tanto da clorofila de origem terrígena quanto marinha. A correlação entre o TAR e as clorinas $(R=0,50)$ pode estar indicando então que a entrada de material terrígeno traz junto clorofila de origem terrígena.

A correlação entre os metais, $\mathrm{Fe} / \mathrm{Ca}$ e $\mathrm{Ti} / \mathrm{Ca}$, com a taxa de sedimentação $(R=0,50$ e $R=0,50)$, com o TAR $(R=0,64)$ e com os alifáticos pesados, $\left(C_{27}, C_{29}\right.$ e $\left.C_{31}\right)(R=0,61)$ mostra que os marcadores de material terrígeno concordam entre si. Vale ressaltar que a correlação do TAR com a somatória do hidrocarbonetos alifáticos pesados mostra que o valor do TAR reflete essa somatória. Muitos outros parâmetros, apresentam correlação entre si, porém a correlação entre eles é fraca, o que não permite muitas conclusões.

De forma a obter uma melhor análise da evolução paleoceanográfica através dos dados gerados, foram realizadas análises estatísticas dividindo o testemunho em função dos Estágios Isotópicos Marinhos: MIS 3: da base do testemunho até 23.000 anos A.P. (início do UMG), MIS 2: de 23.000 anos A.P. a 13.000 anos A.P. (final do YD) e MIS 1: de 13.000 anos A.P. até o tempo presente. São mencionados no texto apenas aqueles com probabilidade de erro $<5 \%(\rho<0,05$, ) e significância estatística maior que 0,5 . 
Tabela 14 (1/2): Correlação estatística de Pearson para o testemunho, da base ao topo.

\begin{tabular}{|c|c|c|c|c|c|c|c|c|c|c|c|c|c|c|c|c|c|}
\hline & T.S. & S.M. & d13C & Alq. & S n-alc. & IPC & Pri/Fit. & TAR & TSM & Clorinas & Álc. (P/L) & Ác. (P/L) & $\mathrm{C} / \mathrm{N}$ & Alif. (L) & Alif. (P) & Álc. (L) & Álc (P) \\
\hline T.S. & $* * *$ & 0,50 & - & 0,36 & 0,29 & - & $-0,22$ & 0,31 & $-0,25$ & 0,30 & $-0,23$ & - & - & - & 0,25 & - & - \\
\hline S.M. & $x x x$ & $* * *$ & 0,51 & - & - & - & 0,35 & - & $-0,28$ & - & 0,69 & - & 0,51 & - & - & $-0,32$ & 0,46 \\
\hline d13C & $x x x$ & $x x x$ & $* * *$ & - & $-0,23$ & - & 0,38 & $-0,24$ & - & $-0,30$ & 0,45 & 0,23 & 0,46 & - & - & $-0,47$ & - \\
\hline Alq. & $x x x$ & $x x x$ & $x x x$ & $* \star *$ & - & 0,50 & - & 0,37 & $-0,39$ & 0,28 & - & - & - & $-0,21$ & 0,20 & - & - \\
\hline S n-alc. & $x x x$ & $x x x$ & $x x x$ & $x x x$ & $* * *$ & $-0,44$ & - & 0,23 & $-0,20$ & 0,38 & $-0,35$ & - & - & 0,50 & 0,52 & 0,26 & - \\
\hline IPC & $x x x$ & $x x x$ & $x x x$ & $x x x$ & $x x x$ & $* * *$ & - & - & - & - & - & - & - & $-0,36$ & $-0,22$ & - & - \\
\hline Pri/Fit. & $x x x$ & $x x x$ & $x x x$ & $x x x$ & $x x x$ & $x x x$ & $* * *$ & $-0,22$ & - & - & 0,24 & - & 0,28 & - & - & - & - \\
\hline TAR & $x x x$ & $x x x$ & $x x x$ & $x x x$ & $x x x$ & $x x x$ & $x x x$ & $* * *$ & $-0,43$ & 0,50 & $-0,30$ & - & $-0,31$ & - & 0,76 & 0,35 & 0,41 \\
\hline TSM & $x x x$ & $x x x$ & $x x x$ & $x x x$ & $x x x$ & $x x x$ & $x x x$ & $x x x$ & $* * *$ & $-0,42$ & $-0,51$ & - & - & - & $-0,47$ & - & - \\
\hline Clorinas & $x x x$ & $x x x$ & $x x x$ & $x x x$ & $x x x$ & $x x x$ & $x x x$ & $x x x$ & $x x x$ & $* * *$ & $-0,42$ & $-0,23$ & $-0,34$ & 0,21 & 0,58 & 0,47 & 0,34 \\
\hline Álcoois (P/L) & $x x x$ & $x x x$ & $x x x$ & $x x x$ & $x x x$ & $x x x$ & $x x x$ & $x x x$ & $x x x$ & $x x x$ & $* * *$ & 0,50 & 0,46 & $-0,25$ & $-0,34$ & $-0,63$ & - \\
\hline Ácidos (P/L) & $x x x$ & $x x x$ & $x x x$ & $x x x$ & $x x x$ & $x x x$ & $x x x$ & $x x x$ & $x x x$ & $x x x$ & $x x x$ & $* * *$ & 0,33 & - & $-0,21$ & $-0,31$ & - \\
\hline $\mathrm{C} / \mathrm{N}$ & $x x x$ & $x x x$ & $x x x$ & $x x x$ & $x x x$ & $x x x$ & $x x x$ & $x x x$ & $x x x$ & $x x x$ & $x x x$ & $x x x$ & $* * *$ & $-0,21$ & $-0,32$ & $-0,47$ & - \\
\hline Alifáticos (L) & $x x x$ & $x x x$ & $x x x$ & $x x x$ & $x x x$ & $x x x$ & $x x x$ & $x x x$ & $x x x$ & $x x x$ & $x x x$ & $x x x$ & $x x x$ & $* * *$ & 0,28 & 0,30 & - \\
\hline Alifáticos (P) & $x x x$ & $x x x$ & $x x x$ & $x x x$ & $x x x$ & $x x x$ & $x x x$ & $x x x$ & $x x x$ & $x x x$ & $x x x$ & $x x x$ & $x x x$ & $x x x$ & $* * *$ & 0,40 & 0,50 \\
\hline Álcoois (L) & $x x x$ & $x x x$ & $x x x$ & $x x x$ & $x x x$ & $x x x$ & $x x x$ & $x x x$ & $x x x$ & $x x x$ & $x x x$ & $x x x$ & $x x x$ & $x x x$ & $x x x$ & $* * *$ & 0,20 \\
\hline Álcoois (P) & $x x x$ & $x x x$ & $x x x$ & $x x x$ & $x x x$ & $x x x$ & $x x x$ & $x x x$ & $x x x$ & $x x x$ & $x x x$ & $x x x$ & $x x x$ & $x x x$ & $x x x$ & $x x x$ & $* \star \star$ \\
\hline Ácidos (L) & $x x x$ & $x x x$ & $x x x$ & $x x x$ & $x x x$ & $x x x$ & $x x x$ & $x x x$ & $x x x$ & $x x x$ & $x x x$ & $x x x$ & $x x x$ & $x x x$ & $x x x$ & $x x x$ & $x x x$ \\
\hline Ácidos (P) & $x x x$ & $x x x$ & $x x x$ & $x x x$ & $x x x$ & $x x x$ & $x x x$ & $x x x$ & $x x x$ & $x x x$ & $x x x$ & $x x x$ & $x x x$ & $x x x$ & $x x x$ & $x x x$ & $x x x$ \\
\hline (Al) & $x x x$ & $x x x$ & $x x x$ & $x x x$ & $x x x$ & $x x x$ & $x x x$ & $x x x$ & $x x x$ & $x x x$ & $x x x$ & $x x x$ & $x x x$ & $x x x$ & $x x x$ & $x x x$ & $x x x$ \\
\hline (Ba) & $x x x$ & $x x x$ & $x x x$ & $x x x$ & $x x x$ & $x x x$ & $x x x$ & $x x x$ & $x x x$ & $x x x$ & $x x x$ & $x x x$ & $x x x$ & $x x x$ & $x x x$ & $x x x$ & $x x x$ \\
\hline (Ca) & $x x x$ & $x x x$ & $x x x$ & $x x x$ & $x x x$ & $x x x$ & $x x x$ & $x x x$ & $x x x$ & $x x x$ & $x x x$ & $x x x$ & $x x x$ & $x x x$ & $x x x$ & $x x x$ & $x x x$ \\
\hline (Sr) & $x x x$ & $x x x$ & $x x x$ & $x x x$ & $x x x$ & $x x x$ & $x x x$ & $x x x$ & $x x x$ & $x x x$ & $x x x$ & $x x x$ & $x x x$ & $x x x$ & $x x x$ & $x x x$ & $x x x$ \\
\hline$(\mathrm{Fe})$ & $x x x$ & $x x x$ & $x x x$ & $x x x$ & $x x x$ & $x x x$ & $x x x$ & $x x x$ & $x x x$ & $x x x$ & $x x x$ & $x x x$ & $x x x$ & $x x x$ & $x x x$ & $x x x$ & $x x x$ \\
\hline (Ti) & $x x x$ & $x x x$ & $x x x$ & $x x x$ & $x x x$ & $x x x$ & $x x x$ & $x x x$ & $x x x$ & $x x x$ & $x x x$ & $x x x$ & $x x x$ & $x x x$ & $x x x$ & $x x x$ & $x x x$ \\
\hline $\mathrm{Ba} / \mathrm{Al}$ & $x x x$ & $x x x$ & $x x x$ & $x x x$ & $x x x$ & $x x x$ & $x x x$ & $x x x$ & $x x x$ & $x x x$ & $x x x$ & $x x x$ & $x x x$ & $x x x$ & $x x x$ & $x x x$ & $x x x$ \\
\hline $\mathrm{Ba} / \mathrm{Ti}$ & $x x x$ & $x x x$ & $x x x$ & $x x x$ & $x x x$ & $x x x$ & $x x x$ & $x x x$ & $x x x$ & $x x x$ & $x x x$ & $x x x$ & $x x x$ & $x x x$ & $x x x$ & $x x x$ & $x x x$ \\
\hline $\mathrm{Ba} / \mathrm{Ca}$ & $x x x$ & $x x x$ & $x x x$ & $x x x$ & $x x x$ & $x x x$ & $x x x$ & $x x x$ & $x x x$ & $x x x$ & $x x x$ & $x x x$ & $x x x$ & $x x x$ & $x x x$ & $x x x$ & $x x x$ \\
\hline $\mathrm{Al} / \mathrm{Ti}$ & $x x x$ & $x x x$ & $x x x$ & $x x x$ & $x x x$ & $x x x$ & $x x x$ & $x x x$ & $x x x$ & $x x x$ & $x x x$ & $x x x$ & $x x x$ & $x x x$ & $x x x$ & $x x x$ & $x x x$ \\
\hline $\mathrm{Sr} / \mathrm{Ti}$ & $x x x$ & $x x x$ & $x x x$ & $x x x$ & $x x x$ & $x x x$ & $x x x$ & $x x x$ & $x x x$ & $x x x$ & $x x x$ & $x x x$ & $x x x$ & $x x x$ & $x x x$ & $x x x$ & $x x x$ \\
\hline $\mathrm{Sr} / \mathrm{Ca}$ & $x x x$ & $x x x$ & $x x x$ & $x x x$ & $x x x$ & $x x x$ & $x x x$ & $x x x$ & $x x x$ & $x x x$ & $x x x$ & $x x x$ & $x x x$ & $x x x$ & $x x x$ & $x x x$ & $x x x$ \\
\hline $\mathrm{Fe} / \mathrm{Ca}$ & $x x x$ & $x x x$ & $x x x$ & $x x x$ & $x x x$ & $x x x$ & $x x x$ & $x x x$ & $x x x$ & $x x x$ & $x x x$ & $x x x$ & $x x x$ & $x x x$ & $x x x$ & $x x x$ & $x x x$ \\
\hline $\mathrm{Ti} / \mathrm{Ca}$ & $x x x$ & $x x x$ & $x x x$ & $x x x$ & $x x x$ & $x x x$ & $x x x$ & $x x x$ & $x x x$ & $x x x$ & $x x x$ & $x x x$ & $x x x$ & $x x x$ & $x x x$ & $x x x$ & $x x x$ \\
\hline
\end{tabular}


Tabela 14 (2/2): Correlação estatística de Pearson para o testemunho, da base ao topo.

\begin{tabular}{|c|c|c|c|c|c|c|c|c|c|c|c|c|c|c|c|c|}
\hline & Ác. (L) & Ác. (P) & (Al) & $(\mathrm{Ba})$ & (Ca) & $(\mathrm{Sr})$ & $(\mathrm{Fe})$ & $(\mathrm{Ti})$ & $\mathrm{Ba} / \mathrm{Al}$ & $\mathrm{Ba} / \mathrm{Ti}$ & $\mathrm{Ba} / \mathrm{Ca}$ & $\mathrm{Al} / \mathrm{Ti}$ & $\mathrm{Sr} / \mathrm{Ti}$ & $\mathrm{Sr} / \mathrm{Ca}$ & $\mathrm{Fe} / \mathrm{Ca}$ & $\mathrm{Ti} / \mathrm{Ca}$ \\
\hline T.S. & - & - & 0,31 & 0,32 & $-0,44$ & $-0,44$ & 0,28 & 0,23 & - & 0,22 & 0,50 & 0,29 & $-0,42$ & 0,43 & 0,50 & 0,50 \\
\hline S.M. & - & - & - & $-0,21$ & - & - & - & - & - & - & - & - & - & - & - & - \\
\hline d13C & $-0,23$ & - & $-0,39$ & $-0,44$ & 0,40 & 0,34 & - & $-0,20$ & - & $-0,44$ & $-0,45$ & $-0,45$ & 0,36 & $-0,43$ & $-0,36$ & $-0,38$ \\
\hline Alq. & - & - & 0,24 & 0,23 & $-0,22$ & $-0,21$ & 0,24 & - & - & - & 0,27 & 0,23 & $-0,22$ & 0,25 & 0,29 & 0,27 \\
\hline S n-alc. & 0,32 & - & 0,26 & 0,35 & $-0,32$ & $-0,27$ & 0,24 & - & - & 0,38 & 0,34 & 0,29 & $-0,28$ & 0,33 & 0,30 & 0,27 \\
\hline IPC & $-0,28$ & - & - & - & - & - & - & - & - & - & - & - & - & - & - & - \\
\hline Pri/Fit. & - & 0,21 & $-0,28$ & $-0,24$ & 0,20 & - & - & $-0,26$ & - & - & $-0,27$ & - & 0,21 & $-0,30$ & $-0,22$ & $-0,30$ \\
\hline TAR & 0,27 & - & 0,44 & 0,50 & $-0,68$ & $-0,72$ & 0,50 & 0,33 & - & 0,38 & 0,64 & 0,44 & $-0,68$ & 0,53 & 0,66 & 0,64 \\
\hline TSM & $-0,05$ & $-0,01$ & $-0,34$ & $-0,31$ & 0,41 & 0,39 & $-0,41$ & $-0,24$ & 0,22 & - & $-0,39$ & $-0,31$ & 0,38 & $-0,40$ & $-0,43$ & $-0,40$ \\
\hline Clorinas & 0,31 & - & 0,65 & 0,71 & $-0,64$ & $-0,53$ & 0,68 & 0,50 & $-0,20$ & 0,54 & 0,65 & 0,59 & $-0,64$ & 0,65 & 0,67 & 0,61 \\
\hline Álcoois (P/L) & $-0,46$ & - & $-0,53$ & $-0,59$ & 0,55 & 0,44 & $-0,46$ & $-0,47$ & - & $-0,39$ & $-0,51$ & $-0,45$ & 0,59 & $-0,53$ & $-0,50$ & $-0,50$ \\
\hline Ácidos (P/L) & $-0,28$ & - & $-0,24$ & $-0,28$ & 0,31 & 0,37 & $-0,30$ & - & - & $-0,25$ & $-0,28$ & $-0,25$ & 0,35 & $-0,19$ & $-0,30$ & $-0,26$ \\
\hline $\mathrm{C} / \mathrm{N}$ & $-0,29$ & - & $-0,45$ & $-0,53$ & 0,36 & 0,26 & $-0,31$ & $-0,42$ & - & $-0,34$ & $-0,42$ & $-0,34$ & 0,42 & $-0,41$ & $-0,36$ & $-0,40$ \\
\hline Alifáticos (L) & 0,32 & 0,20 & 0,23 & 0,25 & - & - & 0,21 & - & - & - & - & - & - & - & - & - \\
\hline Alifáticos (P) & 0,39 & - & 0,47 & 0,50 & $-0,69$ & $-0,66$ & 0,51 & 0,30 & $-0,21$ & 0,44 & 0,64 & 0,50 & $-0,64$ & 0,62 & 0,65 & 0,62 \\
\hline Álcoois (L) & 0,46 & - & 0,57 & 0,63 & $-0,56$ & $-0,44$ & 0,50 & 0,44 & - & 0,46 & 0,57 & 0,52 & $-0,57$ & 0,59 & 0,55 & 0,54 \\
\hline Álcoois (P) & 0,31 & 0,28 & 0,29 & 0,30 & $-0,53$ & $-0,55$ & 0,43 & - & $-0,21$ & 0,36 & 0,50 & 0,40 & $-0,44$ & 0,43 & 0,53 & 0,43 \\
\hline Ácidos (L) & $* * *$ & - & 0,29 & 0,50 & $-0,45$ & $-0,42$ & 0,33 & - & - & 0,54 & 0,40 & 0,35 & $-0,46$ & 0,35 & 0,37 & 0,31 \\
\hline Ácidos (P) & $x x x$ & *** & - & - & - & - & - & - & - & - & - & - & - & - & - & - \\
\hline (Al) & $x x x$ & $x x x$ & $* * *$ & 0,90 & $-0,73$ & $-0,56$ & 0,89 & 0,81 & $-0,63$ & 0,44 & 0,82 & 0,82 & $-0,82$ & 0,83 & 0,85 & 0,83 \\
\hline (Ba) & $x x x$ & $x x x$ & $x x x$ & *** & $-0,75$ & $-0,57$ & 0,84 & 0,75 & $-0,26$ & 0,66 & 0,85 & 0,74 & $-0,82$ & 0,82 & 0,81 & 0,79 \\
\hline (Ca) & $x x x$ & $x x x$ & $x x x$ & $x x x$ & *** & 0,94 & $-0,73$ & $-0,50$ & 0,40 & $-0,60$ & $-0,94$ & $-0,76$ & 0,94 & $-0,91$ & $-0,95$ & $-0,91$ \\
\hline (Sr) & $x x x$ & $x x x$ & $x x x$ & $x x x$ & $x x x$ & *** & $-0,59$ & $-0,30$ & 0,31 & $-0,55$ & $-0,86$ & $-0,66$ & 0,86 & $-0,74$ & $-0,87$ & $-0,83$ \\
\hline$(\mathrm{Fe})$ & $x x x$ & $x x x$ & $x x x$ & $x x x$ & $x x x$ & $x x x$ & $* * *$ & 0,75 & $-0,56$ & 0,41 & 0,74 & 0,72 & $-0,82$ & 0,75 & 0,84 & 0,75 \\
\hline (Ti) & $x x x$ & $x x x$ & $x x x$ & $x x x$ & $x x x$ & $x x x$ & $x x x$ & $* * *$ & $-0,47$ & 0,01 & 0,57 & 0,34 & $-0,72$ & 0,61 & 0,61 & 0,71 \\
\hline $\mathrm{Ba} / \mathrm{Al}$ & $x x x$ & $x x x$ & $x x x$ & $x x x$ & $x x x$ & $x x x$ & $x x x$ & $x x x$ & $* * *$ & - & $-0,39$ & $-0,54$ & 0,45 & $-0,46$ & $-0,52$ & $-0,50$ \\
\hline $\mathrm{Ba} / \mathrm{Ti}$ & $x x x$ & $x x x$ & $x x x$ & $x x x$ & $x x x$ & $x x x$ & $x x x$ & $x x x$ & $x x x$ & $\star * * *$ & 0,65 & 0,75 & $-0,44$ & 0,57 & 0,55 & 0,40 \\
\hline $\mathrm{Ba} / \mathrm{Ca}$ & $x x x$ & $x x x$ & $x x x$ & $x x x$ & $x x x$ & $x x x$ & $x x x$ & $x x x$ & $x x x$ & $x x x$ & $* * *$ & 0,80 & $-0,91$ & 0,94 & 0,96 & 0,95 \\
\hline $\mathrm{Al} / \mathrm{Ti}$ & $x x x$ & $x x x$ & $x x x$ & $x x x$ & $x x x$ & $x x x$ & $x x x$ & $x x x$ & $x x x$ & $x x x$ & $x x x$ & $* * *$ & $-0,67$ & 0,78 & 0,81 & 0,67 \\
\hline $\mathrm{Sr} / \mathrm{Ti}$ & $x x x$ & $x x x$ & $x x x$ & $x x x$ & $x x x$ & $x x x$ & $x x x$ & $x x x$ & $x x x$ & $x x x$ & $x x x$ & $x x x$ & $* * *$ & $-0,86$ & $-0,94$ & $-0,94$ \\
\hline $\mathrm{Sr} / \mathrm{Ca}$ & $x x x$ & $x x x$ & $x x x$ & $x x x$ & $x x x$ & $x x x$ & $x x x$ & $x x x$ & $x x x$ & $x x x$ & $x x x$ & $x x x$ & $x x x$ & *** & 0,93 & 0,91 \\
\hline $\mathrm{Fe} / \mathrm{Ca}$ & $x x x$ & $x x x$ & $x x x$ & $x x x$ & $x x x$ & $x x x$ & $x x x$ & $x x x$ & $x x x$ & $x x x$ & $x x x$ & $x x x$ & $x x x$ & $x x x$ & *** & 0,95 \\
\hline $\mathrm{Ti} / \mathrm{Ca}$ & $x x x$ & $x x x$ & $x x x$ & $x x x$ & $x x x$ & $x x x$ & $x x x$ & $x x x$ & $x x x$ & $x x x$ & $x x x$ & $x x x$ & $x x x$ & $x x x$ & $x x x$ & $\star \star * *$ \\
\hline
\end{tabular}




\subsubsection{Estágio Isotópico Marinho 3: Base do Testemunho a 23.000 anos A.P.}

A Tabela 15 mostra as correlações estatística entre os marcadores analisados durante o Estágio Isotópico Marinho 3.

A taxa de sedimentação apresenta correlação diretamente proporcional com as clorinas $(R=0,52)$ e inversamente proporcional com as relações $P / L$ do ácidos e álcoois $(R=-0,67$ e $R=-0,61)$. Essas relações podem ser explicadas pelo aumento na contribuição de matéria de origem terrígena para o oceano na região nesse período. $\mathrm{O}$ aumento na contribuição de matéria orgânica ocorre devido a retração dos oceanos em função da diminuição da TSM. Essa retração dos oceanos aproximaria a linha de costa do local de coleta do testemunho, aumentando o fluxo de material terrígeno para a área, o que proporcionaria maior quantidade de nutrientes e favoreceria a produção primária, aumentando a quantidade de álcoois e ácidos graxos leves, como mostrado na figura 35 .

As razões entre os metais, indicativas de material terrígeno, $\mathrm{Fe} / \mathrm{Ca}$ e $\mathrm{Ti} / \mathrm{Ca}$, apresentam um aumento nos seus valores ao longo do MIS 3 e se correlacionam com a susceptibilidade magnética $(R=0,84$ e $R=0,88)$, reforçando a hipótese de aumento no fluxo de material terrígeno para meio marinho na região estudada durante o MIS 3. 
Tabela 15 (1/2): Correlação estatística de Pearson para o Estágio Isotópico Marinho 3.

\begin{tabular}{|c|c|c|c|c|c|c|c|c|c|c|c|c|c|c|c|c|c|}
\hline & T.S. & S.M. & d13C & Alq. & S n-alc. & IPC & Pri/Fit. & TAR & TSM & Clorinas & Álc. (P/L) & Ác. (P/L) & $\mathrm{C} / \mathrm{N}$ & Alif. (L) & Alif. (P) & Álc. (L) & Álc (P) \\
\hline T.S. & $* * *$ & $-0,50$ & - & - & - & - & - & 0,52 & - & 0,52 & $-0,67$ & $-0,61$ & - & 0,54 & 0,67 & 0,84 & - \\
\hline S.M. & $x x x$ & *** & - & - & - & - & - & - & - & $-0,44$ & - & - & - & - & - & - & - \\
\hline d13c & $x x x$ & $x x x$ & *** & - & - & - & - & - & - & 0,43 & - & - & - & - & - & - & - \\
\hline Alq. & $x x x$ & $x x x$ & $x x x$ & $* * *$ & - & - & - & - & - & - & - & - & - & - & - & - & - \\
\hline S n-alc. & $x x x$ & $x x x$ & $x x x$ & $x x x$ & *** & - & - & - & - & - & - & - & - & 0,54 & 0,50 & - & $-0,45$ \\
\hline IPC & $x x x$ & $x x x$ & $x x x$ & $x x x$ & $x x x$ & $* \star *$ & - & $-0,50$ & 0,55 & - & - & - & - & - & $-0,45$ & - & - \\
\hline Pri/Fit. & $x x x$ & $x x x$ & $x x x$ & $x x x$ & $x x x$ & $x x x$ & *** & - & - & - & - & - & - & - & - & - & - \\
\hline TAR & $x x x$ & $x x x$ & $x x x$ & $x x x$ & $x x x$ & $x x x$ & $x x x$ & $* \star *$ & $-0,66$ & - & - & - & - & - & 0,94 & 0,46 & $-0,57$ \\
\hline TSM & $x x x$ & $x x x$ & $x x x$ & $x x x$ & $x x x$ & $x x x$ & $x x x$ & $x x x$ & $* * *$ & - & - & - & - & - & $-0,67$ & - & - \\
\hline Clorinas & $x x x$ & $x x x$ & $x x x$ & $x x x$ & $x x x$ & $x x x$ & $x x x$ & $x x x$ & $x x x$ & *** & - & - & - & - & - & - & - \\
\hline Álcoois (P/L) & $x x x$ & $x x x$ & $x x x$ & $x x x$ & $x x x$ & $x x x$ & $x x x$ & $x x x$ & $x x x$ & $x x x$ & $* * *$ & - & - & - & $-0,50$ & $-0,61$ & 0,44 \\
\hline Ácidos (P/L) & $x x x$ & $x x x$ & $x x x$ & $x x x$ & $x x x$ & $x x x$ & $x x x$ & $x x x$ & $x x x$ & $x x x$ & $x x x$ & $\star \star * *$ & - & - & - & - & - \\
\hline $\mathrm{C} / \mathrm{N}$ & $x x x$ & $x x x$ & $x x x$ & $x x x$ & $x x x$ & $x x x$ & $x x x$ & $x x x$ & $x x x$ & $x x x$ & $x x x$ & $x x x$ & $* * *$ & - & - & $-0,47$ & - \\
\hline Alifáticos (L) & $x x x$ & $x x x$ & $x x x$ & $x x x$ & $x x x$ & $x x x$ & $x x x$ & $x x x$ & $x x x$ & $x x x$ & $x x x$ & $x x x$ & $x x x$ & *** & 0,56 & 0,63 & - \\
\hline Alifáticos (P) & $x x x$ & $x x x$ & $x x x$ & $x x x$ & $x x x$ & $x x x$ & $x x x$ & $x x x$ & $x x x$ & $x x x$ & $x x x$ & $x x x$ & $x x x$ & $x x x$ & $* * *$ & 0,65 & $-0,54$ \\
\hline Álcoois (L) & $x x x$ & $x x x$ & $x x x$ & $x x x$ & $x x x$ & $x x x$ & $x x x$ & $x x x$ & $x x x$ & $x x x$ & $x x x$ & $x x x$ & $x x x$ & $x x x$ & $x x x$ & $* * *$ & - \\
\hline Álcoois (P) & $x x x$ & $x x x$ & $x x x$ & $x x x$ & $x x x$ & $x x x$ & $x x x$ & $x x x$ & $x x x$ & $x x x$ & $x x x$ & $x x x$ & $x x x$ & $x x x$ & $x x x$ & $x x x$ & $* * *$ \\
\hline Ácidos (L) & $x x x$ & $x x x$ & $x x x$ & $x x x$ & $x x x$ & $x x x$ & $x x x$ & $x x x$ & $x x x$ & $x x x$ & $x x x$ & $x x x$ & $x x x$ & $x x x$ & $x x x$ & $x x x$ & $x x x$ \\
\hline Ácidos (P) & $x x x$ & $x x x$ & $x x x$ & $x x x$ & $x x x$ & $x x x$ & $x x x$ & $x x x$ & $x x x$ & $x x x$ & $x x x$ & $x x x$ & $x x x$ & $x x x$ & $x x x$ & $x x x$ & $x x x$ \\
\hline (Al) & $x x x$ & $x x x$ & $x x x$ & $x x x$ & $x x x$ & $x x x$ & $x x x$ & $x x x$ & $x x x$ & $x x x$ & $x x x$ & $x x x$ & $x x x$ & $x x x$ & $x x x$ & $x x x$ & $x x x$ \\
\hline (Ba) & $x x x$ & $x x x$ & $x x x$ & $x x x$ & $x x x$ & $x x x$ & $x x x$ & $x x x$ & $x x x$ & $x x x$ & $x x x$ & $x x x$ & $x x x$ & $x x x$ & $x x x$ & $x x x$ & $x x x$ \\
\hline (Ca) & $x x x$ & $x x x$ & $x x x$ & $x x x$ & $x x x$ & $x x x$ & $x x x$ & $x x x$ & $x x x$ & $x x x$ & $x x x$ & $x x x$ & $x x x$ & $x x x$ & $x x x$ & $x x x$ & $x x x$ \\
\hline (Sr) & $x x x$ & $x x x$ & $x x x$ & $x x x$ & $x x x$ & $x x x$ & $x x x$ & $x x x$ & $x x x$ & $x x x$ & $x x x$ & $x x x$ & $x x x$ & $x x x$ & $x x x$ & $x x x$ & $x x x$ \\
\hline$(\mathrm{Fe})$ & $x x x$ & $x x x$ & $x x x$ & $x x x$ & $x x x$ & $x x x$ & $x x x$ & $x x x$ & $x x x$ & $x x x$ & $x x x$ & $x x x$ & $x x x$ & $x x x$ & $x x x$ & $x x x$ & $x x x$ \\
\hline (Ti) & $x x x$ & $x x x$ & $x x x$ & $x x x$ & $x x x$ & $x x x$ & $x x x$ & $x x x$ & $x x x$ & $x x x$ & $x x x$ & $x x x$ & $x x x$ & $x x x$ & $x x x$ & $x x x$ & $x x x$ \\
\hline $\mathrm{Ba} / \mathrm{Al}$ & $x x x$ & $x x x$ & $x x x$ & $x x x$ & $x x x$ & $x x x$ & $x x x$ & $x x x$ & $x x x$ & $x x x$ & $x x x$ & $x x x$ & $x x x$ & $x x x$ & $x x x$ & $x x x$ & $x x x$ \\
\hline $\mathrm{Ba} / \mathrm{Ti}$ & $x x x$ & $x x x$ & $x x x$ & $x x x$ & $x x x$ & $x x x$ & $x x x$ & $x x x$ & $x x x$ & $x x x$ & $x x x$ & $x x x$ & $x x x$ & $x x x$ & $x x x$ & $x x x$ & $x x x$ \\
\hline $\mathrm{Ba} / \mathrm{Ca}$ & $x x x$ & $x x x$ & $x x x$ & $x x x$ & $x x x$ & $x x x$ & $x x x$ & $x x x$ & $x x x$ & $x x x$ & $x x x$ & $x x x$ & $x x x$ & $x x x$ & $x x x$ & $x x x$ & $x x x$ \\
\hline$A l / T i$ & $x x x$ & $x x x$ & $x x x$ & $x x x$ & $x x x$ & $x x x$ & $x x x$ & $x x x$ & $x x x$ & $x x x$ & $x x x$ & $x x x$ & $x x x$ & $x x x$ & $x x x$ & $x x x$ & $x x x$ \\
\hline $\mathrm{Sr} / \mathrm{Ti}$ & $x x x$ & $x x x$ & $x x x$ & $x x x$ & $x x x$ & $x x x$ & $x x x$ & $x x x$ & $x x x$ & $x x x$ & $x x x$ & $x x x$ & $x x x$ & $x x x$ & $x x x$ & $x x x$ & $x x x$ \\
\hline $\mathrm{Sr} / \mathrm{Ca}$ & $x x x$ & $x x x$ & $x x x$ & $x x x$ & $x x x$ & $x x x$ & $x x x$ & $x x x$ & $x x x$ & $x x x$ & $x x x$ & $x x x$ & $x x x$ & $x x x$ & $x x x$ & $x x x$ & $x x x$ \\
\hline $\mathrm{Fe} / \mathrm{Ca}$ & $x x x$ & $x x x$ & $x x x$ & $x x x$ & $x x x$ & $x x x$ & $x x x$ & $x x x$ & $x x x$ & $x x x$ & $x x x$ & $x x x$ & $x x x$ & $x x x$ & $x x x$ & $x x x$ & $x x x$ \\
\hline $\mathrm{Ti} / \mathrm{Ca}$ & $x x x$ & $x x x$ & $x x x$ & $x x x$ & $x x x$ & $x x x$ & $x x x$ & $x x x$ & $x x x$ & $x x x$ & $x x x$ & $x x x$ & $x x x$ & $x x x$ & $x x x$ & $x x x$ & $x x x$ \\
\hline
\end{tabular}


Tabela 15 (2/2): Correlação estatística de Pearson para o Estágio Isotópico Marinho 3.

\begin{tabular}{|c|c|c|c|c|c|c|c|c|c|c|c|c|c|c|c|c|}
\hline & Ác. (L) & Ác. (P) & (Al) & (Ba) & (Ca) & (Sr) & $(\mathrm{Fe})$ & (Ti) & $\mathrm{Ba} / \mathrm{Al}$ & $\mathrm{Ba} / \mathrm{Ti}$ & $\mathrm{Ba} / \mathrm{Ca}$ & $\mathrm{Al} / \mathrm{Ti}$ & $\mathrm{Sr} / \mathrm{Ti}$ & $\mathrm{Sr} / \mathrm{Ca}$ & $\mathrm{Fe} / \mathrm{Ca}$ & $\mathrm{Ti} / \mathrm{Ca}$ \\
\hline T.S. & 0,85 & - & 0,73 & 0,80 & $-0,58$ & - & 0,70 & 0,75 & - & - & 0,88 & - & $-0,84$ & 0,68 & 0,84 & 0,88 \\
\hline S.M. & - & - & - & - & - & - & - & - & - & - & - & - & - & - & - & - \\
\hline d13c & - & - & - & - & - & - & - & - & - & - & - & - & - & - & - & - \\
\hline Alq. & - & - & - & - & - & - & - & - & - & - & - & - & $-0,47$ & - & - & - \\
\hline S n-alc. & - & - & 0,48 & 0,53 & - & - & 0,63 & - & - & - & 0,45 & - & - & - & 0,53 & - \\
\hline IPC & - & - & - & - & - & - & - & - & - & - & - & - & - & - & - & - \\
\hline Pri/Fit. & - & - & - & - & - & - & - & - & - & - & - & - & - & - & - & - \\
\hline TAR & 0,53 & - & - & - & - & - & - & - & - & - & - & - & $-0,48$ & - & - & - \\
\hline TSM & $-0,53$ & - & - & - & - & - & - & - & - & - & - & - & - & - & - & - \\
\hline Clorinas & - & - & - & - & - & - & 0,45 & - & - & - & - & - & - & - & 0,46 & - \\
\hline Álcoois (P/L) & $-0,65$ & - & - & $-0,48$ & 0,56 & - & $-0,45$ & - & - & - & $-0,62$ & - & 0,69 & - & $-0,60$ & $-0,59$ \\
\hline Ácidos (P/L) & - & - & - & - & - & 0,47 & - & - & - & - & - & - & - & - & - & - \\
\hline $\mathrm{C} / \mathrm{N}$ & - & - & - & - & - & - & - & - & - & - & - & - & - & - & - & - \\
\hline Alifáticos (L) & 0,67 & 0,50 & 0,57 & 0,60 & - & - & 0,62 & 0,53 & - & - & 0,46 & - & $-0,50$ & - & 0,50 & 0,43 \\
\hline Alifáticos (P) & 0,73 & - & - & 0,44 & - & - & - & 0,45 & - & - & 0,51 & - & $-0,62$ & - & 0,48 & 0,55 \\
\hline Álcoois (L) & 0,86 & - & 0,67 & 0,76 & $-0,53$ & - & 0,70 & 0,70 & - & - & 0,85 & 0,21 & $-0,83$ & 0,57 & 0,83 & 0,84 \\
\hline Álcoois (P) & - & - & - & - & - & - & - & - & - & - & - & - & - & - & - & - \\
\hline Ácidos (L) & $* * *$ & - & 0,66 & 0,70 & $-0,44$ & - & 0,67 & 0,68 & - & - & 0,74 & - & $-0,84$ & - & 0,74 & 0,76 \\
\hline Ácidos (P) & $x x x$ & $* * *$ & - & - & 0,47 & 0,46 & - & - & - & - & - & - & - & - & - & - \\
\hline (Al) & $x x x$ & $x x x$ & $* * *$ & 0,97 & - & - & 0,88 & 0,87 & $-0,69$ & - & 0,77 & 0,59 & $-0,65$ & 0,68 & 0,75 & 0,72 \\
\hline (Ba) & $x x x$ & $x x x$ & $x x x$ & $\star * * *$ & - & - & 0,91 & 0,89 & $-0,50$ & - & 0,86 & 0,48 & $-0,72$ & 0,73 & 0,83 & 0,81 \\
\hline (Ca) & $x x x$ & $x x x$ & $x x x$ & $x x x$ & $* * *$ & 0,70 & - & - & - & - & $-0,71$ & - & 0,66 & $-0,51$ & $-0,64$ & $-0,68$ \\
\hline (Sr) & $x x x$ & $x x x$ & $x x x$ & $x x x$ & $x x x$ & $* * *$ & - & - & $-0,52$ & - & - & - & - & - & - & - \\
\hline$(\mathrm{Fe})$ & $x x x$ & $x x x$ & $x x x$ & $x x x$ & $x x x$ & $x x x$ & $* * *$ & 0,74 & $-0,45$ & - & 0,76 & 0,54 & $-0,62$ & 0,48 & 0,85 & 0,66 \\
\hline (Ti) & $x x x$ & $x x x$ & $x x x$ & $x x x$ & $x x x$ & $x x x$ & $x x x$ & $* * *$ & $-0,50$ & - & 0,72 & - & $-0,74$ & 0,76 & 0,65 & 0,82 \\
\hline $\mathrm{Ba} / \mathrm{Al}$ & $x x x$ & $x x x$ & $x x x$ & $x x x$ & $x x x$ & $x x x$ & $x x x$ & $x x x$ & $\star \star * *$ & - & - & $-0,63$ & - & - & - & - \\
\hline $\mathrm{Ba} / \mathrm{Ti}$ & $x x x$ & $x x x$ & $x x x$ & $x x x$ & $x x x$ & $x x x$ & $x x x$ & $x x x$ & $x x x$ & $* * *$ & - & 0,76 & - & - & - & - \\
\hline $\mathrm{Ba} / \mathrm{Ca}$ & $x x x$ & $x x x$ & $x x x$ & $x x x$ & $x x x$ & $x x x$ & $x x x$ & $x x x$ & $x x x$ & $x x x$ & $\star * *$ & - & $-0,87$ & 0,78 & 0,96 & 0,95 \\
\hline $\mathrm{Al} / \mathrm{Ti}$ & $x x x$ & $x x x$ & $x x x$ & $x x x$ & $x x x$ & $x x x$ & $x x x$ & $x x x$ & $x x x$ & $x x x$ & $x x x$ & $* * *$ & - & - & - & - \\
\hline $\mathrm{Sr} / \mathrm{Ti}$ & $x x x$ & $x x x$ & $x x x$ & $x x x$ & $x x x$ & $x x x$ & $x x x$ & $x x x$ & $x x x$ & $x x x$ & $x x x$ & $x x x$ & $\star * \star *$ & $-0,57$ & $-0,82$ & $-0,92$ \\
\hline $\mathrm{Sr} / \mathrm{Ca}$ & $x x x$ & $x x x$ & $x x x$ & $x x x$ & $x x x$ & $x x x$ & $x x x$ & $x x x$ & $x x x$ & $x x x$ & $x x x$ & $x x x$ & $x x x$ & $* * *$ & 0,65 & 0,83 \\
\hline $\mathrm{Fe} / \mathrm{Ca}$ & $x x x$ & $x x x$ & $x x x$ & $x x x$ & $x x x$ & $x x x$ & $x x x$ & $x x x$ & $x x x$ & $x x x$ & $x x x$ & $x x x$ & $x x x$ & $x x x$ & $* * *$ & 0,87 \\
\hline $\mathrm{Ti} / \mathrm{Ca}$ & $x x x$ & $x x x$ & $x x x$ & $x x x$ & $x x x$ & $x x x$ & $x x x$ & $x x x$ & $x x x$ & $x x x$ & $x x x$ & $x x x$ & $x x x$ & $x x x$ & $x x x$ & $\star \star \star *$ \\
\hline
\end{tabular}




\subsubsection{Estágio Isotópico Marinho 2: De 23.000 a 13.000 anos A.P.}

A Tabela 16 mostra as correlações estatística entre os marcadores analisados durante o Estágio Isotópico Marinho 2

O MIS 2 foi marcado por aumentos e diminuições bruscas na taxa de sedimentação. Nesse período houve uma diminuição nos valores de $\delta^{13} C_{\text {PDB }} \mathrm{e}$ suscetibilidade magnética, o que é aparentemente contraditório pois diminuição nos valores de $\delta^{13} \mathrm{C}_{\mathrm{PDB}}$ indicam aumento de matéria orgânica provenientes de plantas superiores e a diminuição da suscetibilidade magnética indica a diminuição das fontes terrígenas; porém os valores de $\delta^{13} \mathrm{C}_{\mathrm{PDB}}$ encontrados são típicos de produtores primários marinhos. Os menores valores de TSM registrados ao longo do testemunho ocorrem durante esse período, especialmente durante o Último Máximo Glacial. A média da TSM durante o Estágio Isotópico Marinho 2 foi de $22,2{ }^{\circ} \mathrm{C}$, ou seja, $0,4{ }^{\circ} \mathrm{C}$ mais fria do que a média durante o Estágio Isotópico Marinho 3.

As correlações entre as razões dos metais, Fe/Ca e Ti/Ca e a idade do sedimento ( $R=-0,70$ e $R=-0,58)$ mostram que há um aumento no fluxo de material terrígeno para o meio marinho nesse período.

Verifica-se que nesse período existe pouca correlação entre os parâmetros, não existindo um fator dirigente, o que possivelmente se deve ao fato de que o aumento e diminuições rápidas e inconstantes das taxas de sedimentação no período não teria permitido o equilíbrio entre os parâmetros físicos, químicos e biológicos. 
Tabela 16 (1/2): Correlação estatística de Pearson para o Estágio Isotópico Marinho 2.

\begin{tabular}{|c|c|c|c|c|c|c|c|c|c|c|c|c|c|c|c|c|c|}
\hline & T.S. & S.M. & d13C & Alq. & S n-alc. & IPC & Pri/Fit. & TAR & TSM & Clorinas & Álc. (P/L) & Ác. (P/L) & $C / N$ & Alif. (L) & Alif. (P) & Álc. (L) & Álc (P) \\
\hline T.S. & $* * *$ & - & - & 0,34 & - & - & $-0,25$ & - & - & - & $-0,27$ & 0,24 & - & $-0,21$ & - & - & $-0,24$ \\
\hline S.M. & $x x x$ & $* * *$ & 0,25 & - & - & - & 0,41 & - & 0,30 & - & - & - & 0,42 & - & - & - & - \\
\hline d13C & $x x x$ & $x x x$ & $* * *$ & - & - & $-0,35$ & 0,44 & $-0,24$ & - & - & - & - & - & - & - & - & - \\
\hline Alq. & $x x x$ & $x x x$ & $x x x$ & $* * *$ & - & - & $-0,21$ & - & $-0,37$ & 0,25 & - & 0,38 & $-0,33$ & $-0,30$ & 0,05 & - & - \\
\hline $\mathrm{S}$ n-alc. & $x x x$ & $x x x$ & $x x x$ & $x x x$ & $* \star *$ & - & $-0,13$ & - & - & - & $-0,24$ & - & - & 0,49 & 0,47 & - & - \\
\hline IPC & $x x x$ & $x x x$ & $x x x$ & $x x x$ & $x x x$ & $* * *$ & - & - & 0,03 & - & - & 0,36 & $-0,29$ & $-0,46$ & - & - & - \\
\hline Pri/Fit. & $x x x$ & $x x x$ & $x x x$ & $x x x$ & $x x x$ & $x x x$ & $* * *$ & $-0,33$ & - & - & - & $-0,38$ & 0,32 & - & - & - & - \\
\hline TAR & $x x x$ & $x x x$ & $x x x$ & $x x x$ & $x x x$ & $x x x$ & $x x x$ & $* * *$ & - & - & - & 0,39 & $-0,27$ & $-0,39$ & 0,50 & - & - \\
\hline TSM & $x x x$ & $x x x$ & $x x x$ & $x x x$ & $x x x$ & $x x x$ & $x x x$ & $x x x$ & $* * *$ & - & - & - & - & - & - & - & - \\
\hline Clorinas & $x x x$ & $x x x$ & $x x x$ & $x x x$ & $x x x$ & $x x x$ & $x x x$ & $x x x$ & $x x x$ & *** & - & - & - & - & - & - & - \\
\hline Álcoois (P/L) & $x x x$ & $x x x$ & $x x x$ & $x x x$ & $x x x$ & $x x x$ & $x x x$ & $x x x$ & $x x x$ & $x x x$ & $* * *$ & $-0,36$ & - & - & - & $-0,24$ & - \\
\hline Ácidos (P/L) & $x x x$ & $x x x$ & $x x x$ & $x x x$ & $x x x$ & $x x x$ & $x x x$ & $x x x$ & $x x x$ & $x x x$ & $x x x$ & $* \star \star *$ & $-0,29$ & $-0,39$ & - & - & - \\
\hline $\mathrm{C} / \mathrm{N}$ & $x x x$ & $x x x$ & $x x x$ & $x x x$ & $x x x$ & $x x x$ & $x x x$ & $x x x$ & $x x x$ & $x x x$ & $x x x$ & $x x x$ & $* * *$ & - & $-0,25$ & - & - \\
\hline Alifáticos (L) & $x x x$ & $x x x$ & $x x x$ & $x x x$ & $x x x$ & $x x x$ & $x x x$ & $x x x$ & $x x x$ & $x x x$ & $x x x$ & $x x x$ & $x x x$ & *** & 0,25 & - & 0,28 \\
\hline Alifáticos (P) & $x x x$ & $x x x$ & $x x x$ & $x x x$ & $x x x$ & $x x x$ & $x x x$ & $x x x$ & $x x x$ & $x x x$ & $x x x$ & $x x x$ & $x x x$ & $x x x$ & $* * *$ & - & - \\
\hline Álcoois (L) & $x x x$ & $x x x$ & $x x x$ & $x x x$ & $x x x$ & $x x x$ & $x x x$ & $x x x$ & $x x x$ & $x x x$ & $x x x$ & $x x x$ & $x x x$ & $x x x$ & $x x x$ & $* * *$ & - \\
\hline Álcoois (P) & $x x x$ & $x x x$ & $x x x$ & $x x x$ & $x x x$ & $x x x$ & $x x x$ & $x x x$ & $x x x$ & $x x x$ & $x x x$ & $x x x$ & $x x x$ & $x x x$ & $x x x$ & $x x x$ & $* * *$ \\
\hline Ácidos (L) & $x x x$ & $x x x$ & $x x x$ & $x x x$ & $x x x$ & $x x x$ & $x x x$ & $x x x$ & $x x x$ & $x x x$ & $x x x$ & $x x x$ & $x x x$ & $x x x$ & $x x x$ & $x x x$ & $x x x$ \\
\hline Ácidos (P) & $x x x$ & $x x x$ & $x x x$ & $x x x$ & $x x x$ & $x x x$ & $x x x$ & $x x x$ & $x x x$ & $x x x$ & $x x x$ & $x x x$ & $x x x$ & $x x x$ & $x x x$ & $x x x$ & $x x x$ \\
\hline (Al) & $x x x$ & $x x x$ & $x x x$ & $x x x$ & $x x x$ & $x x x$ & $x x x$ & $x x x$ & $x x x$ & $x x x$ & $x x x$ & $x x x$ & $x x x$ & $x x x$ & $x x x$ & $x x x$ & $x x x$ \\
\hline (Ba) & $x x x$ & $x x x$ & $x x x$ & $x x x$ & $x x x$ & $x x x$ & $x x x$ & $x x x$ & $x x x$ & $x x x$ & $x x x$ & $x x x$ & $x x x$ & $x x x$ & $x x x$ & $x x x$ & $x x x$ \\
\hline (Ca) & $x x x$ & $x x x$ & $x x x$ & $x x x$ & $x x x$ & $x x x$ & $x x x$ & $x x x$ & $x x x$ & $x x x$ & $x x x$ & $x x x$ & $x x x$ & $x x x$ & $x x x$ & $x x x$ & $x x x$ \\
\hline (Sr) & $x x x$ & $x x x$ & $x x x$ & $x x x$ & $x x x$ & $x x x$ & $x x x$ & $x x x$ & $x x x$ & $x x x$ & $x x x$ & $x x x$ & $x x x$ & $x x x$ & $x x x$ & $x x x$ & $x x x$ \\
\hline (Fe) & $x x x$ & $x x x$ & $x x x$ & $x x x$ & $x x x$ & $x x x$ & $x x x$ & $x x x$ & $x x x$ & $x x x$ & $x x x$ & $x x x$ & $x x x$ & $x x x$ & $x x x$ & $x x x$ & $x x x$ \\
\hline (Ti) & $x x x$ & $x x x$ & $x x x$ & $x x x$ & $x x x$ & $x x x$ & $x x x$ & $x x x$ & $x x x$ & $x x x$ & $x x x$ & $x x x$ & $x x x$ & $x x x$ & $x x x$ & $x x x$ & $x x x$ \\
\hline $\mathrm{Ba} / \mathrm{Al}$ & $x x x$ & $x x x$ & $x x x$ & $x x x$ & $x x x$ & $x x x$ & $x x x$ & $x x x$ & $x x x$ & $x x x$ & $x x x$ & $x x x$ & $x x x$ & $x x x$ & $x x x$ & $x x x$ & $x x x$ \\
\hline $\mathrm{Ba} / \mathrm{Ti}$ & $x x x$ & $x x x$ & $x x x$ & $x x x$ & $x x x$ & $x x x$ & $x x x$ & $x x x$ & $x x x$ & $x x x$ & $x x x$ & $x x x$ & $x x x$ & $x x x$ & $x x x$ & $x x x$ & $x x x$ \\
\hline $\mathrm{Ba} / \mathrm{Ca}$ & $x x x$ & $x x x$ & $x x x$ & $x x x$ & $x x x$ & $x x x$ & $x x x$ & $x x x$ & $x x x$ & $x x x$ & $x x x$ & $x x x$ & $x x x$ & $x x x$ & $x x x$ & $x x x$ & $x x x$ \\
\hline $\mathrm{Al} / \mathrm{Ti}$ & $x x x$ & $x x x$ & $x x x$ & $x x x$ & $x x x$ & $x x x$ & $x x x$ & $x x x$ & $x x x$ & $x x x$ & $x x x$ & $x x x$ & $x x x$ & $x x x$ & $x x x$ & $x x x$ & $x x x$ \\
\hline $\mathrm{Sr} / \mathrm{Ti}$ & $x x x$ & $x x x$ & $x x x$ & $x x x$ & $x x x$ & $x x x$ & $x x x$ & $x x x$ & $x x x$ & $x x x$ & $x x x$ & $x x x$ & $x x x$ & $x x x$ & $x x x$ & $x x x$ & $x x x$ \\
\hline $\mathrm{Sr} / \mathrm{Ca}$ & $x x x$ & $x x x$ & $x x x$ & $x x x$ & $x x x$ & $x x x$ & $x x x$ & $x x x$ & $x x x$ & $x x x$ & $x x x$ & $x x x$ & $x x x$ & $x x x$ & $x x x$ & $x x x$ & $x x x$ \\
\hline $\mathrm{Fe} / \mathrm{Ca}$ & $x x x$ & $x x x$ & $x x x$ & $x x x$ & $x x x$ & $x x x$ & $x x x$ & $x x x$ & $x x x$ & $x x x$ & $x x x$ & $x x x$ & $x x x$ & $x x x$ & $x x x$ & $x x x$ & $x x x$ \\
\hline $\mathrm{Ti} / \mathrm{Ca}$ & $x x x$ & $x x x$ & $x x x$ & $x x x$ & $x x x$ & $x x x$ & $x x x$ & $x x x$ & $x x x$ & $x x x$ & $x x x$ & $x x x$ & $x x x$ & $x x x$ & $x x x$ & $x x x$ & $x x x$ \\
\hline
\end{tabular}


Tabela 16 (2/2): Correlação estatística de Pearson para o Estágio Isotópico Marinho2.

\begin{tabular}{|c|c|c|c|c|c|c|c|c|c|c|c|c|c|c|c|c|}
\hline & Ác. (L) & Ác. (P) & (AI) & (Ba) & (Ca) & (Sr) & $(\mathrm{Fe})$ & (Ti) & $\mathrm{Ba} / \mathrm{Al}$ & $\mathrm{Ba} / \mathrm{Ti}$ & $\mathrm{Ba} / \mathrm{Ca}$ & $\mathrm{Al} / \mathrm{Ti}$ & $\mathrm{Sr} / \mathrm{Ti}$ & $\mathrm{Sr} / \mathrm{Ca}$ & $\mathrm{Fe} / \mathrm{Ca}$ & $\mathrm{Ti} / \mathrm{Ca}$ \\
\hline T.S. & - & - & - & - & $-0,40$ & $-0,32$ & - & - & - & - & 0,42 & - & $-0,33$ & 0,32 & 0,43 & 0,39 \\
\hline S.M. & - & - & $-0,51$ & $-0,44$ & 0,43 & - & - & $-0,35$ & 0,39 & - & $-0,57$ & $-0,29$ & 0,40 & $-0,67$ & $-0,55$ & $-0,60$ \\
\hline d13C & - & - & $-0,25$ & - & 0,49 & 0,35 & - & - & - & - & $-0,49$ & $-0,39$ & 0,25 & $-0,46$ & $-0,45$ & $-0,39$ \\
\hline Alq. & $-0,33$ & - & 0,26 & 0,24 & - & - & - & - & - & - & 0,27 & 0,24 & - & 0,29 & 0,34 & 0,25 \\
\hline S n-alc. & - & - & - & - & - & - & - & - & - & 0,23 & - & - & - & - & - & - \\
\hline IPC & $-0,34$ & - & 0,26 & - & - & - & - & - & $-0,26$ & - & 0,26 & 0,41 & - & 0,23 & 0,29 & - \\
\hline Pri/Fit. & 0,37 & - & $-0,27$ & $-0,24$ & 0,28 & - & - & $-0,23$ & - & - & $-0,36$ & - & 0,30 & $-0,40$ & $-0,32$ & $-0,41$ \\
\hline TAR & - & - & & - & $-0,29$ & $-0,45$ & - & - & - & - & - & - & $-0,34$ & - & - & 0,25 \\
\hline TSM & 0,25 & - & - & - & - & - & - & - & - & - & - & - & - & $-0,24$ & - & - \\
\hline Clorinas & $-0,26$ & - & 0,32 & 0,32 & - & - & 0,31 & - & - & - & - & - & - & - & - & - \\
\hline Álcoois (P/L) & - & 0,50 & $-0,33$ & $-0,30$ & - & - & - & $-0,28$ & - & - & - & - & - & $-0,29$ & $-0,27$ & $-0,28$ \\
\hline Ácidos (P/L) & $-0,36$ & - & - & - & $-0,32$ & - & - & - & - & - & 0,35 & - & $-0,31$ & 0,34 & 0,37 & 0,41 \\
\hline $\mathrm{C} / \mathrm{N}$ & 0,33 & - & $-0,37$ & $-0,31$ & - & - & - & $-0,29$ & 0,27 & - & $-0,29$ & - & - & $-0,32$ & $-0,31$ & $-0,34$ \\
\hline Alifáticos (L) & - & - & - & - & - & - & - & - & - & - & - & - & - & - & - & - \\
\hline Alifáticos (P) & 0,03 & - & - & - & $-0,27$ & - & - & - & - & - & - & - & - & - & - & - \\
\hline Álcoois (L) & - & - & 0,26 & 0,27 & - & - & - & - & - & - & - & 0,24 & - & 0,27 & & - \\
\hline Álcoois (P) & 0,45 & 0,59 & - & - & - & $-0,25$ & - & $-0,27$ & - & 0,25 & - & - & - & - & - & - \\
\hline Ácidos (L) & $* * *$ & 0,60 & $-0,24$ & - & - & - & - & $-0,34$ & - & - & - & - & - & - & - & $-0,24$ \\
\hline Ácidos (P) & $x x x$ & $* * \star$ & - & - & - & - & - & - & - & - & - & - & - & - & - & - \\
\hline (Al) & $x x x$ & $x x x$ & $* * *$ & 0,88 & - & - & 0,72 & 0,71 & $-0,77$ & - & 0,51 & 0,52 & $-0,45$ & 0,50 & 0,61 & 0,56 \\
\hline (Ba) & $x x x$ & $x x x$ & $x x x$ & $* * *$ & - & 0,24 & 0,69 & 0,65 & $-0,38$ & - & 0,56 & 0,43 & $-0,36$ & 0,50 & 0,55 & 0,48 \\
\hline (Ca) & $x x x$ & $x x x$ & $x x x$ & $x x x$ & *** & 0,87 & 0,47 & 0,19 & 0,12 & $-0,30$ & $-0,84$ & $-0,36$ & 0,56 & $-0,68$ & $-0,78$ & $-0,71$ \\
\hline (Sr) & $x x x$ & $x x x$ & $x x x$ & $x x x$ & $x x x$ & $* * *$ & 0,60 & 0,37 & - & $-0,24$ & $-0,59$ & - & 0,53 & - & $-0,54$ & $-0,49$ \\
\hline$(\mathrm{Fe})$ & $x x x$ & $x x x$ & $x x x$ & $x x x$ & $x x x$ & $x x x$ & $* * *$ & 0,69 & $-0,50$ & - & - & - & - & - & - & - \\
\hline (Ti) & $x x x$ & $x x x$ & $x x x$ & $x x x$ & $x x x$ & $x x x$ & $x x x$ & $* * *$ & $-0,52$ & $-0,63$ & - & - & $-0,59$ & - & 0,29 & 0,54 \\
\hline $\mathrm{Ba} / \mathrm{Al}$ & $x x x$ & $x x x$ & $x x x$ & $x x x$ & $x x x$ & $x x x$ & $x x x$ & $x x x$ & $* * *$ & 0,30 & $-0,26$ & $-0,45$ & 0,40 & $-0,30$ & $-0,48$ & $-0,45$ \\
\hline $\mathrm{Ba} / \mathrm{Ti}$ & $x x x$ & $x x x$ & $x x x$ & $x x x$ & $x x x$ & $x x x$ & $x x x$ & $x x x$ & $x x x$ & $* * *$ & 0,35 & 0,71 & 0,39 & 0,25 & - & - \\
\hline $\mathrm{Ba} / \mathrm{Ca}$ & $x x x$ & $x x x$ & $x x x$ & $x x x$ & $x x x$ & $x x x$ & $x x x$ & $x x x$ & $x x x$ & $x x x$ & $* * *$ & 0,50 & $-0,65$ & 0,82 & 0,92 & 0,84 \\
\hline $\mathrm{Al} / \mathrm{Ti}$ & $x x x$ & $x x x$ & $x x x$ & $x x x$ & $x x x$ & $x x x$ & $x x x$ & $x x x$ & $x x x$ & $x x x$ & $x x x$ & $* * *$ & - & 0,45 & 0,50 & - \\
\hline $\mathrm{Sr} / \mathrm{Ti}$ & $x x x$ & $x x x$ & $x x x$ & $x x x$ & $x x x$ & $x x x$ & $x x x$ & $x x x$ & $x x x$ & $x x x$ & $x x x$ & $x x x$ & $* * *$ & $-0,36$ & $-0,72$ & $-0,89$ \\
\hline $\mathrm{Sr} / \mathrm{Ca}$ & $x x x$ & $x x x$ & $x x x$ & $x x x$ & $x x x$ & $x x x$ & $x x x$ & $x x x$ & $x x x$ & $x x x$ & $x x x$ & $x x x$ & $x x x$ & $\star \star \star *$ & 0,76 & 0,72 \\
\hline $\mathrm{Fe} / \mathrm{Ca}$ & $x x x$ & $x x x$ & $x x x$ & $x x x$ & $x x x$ & $x x x$ & $x x x$ & $x x x$ & $x x x$ & $x x x$ & $x x x$ & $x x x$ & $x x x$ & $x x x$ & $\star * *$ & 0,87 \\
\hline $\mathrm{Ti} / \mathrm{Ca}$ & $x x x$ & $x x x$ & $x x x$ & $x x x$ & $x x x$ & $x x x$ & $x x x$ & $x x x$ & $x x x$ & $x x x$ & $x x x$ & $x x x$ & $x x x$ & $x x x$ & $x x x$ & $\star \star * *$ \\
\hline
\end{tabular}




\subsubsection{Estágio Isotópico Marinho 1: De 13.000 A.P. até o tempo presente}

A Tabela 17 mostra as correlações estatística entre os marcadores analisados durante o Estágio Isotópico Marinho 1

Nesse período, em direção ao presente, ocorreu um aumento na taxa de sedimentação, diminuição na SM, diminuição do IPC, diminuição da relação entre ácidos e álcoois pesados/leves, elevação da TSM, diminuição nas razões de $\mathrm{Fe} / \mathrm{Ca}$ e Ti/Ca (Figura 33 e 35). Esses resultados apontam para uma redução na quantidade de matéria orgânica de origem terrestre transportada para o meio marinho. Há correlações significativas entre alquenonas e clorinas $(R=0,82)$, alquenonas e ácidos pesados $(R=0,80)$, alquenonas e alifáticos pesados $(R=0,85)$, entre clorinas e ácidos pesados $(R=0,77)$, e entre clorinas e alifáticos pesados $(R=0,93)$. Essas correlações mostram que a redução no fluxo de material de origem terrígena durante o Holoceno causou a redução na produtividade primária. A média da TSM observada durante o Holoceno foi de $23,6^{\circ} \mathrm{C}, 1,4^{\circ} \mathrm{C}$ mais quente do que a média do Estágio Isotópico Marinho 2 , sugerindo a hipótese contrária a apresentada no MIS 3 , ou seja a transgressão do mar: o aumento no nível do oceano afastando o local de coleta do testemunho das fontes de material terrígeno.

A Tabela 17 mostra ainda correlação significativa entre os outros parâmetros. Nota-se que, durante o Holoceno, todos os parâmetros que se correlacionaram com probabilidade de erro menor do que 5\% $(\rho<0,05)$ apresentam significância estatística maior que 0,6. Isso mostra que, na região, o Holoceno têm sido um período mais estável do ponto de vista do equilíbrio entre os marcadores geoquímicos do que o MIS 3 e o MIS 2, provavelmente em função da manutenção das taxas de sedimentação e maior estabilidade climática. 
Tabela 17 (1/2): Correlação estatística de Pearson para o Estágio Isotópico Marinho 1.

\begin{tabular}{|c|c|c|c|c|c|c|c|c|c|c|c|c|c|c|c|c|c|}
\hline & T.S. & S.M. & d13C & Alq. & S n-alc. & IPC & Pri/Fit. & TAR & TSM & Clorinas & Álc. (P/L) & Ác. (P/L) & $\mathrm{C} / \mathrm{N}$ & Alif. (L) & Alif. (P) & Álc. (L) & Álc (P) \\
\hline T.S. & $* * *$ & $-0,74$ & - & - & - & - & - & - & 0,88 & $-0,74$ & - & - & - & - & - & - & - \\
\hline S.M. & $x x x$ & $* * *$ & - & - & - & 0,83 & - & - & $-0,74$ & - & 0,85 & 0,85 & - & - & - & - & 0,79 \\
\hline d13C & $x x x$ & $x x x$ & $* * *$ & - & - & - & - & - & - & - & - & - & - & - & - & - & - \\
\hline Alq. & $x x x$ & $x x x$ & $x x x$ & $* * *$ & - & - & - & 0,88 & - & 0,82 & - & - & - & - & 0,85 & - & - \\
\hline S n-alc. & $x x x$ & $x x x$ & $x x x$ & $x x x$ & $* \star *$ & - & - & - & - & - & - & - & - & - & - & - & - \\
\hline IPC & $x x x$ & $x x x$ & $x x x$ & $x x x$ & $x x x$ & $* \star \star$ & - & - & - & - & 0,77 & 0,74 & - & - & - & - & 0,74 \\
\hline Pri/Fit. & $x x x$ & $x x x$ & $x x x$ & $x x x$ & $x x x$ & $x x x$ & *** & - & - & - & - & - & - & - & - & - & - \\
\hline TAR & $x x x$ & $x x x$ & $x x x$ & $x x x$ & $x x x$ & $x x x$ & $x x x$ & $* * *$ & $-0,81$ & 0,93 & - & - & - & - & 0,98 & - & - \\
\hline TSM & $x x x$ & $x x x$ & $x x x$ & $x x x$ & $x x x$ & $x x x$ & $x x x$ & $x x x$ & $* * *$ & $-0,91$ & $-0,78$ & - & - & - & $-0,83$ & - & $-0,81$ \\
\hline Clorinas & $x x x$ & $x x x$ & $x x x$ & $x x x$ & $x x x$ & $x x x$ & $x x x$ & $x x x$ & $x x x$ & $* * *$ & - & - & - & - & 0,93 & - & 0,67 \\
\hline Álcoois (P/L) & $x x x$ & $x x x$ & $x x x$ & $x x x$ & $x x x$ & $x x x$ & $x x x$ & $x x x$ & $x x x$ & $x x x$ & *** & 0,92 & - & - & 0,67 & - & 0,98 \\
\hline Ácidos (P/L) & $x x x$ & $x x x$ & $x x x$ & $x x x$ & $x x x$ & $x x x$ & $x x x$ & $x x x$ & $x x x$ & $x x x$ & $x x x$ & $* * *$ & - & - & - & - & 0,91 \\
\hline $\mathrm{C} / \mathrm{N}$ & $x x x$ & $x x x$ & $x x x$ & $x x x$ & $x x x$ & $x x x$ & $x x x$ & $x x x$ & $x x x$ & $x x x$ & $x x x$ & $x x x$ & $* \star *$ & - & - & - & - \\
\hline Alifáticos (L) & $x x x$ & $x x x$ & $x x x$ & $x x x$ & $x x x$ & $x x x$ & $x x x$ & $x x x$ & $x x x$ & $x x x$ & $x x x$ & $x x x$ & $x x x$ & $* * *$ & - & - & - \\
\hline Alifáticos (P) & $x x x$ & $x x x$ & $x x x$ & $x x x$ & $x x x$ & $x x x$ & $x x x$ & $x x x$ & $x x x$ & $x x x$ & $x x x$ & $x x x$ & $x x x$ & $x x x$ & $* * *$ & - & 0,72 \\
\hline Álcoois (L) & $x x x$ & $x x x$ & $x x x$ & $x x x$ & $x x x$ & $x x x$ & $x x x$ & $x x x$ & $x x x$ & $x x x$ & $x x x$ & $x x x$ & $x x x$ & $x x x$ & $x x x$ & $* * *$ & - \\
\hline Álcoois (P) & $x x x$ & $x x x$ & $x x x$ & $x x x$ & $x x x$ & $x x x$ & $x x x$ & $x x x$ & $x x x$ & $x x x$ & $x x x$ & $x x x$ & $x x x$ & $x x x$ & $x x x$ & $x x x$ & $* * *$ \\
\hline Ácidos (L) & $x x x$ & $x x x$ & $x x x$ & $x x x$ & $x x x$ & $x x x$ & $x x x$ & $x x x$ & $x x x$ & $x x x$ & $x x x$ & $x x x$ & $x x x$ & $x x x$ & $x x x$ & $x x x$ & $x x x$ \\
\hline Ácidos (P) & $x x x$ & $x x x$ & $x x x$ & $x x x$ & $x x x$ & $x x x$ & $x x x$ & $x x x$ & $x x x$ & $x x x$ & $x x x$ & $x x x$ & $x x x$ & $x x x$ & $x x x$ & $x x x$ & $x x x$ \\
\hline (Al) & $x x x$ & $x x x$ & $x x x$ & $x x x$ & $x x x$ & $x x x$ & $x x x$ & $x x x$ & $x x x$ & $x x x$ & $x x x$ & $x x x$ & $x x x$ & $x x x$ & $x x x$ & $x x x$ & $x x x$ \\
\hline (Ba) & $x x x$ & $x x x$ & $x x x$ & $x x x$ & $x x x$ & $x x x$ & $x x x$ & $x x x$ & $x x x$ & $x x x$ & $x x x$ & $x x x$ & $x x x$ & $x x x$ & $x x x$ & $x x x$ & $x x x$ \\
\hline (Ca) & $x x x$ & $x x x$ & $x x x$ & $x x x$ & $x x x$ & $x x x$ & $x x x$ & $x x x$ & $x x x$ & $x x x$ & $x x x$ & $x x x$ & $x x x$ & $x x x$ & $x x x$ & $x x x$ & $x x x$ \\
\hline (Sr) & $x x x$ & $x x x$ & $x x x$ & $x x x$ & $x x x$ & $x x x$ & $x x x$ & $x x x$ & $x x x$ & $x x x$ & $x x x$ & $x x x$ & $x x x$ & $x x x$ & $x x x$ & $x x x$ & $x x x$ \\
\hline$(\mathrm{Fe})$ & $x x x$ & $x x x$ & $x x x$ & $x x x$ & $x x x$ & $x x x$ & $x x x$ & $x x x$ & $x x x$ & $x x x$ & $x x x$ & $x x x$ & $x x x$ & $x x x$ & $x x x$ & $x x x$ & $x x x$ \\
\hline (Ti) & $x x x$ & $x x x$ & $x x x$ & $x x x$ & $x x x$ & $x x x$ & $x x x$ & $x x x$ & $x x x$ & $x x x$ & $x x x$ & $x x x$ & $x x x$ & $x x x$ & $x x x$ & $x x x$ & $x x x$ \\
\hline $\mathrm{Ba} / \mathrm{Al}$ & $x x x$ & $x x x$ & $x x x$ & $x x x$ & $x x x$ & $x x x$ & $x x x$ & $x x x$ & $x x x$ & $x x x$ & $x x x$ & $x x x$ & $x x x$ & $x x x$ & $x x x$ & $x x x$ & $x x x$ \\
\hline $\mathrm{Ba} / \mathrm{Ti}$ & $x x x$ & $x x x$ & $x x x$ & $x x x$ & $x x x$ & $x x x$ & $x x x$ & $x x x$ & $x x x$ & $x x x$ & $x x x$ & $x x x$ & $x x x$ & $x x x$ & $x x x$ & $x x x$ & $x x x$ \\
\hline $\mathrm{Ba} / \mathrm{Ca}$ & $x x x$ & $x x x$ & $x x x$ & $x x x$ & $x x x$ & $x x x$ & $x x x$ & $x x x$ & $x x x$ & $x x x$ & $x x x$ & $x x x$ & $x x x$ & $x x x$ & $x x x$ & $x x x$ & $x x x$ \\
\hline $\mathrm{Al} / \mathrm{Ti}$ & $x x x$ & $x x x$ & $x x x$ & $x x x$ & $x x x$ & $x x x$ & $x x x$ & $x x x$ & $x x x$ & $x x x$ & $x x x$ & $x x x$ & $x x x$ & $x x x$ & $x x x$ & $x x x$ & $x x x$ \\
\hline $\mathrm{Sr} / \mathrm{Ti}$ & $x x x$ & $x x x$ & $x x x$ & $x x x$ & $x x x$ & $x x x$ & $x x x$ & $x x x$ & $x x x$ & $x x x$ & $x x x$ & $x x x$ & $x x x$ & $x x x$ & $x x x$ & $x x x$ & $x x x$ \\
\hline $\mathrm{Sr} / \mathrm{Ca}$ & $x x x$ & $x x x$ & $x x x$ & $x x x$ & $x x x$ & $x x x$ & $x x x$ & $x x x$ & $x x x$ & $x x x$ & $x x x$ & $x x x$ & $x x x$ & $x x x$ & $x x x$ & $x x x$ & $x x x$ \\
\hline $\mathrm{Fe} / \mathrm{Ca}$ & $x x x$ & $x x x$ & $x x x$ & $x x x$ & $x x x$ & $x x x$ & $x x x$ & $x x x$ & $x x x$ & $x x x$ & $x x x$ & $x x x$ & $x x x$ & $x x x$ & $x x x$ & $x x x$ & $x x x$ \\
\hline $\mathrm{Ti} / \mathrm{Ca}$ & $x x x$ & $x x x$ & $x x x$ & $x x x$ & $x x x$ & $x x x$ & $x x x$ & $x x x$ & $x x x$ & $x x x$ & $x x x$ & $x x x$ & $x x x$ & $x x x$ & $x x x$ & $x x x$ & $x x x$ \\
\hline
\end{tabular}


Tabela 17 (2/2): Correlação estatística de Pearson para o Estágio Isotópico Marinho 1.

\begin{tabular}{|c|c|c|c|c|c|c|c|c|c|c|c|c|c|c|c|c|}
\hline & Ác. (L) & Ác. (P) & (Al) & (Ba) & (Ca) & $(\mathrm{Sr})$ & $(\mathrm{Fe})$ & $(\mathrm{Ti})$ & $\mathrm{Ba} / \mathrm{Al}$ & $\mathrm{Ba} / \mathrm{Ti}$ & $\mathrm{Ba} / \mathrm{Ca}$ & $\mathrm{Al} / \mathrm{Ti}$ & $\mathrm{Sr} / \mathrm{Ti}$ & $\mathrm{Sr} / \mathrm{Ca}$ & $\mathrm{Fe} / \mathrm{Ca}$ & $\mathrm{Ti} / \mathrm{Ca}$ \\
\hline T.S. & - & - & - & - & - & 0,71 & - & - & - & - & $-0,78$ & $-0,72$ & - & $-0,69$ & $-0,71$ & $-0,66$ \\
\hline S.M. & - & - & 0,68 & - & $-0,87$ & $-0,83$ & 0,76 & - & - & - & 0,67 & 0,83 & - & 0,85 & 0,83 & 0,77 \\
\hline d13C & - & - & - & - & - & - & - & - & - & - & - & - & - & - & - & - \\
\hline Alq. & 0,69 & 0,80 & - & 0,73 & - & - & - & - & - & 0,78 & - & - & - & - & - & - \\
\hline S n-alc. & 0,76 & - & - & - & - & - & - & - & 0,79 & - & - & - & - & - & - & - \\
\hline IPC & - & - & 0,78 & - & $-0,83$ & $-0,68$ & 0,83 & - & - & - & 0,74 & 0,78 & $-0,76$ & 0,94 & 0,87 & 0,89 \\
\hline Pri/Fit. & 0,78 & - & - & - & - & - & - & - & 0,74 & - & - & - & - & - & - & - \\
\hline TAR & - & 0,82 & - & 0,74 & - & $-0,72$ & - & - & - & 0,89 & 0,68 & - & - & - & - & - \\
\hline TSM & - & - & - & $-0,71$ & 0,81 & 0,78 & - & - & - & $-0,72$ & - & - & - & $-0,76$ & $-0,71$ & $-0,71$ \\
\hline Clorinas & - & 0,77 & - & 0,87 & $-0,72$ & $-0,72$ & - & - & - & 0,90 & 0,83 & - & - & - & - & - \\
\hline Álcoois (P/L) & - & 0,68 & - & - & $-0,88$ & $-0,85$ & 0,68 & - & - & - & 0,68 & 0,68 & $-0,70$ & 0,81 & 0,75 & 0,74 \\
\hline Ácidos (P/L) & - & - & - & - & $-0,71$ & $-0,68$ & - & - & - & - & - & - & - & - & - & - \\
\hline $\mathrm{C} / \mathrm{N}$ & $-0,67$ & - & - & - & - & - & - & - & - & - & - & - & - & - & - & - \\
\hline Alifáticos (L) & - & - & - & - & - & - & - & - & - & - & - & - & - & - & - & - \\
\hline Alifáticos (P) & - & 0,88 & - & 0,76 & $-0,69$ & $-0,76$ & - & - & - & 0,88 & 0,72 & - & - & - & - & - \\
\hline Álcoois (L) & - & - & - & - & - & - & - & - & - & - & - & - & - & - & - & - \\
\hline Álcoois (P) & - & 0,76 & - & - & $-0,83$ & $-0,80$ & - & - & - & - & 0,68 & - & - & 0,77 & 0,68 & 0,69 \\
\hline Ácidos (L) & $* * *$ & - & - & - & - & - & - & - & 0,92 & 0,71 & - & - & - & - & - & - \\
\hline Ácidos (P) & $x x x$ & $\star * *$ & - & - & - & - & - & - & - & 0,70 & - & - & - & - & - & - \\
\hline (Al) & $x x x$ & $x x x$ & $* * *$ & - & $-0,79$ & - & 0,97 & 0,75 & - & - & 0,79 & 0,95 & $-0,86$ & 0,88 & 0,95 & 0,92 \\
\hline (Ba) & $x x x$ & $x x x$ & $x x x$ & $* * *$ & $-0,67$ & $-0,62$ & 0,59 & - & - & 0,91 & 0,91 & - & $-0,76$ & - & - & 0,73 \\
\hline (Ca) & $x x x$ & $x x x$ & $x x x$ & $x x x$ & $* * *$ & 0,96 & $-0,86$ & - & - & - & $-0,90$ & $-0,84$ & 0,89 & $-0,94$ & $-0,92$ & $-0,93$ \\
\hline (Sr) & $x x x$ & $x x x$ & $x x x$ & $x x x$ & $x x x$ & $* * *$ & $-0,72$ & - & - & - & $-0,82$ & $-0,74$ & 0,79 & $-0,81$ & $-0,81$ & $-0,80$ \\
\hline$(\mathrm{Fe})$ & $x x x$ & $x x x$ & $x x x$ & $x x x$ & $x x x$ & $x x x$ & $* * *$ & - & - & - & 0,81 & 0,97 & $-0,84$ & 0,92 & 0,99 & 0,93 \\
\hline (Ti) & $x x x$ & $x x x$ & $x x x$ & $x x x$ & $x x x$ & $x x x$ & $x x x$ & $\star \star \star *$ & - & - & - & - & $-0,78$ & - & - & 0,72 \\
\hline $\mathrm{Ba} / \mathrm{Al}$ & $x x x$ & $x x x$ & $x x x$ & $x x x$ & $x x x$ & $x x x$ & $x x x$ & $x x x$ & $* * *$ & 0,69 & - & - & - & - & - & - \\
\hline $\mathrm{Ba} / \mathrm{Ti}$ & $x x x$ & $x x x$ & $x x x$ & $x x x$ & $x x x$ & $x x x$ & $x x x$ & $x x x$ & $x x x$ & $* * *$ & 0,76 & - & - & - & - & - \\
\hline $\mathrm{Ba} / \mathrm{Ca}$ & $x x x$ & $x x x$ & $x x x$ & $x x x$ & $x x x$ & $x x x$ & $x x x$ & $x x x$ & $x x x$ & $x x x$ & $* * *$ & 0,75 & $-0,89$ & 0,91 & 0,87 & 0,93 \\
\hline $\mathrm{Al} / \mathrm{Ti}$ & $x x x$ & $x x x$ & $x x x$ & $x x x$ & $x x x$ & $x x x$ & $x x x$ & $x x x$ & $x x x$ & $x x x$ & $x x x$ & $* * *$ & $-0,76$ & 0,88 & 0,96 & 0,87 \\
\hline $\mathrm{Sr} / \mathrm{Ti}$ & $x x x$ & $x x x$ & $x x x$ & $x x x$ & $x x x$ & $x x x$ & $x x x$ & $x x x$ & $x x x$ & $x x x$ & $x x x$ & $x x x$ & $* * *$ & $-0,89$ & $-0,87$ & $-0,95$ \\
\hline $\mathrm{Sr} / \mathrm{Ca}$ & $x x x$ & $x x x$ & $x x x$ & $x x x$ & $x x x$ & $x x x$ & $x x x$ & $x x x$ & $x x x$ & $x x x$ & $x x x$ & $x x x$ & $x x x$ & $* * *$ & 0,96 & 0,98 \\
\hline $\mathrm{Fe} / \mathrm{Ca}$ & $x x x$ & $x x x$ & $x x x$ & $x x x$ & $x x x$ & $x x x$ & $x x x$ & $x x x$ & $x x x$ & $x x x$ & $x x x$ & $x x x$ & $x x x$ & $x x x$ & $* * *$ & 0,96 \\
\hline $\mathrm{Ti} / \mathrm{Ca}$ & $x x x$ & $x x x$ & $x x x$ & $x x x$ & $x x x$ & $x x x$ & $x x x$ & $x x x$ & $x x x$ & $x x x$ & $x x x$ & $x x x$ & $x x x$ & $x x x$ & $x x x$ & *** \\
\hline
\end{tabular}




\section{Capítulo 6}

\section{Identificação de Eventos Climáticos nos Estágios Isotópicos Marinhos e Ciclicidade da TSM}

Nos últimos 34.800 anos, período compreendido no estudo, há a ocorrência de 6 eventos climáticos de resfriamento do planeta, o Evento Heinrich 3, há cerca de 28.000 anos, o Evento Heinrich 2, há cerca de 21.000 anos, o Último Máximo Glacial (UMG), entre 23 e 18.000 anos A.P., o Evento Heinrich 1, há cerca de 15.000 anos e o Evento Younger Dryas, há cerca de 12.000 anos, além da chamada Pequena Idade do Gelo, entre 1.800 e 1300 anos A.P. Esses eventos climáticos foram mais sentidos no Hemisfério Norte, em função da maior massa de terra em latitudes mais altas. No Hemisfério Sul, principalmente na costa brasileira, pouco se sabe sobre a influência desses eventos.

Com exceção do evento Heinrich 3, e da Pequena Idade do Gelo, todos os outros eventos citados ocorreram dentro do período chamado de Estágio Isotópico Marinho 2. O MIS 2 compreende o período entre o início do Último Máximo Glacial, iniciado há 23.000 anos A.P. e o final do evento Younger Dryas, 13.000 anos A.P. Durante esse período ocorreram grandes mudanças climáticas no planeta, relacionadas com os ciclos de Milankovitch de precessão de equinócios e de inclinação do eixo terrestre e ciclos não orbitais, como os ciclos de luminosidade solar. O Último Máximo Glacial representou o período mais frio do planeta nos últimos 100.000 anos.

A análise do testemunho pelos valores médios dos resultados dos marcadores geoquímicos orgânicos (Fig. 38) permitiu identificar todos esses eventos de resfriamento, exceto a Pequena Idade do Gelo (a idade da fração mais recente do testemunho foi estimada em 3.000 anos A.P.) e em especial os eventos do MIS 2 uma vez que 70 das 102 frações obtidas do testemunho correspondem a sedimentos depositados durante esse MIS. 


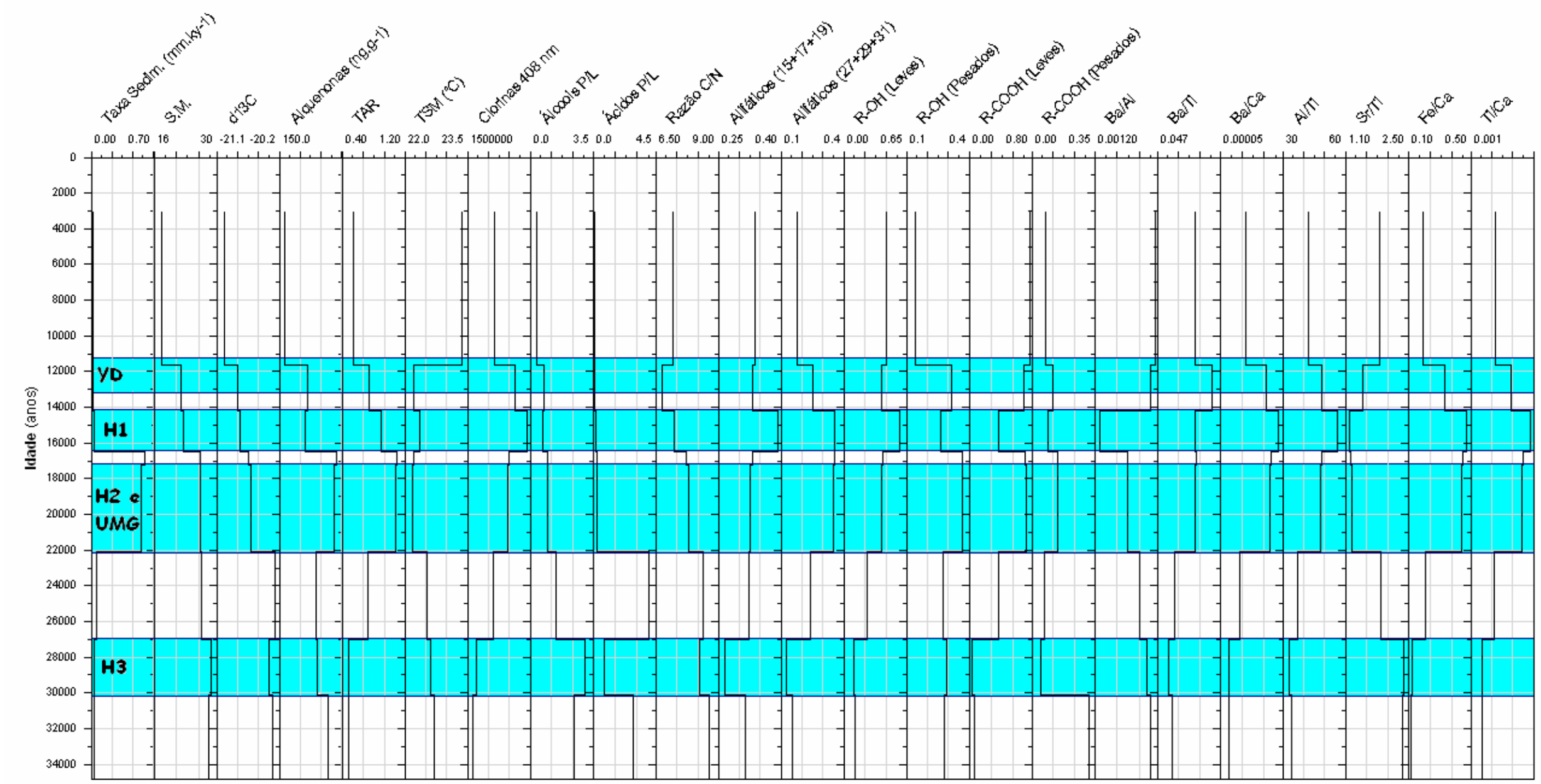

max:: 34800 anos

Figura 38: Valores médios dos marcadores geoquímicos orgânicos durante os eventos climáticos 


\subsection{No Estágio Isotópico Marinho 3}

\subsubsection{Evento Heinrich 3}

Os resultados permitiram observar uma pequena diminuição na temperatura superficial marinha durante o evento Heinrich 3 , que foi acompanhada pela redução da concentração das alquenonas, TAR, $\delta^{13} C_{P D B}$ relação $P / L$ dos ácidos e razão $C / N$ e pelo aumento do IPC, relação pristano/fitano e das relações pesados/leves dos álcoois. Porém as oscilações desses parâmetros foram pequenas, indicando que, pelo menos na região de coleta do testemunho, os efeitos do Evento Heinrich 3 não foram tão sentidos.

\subsection{No Estágio Isotópico Marinho 2}

\subsubsection{Evento Heinrich 2 e Último Máximo Glacial}

Durante o evento Heinrich 2 e o UMG observou-se uma diminuição média de $0,6^{\circ} \mathrm{C}$ na TSM em relação ao evento Heinrich 3, acompanhado por diminuição nos valores de $\delta^{13} \mathrm{C}_{\mathrm{PDB}}$, e diminuição na razão $\mathrm{C} / \mathrm{N}$. Observou-se um aumento expressivo na taxa de sedimentação, na concentração de alquenonas, no valor de TAR, clorinas e relação pesados/leves de ácidos e álcoois e aumento nas razões dos metais $\mathrm{Fe} / \mathrm{Ca}$ e $\mathrm{Ti} / \mathrm{Ca}$. Os resultados apontam o período do evento Heinrich 2 e UMG como o período de menor TSM dos últimos 35.000 anos na região onde o testemunho foi coletado, com TSM média de $22,1^{\circ} \mathrm{C}$, e os marcadores apontando para um aumento na quantidade material orgânico derivado do continente para o meio marinho.

\subsubsection{Evento Heinrich 1}

$\mathrm{O}$ evento $\mathrm{H} 1$ apresentou TSM média ligeiramente superior à encontrada durante $\circ \mathrm{H} 2$ e ० UMG, porém a taxa de sedimentação assumiu valores semelhantes aos encontrados antes do ebento Heinrich 2 e UMG e os marcadores geoquímicos orgânicos não apontam para mudanças de fontes de matéria orgânica em comparação ao evento Heinrich 2 e ao UMG. 


\subsubsection{Evento Younger Dryas}

Durante o Younger Dryas observou-se redução da TSM, que assumiu valores semelhantes aos encontrados durante o evento Heinrich 2 e UMG. $O$ fluxo de matéria orgânica terrígena para o meio marinho parece ser o mesmo desde o início do MIS 2, que se encerra junto com o final do Younger Dryas.

\subsection{No Estágio Isotópico Marinho 1 - Holoceno}

Com o final do Youger Dryas, e início do MIS 1, ou Holoceno, observouse um aumento de $1,2{ }^{\circ} \mathrm{C}$ na TSM média da região do testemunho, e os marcadores apontam para uma diminuição no fluxo de matéria orgânica terrígena para o meio marinho. O gráfico com os valores médios dos marcadores geoquímicos permitem ver com clareza o final do MIS 2, com a inversão na tendência de queda da TSM.

\subsection{Ciclicidade da variação de temperatura}

Devido à fração mais antiga do testemunho ter apenas 34.800 anos, não é possível verificar ciclicidade da variação da TSM que seja relacionado ao ciclos orbitais, ciclos de Milankovitch. O único registro de variação da TSM relacionada a ciclos orbitais, precessão de equinócios e inclinação do eixo terrestre, é o registro do Último Máximo Glacial. Outros ciclos de curta duração são atribuídos a fatores tais como mudança no padrão de circulação oceânica, mudança na cobertura das geleiras, variações no conteúdo do gás atmosférico, atividade vulcânica, atividade solar e fatores geodinâmicos, detalhados em Lowe e Walker (1997).

De forma a encontrar uma periodicidade nas variações de temperatura no testemunho analisado, aplicou-se uma análise de séries temporais utilizando o programa Palaeontological Statistics. Foram gerados dois gráficos; um periodograma e um ajuste senoidal da temperatura.

O periodograma (Fig. 39) aponta para ciclos de temperatura a cada 3.300 anos, com ocorrência de freqüências que são, aproximadamente, múltiplas entre si ( $\approx 1.000$ anos, $\approx 3.300$ anos $e \approx 10.200$ anos). O pico de maior força indica um ciclo de 20.000 anos e reflete a variação da temperatura no 
Último Máximo Glacial. Como tal amplitude de temperatura é observada apenas uma vez no período estudado, esse ciclo de variação de temperatura não têm significância estatística e não pode ser considerado.

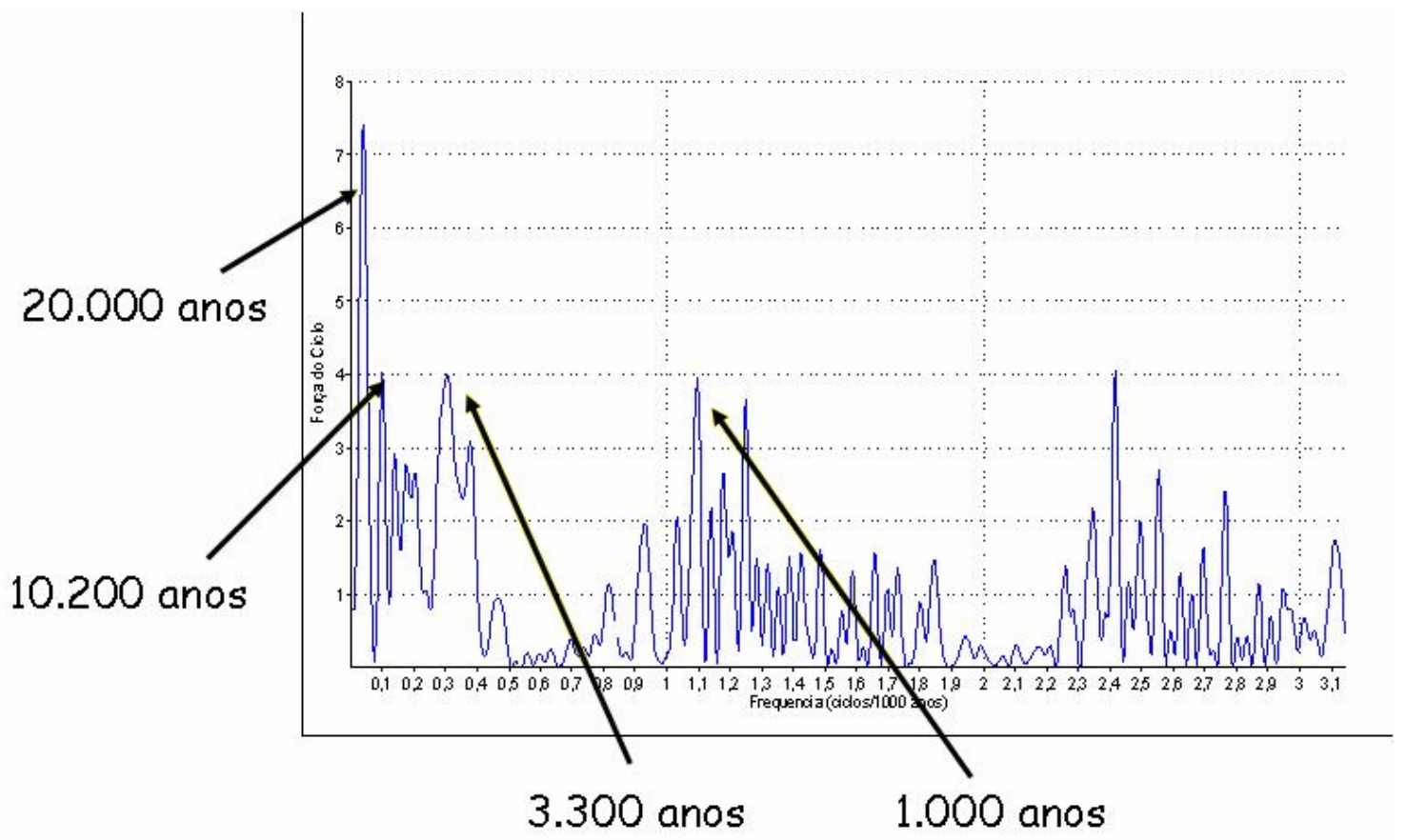

Figura 39: Periodograma.

Apesar de, no periodograma, as forças dos ciclos não atingirem o valor mínimo de 5\%, realizando um ajuste senoidal de 3.300 anos para a temperatura (Fig. 40) fica evidente a existência de ciclos de temperaturas com período de 3.300 anos, como sugerido pelo periodograma.

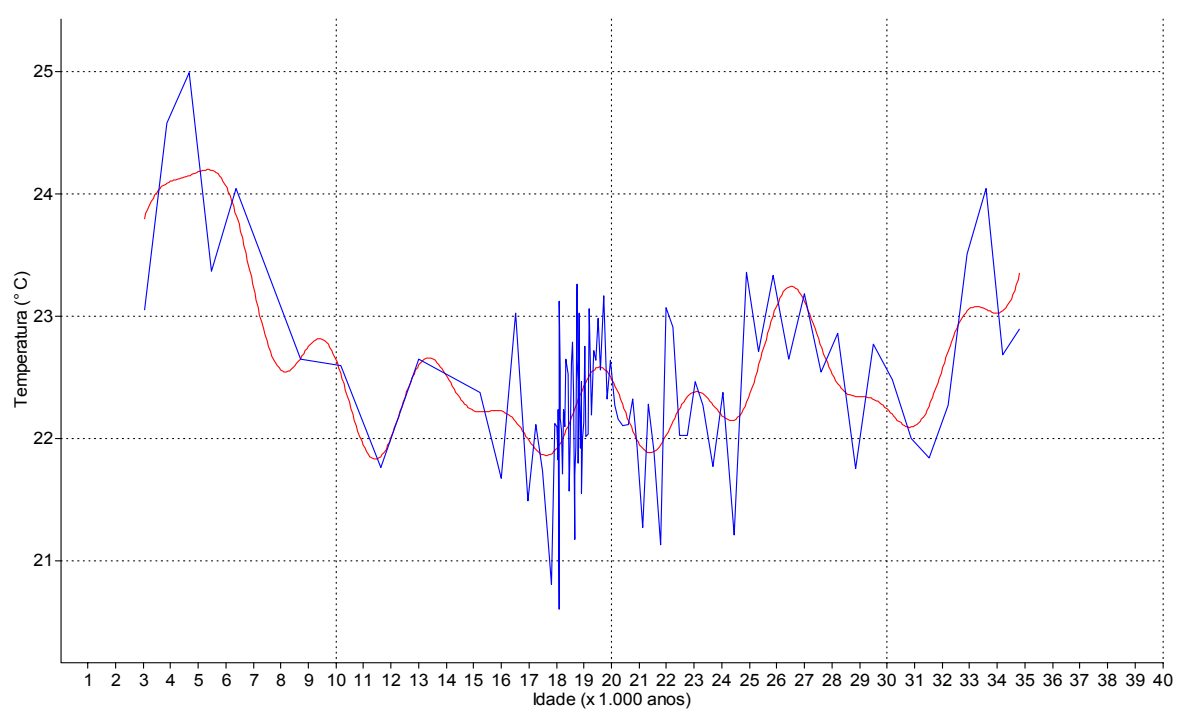

Figura 40: Ajuste senoidal da variação da TSM para 3.300 anos. 


\subsection{Discussão dos Resultados das Amostras de Sedimento do Testemunho}

No testemunho analisado apenas os 20 primeiros centímetros da coluna sedimentar correspondem ao Holoceno, a maior parte da coluna sedimentar, de $19 \mathrm{~cm}$ a $160 \mathrm{~cm}$, consiste de sedimentos do MIS 2 (23.000 anos A.P. a 13.000 anos A.P.), e últimos 43 centímetros correspondem ao MIS 3. Apesar dessa grande variação da taxa de sedimentação na região durante os últimos 34.800 anos foi possível identificar cada um dos Estágios Isotópicos Marinhos e, em função do grande números de frações correspondentes ao MIS 2, foi possível detalhar esse período. A análise dos valores médios dos biomarcadores e da TSM permitiu identificar os 4 eventos climáticos durante 0 MIS 2, o H2, o UMG, o H1 e o YD. A variação da TSM média mostrou de forma clara o final do MIS 2 e o início do Holoceno.

Os valores médios de TSM mostram que de 34.800 anos A.P. (base do testemunho) até o final do Estágio Isotópico Marinho 2, começo do Holoceno, ocorreu uma diminuição quase que contínua da TSM na região. Junto com a diminuição da TSM nesse período ocorreu um aumento no fluxo de materiais de origem terrígena para o meio marinho, atingindo o clímax há 18.000 anos, com os menores valores de TSM e maiores quantidades de material terrígeno, como mostram os marcadores orgânicos moleculares. Há 12.000 anos, com o início do Holoceno, ocorreu uma inversão nesse padrão, a TSM voltou a aumentar, atingindo os maiores valores e ocorreu a diminuição do fluxo de material de origem terrígena para o meio marinho na região.

Trabalhos relatando paleoníveis marinhos durante o período glacial, propõem o nível do mar 110 metros abaixo do atual em 18.000 anos A.P. (Kowsmann e Costa, 1974), 130 metros abaixo do nível atual, em 14.00016.000 anos A.P. (Kowsmann e Costa, 1979), e entre 120 e 130 metros abaixo do atual em 17.500 anos A.P. (Correa, 1996). Para a região de São Sebastião, Costa et al. (1988) estabelecem nível marinho entre 110 e 130 metros abaixo do atual em 15.000 anos A.P. e 60 metros abaixo em 11.000 anos A.P. Furtado et al. (1992) indicam em 12.000 anos A.P. nível do mar 100 metros abaixo do atual, 65 metros abaixo do atual em 11.000 anos A.P. e 30 metros abaixo do atual em 9.000 anos A.P. Para o período pós glacial, marcado por transgressão 
marinha, com registro de fases de estabilização na atual plataforma continental, existem registros que evidenciam paleoníveis marinhos em posição superior a atual a partir de 7.000 anos A.P. (Suguiu e Martin, 1978).

No Brasil curvas que representem a variação do nível relativo do mar antes do UMG são escassas. Destacam-se as curvas de Kowsmann e Costa (1974) baseadas na curva de Curray $(1961,1965)$ para a costa Norte Americana, a curva de Corrêa (1996) para a plataforma continental do Rio Grande do Sul e a curva de Klein (2006) para a região de São Sebastião. A Figura 41 (Klein, 2006) compila essas curvas.

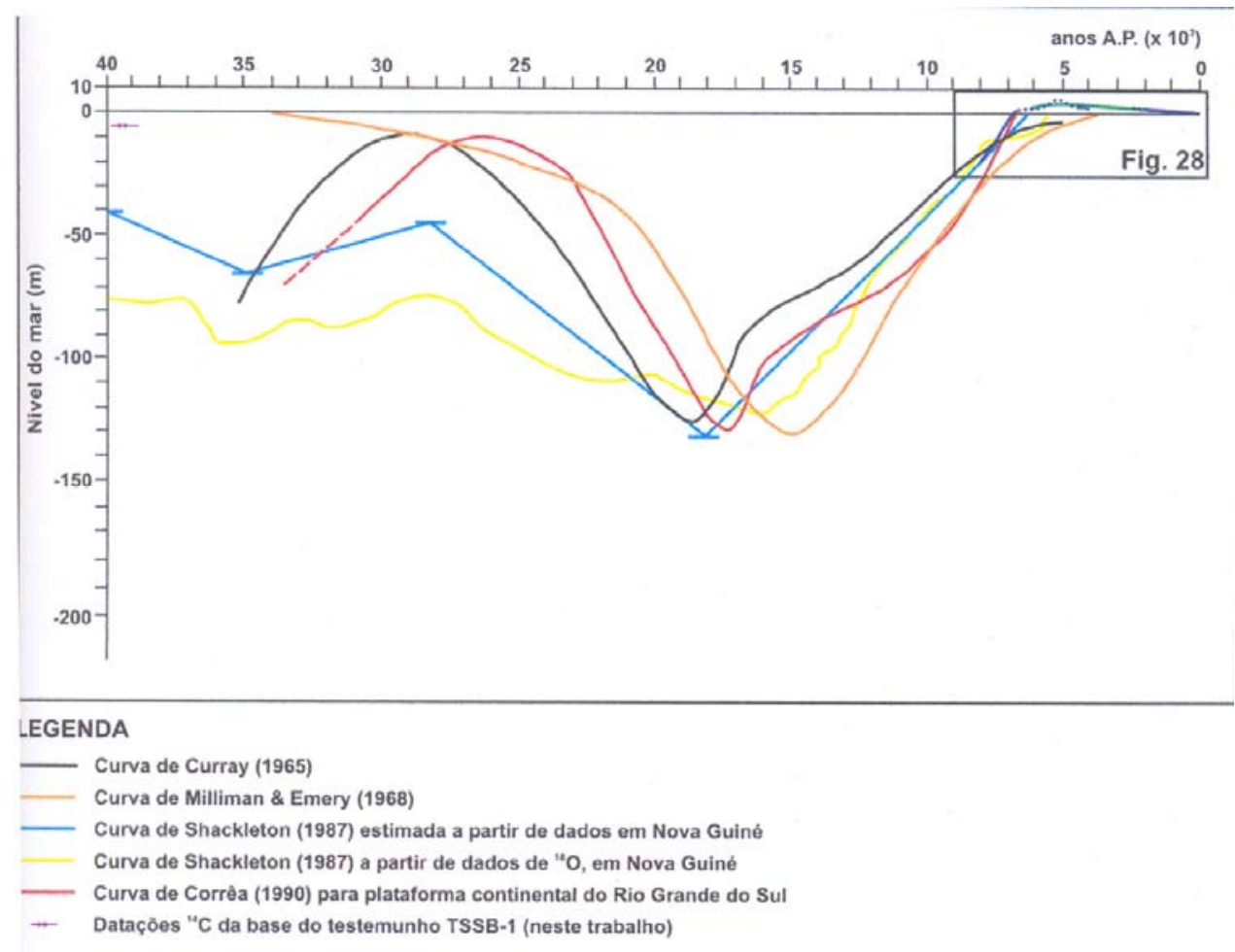

Figura 41: Curvas de variação relativa do nível do mar (extraída de Klein, 2006).

A comparação das curvas de variação relativa do nível do mar com as variações de temperatura e da quantidade de material terrígeno nos últimos 34.800 anos na região de coleta do testemunho mostra que essas variações são correlacionadas, ou seja, o menor nível relativo do mar foi observado em torno de 18.000 anos A.P., o que coincide com os menores valores de TSM e 
maiores quantidades de materiais terrígenos e é, portanto, a variação do nível do mar que rege a quantidade de material terrígeno encontrado na região.

Durante os períodos onde o nível relativo do mar é alto, como foi no MIS 3 e é no Holoceno, o deslocamento das águas quentes oligotróficas da Corrente do Brasil em direção à costa impede o aumento da produtividade primaria marinha, além disso, o revolvimento do sedimento impede a deposição de lama e consequentemente de matéria orgânica. As baixas taxas de sedimentação nesses períodos são conseqüência do efeito de erosão da superfície marinha, descrita por Mahiques et al. (2004), na área estudada. Durante os períodos onde o nível relativo do mar foi baixo, como no MIS 2, com o alargamento da área costeira, a Corrente do Brasil é deslocada em direção ao oceano, permitindo a entrada de nutrientes, verificada pelo aumento na quantidade de material terrígeno.

O modelo de deslocamento da Corrente do Brasil pode ser também um fator influente na TSM (Fig. 42). Durante o MIS 3 e o Holoceno, com o nível relativo do mar alto, as águas quentes da Corrente do Brasil se aproximam da costa, resultando em maiores valores de TSM na região. Durante o MIS 2, com o nível relativo do mar baixo, as águas quentes da Corrente do Brasil se afastam da costa, permitindo maior influência das águas costeiras e resultando em menores valores de TSM (Mahiques et al., 2007).

A periodicidade da variação da TSM coincide com um evento de aquecimento conhecido como ciclo de Dansgaard-Oeschger. Existe no Hemisfério Norte o registro de 23 ocorrências desse ciclo desde 110.000 até 19.000 anos A.P. e estão intimamente relacionadas com os Eventos Heinrich. (Dansgaard et al. 1984, Broecker et al. 1992, Bond et al. 1999). Um estudo recente (Stoykova et al, 2006) sobre variações climáticas causadas por ciclos solares não orbitais, ou seja, ciclos de luminosidade solar, aponta para ciclos de luminosidade com duração de 11.500 anos (mais intenso) e um ciclo menos intenso com duração de 3.300 anos, coincidindo também com o ciclo observado no registro de TSM. 

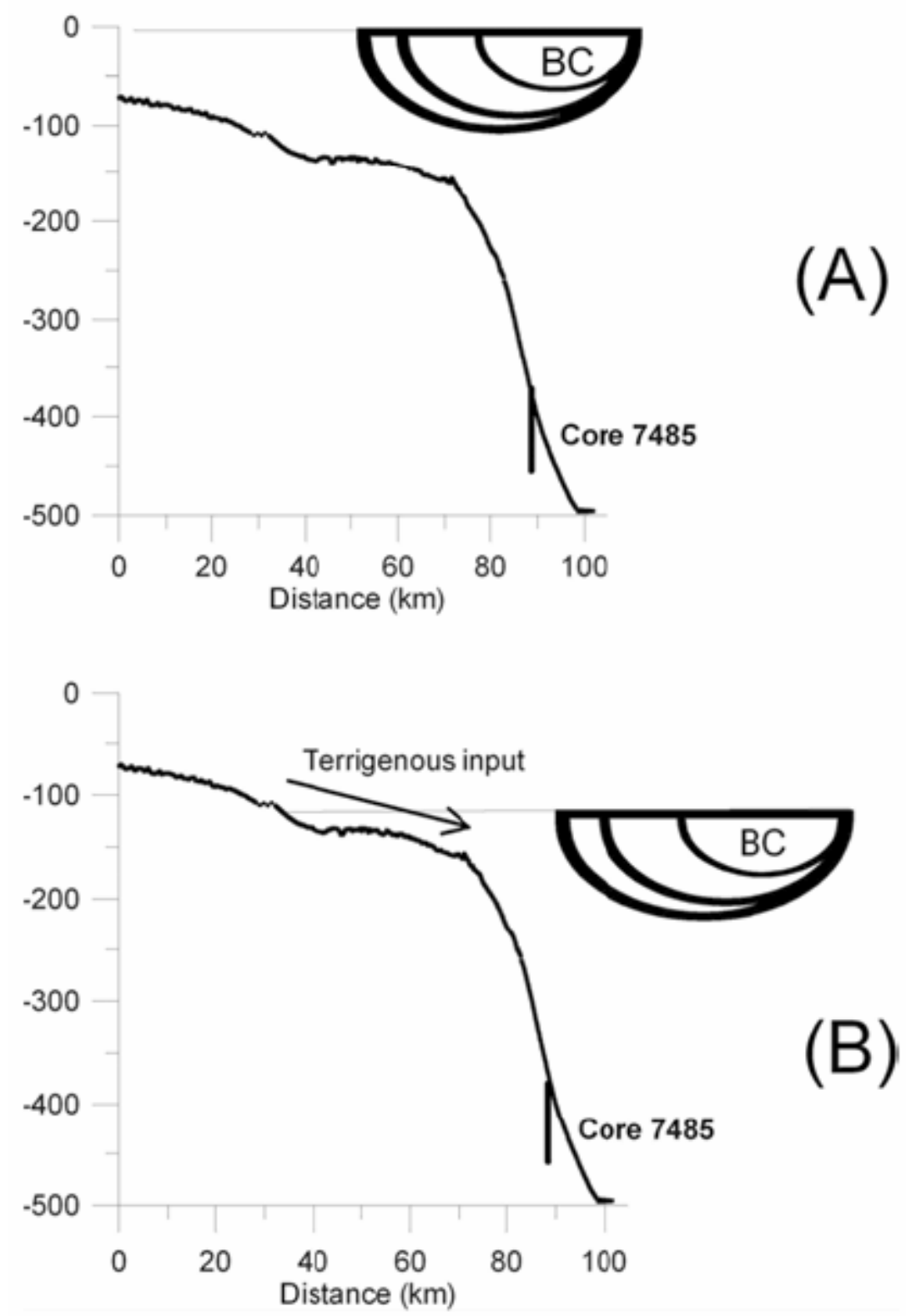

Figura 42: Modelo esquemático para a posição da Corrente do Brasil em diferentes condições climáticas: (A) Presente e MIS 3; (B) MIS 2.

Os eventos climáticos descritos nesse trabalho, eventos Heinrich 3, 2 e 1 e Younger Dryas são eventos correlacionados com a diminuição da TSM no Atlântico Norte, porém diversos trabalhos relatam a existência de uma anti-fase térmica entre as águas do Atlântico Norte e o Atlântico Sul, ou seja, em períodos de resfriamento das águas do Atlântico Norte ocorre o aquecimento das águas do Atlântico Sul (Charles et al. 1996, Little et al. 1997, Blunier et al. 1998, Vidal et al., 1999). Vidal et al. (1999) atribui essa anti-fase térmica nas águas superficiais do Atlântico à resposta do Attântico Sul às mudanças brutas 
na produção da Água de Fundo do Atlântico Norte (NADW). O transporte de calor entre os hemisférios no Oceano Atlântico, em direção ao norte, é associado à Corrente do Golfo, que transporta águas quentes em direção ao norte e à formação da NADW, que é a imersão das águas frias e salinas ao norte do Atlântico Norte. A interrupção da Corrente do Golfo e/ou formação da NADW cessa a circulação termohalina no Atlântico Norte, causando duas conseqüências imediatas: o resfriamento nas altas latitudes do Hemisfério Norte, já que águas quentes da Corrente do Golfo não são transportadas para essa região; e o aquecimento de algumas partes do Atlântico Sul, já que essas águas quentes não são transportadas para o Norte. Apesar de vários trabalhos descreverem essa anti-fase térmica em algumas regiões do Atlântico Sul (Sowers e Bender, 1995, Jouzel et al., 1995, Blunier et al., 1997, 1998) alguns outros trabalhos apontam para uma sincronia térmica em fase entre os hemisférios em outras regiões do Atlântico Sul (Lowell et al., 1995, Bard et al. 1997), e, em particular, um trabalho baseado em reconstruções de paleotemperaturas a partir das alquenonas em testemunhos no Oceânico Índico a $23^{\circ} \mathrm{S}$, latitude semelhante a do testemunho analisado no presente trabalho, mostrou que houve uma sincronia térmica em fase, através da comparação dos registros de TSM das alquenonas com registros de um testemunho de gelo extraído na Groelândia (Bard et al. 1997).

No presente trabalho constatou-se que os eventos climáticos de resfriamento do Atlântico Norte, ocorridos no período, coincidiram com o resfriamento das águas superficiais da região estudada, mostrando que nas águas superficiais na zona do Embaiamento de São Paulo houve uma fase térmica com os resfriamentos ocorridos no Atlântico Norte.

Alguns trabalhos relatam para o Atlântico Norte, durante o MIS2, temperatura das águas superficiais de $4^{\circ} \mathrm{C}$ a $6^{\circ} \mathrm{C}$ mais frias do que as atuais. (Kreitz at al, 2000, Yamamoto at al, 2000, Seki at al, 2002). Na região estudada, observou-se uma variação máxima de TSM de $4,5^{\circ} \mathrm{C}$ entre MIS 2 e o Holoceno, mostrando que a TSM na região sofreu, em alguns períodos, variações semelhantes às observadas em regiões do Atlântico Norte.

A grande maioria dos trabalhos de reconstruções paleoceanográficas e de paleotemperaturas são realizadas longe da costa, fora da plataforma continental, em locais pouco afetados por variações do nível relativo do mar. 0 
presente trabalho permitiu observar variações no fluxo de material terrígeno para o meio marinho na plataforma continental superior da região Sudeste do Brasil em função de variações no nível relativo do mar e permitiu observar variações de TSM resultante de eventos climáticos e deslocamentos da Corrente do Brasil. 


\section{Capítulo 7}

\section{Conclusões}

O trabalho realizado gerou os primeiros dados de TSM calculada a partir das alquenonas para a região da margem continental do Sudeste do Brasil. Até então nenhuma calibração de TSM- $U_{37}^{k^{\prime}}$ havia sido realizada na área, e um único trabalho utilizando alquenonas para a determinação de TSM havia sido realizado ao sul da região mencionada para verificar a validade da calibração da TSM com o índice $U_{37}^{k^{\prime}}$.

A semelhança dos dados de TSM gerados nesse trabalho com dados de TSM extraídos de programas multinacionais e a semelhança entre a calibração das TSMs, extraídas dos programas, e os índices $U_{37}^{k^{\prime}}$, obtidos dos sedimentos, com a calibração de TSM- $U_{37}^{k^{\prime}}$ nos oceanos mostraram que a validade da calibração se estende para toda a margem continental do Sudeste do Brasil.

A análise dos marcadores orgânicos moleculares nos sedimentos superficiais na região do embaiamento de São Paulo permitiu verificar a divisão da região em dois compartimentos distintos em relação ao tipo de matéria orgânica depositada e em relação a temperatura superficial marinha. Um compartimento ao norte da llha de São Sebastião, marcado por maiores valores de TSM, recebendo menor contribuição de material terrígeno e de menor produtividade primária. Outro compartimento ao sul da llha de São Sebastião, marcado por menores valores de TSM, recebendo maior quantidade de material de origem terrígena e de maior produtividade primária.

Quando analisada a dispersão AlxTi na região do Embaiamento de São Paulo verificou-se que esses metais não apresentam correlação significativa. Porém, quando foi analisada essa mesma dispersão para os sedimentos do testemunho observou-se um correlação significativa. Isso fornece mais um indício de que há uma diferença significativa na natureza da matéria orgânica recebida na região ao norte e na região ao sul da llha de São Sebastião. Diferenças quanto a natureza da matéria orgânica depositada em ambos os 
compartimentos são fornecidas também pelo fato de que os álcoois pesados respondem de forma diferente dos outros marcadores numa análise espacial da área, mas respondem da mesma forma que os outros maçadores numa análise temporal.

A concordância dos resultados dos biomarcadores com diversos outros trabalhos que mencionam essa divisão da área e a concordância dos resultados de TSM obtidos através das alquenonas com dados de programas multinacionais validam a aplicação dos marcadores orgânicos moleculares para estudos oceanográficos e paleoceanográficos na região.

O testemunho estudado apresentou grandes variações na taxa de sedimentação no período compreendido entre 21 e 17 mil anos A.P., sendo que tanto o aumento quanto a diminuição da taxa de sedimentação aconteceram de maneira abrupta, em um curto intervalo de tempo. Com exceção desse período, as variações na taxa de sedimentação ocorreram de maneira lenta e gradual.

Resfriamentos globais, como o ocorrido no UMG, resultam em acúmulo de água nos pólos e conseqüente diminuição do nível do mar. A diminuição do nível do mar teria feito com que a área de terra emersa ficasse mais próxima ao local onde o testemunho foi coletado, o que colocaria as fontes de material terrígeno mais próximos à região do testemunho. Períodos mais frios resultam também em intensificação dos ventos, que teriam favorecido o transporte de material do continente para o mar. Então a combinação desses dois fatores teriam proporcionado um maior fluxo de material terrígeno para o meio marinho naquela região, aumentando portando a taxa de sedimentação, o valor de TAR, as razões $\mathrm{Fe} / \mathrm{Ca}$ e $\mathrm{Ti} / \mathrm{Ca}$, gerando valores mais negativos para $\circ \delta^{13} \mathrm{C} \mathrm{e}$ aumentando a quantidade de nutrientes no meio, promovendo a produtividade primária, como é observado durante o MIS 3 e o MIS 2.

Possivelmente devido às grandes variações nas taxas de sedimentação, no período compreendido entre 19,4 e 17,5 mil anos A.P. os parâmetros físicos e químicos e biológicos durante o MIS 2 não apresentam boas correlações. As grandes variações nas taxas de sedimentação em curtos espaços de tempo não teriam possibilitado o equilíbrio entre os marcadores

O intervalo do testemunho correspondente ao Holoceno é caracterizado pelo restabelecimento das taxas de sedimentação aos níveis anteriores ao 
período entre 19,5 e 17,5 mil anos, com uma diminuição gradual da taxa de sedimentação e aumento na TSM.

De forma inversa aos períodos de resfriamento, períodos de aquecimento resultam em elevação dos níveis dos oceanos, fazendo com que a região onde foi coletado o testemunho fique mais longe do continente, afastando portanto as fontes terrígenas e resultando em diminuição nas taxas de sedimentação e, consequentemente, no fluxo de material de origem terrígena para o meio marinho, representado pelo TAR, pelo IPC, pela razão dos metais e pela suscetibilidade magnética.

O resfriamento das águas superficiais na região do Embaiamento de São Paulo durante os eventos climáticos ocorridos no MIS 2 mostra que, pelo menos nessa região, não ocorreu a anti-fase térmica entre os hemisférios, já foi observada em outras regiões do Atlântico Sul durante os eventos de rápida diminuição da TSM no Atlântico Norte.

Os resultados mostraram ainda que a variação da TSM no Atlântico Sul, durante eventos de resfriamento global, pode alcançar valores comparáveis às variações observados em algumas regiões do Atlântico Norte.

A análise de séries temporais apontou para uma ciclicidade de altos e baixos da temperatura superficial oceânica em períodos de 3.300 anos. Essa periodicidade coincide com um evento conhecido como ciclo de DansgaardOeschger e com um ciclo de luminosidade solar com período semelhante. 


\section{Capítulo 8}

\section{Bibliografia}

Anderson, R.F., Winckler, G. (2005). Problems with paleoproductivity proxies Paleoceanography, 20, PA3012, doi:10.1029/2004PA001107.

Averyt, K.B., Paytan, A. (2004). A comparison of multiple proxies for export production in the equatorial Pacific. Paleoceanography. 19, PA4003, doi:10.1029/2004PA001005.

Baker, E.W., and Palmer, S.E. (1979). Chorophyll diagenesis in IPOD Leg 47A, Site 397 core samples. In "Init. Rep. Deep-Sea Drill. Proj., 47 Pt. 1." (U. von Rad, W.B.F. ryan, Eds.), pp. 547-551. U.S. Government Printing Office, Washington.

Baker, E.W., and Palmer, S.E., and Huang, W.Y. (1978). Early and intermediate chlorophyll diagenesis of Black Sea sediments: sites 379, 380 and 381. In "Init. Repts. DSDP, 42, Pt.2." (D.A. Ross, Y.P. Neprochnov, and e.al., Eds.), pp. 707715. U.S. Government Printing Office, Washington.

Bard, E., Arnold, M., Fairbanks, R.G., Hamelin, B. (1993). 230U, 234U and 14C ages obtained by mass spectrometry in corals. Radiocarbon. 35, 191-199.

Bard, E., Rostek, F., Sonzogni, C. (1997). Interhemispheric synchrony of the last deglaciation inferred from alkenone paleothermometry. Nature. 385, 707710.

Bard, E., Rostek, F., Turon, J.L. and Gendreau, S. (2000). Hydrological impact of Heirich events in the subtropical Northeast Atlantic. Science. 289, 1321-1324. 
Benthien, A., Muller, P.J. (2000) Anomalously low alkenone temperature caused by lateral particle and sediment transport in the Malvinas Current region, western Argentine Basin. Deep-Sea Research I. 47, 2369-2393.

Bicego, M.C. Weber, R.R., Ito, R.G. (1996). Aromatic hydrocarbons on surface waters od Admiralty Bay, Kind George Island, Antarctica. Marine Pollution Bulletin. 32, 549-553.

Blumer, M. Guillard, R.R.L., and Chase, T. (1971). Hydrocarbons of marine phytoplankton. Marine Biology. 8, 183-189.

Blunier, T., Chappelaz, J., Schwander, J., Dallenbach, A., Stauffer, B., Stocker, T.F., Raynaud, D., Jouzel, J., Clausen, H.B., Hammer, C.D., Johnsen, J. (1998). Asynchrony of Antarctic and Greenland climate change during the last glacial period. Nature. 365,143-147.

Bond, G.C., Showers, W., Elliot, M., Evans, M., Lotti, R., Hajdas, I., Bonani, G., Johnson, S. (1999). The North Atlantic's 1-2 kyr climate rhythm: relation to Heinrich events, Dansgaard/Oeschger cycles and the little ice age. In: Clark, P.U., Webb, R.S., Keigwin, L.D. (Eds.), Mechanisms of Global Change at Millennial Time Scales. Geophysical Monograph 112, American Geophysical Union, Washington DC, pp. 59-76.

Brassel, S.C. (1993). Application of biomarkers for delineating marine paleoclimatic fluctuations during the Pleistocene. In "Organic Geochemistry: Principles and Applications." (M.H. Engel and S.A. Macko, Eds.) Plenum Press, New York.

Brassel, S.C., Brereton, R.G., Eglinton, G., Grimalt, J., Liebezeit, G., Marlowe, I.T., Pflaumann, U., and Sarnthein, M. (1986a). Paleoclimatologic signals recognized by cheochemetric treatment of molecular stratigraphic data. Organic Geochemistry. 10, 649-660. 
Brassel, S.C., Eglinton, G., Marlowe, I.T., Pflaumann, U., and Sarnthein, M. (1986b). Molecular Stratigraphy: a New tool for climatic assessment. Nature. 320, 129-133.

Brassel, S.C., Eglinton, G., Maxwell, J.R., and Philip, R.P. (1978). Natural background of alkalines in the aquatic environmental. In "Aquatic pollutants and Biological effects" (O. Huntzinger, L.H. Lelyveld, and B.C.J. Zoetman, Eds., pp 69-86. Pergamond Press, Oxford.

Broecker, W.S., Bond, G.C., Klass, M., Clark, E., McMannus, J. (1992). Origin of Northern Atlantic Heinrich events. Climate Dynamics. 6, 265-273.

Calado, L. (2006). Dinâmica da interação da atividade de meso-escala da Corrente do Brasil com o fenômeno de ressurgência costeira ao largo de Cabo Frio e Cabo de São Tomé, RJ. Tese de Doutorado. Instituto Oceanográfico. Universidade de São Paulo, São Paulo,144 pp.

Caldicott, A.B., and Eglinton, G. (1973). Surface waxes; In "Phytochemistry 3, Inorganic Elements and Special Groups of Chemicals." (L.P. Miller, Ed.), pp 163. Van Nostrand Reinhold, New York.

Camargo, S.S.B. (2001). A posição climatológica da frente da Corrente do Brasil entre $21^{\circ}$ e $25^{\circ} \mathrm{S}$. Monografia de Graduação. Instituto Oceanográfico. Universidade de São Paulo, São Paulo. 57p.

Campos, E.J.D, Lorenzeetti, J.A., Stevenson, M.R., Stech; J.L., Souza, R.B. (1996). Penetration of waters from the Brazil-Malvinas confluence region along the South American continental shelf up to $23^{\circ} \mathrm{S}$. Anais da Academia Brasileira de Ciências. 69, 49-58.

Castro Filho, B.M. (1996). Correntes e massas de água da plataforma continental norte de São Paulo. Tese de Livre-docência. Instituto Oceanográfico - USP. São Paulo. 249p. 
Charles, C., Lynch-Steglitz, J., Ninnemann, U.S., Fairbanks, R.G. (1996). Climate connection between hemispheres reveales by deep sea sediment core/ice core correlations. Earth Planet Science Letters. 142, 19-27.

Clark, J.R., and Blumer, M. (1967). Distribution of $n$-paraffins in marine organisms and sediments. Limnology and Oceanography. 12, 79-87.

COHMAP Members. (1988). Climatic changes of the last 18,000 years: Observations and model simulations. Science. 241,1043-1052.

Comet, P.A., and Eglinton, G. (1987). The use of lipids as facies indicators. Geological Society Special Publication. In "Marine Petroleum Source Rocks." (J; Brooks, and J. Fleet, Eds). Blackwell, Oxford. 26, 99-117.

Conte, M.H., Eglinton, G., and Madureira, L.A.S. (1992). Long chain alkenones and alkyl alkenoates as paleotemperature indicators : their production, flux and early sedimentary diagenesis in the Eastern North Atlantic. Organic Geochemistry. 19, 287-298.

Conte, M.H., Eglinton, G. (1993). Alkenone and alkenoate distributions within the euphotic zone of the eastern North Atlantic: correlation and production temperature. Deep Sea Research. 40, 1935-1961.

Conte, M.H., Thompson, A., and Eglinton, G. (1994a). Primary production of lipid biomarker compounds by Emiliania huxleyi. Results from an experimental mesocosm study in fjords of southwestern Norway. Sarsia. 79, 319-331.

Conte, M.H., Volkman, J.K., Eglinton, G., (1994b). "Lipid Biomarkers of the Haptophyta." The Systematic Association Special Volume. In: B.S.C. Leadbeater (Ed.), The Haptophyte Algae, 51 (Ed. by B.S.C. Leadbeater), pp. 351-377. Clarendon Press, Oxford.

Conte, M.H., Thompson, A., Eglinton, G., and Green, J.C. (1995). Lipid biomarker diversity in the coccolithophorid Emiliania huxleyi 
(prymnesiophyceae) and the related species Gephyrocapsa oceanica. Geochemica et Cosmochimica Acta. 62, 51-68.

Conte, M.H., Thompson, A., Lesley, D., and Harris, P.G. (1998). Genetic and physiological influences on the alkenone/alkenoate versus growth temperature relationship in Emiliania huxleyi and Gephirocapsa oceanica. Geochimica et Cosmochimica Acta. 62, 51-68.

Conte, M.H., Weber, J.C., King, L.L., and Wakeham, S.G. (2001). The alkenone temperature signal in western North Atlantic surface waters. Geochemica et Cosmochemica Acta. 65, 4275-4287.

Correa, I.C.S. (1996) Les variations du nivel de la mer durant les derniers 17.500 ans BP: l'exemple de la plate-forme continentale du Rio Grande do SulBrésil. Marine Geology. 130, 163-178.

Costa, M.P.A., Alves, E.C., Pacheco, P.G., Maia, A.S. (1988). Prováveis estabilizações do nível do mar holocênico em trechos da Plataforma Continental entre o norte de São Paulo e o Sul do Rio de Janeiro, constatadas através de morfologia de detalhe. In: 35 Congresso Brasileiro de Geologia, Belém-PA, v.2, p. 436-450.

Cranwell, P.A. (1973). Chain length distribution of $n$-alkanes from lake sediments in relation to post-glacial environment change. Freshwater Biology. 3, 259-265.

Cranwell, P.A. (1976). Decomposition of aquatic biota and sediment formation: organic compounds in detritus resulting from microbial attack on the alga Ceratium hirundinella. Freshwater Biology. 6, 481-488.

Cranwell, P.A., Eglinton, G., and Robinson, N. (1987). Lipids of aquatic organisms as potencial contributors to lacustrine sediments-II. Organic Geochemistry. 11, 513-527. 
Cripps, G.C. (1989). Problems in the identification of anthropogenic hydrocarbons against natural background levels in Antarctic. Antarctic Science. 1, 307-312.

Cripps, G.C. (1992). Natural and Anthropogenic hydrocarbons in the Antarctic marine environment. Marine Pollution Bulletin. 25, 266-273.

Curray, J.R. (1961) Late Quaternary sea level: A discussion. Geology Society America Bulletin. 72, 1707-1712.

Curray, J.R. (1965) Late Quaternary history, continental shelves of the United States. In: Wright Jr, H.E. \& D.G.Frey (eds). The Quaternary of the United States. Princeton, N.J. Princeton University Press. p. 723-735.

de Leeuw, J.W., van der Meer, F.W., Rijpstra, W.I.C., and Schenck, P.A. (1980). On the occurrence and structural identification of long chain unsaturated ketones and hydrocarbons in sediments. In "Advances in Organic Geochemistry 1979." (A.G. Douglas, A, and J.R. Maxwell, Eds), p. 211-217. Pergamon Oxford.

Dansgaard W,.., Johnsen, S.J., Clausen, H.B., Dahl-Jensen, D., Gundestrup, N., Hammer, C.U. (1984). North Atlantic climatic oscillations revealed by deep Greenland ice cores. In: Hansen, J.E., and Takahashi, T. (eds). Climate Processes and Climate Sensitivity. American Geophysical Union, Washington, D.C. p. $288-298$.

Dymond, J.R., Suess, F., Lyle, M. (1992). Barium in deep-sea sediment: A geochemical proxy for paleoproductivity. Paleoceanography. 7, 163-181.

Farrimond, P., Eglinton, G., and Bressell, S.C. (1986). Alkenones in Cretacious black shales, Black-Bahama Basin, western North Atlantic. Organic Geochemistry. 10, 897-903. 
Figueira, R.C.L., Tessler, M.G., Mahiques, M.M., Cunha, I.I.L. 2005. Distribution of ${ }^{137} \mathrm{Cs}$, ${ }^{238} \mathrm{Pu}$, and ${ }^{239+240} \mathrm{Pu}$ in sediments of the southeastern Brazilian shelfSW Atlantic margin. Science of Total Environment. 357, 146-159.

Flores, J.A., Sierro, F.J.G.F., Vasquez, A., and Zamarreno, I. (1997). The last 100,000 years in the western Mediterranean: Sea surface water and frontal dynamics as revealed by coccolithophores. Marine Micropaleontology. 29, 351366.

Francisconi, O., Costa, M.P.A., Coutonho, M.G.N., Vicalvi, M.A. (1974). Geologia costeira e sedimentos da Plataforma Continental Brasileira. In: XXVIII CBG. Anais. Porto Alegre, Sociedade Brasileira de Geologia. Vol. 1. p. 305321.

Freeman, K.H., and Wakeham, S.G. (1991). Variations in the distributions and isotopic compositions of alkenones in Black Sea particles and sediments. Advances in Organic Geochemistry. 19, 277-285.

Furtado, V.V., Bonetti Filho, J., Conti, L.A. (1996) Paleo river valley morphology and sea level changes at southeastern Brazilian Continental Shelf. An. Acad. Bras. Ci. 68 (1), 163-169.

Gelpi, E., Schneider, J., Mann., and Oró, J. (1970). Hydrocarbons of geochemical significance in microscopic algae. Phitochemistry. 9, 603-612.

Green, G.; J.H. Skerratt, R. Leeming \& P.D. Nichols. (1992). Hydrocarbons and coprostanol levels in seawater, sea-ice algae and sediments near Davis Station in Eastern Antarctic: a regional survey and preliminary results for a field fuel spill experiment. Marine Pollution Bulletin. 25, 293-302.

Grimalt, J.O., Calvo, E., and Pelejero, C. (2001). Sea surface temperature errors in $\mathrm{U}-37^{\prime}(\mathrm{K})$ estimation due to alkenone measurements near the limit of detection. Paleoceanography. 16, 226-232. 
Grootes, P.M., Stuiver, M., White, J.W.C., Johnsen, S.J., and Jouzel, J. (1993). Comparison of oxygen isotope records from GISP2 and GRIP Greenland ice cores. Nature. 366, 552-554.

Goutw, M., and Saliot, A. (1980). Relationship between dissolved and particulate fatty acid and hydrocarbons, chlorophyll a and zooplankton biomass in Villefranche Bay, Mediterranean Sea. Marine Chemistry. 8, 299-318.

Han, J., and Calvin, M. (1970). Branched alkanes from blue-green algae. Journal of the Chemical Society, Chemical communications. 1,1490-1491.

Harada, N., Shin, K.H., Murata, A., Uchida, M., and Nakatani, T. (2003). Characteristics of alkenones synthesized by a bloom of Emiliania huxleyi in the Bering Sea. Geochemica et Cosmochimica Acta. 67, 1507-1519.

Harwood, J.L., and Russell, N.J. (1984). "Lipids in plants and microbes." Allen and Unwin London. 169p.

Harris, P.G., Zhao, M., Rosell-Melé, A., Tiedmann, R., Sarnthein, M., and Maxwell, J.R. (1996). Chlorin accumulation rate as a proxy for Quaternary marine primary productivity. Nature. 383, 63-65.

Hayes, J.M. (1993). Factors controlling ${ }^{13} \mathrm{C}$ contents of sedimentary organic compounds: Principles and evidences. Marine Geology. 113, 111-125.

Hedges, J.I., and Oades, J.M. (1997). Comparative organic geochemistry of soils and marine sediments. Organic Geochemistry. 27, 319-361.

Heezen, B.C.; Tharp, M., Ewing, M. (1959). The floors of the Oceans - The North Atlantic. Geol. Soc. Am. Special Paper 65. New York. 112p.

Herbert, T.D. (2001). Review of alkenone calibrations (culture, water column, and sediments). Geochemistry, Geophysics, and Geosystems 2, Paper number 2000 GC000055. 
Higginson, M. (1999). "Chlorin Pigment Stratigraphy as a New and Rapid Paleoceanographic proxy in the Quaternary." University of Bristol.

Huang, Y.S., Dupont, L., Sarnthein, M., Hayes, J.M. and Eglinton, G. (2000). Mapping of C-4 plant input from North West Africa into North East Atlantic sediments. Geochimica et Cosmochimica Acta. 64, 3505-3513.

Hunt, J.M. (1979). "Petroleum Geochemistry and Geology." W.H. Freeman and Company, San Francisco. 617p.

IBGE - Instituto Brasileiro de Geografia e Estatística. http://www.ibge.gov.br/home/

Ikehara, M., Kawamura, K., Ohkouchi, N., Murayama, T., and Taira, A. (2000). Variations of terrestrial input and marine productivity in the Southern Ocean $\left(48^{\circ} \mathrm{S}\right)$ during the last two deglaciations. Paleoceanography. 15, 170-180.

IPT. (1981). Mapa Geomorfológico do Estado de São Paulo. PróMinério/Promocet. São Paulo. Vol. 1. p. 47-56.

Jackson, L.L. and Blomquist, G.J. (1976). Insect waxes. In "Chemistry and Biochemistry of Natural Waxes." (P.E. Kolattukudy, Ed.), Elsevier, Amsterdam. p. 201-233.

Jeffrey, S.W., and Vesk, M. (1995). Introduction to marine phytoplankton and their pigments signatures. In "Phytoplankton pigments in oceanography." (S.W. Jeffrey, R.F.C. Mantoura, and S.W. Wright, Eds.), p. 37-85. UNESCO, Paris.

Johns, R.B., Nichols, P.D., Perry, G.J. (1979). Fatty acid composition of ten marine algae from Australian waters. Phytochem. 18, 799-802. 
Kawamura, K., Ishiwatari, R., and Ogura, K. (1987). Early diagenesis of matter in the water column and sediments: Microbial degradation and resynthesis of lipids in Lake Haruna. Organic Geochemistry. 11, 251-264.

Kawamura, K. (1995). Land-derived lipid class compounds in the deep-sea sediments and marine aerosols from North Pacific. In "Biogeochemical Processes and Ocean Flux in the Western Pacific." (H. Sakai, and Y. Nozaki, Eds), p. 31-51. TERRAPUB, Tokio.

Kitagawa, H., van der Plicht, J. (1998). Atmospheric radiocarbon calibration to 45000 y (B.P.): Late Glacial fluctuations and cosmogenic isotope production. Science. 279: 1187-1190.

Klein, D.A. (2006). Registros de variações ambientais no Canal de São Sebastião (estado de São Paulo), durante o último ciclo glacial. Dissertação de Mestrado. Instituto Oceanográfico, Universidade de São Paulo. IO

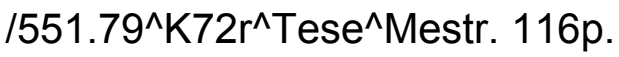

Klump, J., Hebbein, D., Wefer, G. (2000). The impact of sediment provenance on barium-based productivity estimates. Marine Geology. 169, 259-271.

Kowsmann, R.O., Costa, M.P.A. (1974). Paleolinhas de costa na Plataforma Continental das regiões sul e norte brasileira. Revista Brasileira de Geociências. 4, 215-222.

Kowsmann, R.O., Costa, M.P.A. (1979). Sedimentação quaternária da margem continental brasileira e das áreas oceânicas adjacentes (relatório final). Rio de janeiro, Série Projeto REMAC 8. Petrobrás, 55p.

Kelly, B.J., and Maxwell, J.R. (1991). Structural characterization of the major chlorines in recent sediment. Organic Geochemistry. 17, 663-669.

Kennicutt II, M.C., and Comet, P.A. (1992). Resolution of sediment hydrocarbon sources: multiparameter approaches. In "Organic Matter: Productivity, 
Accumulation and Preservation in Recent and Ancient Sediments." (J.K.Whelan and J.W. Farrington, Eds.), pp. 308-339. Columbia University Press, New York.

Kreitz, S.F., Herbert, T.D., Schuffert, J.D. (2000). Alkenones Paleothermometry and orbital scale changes in sea surface temperature at site 1020, northern California margin. Proc. Ocean Drill Program Sci. Results. 167, 249-254.

Killops, S.D., Killops, V. (2005). Introduction to organic geochemistry. Blackwell Publishing Ltd. Second Edition. 408p.

Kornilova, O.V. (2005). Investigation of the North Atlantic Heinrich Events using molecular approach. Unpublished thesis, University of Durhan.

Kutzbach, JE, Webb III, T. (1993). Conceptual basis for understanding lateQuaternary climates. p. 5-11 in Wright, HE, JE Kutzbach, T Webb III, W.F. Ruddiman, FA Street-Perrott, and PJ Bartlein (eds.) Global Climates Since the Last Glacial Maximum. University of Minnesota Press. Minneapolis.

Li, J., Philip, R.P., Pu, F., and Allen, J. (1996). Long chain alkenones in Quinghai Lake sediments. Geochimica et Cosmochimica Acta. 60, 235-241.

Lima, M.R.B.L.M.A. (2000). Natureza e origem da matéria orgânica depositada nos sedimentos superficiais ao longo da Plataforma Continental Norte entre as cidades do Rio de Janeiro (RJ) e São Francisco do Sul (SC). Dissertação de Mestrado. Instituto Oceanográfico, USP. 115p.

Little, M., Schineider, R.R., Kroon, D., Price, B. Summerhayes, C., Segl, M. (1997). Trade wind forcing of upwelling seasonality, and Heinrich events as a response to sub-Milankovitch climate variatiability. Paleoceanography. 12, 568576.

Lombardi, P. (1990). A rapid, safe, and convenient procedure for the preparation and use of diazomethane. Chemistry \& Industry. 21 (5), 708-710. 
Louda, J.W., Palmer, S.E., and Baker, E.W. (1980) Early products of Chorophyll in Japan Trench sediments of Deep-Sea Drilling Project. Sites 434, 435 and 436. Initial reports of the Deep Sea Drilling Project 56. 57 (2), 1391-1396.

Louda, J.W., Liu, L, and Baker, E.W. (2002). Senescence and death related alteration of chlorophylls and carotenoid in marine phytoplankton. Organic Geochemistry. 33, 1635-1653.

Lowe, J.L., Walker, M.J.L. (1997). Reconstructing Quaternary Environments. Longmann, Scientific \& Technical. 446p.

Lowell, T.V., Heusser, C.J., Andersen, B.G., Moreno, P.I., Hauser, A., Heusser, L.E., Schluechter, C., Marchant, D.R., Denton, G.H. (1995). Interhemispheric correlation of Late Pleistocene glacial events. Science. 269, 1541-1549.

Madureira, L.A.S, van Kreveld, S.A., Egliton, G., Conte, M.H., Ganssen, G., van Hinte, J.E., and Ottens, J.J. (1987). Late Quaternary high-resolution biomarkers and other sedimentary climate proxies in a Northeast Atlantic core. Paleoceanography. 12, 255-269.

Madureira, L.A.S., Conte, M.H., and Eglinton, G. (1995). Early diagenesis of lipid biomarker compounds in North Atlantic sediments. Paleoceanography. 10, 627-642.

Mahiques, M.M. (1992). Transporte de sedimento na região costeira de Ubatuba, São Paulo. In: XXXVII Congresso Brasileiro de Geologia. Boletim de resumos expandidos. São Paulo, Sociedade Brasileira de Geologia. Vol. 1; p. 187.

Mahiques, M.M., Silveira, I.C.A., Sousa, S.H.M., Rodrigues, M. (2002). PostLGM sedimentation on the outer shelf/upper slope of the northernmost part of São Paulo Bight, south-eastern Brazil. Marine Geology. 181, 387-400. 
Mahiques, M.M., Tessler, M.G., Ciotti, M.M., Silveira, I.C.A., Sousa, S.H.M., Figueira, R.C.L., Tassinari, C.C.G., Furtado, V.V., Passos, R.F. (2004). Hydrodynamically driven pattern of recent sedimentation in the shelf and upper slope off Southeast Brazil. Cont. Shelf Res. 24, 1685-1697.

Mahiques, M.M., Fukumoto, M.M., Silveira, I.C.A, Figueira, R.C.L., Bicego, M.C., Lourenço, R.A., Mello e Sousa, S.H. (2007). Sedimentary Changes on the Southeastern Brazilian upper slope during the last 35,000 years. Annals of the Brazilian Academy of Sciences. 79(1), 171-181.

Marlowe, I., (1984). Lipids as palaeoclimatic indicators. Unpublished thesis, University of Bristol.

Marlowe, I.T., Green, J.C., Neal, A.C., Brassell, S.C., Eglinton, G., Course, P.A., (1984). "Long chain (n-C37-C39) Alkenones in the Prymensiophyceae. Distribution of Alkenones and lipids and their Taxonomic significance." British Phycology Journal. 19, 203-216.

Marlowe, I.T., Brassell, S.C., Eglinton, G., and Green, J.C. (1990). Long alkenones and alkyl alkenoates and the fossil coccolith record of marine sediments. Chemical Geology. 88, 349-375.

Martins, L.R.; Urien, C.M., Butler, L.W. (1972). Províncias fisiográficas e sedimentos da margem continental atlântica da América do Sul. In: Congresso Brasileiro de Geologia. Anais. Belém, Sociedade Brasileira de Geologia. Vol. 2. p. 105-114.

Meyers, P.A. (1997). Organic Geochemical proxies of paleoceanographic, paleolimnologic, and paleoclimatic processes. Organic Geochemistry. 27, 213250.

Meyers, P.A., and Ishiwatari, R. (1993a). "The early diagenesis on organic matter in lacustrine sediments." In "Organic Geochemistry, Principles and Applications." (M.H. Engel, and S.A. Macko, Eds.). Plenum Press, New York. 
Meyers, P.A., and Ishiwatari, R. (1993b). Lacustrine organic geochemistry - an overview of indicators of organic matter sources and diagenesis in lake sediments. Organic Geochemistry. 20, 867-900.

Meyers, P.A., and Benson, L.V. (1988). Sedimentary biomarker and isotopic indicators of the paleoclimatic history of the lake basin, western Nevada. Organic Chemistry. 13, 807-813.

Miles, J.A. (1994). "Illustrate Glossary of Petroleum Geochemistry." Claredon Press, Oxford. 150p.

Milliman, J.D., Emery, K.O. (1968) Sea levels during the past 35,000 years. Science. Washington D.C. 162, 1121-1123.

Morrison, R., Boyd, R. (1995). Organic Chemistry. $6^{\circ}$ ed. Prentice Hall. 1360p.

Muller, P.J., Kirst, G., Ruhland, G., von Storch, I., and Rosell-Melé, A. (1998). Calibration of the alkenone paleotemperature index U-37(K') based on coretops from the eastern South Atlantic and the global ocean (60 degrees $\mathrm{N}-60$ degrees S). Geochimia et Cosmochimia Acta. 62, 1757-1772.

Murray, R.W., Leinen, M. (1996). Scavenged excess aluminum and its relationship to bulk titanium in biogenic sediment from the central equatorial Pacific Ocean. Geochimica et Cosmochimica Acta. 60, 3869-3878.

Murray, R.W., Knowlton, C., Leinen, M., Mix, A.C., Polsky, C.H. (2000). Export production and terrigenous matter in the central equatorial Pacific Ocean during interglacial oxygen isotope Stage 11. Global Planet Change. 24, 59-78.

Ohkouchi, N., Nawamura, K., Kawahata, H., and Taira, A. (1997). Latitudinal distributions of terrestrial biomarkers in the sediments from the Central Pacific. Geochimica et Cosmochimica Acta. 61, 1911-1918. 
Pattan, J.N., Masuzawa, T., Divakar Naiudu, P., Parthiban, G.,Yamamoto, M. (2003). Productivity fluctuations in the southeastern Arabian Sea during the last 140 ka. Palaeogeography, Palaeoclimatology, Palaeoecology. 193, 575-590.

Paytan, A., Kastner, M., Chavez, F.P. (1996). Glacial to interglacial fluctuations in productivity in the equatorial Pacific as indicated by marine barite. Science. $274,1355-1357$.

Pelejero, C., and Calvo, E. (2003). The upper end of the UK37' temperature calibration revisited. Geochemistry, Geophysics, Geosystems. 4, art no. 1014.

Peters, K.E., Moldowan, J.M., (1993) The biomarkers guide. Prentice-Hall, London. 490p.

Philip, R.P. (1985). Biological markers in fossil fuel production. Mass Spectrometry Reviews. 4, 1-54.

Piola A.R., Campos, E.J.D., Möller, O., Charo, M., Martinez., 2000. Subtropical Shelf Front off eastern South America. Journal of Geophysical Research. 105 (C3), 6565-6578.

Prahl, F.G., Herbert, T., Ohkouchi, N., Pagani, M., Repeta, D., Rosell-Melé, A., and Sikes, E. (2000). Status of alkenone paleothermometer calibration: Report from Working Group 3. Geochemistry, Geophysics, Geosystems. 1, Paper number $2000 \mathrm{GC} 000058$.

Prahl, F.G., Muehlhausen, L.A., and Zahnle, D.I. (1988). Further Evaluation of Long-Chain Alkenones as Indicators of Paleoceanographic Conditions. Geochimica et Cosmochimica Acta. 52, 2303-2310.

Prahl, F.G., Wakehan, S.G. (1987). "Calibration of instauration patterns in longchain ketone compositions for paleotemperature assessment". Nature. 330, 367-369. 
Prahl, F.G., Muehlhausen, L.A. (1989). "An organic geochemical assessment of oceanographic conditions at Manop site C over the past 26,000 years." Paleoceanography. 4, 495-510.

Prahl, F.G., Ertel, J.R., Goñi, M.A., Sparrow, M.A., Eversmeyer, B. (1994). "Terrestrial organic carbon contributions to sediments on the Washington margin." Geochimica et Cosmochimica Acta. 58, 3035-3048.

Poynter, J.G., and Eglinton, G. (1991). "The biomarker concept - strength and weaknesses." Fresenius Journal of Analytical Chemistry. 339, 725-731.

Rau, G.H., Takahashi, T., Des Marais, D.J., Sullivan, C.W. (1991). Particulate organic matter $d^{13} \mathrm{C}$ variations across the Drake Passage. Journal of Geophysic Research. 96, 15131-15135.

Rocha, J., Milliman, J.D., Santana, C.I., Vicalvi, M.A. 1975. Continental Margin sedimentation off Brazil. Part 5: Southearn Brazil. Contrib. Sedimentol. 4, 117150.

Rosell-Melé, A. (1994). "Long-chain alkenones, alkyl alkenoates and total pigment abundances as climatic proxy-indicators in the Northeastern Atlantic." Unpublished Ph.D. thesis, University of Bristol.

Rosell-Melé, A., Carter,J., Parry, A., and Eglinton G. (1995a). Determination of the UK37 index in geological samples. Analytical Chemistry. 67, 1283-1289.

Rosell-Melé, A., Maslin, M.A., Maxwell, J.R., and Schaeffer, P. (1997). Biomarker evidence for Heinrich events. Geochimica et Cosmochimica Acta. 61, 1671-1678.

Rosell-Melé, A., Carter, J., and Eglinton, G. (1993). Distributions of long chain alkenones and alkyl alkenoates in marine surface sediments from the North East Atlantic. Organic Geochemistry. 22, 501-509. 
Rosell-Melé, A. (1998). Interhemispheric appraisal of the value of alkenones indices as temperature and salinity proxies in high latitude locations. Paleoceanography.13, 694-703.

Rosell-Melé, A., and Koç, N. (1997). Paleoclimatic Significance of the Stratigraphic Occurrence of Photosynthetic Biomarker Pigments. Nordic Seas Geology. 25, 49-52.

Rosell-Melé, A., Bard, E., Grimalt, J., Harrison, I., Boloubassi, I., Comes, P., Emeis, K-C., Epstein, B., Fahl, K., Farrimond, P., Fluegge, K., Freeman, K., Goni, M., Güntner, U., Hartz, D., Hellebust, S., Herbert, T., Ikehara, M., Ishiwatari, R., Kawamura, K., Kenig, F., Leeuw, J., Lehman, S., Müller, P., Phkouchi, N., Pancost, R.D., Prahl, F., Quinn, J., Rontani, J.Rostek, F., Rullkotter, J., Sachs J., Sanders, D., Sawada, K., Scheineider, R., Schulz-Bull, D., Sikes, E., Ternois, Y., Versteegh, G., Volkman, J., and Wakeham, S. (2001). Precision of the corrent methods to measure alkenones relative (UK37') and absolute abundance in sediments: results of an inter-laboratory comparison study. Geochemistry, Geophysics, Geosystems. 2, Paper number 2000 G000141.

Rosell-Melé, A., Weinelt, M., Sarnthein, M., Koç, N., and Jensen, E. (1998). Variability of the Arctic front during the last climate cycle: application of a novel molecular proxy. Terra Nova. 10, 86-89.

Sawada, K., Handa, N., Shiraiwa, Y., Danbara, A., and Montani, S. (1996). Long chain alkenones and alkyl alkenoates in the coastal and pelagic sediments of the northwest North Pacific, with special reference to the reconstruction of Emiliania huxleyi and Gephirocapsa oceanica ratios. Organic Geochemistry. 24, 751-764.

Schroeder, J.O., Murray, R.W., Leinen, M, Pflaum, R.C., Janecek, T.R. (1997). Barium in equatorial pacific carbonate sediment: Terrigenous, oxide, and biogenic associations. Paleoceanography. 12, 125-146. 
Schulz, H.D., Zabel, M. (2000). Marine Geochemistry. Springer-Verlag Berlin Heidelberg New York. 455p.

Schulz, H.M., Schoner, A., and Emeis, K.C. (2000). Long chain alkenone pattern in the Baltic Sea - an ocean - freshwater transition. Geochimica et Cosmochimica Acta. 64, 469-477.

Seki, O., Ishiwatari, R., Matsumoto, K. (2002). Millenial climate oscillations in NE Pacific surface waters over the last 82 Kyr: New evidence from alkenones. Geophysical Research Letter. Vol 29, No 23, 2144.

Sericano, J.L. (1998). Quantitative determination of chlorinated hydrocarbons by gas chromatography/electron capture detection. Geochemical and Environmental Research Group, Standard Operating Procedures (SOP-9810), $21 p$.

Sicre, M.A., Bard, E., Ezat, U., and Rostek, F. (2002). Alkenone distribution in the North Atlantic and Nordic Sea surface waters. Geochemistry, Geophysics and Geosystems. 3, 10.1029/2001GC000159.

Sikes, E.L., and Volkman, J.K.(1993). Calibration of alkenones instauration ratios (UK37) for paleotemperature estimation in cold polar waters. Geochimica et Comochimica Acta. 57, 1883-1889.

Sikes, E.L., Volkman, J.K., Robertson, L.G., and Pichon, J.J. (1997). Alkenones and alkenes in surface waters and sediments of the Southern Ocean: Implications for paleotemperature estimation in polar regions. Geochimica et Cosmochimica Acta. 61, 1495-1505.

Sikes, E.L., and Sicre, M.A. (2002). Relationship of the tetra-unsaturated C-37 alkenone to salinity and temperature. Implications for paleoproxy applications. Geohemistry, Geophysics, Geosystems. 3, paper number 1063. 
Simoneit, B.R.T. (2002). Biomass burning - a review of organic tracers for smoke from incomplete combustion. Applied Geochemistry. 17, 129-162.

Sonzogni, C., Bard, E., Rostek, F., Lafont, A., Rosell-Melé, A., and Eglinton, G. (1997). Core top calibration of the alkenone index versus sea surface temperature in the Indian Ocean. Deep Sea Research. 44, 1445-1460.

Spooner, N., Harvey, R., Pearce, G.E.S., Eckardt, C.B., and Maxwell, J.R. (1994). Biological defunctionalisation of chlorophyll in the aquatic environment II: action of endogenous alga enzymes and aerobic bacteria. Organic Geochemistry. 22, 773-780.

Stein, R. (1991). Accumulation of organic carbon in marine sediments. Lecture, notes in Earth Sciences. Berlin, Springer-Verlag. 217p.

Stevenson, M.R., Brito, D.D., Stech, J.L., Kampel, M. (1998). How cold water biota arrive in tropical bay near Rio de Janeiro, Brazil ? Continental Shelf Research. 13, 1595-1612.

Stoykova, D., Sauro, U., Borsato, A., Cucchi, F., Forti, P., Frísia, S. (2006). Climatic cycles from annual to orbital scale, their origin and stability. Geophysical Research Abstracts. SRef-ID: 1607-7962/gra/EGU06-A-02949.

Suguiu, K., Martin, L. (1978) Quaternary marine formations of the state of São Paulo and southern Rio de Janeiro. In: Symposium on Coastal Evolution in the Quaternary 1978, São Paulo. Spec. Publ. 1, 1-55.

Summerhayes, C.P., Kroon, D., Rosell-Melé, A., Jordan, R.W., Schrader, H.J., Hearn, R., Villanueva, J., Grimalt, J.O., and Eglinton, G. (1995). Variability in the Benguela Current upwelling system over the past 70,000 years. Progress in Oceanography. 35, 207-251.

Summons, R.E. (1993). Biogeochemical cycles: a review of fundamental aspects of organic matter formation, preservation and composition. In "Organic 
Geochemistry: Principles and Applications." (M.H. Engel and S.A. Macko, Eds.) Plenum Press, New York.

Sun, M.Y., Lee, C., and Aller, R.C. (1993). Laboratory studies of oxid and anoxid degradation of Chorophyll-a in Long Island Sound sediments. Geochimica et Cosmochimica. Acta 57, 147-157.

Taylor, S.R., McLennan, S.M. (1985). The continental crust: its composition and evolution. An examination of the geochemical record preserved in sedimentary rocks. Oxford, Blackwell. 311p.

Teece, M.A., Getlife, J.M., Leftley, J.W., Parkers, R.J., and Maxwell, J.R. (1998). Microbial degradation of the marine prymnesiophyte Emiliania huxleyi under oxic and anoxic conditions as a model for early diagenesis: long chain alkadienes, alkenones and alkyl alkenoates. Organic Geochemistry. 29, 863880.

Ternois, Y., Sicre, M.A., Boireau., Conte, M.H., and Eglinton, G. (1997). Evaluation of long-chain alkenones as paleo-temperature indicators in the Mediterranean Sea. Deep sea Research. 44, 271-286.

Ternois, Y., Sicre, M.A., Boireau, A., Beuort, L., Miguel, .C., and Jeandel, C. (1998). Hydrocarbons, sterols and alkenones in sinking particles in the Indian Ocean sector of the Southern Ocean. Organic Geochemistry. 28, 489-501.

Thiel, V., Jenisch, A., Landmann, G., Reimer, A., and Michaelis, W. (1997). Unusual distribution of long chain alkenones and tetramethymanol from the high alkaline Lake Van, Turkey. Geochimica et Cosmochimica Acta. 61, 2053-2064.

Thierstein, H.R., Geitzenauer, K., Molfino, B., and Shackleton, N.J. (1997). Global synchronicity of late Quaternary coccolith datum levels: validation by oxygen isotopes. Geology. 5, 400-404. 
Thompson, L.G. et al. (1998). A 25,000 year tropical climate history from Bolivian ice cores. Science. 282, 1858-1864 .

Tissot, A.P., and Welte, D.H. (1978). "Petroleum Formation and Occurrence" Spinger-Verlag. Berlin. 699p.

Vidal, L., Schneider, R.R., Marchal, O., Bickert, T., Stocker, T.F., Wefer, G. (1999). Link Between the North and South Atlantic during the Heinrich events of the last glacial period. Climate Dynamics. 15, 909-919.

Villanueva, J., Grimalt, J.O. (1999). Pitfalls in chromatographic determination of the alkenone $U^{k}{ }_{37}$ index for paleotemperature estimation. Journal of Chromatography A. 723 (1996), 285-291.

Volkman, J.K., Barret, S.M., Blackburn, S.I., and Sikes, E.L. (1995). Alkenones in Gephyrocapsa oceanica: Implications for studies of paleoclimate. Geochimica et Cosmochimica Acta. 59, 513-520.

Volkman, J.K., Eglinton, G., Corner, E.D.S., and Forsberg, T.E.V. (1980a). Long chains alkenes and alkenones in the marine coccolithophorid Emiliania huxleyi. Phytochemistry.19, 2619-2622.

Volkman, J.K., Eglinton, G., Corner, E.D.S., Sargent, J.R., (1980b) Novel unsaturated straight-chain C37-C39 methyl and ethyl ketones in marine sediments and coccolithophore Emiliana huxleyi. In: "Advances in Organic Geochemistry. 1979." (Ed. by J.R. Maxwell), p. 219-227. Pergamon, Oxford.

Volkman, J.K., Barrett, S.M., Blackburn, S.I., Mansour, M.P., Sikes, E.L., and Gelin, F. (1998). Microalgal biomarker: A review of recent research developments. Organic Geochemistry. 29, 1163-1179.

Wade, T.I.; Cantillo, Y.A. (1994). Use of standards and reference materials in the measurement of chlorinated hydrocarbons residues. Chemistry Workbook. NOAA Technical Memorandum NOS ORCA 77, Silver Spring, Maryland, 59p. 
Westernhausen, L., Poynter, J., Eglinton, G., Erlenkeuser, H., Sarnthein, M. (1993). Marine and terrigenous origin of organic matter in modern sediments of the equatorial East Atlantic: the $d^{13} \mathrm{C}$ and molecular record. Deep Sea Research. 40, 1087-1121.

Wei, G., Liu, Y., Li, X., Chen, M., Wei W. (2003). High-resolution elemental records from the South China Sea and their paleoproductivity implications. Paleoceanography. 18(2), 1054. doi: 10.1029/2002PA000826.

Yamamoto, M., Yamamoto, M., Tada, R. (2000). Late Quaternary records of organic carbon, calcium carbonate and biomarkers from site 1016 off Point Conception, California Margin. Proc. Ocean Drill Program Sci. Results. 167, 183-194.

Yen, T.F. (1975). Genesis and degradation of petroleum hydrocarbons in marine environments. In "Marine Chemistry in the Coastal Environment." (T.M. Church, Ed), p. 237. ACS Symposium Series 18, Washington D.C.

Youngblood, W.H., and Blumer, M. (1973). Alkanes and alkenes in marine benthic algae. Marine Biology. 21, 163-172.

Youngblod, W.H., Blumer, M., Guillard, R.R.L., and Fiore, F. (1971). Saturated and unsaturated hydrocarbons in marine benthic algae. Marine Biology. 8, 190201.

Zembruscki, S.G., Barreto, H.T., Palma, J.C., Milliman, J.D. (1972). Estudo preliminar das províncias geomorfológicas da margem continental brasileira. $\underline{\mathrm{In}}$ : XXVI Congresso Brasileiro de Geologia. Anais. Belém, Sociedade Brasileira de Geologia. Vol. 2. p. 187-210.

Zembruscki, S.G. (1979). Geomorfologia da margem continental Sul Brasileira e das Bacias Adjacentes. In: Geomorfologia na margem continental brasileira e 
das áreas oceânicas adjacentes. Projeto REMAC. Rio de Janeiro, Petrobrás. Vol. 7, 129-177.

Zhao, M., Dupont, J., Eglinton, G., and Teece, M. (2003). n-Alkane and pollen reconstruction of terrestrial climate and vegetation for N.W. Africa over the last 160 Kyrs. Organic Geochemistry. 34, 131-143. 
Anexo 1 : Espectros de Massa para identificação dos álcoois e ácidos graxos.
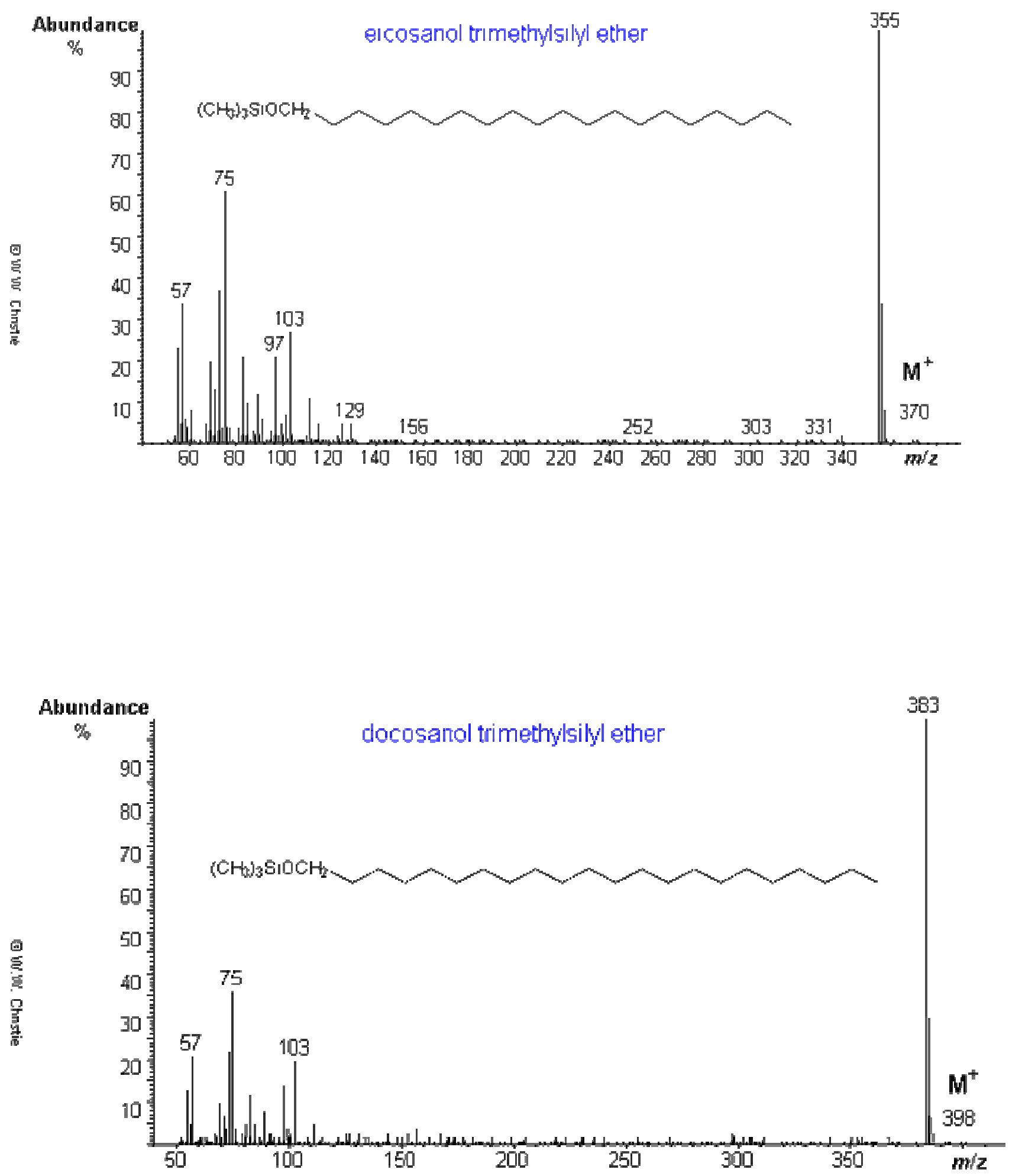

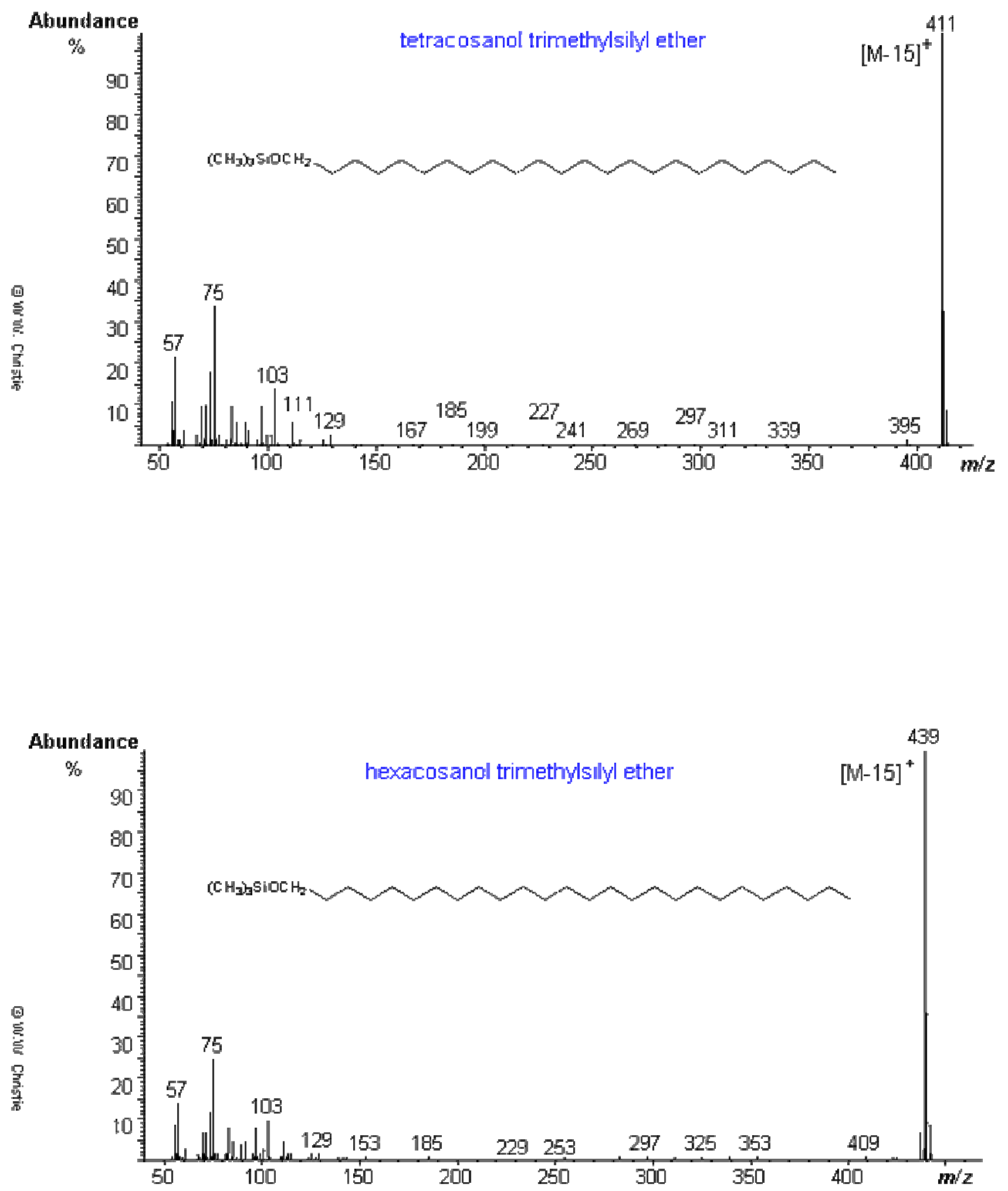

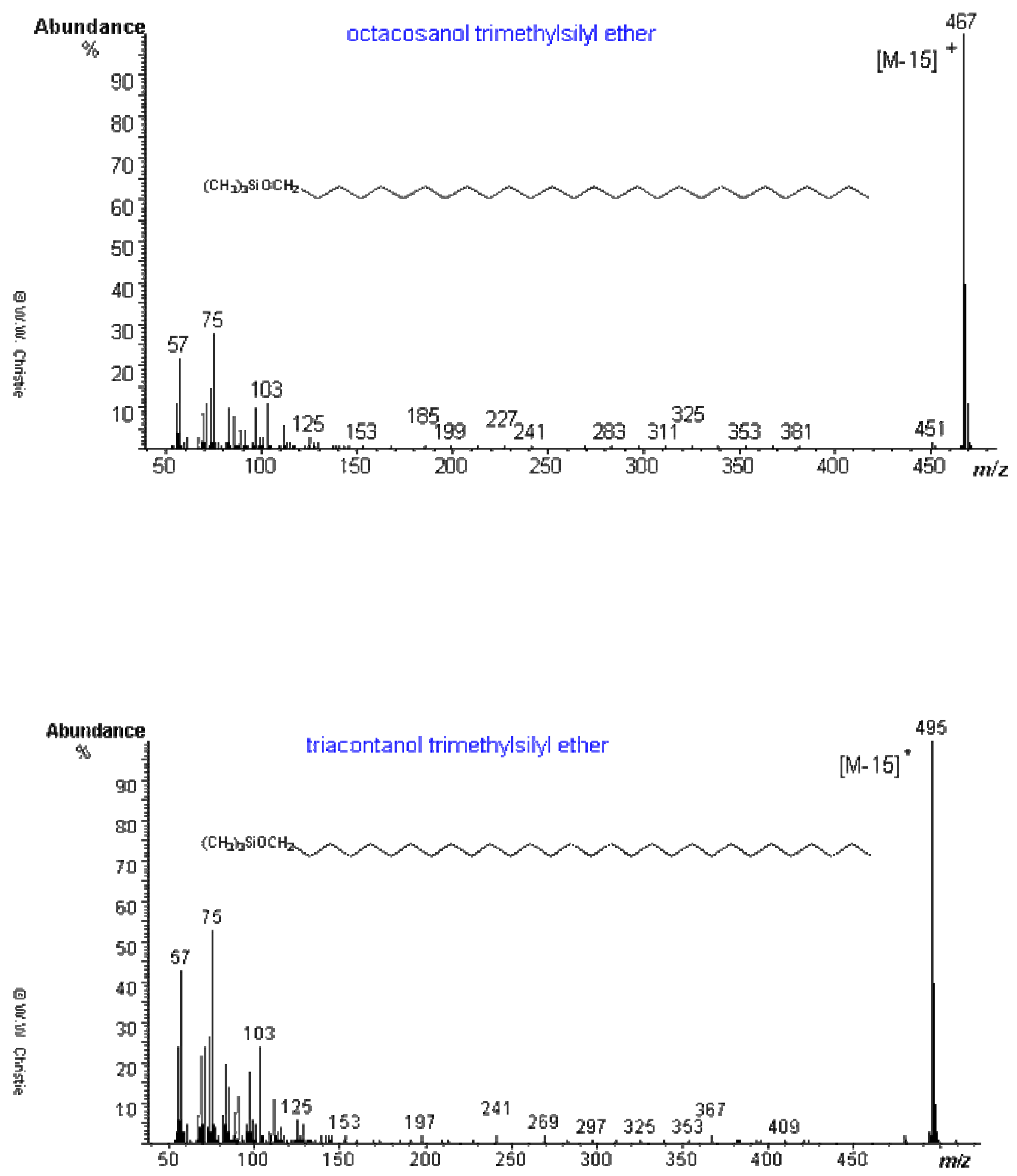


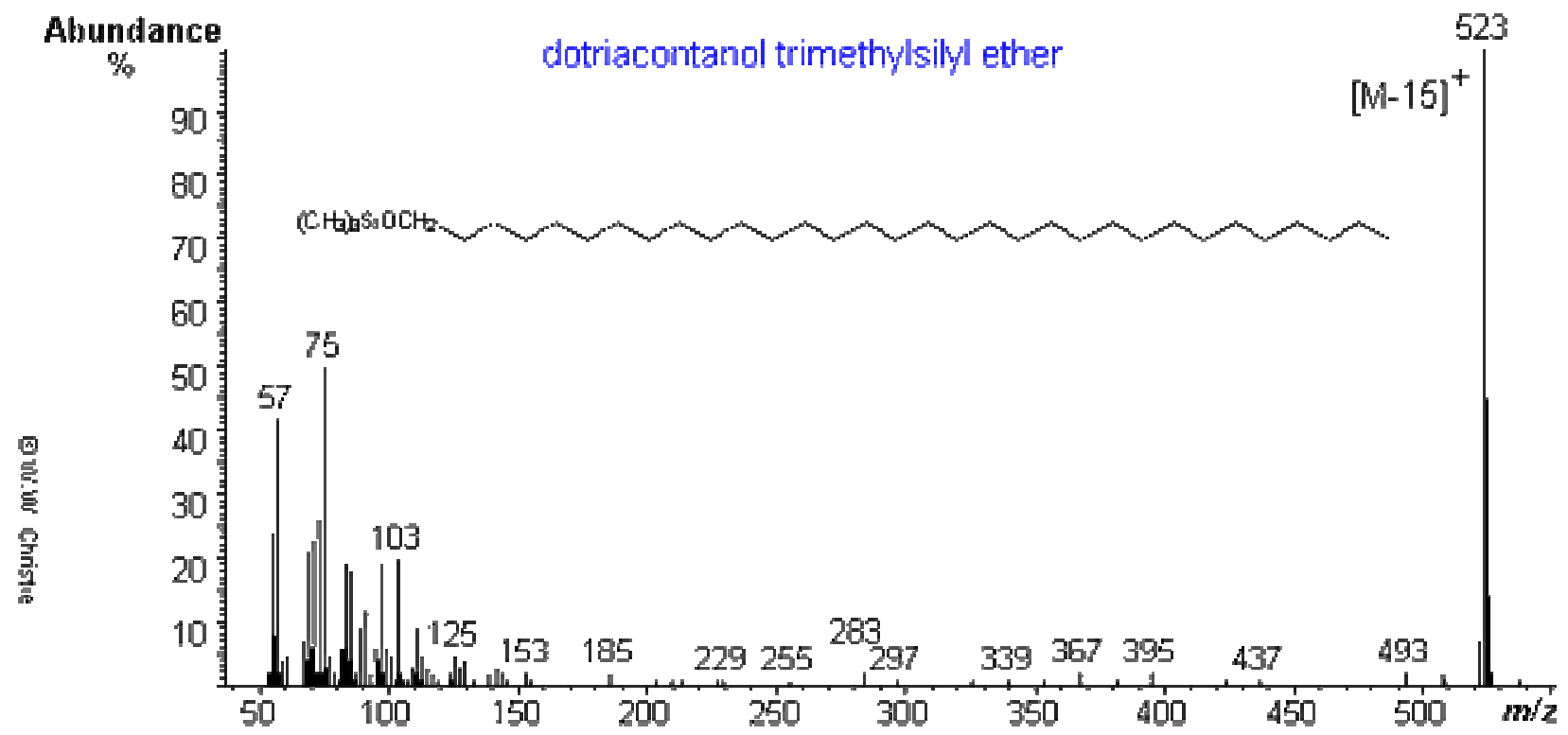

dodecanoic acid - methyl esther

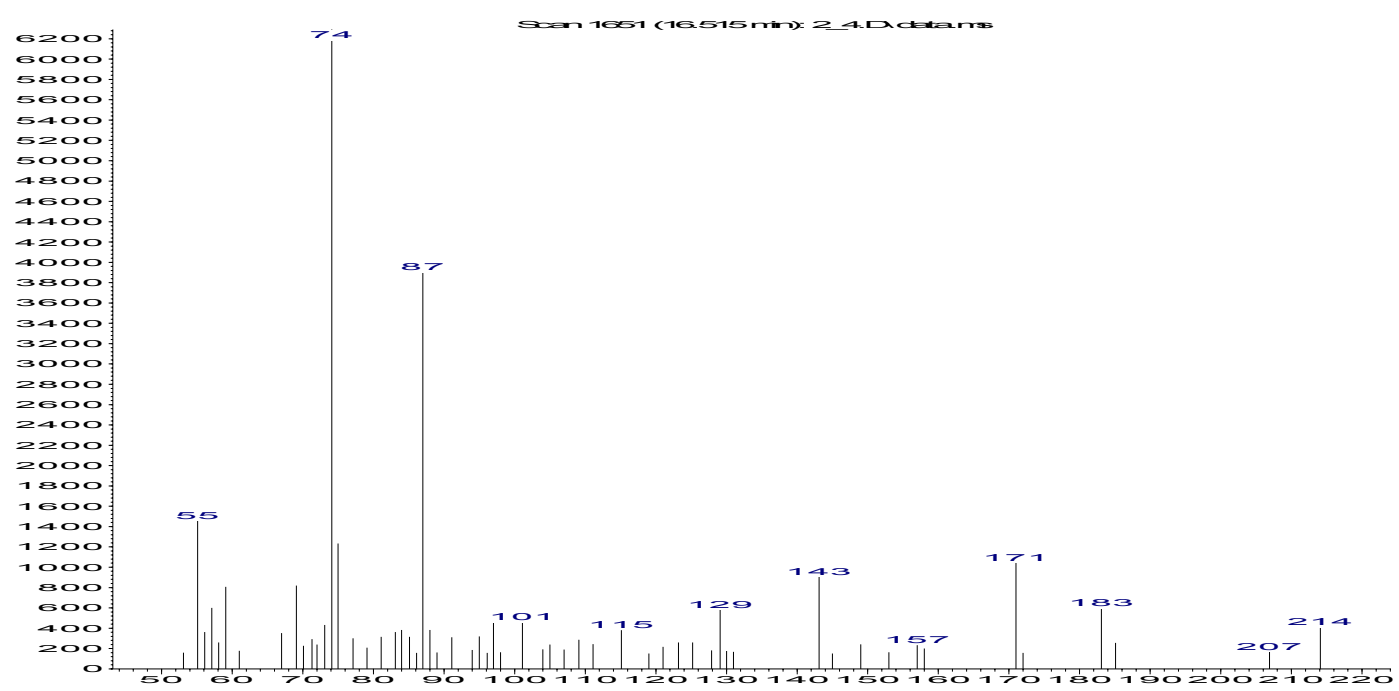


Abundance

tetradecanoic acid - methyl esther

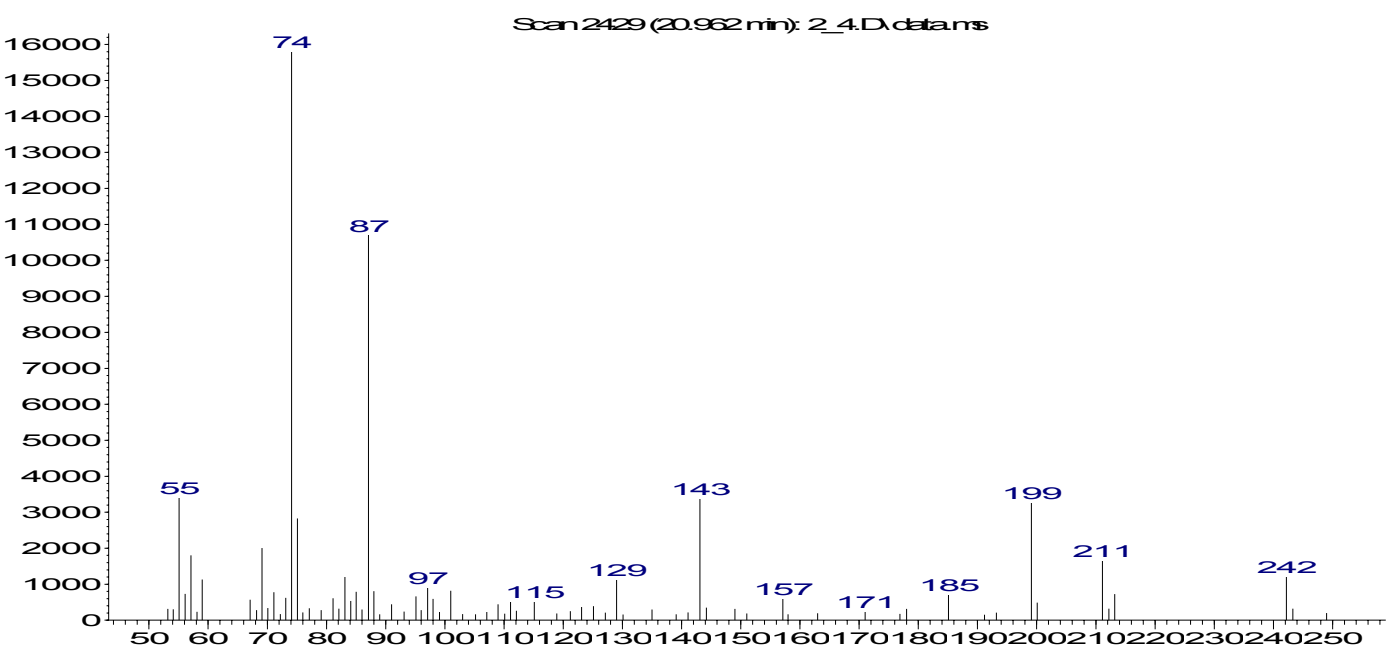

hexadecanoic acid - methyl esther

Abundance

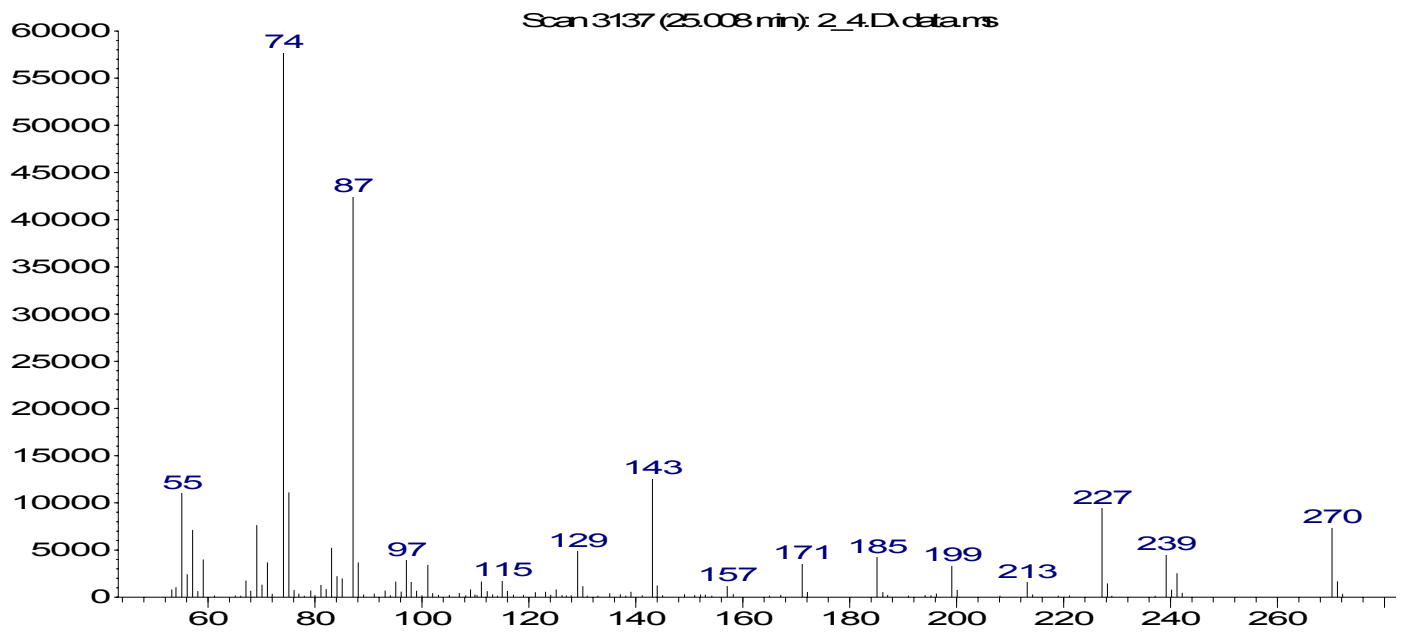


Abundance octadecanoic acid - methyl esther

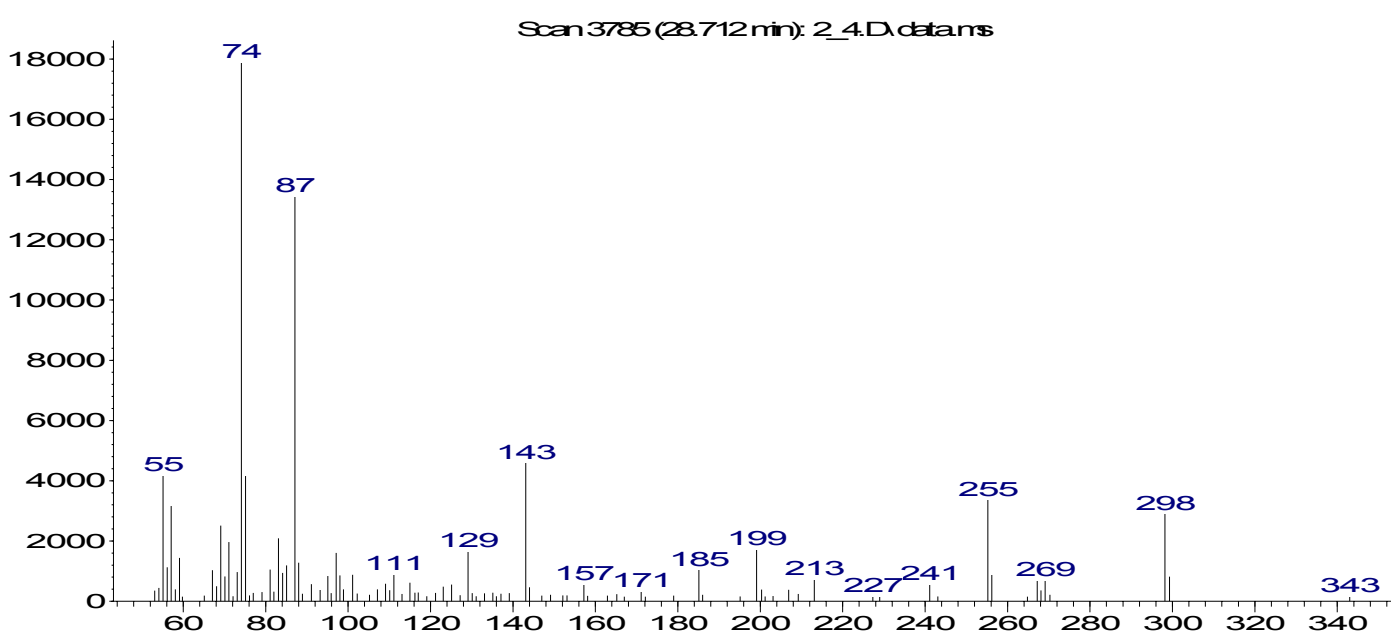

m/z-->

eicosanoic acid - methyl esther

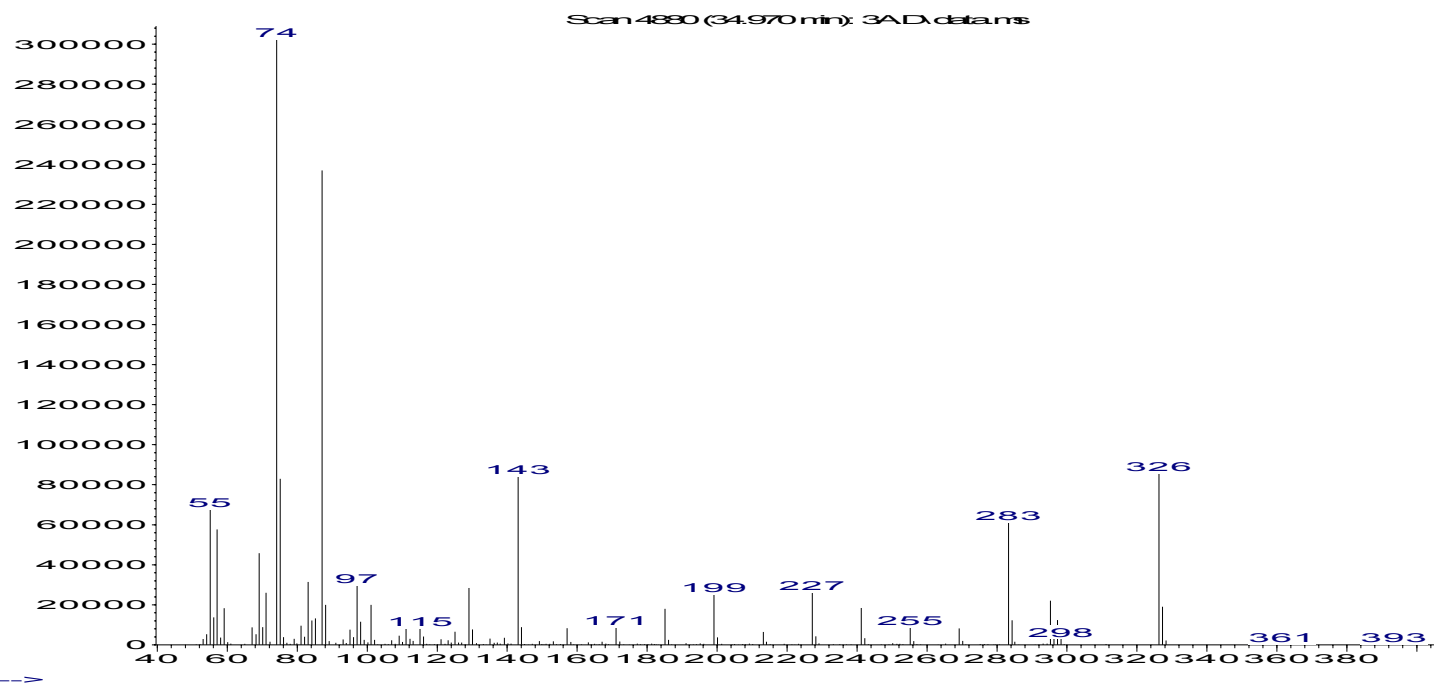


docosanoic acid - methyl esther

Abundance

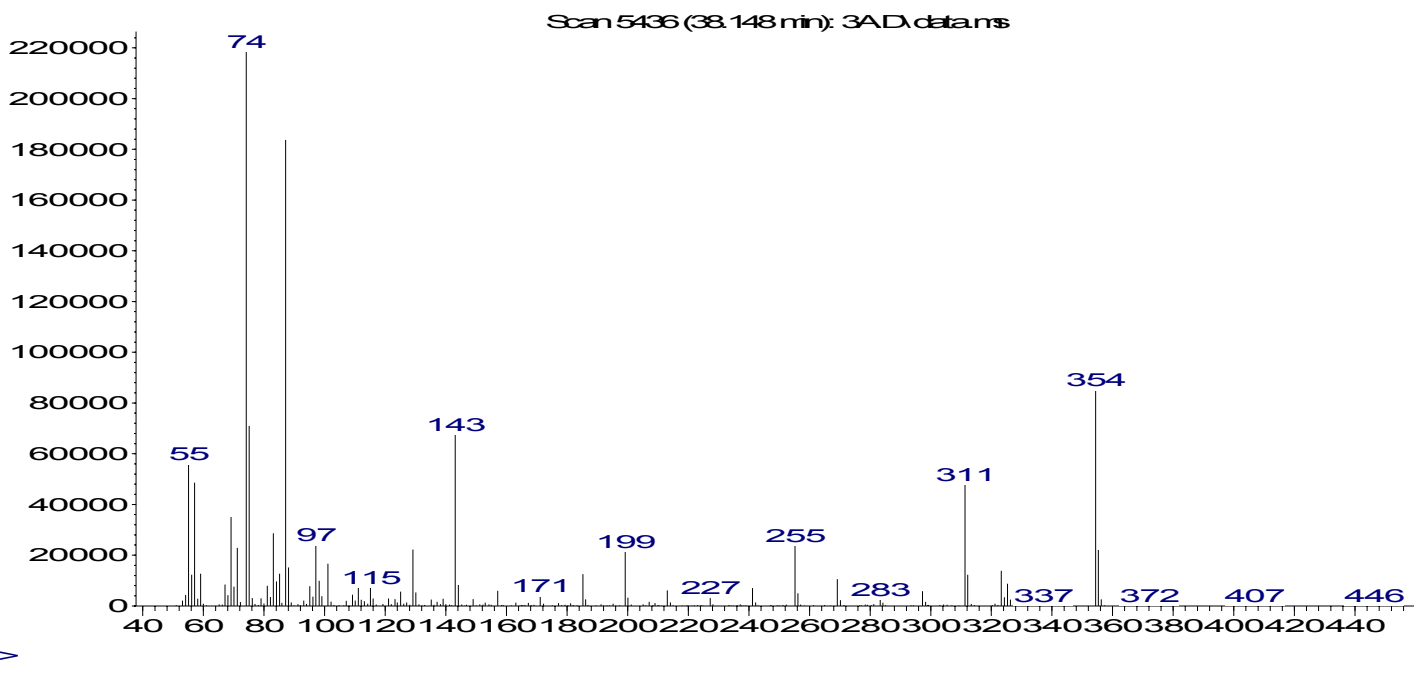

$m / z-->$

tetracosanoic acid - methyl esther

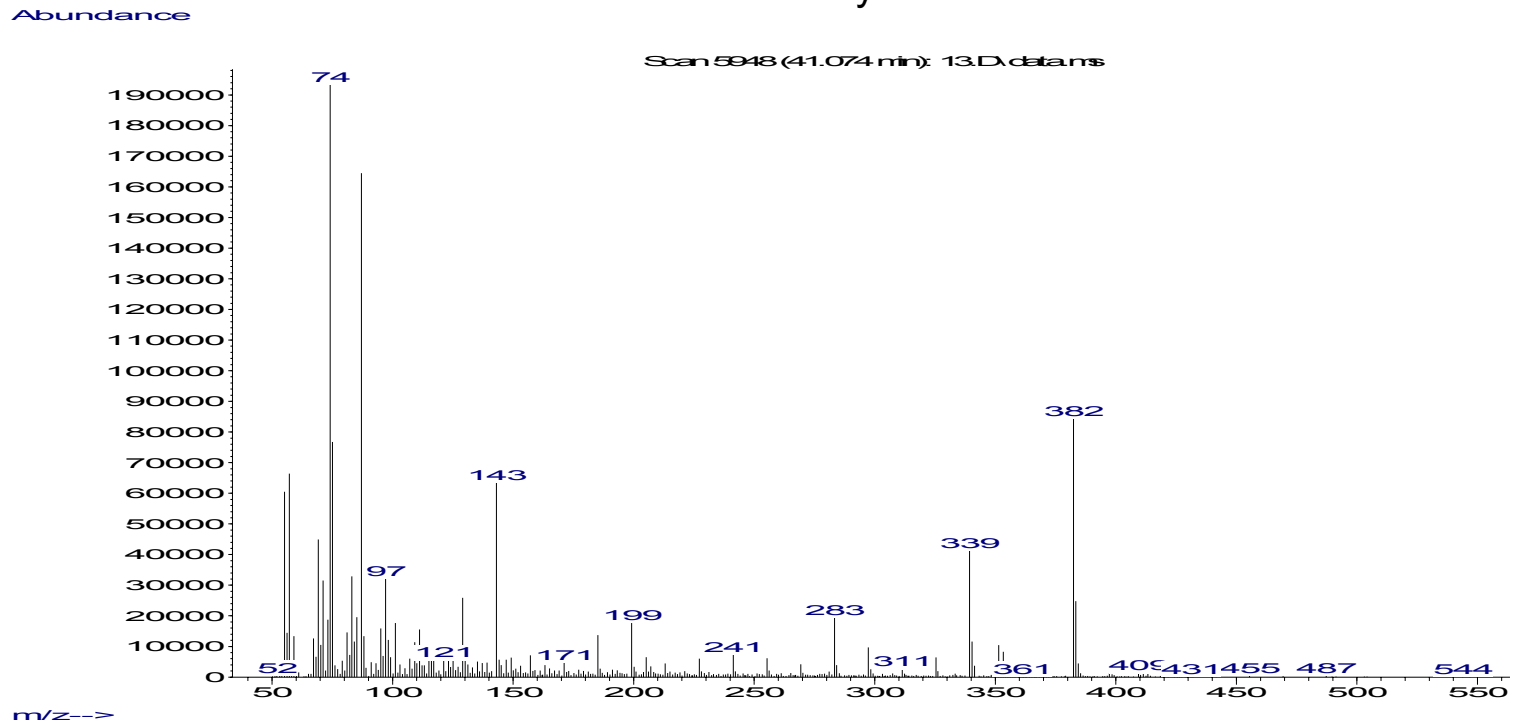



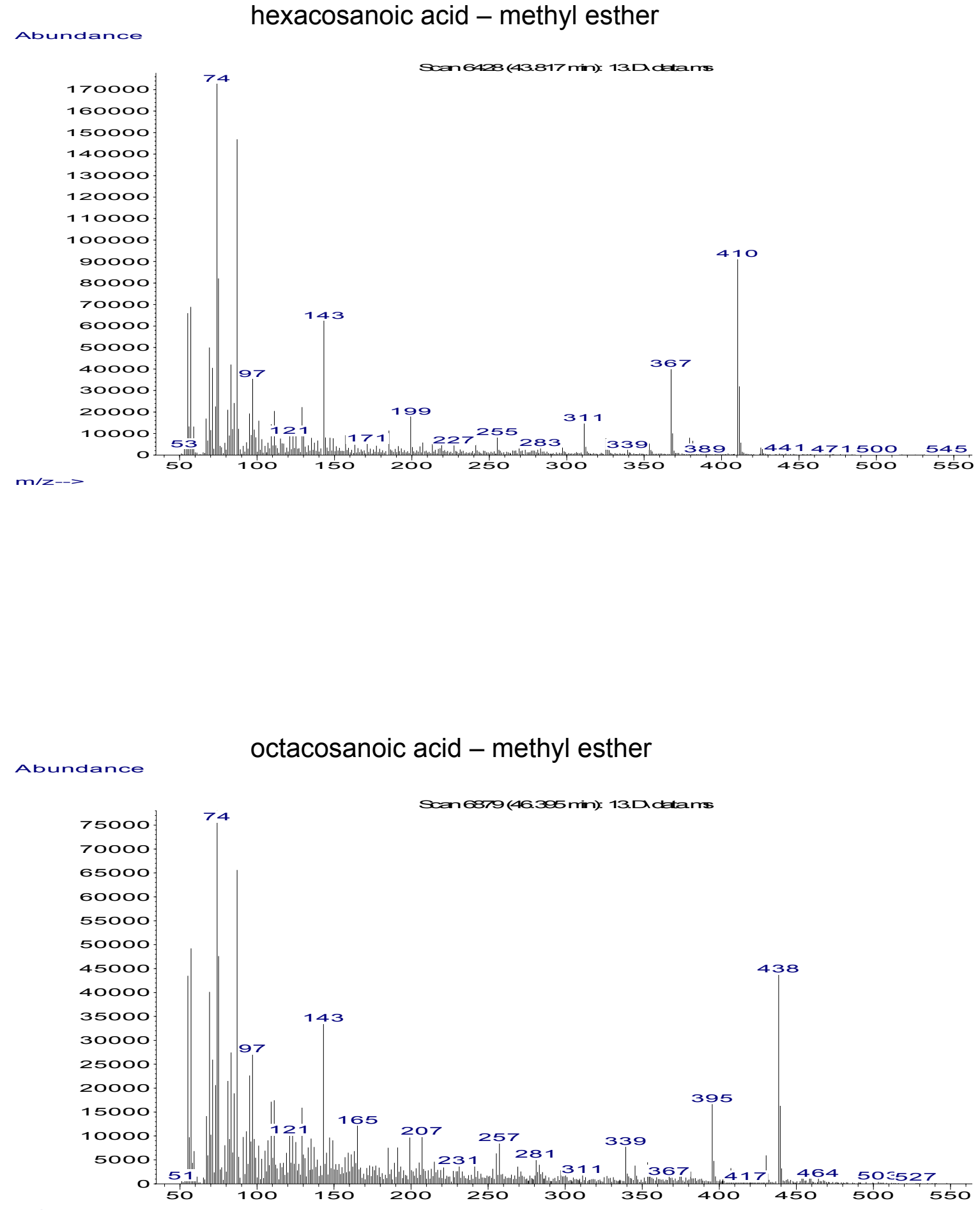
Anexo 2 (1/4): Resultados das análises do testemunho.

\begin{tabular}{|c|c|c|c|c|c|c|c|c|c|c|c|c|c|c|c|c|c|c|c|c|}
\hline $\begin{array}{l}\text { Idade } \\
\text { (anos) }\end{array}$ & $\begin{array}{c}\text { T.S. } \\
\text { (mm.ky-1) }\end{array}$ & S.M. & $\delta^{13} \mathrm{C}$ & $\begin{array}{c}\text { Alq. } \\
\text { (ng.g-1) }\end{array}$ & $\begin{array}{l}\Sigma \text { n-alc. } \\
(\mu \mathrm{g} . \mathrm{g}-1)\end{array}$ & IPC & Pri/Fit. & TAR & $\begin{array}{c}\text { TSM - USP } \\
\left({ }^{\circ} \mathrm{C}\right)\end{array}$ & $\begin{array}{c}\text { TSM - UAB } \\
\left({ }^{\circ} \mathrm{C}\right)\end{array}$ & $\begin{array}{l}\text { Clorin. } \\
408 \mathrm{~nm}\end{array}$ & $\begin{array}{l}\text { Clorin. } \\
662 \mathrm{~nm} \\
\end{array}$ & $\begin{array}{l}\text { Álc. } \\
\text { (P/L) }\end{array}$ & $\begin{array}{l}\text { Ác. } \\
\text { (P/L) }\end{array}$ & $\mathrm{C} / \mathrm{N}$ & $\begin{array}{c}\text { Alif. } \\
\text { L }\end{array}$ & $\begin{array}{c}\text { Alif. } \\
\mathbf{P} \\
\end{array}$ & $\begin{array}{c}\mathrm{R}-\mathrm{OH} \\
\mathrm{L} \\
\end{array}$ & $\begin{array}{c}\mathrm{R}-\mathrm{OH} \\
\mathrm{P} \\
\end{array}$ & $\begin{array}{c}\mathrm{R}-\mathrm{COOH} \\
\mathrm{L}\end{array}$ \\
\hline 3020 & 0,02 & 12,6 & $-21,2$ & 266,91 & 3,65 & 1,42 & 2,18 & 1,06 & 23,05 & 23,84 & 3049603 & 755171 & 0,22 & 0,06 & 6,1 & 0,29 & 0,31 & 0,56 & 0,12 & 2,07 \\
\hline 3851 & 0,03 & 12,6 & $-21,2$ & 129,29 & 2,09 & 2,31 & 1,68 & 0,14 & 24,58 & 25,35 & 1738973 & 322492 & 0,13 & 0,07 & 6,21 & 0,44 & 0,06 & 0,41 & 0,05 & 0,84 \\
\hline 4634 & 0,03 & 14,2 & -21 & 116,6 & 1,99 & 2,67 & 1,61 & 0,18 & 24,99 & 25,42 & 1203048 & 225039 & 0,11 & 0,09 & 7 & 0,38 & 0,07 & 0,50 & 0,06 & 0,59 \\
\hline 5441 & 0,02 & 15,6 & $-20,7$ & 111,33 & 1,35 & 2,05 & 1,73 & 0,34 & 23,37 & 22,64 & 1923270 & 402708 & 0,15 & 0,10 & 7,62 & 0,27 & 0,09 & 0,59 & 0,09 & 0,36 \\
\hline 6345 & 0,02 & 18,2 & $-20,9$ & 76,49 & 2,55 & 1,95 & 1,62 & 0,33 & 24,04 & 23,67 & 1645606 & 301027 & 0,21 & 0,11 & 8,34 & 0,31 & 0,10 & 0,33 & 0,07 & 0,30 \\
\hline 8709 & 0,02 & 20,3 & $-21,3$ & 208,96 & 1,74 & 2,87 & 1,97 & 0,82 & 22,65 & 22,64 & 2529972 & 465639 & 0,79 & 0,18 & 7,74 & 0,35 & 0,28 & 0,41 & 0,32 & 0,73 \\
\hline 10138 & 0,01 & 21,6 & $-20,9$ & 183,11 & 1,88 & 4 & 1,38 & 0,65 & 22,59 & 23,45 & 2648401 & 483900 & 0,47 & 0,11 & 7,6 & 0,30 & 0,20 & 0,34 & 0,16 & 0,41 \\
\hline 11603 & 0,01 & 22 & $-20,9$ & 173,18 & 1,71 & 4,29 & 1,62 & 0,82 & 21,76 & 22,74 & 3050381 & 596431 & 0,66 & 0,15 & 7,03 & 0,35 & 0,29 & 0,45 & 0,30 & 0,90 \\
\hline 13002 & 0,02 & 22,1 & $-20,7$ & 217,56 & 1,26 & 5 & 1,49 & 0,68 & 22,65 & 23,24 & 2551028 & 462965 & 0,83 & 0,19 & 6,52 & 0,31 & 0,21 & 0,35 & 0,34 & 0,50 \\
\hline 15209 & 0,02 & 22,4 & $-20,8$ & 189,95 & 2,24 & 2,39 & 1,44 & 0,98 & 22,37 & 22,21 & 3265437 & 641276 & 0,96 & 0,21 & 7,75 & 0,39 & 0,39 & 0,80 & 0,34 & 0,55 \\
\hline 15957 & 0,03 & 22,5 & $-20,7$ & 197,92 & 4,42 & 2,34 & 1,49 & 0,95 & 21,67 & 22,13 & 3164504 & 611444 & 0,42 & 0,26 & 7,07 & 0,38 & 0,36 & 0,37 & 0,30 & 0,46 \\
\hline 16517 & 0,04 & 22,6 & $-20,8$ & 184,17 & 1,89 & 4,18 & 1,37 & 0,78 & 23,02 & 22,84 & 2939807 & 539372 & 0,83 & 0,25 & 6,85 & 0,41 & 0,32 & 0,59 & 0,15 & 0,12 \\
\hline 16930 & 0,06 & 22,7 & $-20,8$ & 183,23 & 2,03 & 3,54 & 1,51 & 0,86 & 21,49 & 22,47 & 3190380 & 589072 & 0,26 & 0,11 & 6,63 & 0,40 & 0,34 & 0,36 & 0,32 & 0,09 \\
\hline 17240 & 0,07 & 22,7 & $-20,6$ & 284,48 & 1,95 & 2,77 & 1,93 & 1,38 & 22,11 & 22,79 & 3082848 & 579717 & 0,87 & 0,76 & 7,53 & 0,28 & 0,39 & 0,50 & 0,35 & 0,21 \\
\hline 17483 & 0,09 & 23,2 & $-20,8$ & 328,17 & 2,33 & 3,28 & 1,63 & 0,94 & 21,73 & 22,49 & 2817999 & 498205 & 0,70 & 0,56 & 7,23 & 0,38 & 0,36 & 0,59 & 0,43 & 0,41 \\
\hline 17672 & 0,12 & 23,8 & $-20,8$ & 395,68 & 2,37 & 1,17 & 1,65 & 1,47 & 21,18 & 22,15 & 2564963 & 507565 & 0,72 & 0,28 & 7,18 & 0,31 & 0,46 & 0,43 & 0,45 & 0,76 \\
\hline 17813 & 0,17 & 25 & -21 & 647,82 & 1,67 & 6,01 & 1,84 & 1,22 & 20,8 & 21,66 & 3457030 & 801231 & 1,05 & 0,21 & 7,43 & 0,30 & 0,36 & 0,45 & 0,34 & 0,15 \\
\hline 17915 & 0,24 & 25,4 & $-21,1$ & 418,68 & 1,24 & 8,99 & 1,69 & 1,78 & 22,12 & 22,29 & 2380700 & 419784 & 0,77 & 0,62 & 7,39 & 0,20 & 0,35 & 0,40 & 0,34 & 0,07 \\
\hline 17983 & 0,37 & 25,4 & $-20,8$ & 340,61 & 1,83 & 4,22 & 1,4 & 1,15 & 22,09 & 21,9 & 2201318 & 386039 & 0,84 & 0,89 & 7,54 & 0,32 & 0,37 & 0,64 & 0,28 & 0,08 \\
\hline 18025 & 0,64 & 24,6 & $-20,9$ & 257,46 & 1,94 & 2,84 & 1,3 & 1,71 & 21,82 & 22,09 & 2458645 & 432949 & 0,44 & 1,22 & 6,94 & 0,25 & 0,43 & 0,57 & 0,23 & 0,08 \\
\hline 18048 & 1,29 & 24,8 & $-20,7$ & 316,16 & 1,94 & 3,4 & 1,56 & 1,29 & 21,94 & 22,05 & 2719212 & 491175 & 0,41 & 0,77 & 7,41 & 0,27 & 0,34 & 0,58 & 0,39 & 0,75 \\
\hline 18058 & 3 & 25 & $-20,7$ & 380,56 & 1,83 & 3,79 & 1,49 & 1,25 & 22,23 & 22,21 & 3000463 & 578586 & 0,68 & 0,47 & 7,31 & 0,28 & 0,35 & 0,57 & 0,34 & 0,34 \\
\hline 18064 & 4,17 & 25,1 & $-20,4$ & 402,25 & 4,2 & 2,85 & 1,31 & 1,08 & 20,6 & 20,77 & 2911296 & 568425 & 0,59 & 0,40 & 7,68 & 0,30 & 0,33 & 0,17 & 0,06 & 0,03 \\
\hline 18070 & 2,03 & 25,1 & $-20,6$ & 351,48 & 1,61 & 5,81 & 1,38 & 1,49 & 22,56 & 22,51 & 3206781 & 657290 & 0,56 & 0,76 & 7,29 & 0,26 & 0,38 & 0,23 & 0,25 & 0,50 \\
\hline 18084 & 1,12 & 25,1 & $-20,6$ & 303,83 & 2,68 & 3,6 & 1,33 & 1,44 & 23,12 & 23,26 & 2167480 & 382793 & 0,35 & 1,30 & 7,78 & 0,32 & 0,45 & 0,43 & 0,50 & 0,82 \\
\hline 18105 & 0,8 & 25 & $-20,7$ & 191,52 & 3,16 & 2,22 & 1,71 & 1,04 & 22,56 & 22,85 & 2925511 & 537569 & 1,16 & 0,19 & 7,86 & 0,35 & 0,36 & 0,34 & 0,49 & 0,80 \\
\hline 18134 & 0,64 & 24,7 & $-20,7$ & 262,27 & 1,91 & 3,38 & 1,77 & 1,16 & 22,16 & 22,53 & 2328588 & 397258 & 1,45 & 0,19 & 7,49 & 0,33 & 0,38 & 0,24 & 0,33 & 0,41 \\
\hline 18167 & 0,55 & 25,2 & $-20,6$ & 165,94 & 1,38 & 3,35 & 1,88 & 1,02 & 22,07 & 22,43 & 2130295 & 344945 & 1,37 & 0,27 & 8,02 & 0,28 & 0,29 & 0,40 & 0,41 & 0,90 \\
\hline 18206 & 0,5 & 25,2 & $-20,6$ & 150,71 & 2,62 & 1,75 & 1,76 & 1,46 & 21,71 & 21,75 & 2620133 & 489411 & 1,02 & 0,17 & 8,23 & 0,39 & 0,57 & 0,32 & 0,57 & 0,99 \\
\hline 18248 & 0,46 & 26,1 & $-21,1$ & 188,61 & 1,65 & 3,64 & 1,93 & 1,15 & 22,23 & 22,33 & 2893925 & 534296 & 1,79 & 0,34 & 7,88 & 0,31 & 0,36 & 0,34 & 0,47 & 0,71 \\
\hline 18292 & 0,44 & 26,7 & -21 & 215,17 & 2,71 & 1,82 & 0,53 & 1,21 & 22,09 & 22,08 & 2681920 & 487539 & 1,37 & 0,19 & 8,16 & 0,34 & 0,41 & 0,34 & 0,39 & 0,84 \\
\hline
\end{tabular}


(1/4)

\begin{tabular}{|c|c|c|c|c|c|c|c|c|c|c|c|c|c|c|c|}
\hline $\begin{array}{l}\text { Idade } \\
\text { (anos) }\end{array}$ & $\begin{array}{c}\mathrm{R}-\mathrm{COOH} \\
\mathbf{P} \\
\end{array}$ & (Al) & (Ba) & $\begin{array}{c}\text { (Ca) } \\
\mu \mathrm{g} \cdot \mathrm{g}^{-1} \\
\end{array}$ & $(\mathrm{Sr})$ & $(\mathrm{Fe})$ & (Ti) & $\mathrm{Ba} / \mathrm{Al}$ & $\mathrm{Ba} / \mathrm{Ti}$ & $\mathrm{Ba} / \mathrm{Ca}$ & $\mathrm{Al} / \mathrm{Ti}$ & $\mathrm{Sr} / \mathrm{Ti}$ & $\mathrm{Sr} / \mathrm{Ca}$ & $\mathrm{Fe} / \mathrm{Ca}$ & $\mathrm{Ti} / \mathrm{Ca}$ \\
\hline 3020 & 0,12 & 7118 & 19,8 & 71300 & 388 & 9920 & 204 & 0,0028 & 0,0971 & 0,0003 & 34,89 & 1,902 & 0,005 & 0,139 & 0,0029 \\
\hline 3851 & 0,06 & 9196 & 14 & 78842 & 442 & 10478 & 255 & 0,0015 & 0,0549 & 0,0002 & 36,06 & 1,733 & 0,006 & 0,133 & 0,0032 \\
\hline 4634 & 0,05 & 7414 & 11,4 & 82279 & 438 & 9730 & 202 & 0,0015 & 0,0564 & 0,0001 & 36,7 & 2,168 & 0,005 & 0,118 & 0,0025 \\
\hline 5441 & 0,04 & 7243 & 11,3 & 85984 & 462 & 9847 & 193 & 0,0016 & 0,0585 & 0,0001 & 37,53 & 2,394 & 0,005 & 0,115 & 0,0022 \\
\hline 6345 & 0,03 & 6632 & 10,3 & 72647 & 387 & 8548 & 179 & 0,0016 & 0,0575 & 0,0001 & 37,05 & 2,162 & 0,005 & 0,118 & 0,0025 \\
\hline 8709 & 0,13 & 9425 & 13,3 & 58311 & 354 & 13517 & 200 & 0,0014 & 0,0665 & 0,0002 & 47,13 & 1,77 & 0,006 & 0,232 & 0,0034 \\
\hline 10138 & 0,05 & 15454 & 19,1 & 48731 & 346 & 21186 & 249 & 0,0012 & 0,0767 & 0,0004 & 62,06 & 39 &, 007 & ,435 & 0,0051 \\
\hline 11603 & 0,13 & 11123 & 20,9 & 48276 & 342 & 14820 & 233 & 0,0019 & 0,0897 & 0,0004 & 47,74 & 1,468 & 0,007 & 0,307 & 0,0048 \\
\hline 13002 & 0,10 & 11328 & 16,1 & 47328 & 340 & 17192 & 228 & 0,0014 & 0,0706 & 0,0003 & 49,68 & 1,491 & 0,007 & 0,363 & 0,0048 \\
\hline 15209 & 0,14 & 13681 & 17,8 & 49311 & 370 & 19986 & 246 & 0,0013 & 0,0724 & 0,0004 & 55,61 & 1,504 & 0,008 & 0,405 & 0,005 \\
\hline 15957 & 0,11 & 17489 & 20,6 & 44307 & 331 & 21249 & 308 & 0,0012 & 0,0669 & 0,0005 & 56,78 & 1,075 & 0,007 & 0,48 & 0,007 \\
\hline 16517 & 0,01 & 16466 & 20,6 & 35728 & 295 & 19410 & 295 & 0,0013 & 0,0698 & 0,0006 & 55,82 & 1 & 0,008 &, 543 & 0,0083 \\
\hline 16930 & 0,07 & 14275 & 18,1 & 41352 & 305 & 20784 & 301 & 0,0013 & 0,0601 & 0,0004 & 47,43 & 1,013 & 0,007 & 0,503 & 0,0073 \\
\hline 17240 & 0,12 & 12597 & 16,5 & 32402 & 250 & 17153 & 262 & & & & & 0,954 & 008 & 29 & 081 \\
\hline 17483 & 0,11 & 13593 & 17,9 & 35711 & 282 & 19823 & 219 & 0,0013 & 0,0817 & 0,0005 & 62,07 & 1,288 & 0,008 & 0,555 & 0,0061 \\
\hline 17672 & 0,16 & 11498 & 17 & 32754 & 252 & 17458 & 268 & 0,0015 & 0,0634 & 0,0005 & 42,9 & 0,94 & 0,008 & 0,533 & 0,0082 \\
\hline 17813 & 0,09 & 14160 & 18,3 & 42060 & 318 & 20303 & 263 & 0,0013 & 0,0696 & 0,0004 & 53,84 & 1,209 & 0,008 & 0,483 & 0,0063 \\
\hline 17915 & 0,06 & 10196 & 14,2 & 33988 & 250 & 14422 & 158 & 0,0014 & 0,0899 & 0,0004 & 64,53 & 1,582 & 0,007 & 0,424 & 0,0046 \\
\hline 17983 & 0,09 & 11590 & 16,7 & 35829 & 275 & 17011 & 259 & 0,0014 & 0,0645 & 0,0005 & 44,75 & 1,062 & 0,008 & 0,475 & 0,0072 \\
\hline 18025 & 0,06 & 11345 & 16,2 & 33332 & 261 & 16233 & 250 & 0,0014 & 0,0648 & 0,0005 & 45,38 & 1,044 & 0,008 & 0,487 & 0,0075 \\
\hline 18048 & 0,35 & 14887 & 19,6 & 37920 & 288 & 19961 & 277 & 0,0013 & 0,0708 & 0,0005 & 53,74 & 1,04 & 0,008 & 0,526 & 0,0073 \\
\hline 18058 & 0,14 & 13124 & 17,4 & 32640 & 251 & 17896 & 277 & 0,0013 & 0,0628 & 0,0005 & 47,38 & 0,906 & 0,008 & 0,548 & 0,0085 \\
\hline 18064 & 0,03 & 12057 & 17,1 & 34133 & 261 & 17675 & 247 & 0,0014 & 0,0692 & 0,0005 & 48,81 & 1,057 & 0,008 & 0,518 & 0,0072 \\
\hline 18070 & 0,16 & 12015 & 17,2 & 36295 & 279 & 18392 & 256 & 0,0014 & 0,0672 & 0,0005 & 46,93 & 1,09 & 0,008 & 0,507 & 0,0071 \\
\hline 18084 & 0,16 & 10895 & 16,1 & 31394 & 238 & 16868 & 238 & 0,0015 & 0,0676 & 0,0005 & 45,78 & 1 & 0,008 & 0,537 & 0,0076 \\
\hline 18105 & 0,15 & 9894 & 19,7 & 31332 & 242 & 15240 & 182 & 0,002 & 0,1082 & 0,0006 & 54,36 & 1,33 & 0,008 & 0,486 & 0,0058 \\
\hline 18134 & 0,11 & 10325 & 16,4 & 35491 & 262 & 16439 & 240 & 0,0016 & 0,0683 & 0,0005 & 43,02 & 1,092 & 0,007 & 0,463 & 0,0068 \\
\hline 18167 & 0,16 & 12369 & 16,1 & 33575 & 245 & 17228 & 252 & 0,0013 & 0,0639 & 0,0005 & 49,08 & 0,972 & 0,007 & 0,513 & 0,0075 \\
\hline 18206 & 0,34 & 11635 & 15,6 & 31733 & 232 & 15877 & 250 & 0,0013 & 0,0624 & 0,0005 & 46,54 & 0,928 & 0,007 & 0,5 & 0,0079 \\
\hline 18248 & 0,13 & 11865 & 15,9 & 31212 & 226 & 17022 & 226 & 0,0013 & 0,0704 & 0,0005 & 52,5 & 1 & 0,007 & 0,545 & 0,0072 \\
\hline 18292 & 0,18 & 11180 & 15,8 & 37964 & 285 & 16935 & 226 & 0,0014 & 0,0699 & 0,0004 & 49,47 & 1,261 & 0,008 & 0,446 & 0,006 \\
\hline
\end{tabular}


(2/4)

\begin{tabular}{|c|c|c|c|c|c|c|c|c|c|c|c|c|c|c|c|c|c|c|c|c|}
\hline $\begin{array}{l}\text { Idade } \\
\text { (anos) }\end{array}$ & $\begin{array}{c}\text { T.S. } \\
\text { (mm.ky-1) }\end{array}$ & S.M. & $\delta^{13} \mathrm{C}$ & $\begin{array}{c}\text { Alq. } \\
\text { (ng.g-1) }\end{array}$ & $\begin{array}{c}\Sigma \text { n-alc. } \\
(\mu \mathrm{g} \cdot \mathrm{g}-1)\end{array}$ & IPC & Pri/Fit. & TAR & $\begin{array}{c}\text { TSM - USP } \\
\left({ }^{\circ} \mathrm{C}\right)\end{array}$ & $\begin{array}{c}\text { TSM - UAB } \\
\left({ }^{\circ} \mathrm{C}\right)\end{array}$ & $\begin{array}{l}\text { Clorin. } \\
408 \mathrm{~nm}\end{array}$ & $\begin{array}{l}\text { Clorin. } \\
662 \mathrm{~nm}\end{array}$ & $\begin{array}{l}\text { Álc. } \\
\text { (P/L) }\end{array}$ & $\begin{array}{l}\text { Ác. } \\
\text { (P/L) }\end{array}$ & $C / N$ & $\begin{array}{c}\text { Alif. } \\
\text { L }\end{array}$ & $\begin{array}{c}\text { Alif. } \\
\text { P }\end{array}$ & $\begin{array}{c}\mathrm{R}-\mathrm{OH} \\
\mathrm{L} \\
\end{array}$ & $\begin{array}{c}\mathrm{R}-\mathrm{OH} \\
\mathbf{P} \\
\end{array}$ & $\begin{array}{c}\mathrm{R}-\mathrm{COOH} \\
\mathrm{L}\end{array}$ \\
\hline 18339 & 0,43 & 26,1 & $-20,9$ & 220,04 & 2,43 & 2,76 & 1,95 & 0,84 & 22,65 & 22,85 & 2506703 & 423256 & 1,14 & 0,22 & 7,73 & 0,31 & 0,26 & 0,36 & 0,35 & 0,98 \\
\hline 18385 & 0,43 & 24,8 & $-20,4$ & 197,7 & 3,48 & 2,04 & 1,84 & 0,9 & 22,52 & 22,79 & 2621910 & 443210 & 0,96 & 0,15 & 7,33 & 0,37 & 0,33 & 0,25 & 0,39 & 0,98 \\
\hline 18432 & 0,43 & 24,8 & -21 & 131,72 & 3,2 & 1,34 & 1,11 & 1,75 & 21,57 & 22 & 2376142 & 428490 & 1,56 & 0,15 & 7,39 & 0,39 & 0,68 & 0,35 & 0,44 & 0,77 \\
\hline 18477 & 0,45 & 24,6 & $-20,9$ & 186,17 & 1,76 & 2,41 & 1,74 & 1,06 & 22 & 22,08 & 2934798 & 687156 & 1,27 & 0,17 & 7,29 & 0,33 & 0,35 & 0,29 & 0,41 & 0,62 \\
\hline 18520 & 0,48 & 24,2 & $-20,8$ & 191,48 & 2,01 & 2,71 & 1,92 & 0,8 & 22,62 & 22,66 & 2537188 & 458174 & 1,41 & 0,22 & 7,92 & 0,32 & 0,26 & 0,36 & 0,33 & 1,35 \\
\hline 18560 & 0,53 & 23,9 & $-20,6$ & 197,08 & 1,76 & 4 & 2,45 & 1,5 & 22,79 & 22,83 & 2175125 & 377083 & 0,92 & 0,11 & 7,64 & 0,27 & 0,41 & 0,47 & 0,27 & 1,00 \\
\hline 18596 & 0,59 & 23,6 & $-20,9$ & 161,66 & 2,15 & 2,06 & 1,92 & 0,9 & 22,37 & 22,93 & 2333252 & 350173 & 0,58 & 0,09 & 8,59 & 0,36 & 0,32 & 0,38 & 0,37 & 0,60 \\
\hline 18628 & 0,66 & 23,6 & $-20,7$ & 195,28 & 1,93 & 2,58 & 2,45 & 0,76 & 21,17 & 22,81 & 2630910 & 430487 & 0,98 & 0,17 & 8,54 & 0,38 & 0,29 & 0,49 & 0,39 & 0,80 \\
\hline 18656 & 0,73 & 28,7 & $-20,7$ & 201,33 & 4,17 & 1,7 & 1,86 & 0,78 & 21,7 & 22,47 & 2431921 & 410981 & 0,79 & 0,15 & 8,51 & 0,41 & 0,32 & 0,58 & 0,51 & 1,01 \\
\hline 18683 & 0,79 & 28,5 & $-20,4$ & 268 & 2,51 & 2,08 & 2,66 & 1 & 21,93 & 22,13 & 2175006 & 383366 & 0,88 & 0,16 & 8,01 & 0,34 & 0,34 & 0,43 & 0,44 & 1,04 \\
\hline 18707 & 0,85 & 28,3 & $-20,6$ & 176,21 & 1,74 & 2,59 & 2,23 & 0,79 & 23,26 & 23,53 & 2404442 & 403164 & 1,02 & 0,14 & 8,59 & 0,33 & 0,26 & 0,47 & 0,46 & 0,64 \\
\hline 18730 & 0,88 & 28,1 & $-20,7$ & 198,51 & 1,47 & 3,21 & 2,01 & 0,91 & 22,65 & 22,88 & 3393921 & 617268 & 0,97 & 0,24 & 8,78 & 0,31 & 0,28 & 0,53 & 0,43 & 0,97 \\
\hline 18753 & 0,9 & 28,1 & $-20,7$ & 200,29 & 2,27 & 2,03 & 2,37 & 1,09 & 22,46 & 23,42 & 2803207 & 459281 & 0,82 & 0,20 & 8,14 & 0,34 & 0,38 & 0,28 & 0,36 & 0,98 \\
\hline 18775 & 0,9 & 27,7 & $-20,6$ & 224,88 & 1,34 & 3,94 & 1,94 & 0,86 & 21,79 & 23,22 & 2459676 & 388742 & 1,27 & 0,10 & 7,63 & 0,27 & 0,23 & 0,40 & 0,33 & 0,78 \\
\hline 18797 & 0,87 & 27,1 & $-20,5$ & 217,91 & 1,64 & 2,94 & 1,96 & 0,91 & 23,02 & 22,91 & 3139175 & 577607 & 0,83 & 0,17 & 8,14 & 0,30 & 0,28 & 0,70 & 0,40 & 0,88 \\
\hline 18821 & 0,82 & 26,9 & $-20,6$ & 232,36 & 4,97 & 1,69 & 1,92 & 0,95 & 22,4 & 22,53 & 2790150 & 440530 & 0,57 & 0,17 & 7,78 & 0,43 & 0,41 & 0,63 & 0,42 & 0,86 \\
\hline 18846 & 0,76 & 27,1 & $-20,6$ & 218,36 & 4,21 & 1,61 & 1,77 & 1,13 & 21,92 & 22,25 & 3013272 & 509607 & 0,66 & 0,19 & 7,98 & 0,36 & 0,41 & 0,42 & 0,37 & 0,60 \\
\hline 18874 & 0,7 & 27,1 & $-20,4$ & 241,85 & 1,64 & 3,24 & 2,4 & 0,9 & 22,46 & 22,99 & 2205033 & 352504 & 0,88 & 0,18 & 8,19 & 0,33 & 0,30 & 0,31 & 0,28 & 1,03 \\
\hline 18904 & 0,63 & 27,2 & $-20,5$ & 275 & 2,82 & 2,43 & 2,06 & 1,04 & 21,55 & 22,26 & 2739292 & 453298 & 0,93 & 0,15 & 8,38 & 0,35 & 0,37 & 0,54 & 0,35 & 1,00 \\
\hline 18938 & 0,56 & 26,7 & $-20,7$ & 219,15 & 4,18 & 1,72 & 2,21 & 0,92 & 22 & 22,12 & 2887187 & 454987 & 0,65 & 0,19 & 8,15 & 0,40 & 0,37 & 0,40 & 0,34 & 1,13 \\
\hline 18975 & 0,5 & 26,5 & $-20,4$ & 221,18 & 1,77 & 2,8 & 1,75 & 1,03 & 22,13 & 22,12 & 2429898 & 355096 & 0,85 & 0,16 & 8,08 & 0,33 & 0,34 & 0,35 & 0,39 & 1,18 \\
\hline 19018 & 0,45 & 26,7 & $-20,6$ & 212,48 & 2,22 & 2,66 & 2,43 & 0,79 & 22,75 & 22,46 & 2624776 & 405725 & 1,12 & 0,19 & 7,87 & 0,37 & 0,29 & 0,39 & 0,41 & 0,98 \\
\hline 19065 & 0,4 & 26,7 & $-20,2$ & 229,85 & 1,69 & 2,88 & 2,09 & 0,98 & 22,01 & 22,62 & 2781673 & 457572 & 1,04 & 0,17 & 8,11 & 0,31 & 0,30 & 0,40 & 0,45 & 0,77 \\
\hline 19118 & 0,36 & 26,8 & $-20,5$ & 290,43 & 2,14 & 2,73 & 2,55 & 1,06 & 22,03 & 22,69 & 2242848 & 346342 & 1,11 & 0,20 & 7,36 & 0,35 & 0,37 & 0,56 & 0,46 & 1,34 \\
\hline 19177 & 0,32 & 26,7 & $-20,5$ & 221,4 & 1,69 & 3,13 & 2,22 & 0,81 & 23,06 & 23,63 & 2684748 & 445473 & 0,81 & 0,14 & 7,52 & 0,39 & 0,32 & 0,37 & 0,37 & 1,02 \\
\hline 19244 & 0,29 & 26,8 & $-20,4$ & 216,45 & 1,69 & 3,13 & 2,22 & 0,81 & 22,19 & 23,01 & 2558780 & 417313 & 1,01 & 0,18 & 7,26 & 0,39 & 0,32 & 0,43 & 0,34 & 1,13 \\
\hline 19318 & 0,26 & 27,2 & $-20,4$ & 210,84 & 1,83 & 2,35 & 1,83 & 1,23 & 22,72 & 21,93 & 1982808 & 292183 & 0,79 & 0,14 & 7,37 & 0,33 & 0,41 & 0,49 & 0,36 & 1,12 \\
\hline 19400 & 0,23 & 27,2 & $-20,5$ & 160,15 & 2,21 & 2,2 & 2,02 & 1 & 22,64 & 21,88 & 1276502 & 181206 & 0,74 & 0,16 & 7,72 & 0,29 & 0,29 & 0,31 & 0,44 & 0,96 \\
\hline 19490 & 0,21 & 28,2 & $-20,4$ & 188,1 & 1,92 & 1,96 & 1,99 & 0,93 & 22,98 & 23,31 & 2266030 & 375313 & 1,45 & 0,19 & 7,79 & 0,32 & 0,29 & 0,54 & 0,25 & 0,70 \\
\hline 19590 & 0,19 & 30,2 & $-20,9$ & 197,1 & 1,27 & 3,4 & 1,83 & 0,83 & 22,56 & 23,19 & 2496556 & 452304 & 0,45 & 0,13 & 8,41 & 0,29 & 0,24 & 0,37 & 0,32 & 0,62 \\
\hline 19700 & 0,17 & 32,3 & $-20,9$ & 197,88 & 3,94 & 1,89 & 2,25 & 0,97 & 23,16 & 23,48 & 3146768 & 608250 & 0,85 & 0,21 & 7,88 & 0,32 & 0,31 & 0,29 & 0,32 & 0,24 \\
\hline 19820 & 0,16 & 32,2 & $-20,6$ & 228,32 & 1,49 & 3,53 & 2,4 & 0,77 & 22,32 & 21,94 & 2761413 & 496209 & 1,12 & 0,50 & 7,79 & 0,35 & 0,27 & 0,25 & 0,37 & 0,58 \\
\hline
\end{tabular}


(2/4)

\begin{tabular}{|c|c|c|c|c|c|c|c|c|c|c|c|c|c|c|c|}
\hline $\begin{array}{l}\text { Idade } \\
\text { (anos) }\end{array}$ & $\begin{array}{c}\mathrm{R}-\mathrm{COOH} \\
\mathbf{P} \\
\end{array}$ & (Al) & (Ba) & $\begin{array}{c}\text { (Ca) } \\
\mu \mathrm{g} \cdot \mathrm{g}^{-1}\end{array}$ & $(\mathrm{Sr})$ & $(\mathrm{Fe})$ & (Ti) & $\mathrm{Ba} / \mathrm{Al}$ & $\mathrm{Ba} / \mathrm{Ti}$ & $\mathrm{Ba} / \mathrm{Ca}$ & $\mathrm{Al} / \mathrm{Ti}$ & $\mathrm{Sr} / \mathrm{Ti}$ & $\mathrm{Sr} / \mathrm{Ca}$ & $\mathrm{Fe} / \mathrm{Ca}$ & $\mathrm{Ti} / \mathrm{Ca}$ \\
\hline 18339 & 0,15 & 11961 & 16,8 & 33867 & 263 & 17170 & 240 & 0,0014 & 0,07 & 0,0005 & 49,84 & 1,096 & 0,008 &, 507 & 0,0071 \\
\hline 18385 & 0,15 & 10494 & 15,9 & 36653 & 270 & 15700 & 215 & 0,0015 & 0,074 & 0,0004 & 48,81 & 1,256 & 0,007 & 0,428 & ,0059 \\
\hline 18432 & 0,13 & 9143 & 13,5 & 33480 & 243 & 13632 & 191 & 0,0015 & 0,0707 & 0,0004 & 47,87 & 1,272 & 0,007 & 0,407 & 0,0057 \\
\hline 18477 & 0,13 & 10648 & 15,3 & 31554 & 240 & 15709 & 210 & 0,0014 & 0,0729 & 0,0005 & 50,7 & 1,143 & 0,008 & 0,498 & 0,0067 \\
\hline 18520 & 0,15 & 9145 & 13,7 & 34653 & 238 & 14019 & 178 & 0,0015 & 0,077 & 0,0004 & 51,38 & 1,337 & 0,007 & 405 & 0051 \\
\hline 18560 & 0,09 & 12207 & 16,4 & 31055 & 239 & 17256 & 212 & 0,0013 & 0,0774 & 0,0005 & 57,58 & 1,127 & 0,008 & 0,556 & 0,0068 \\
\hline 18596 & 0,10 & 9727 & 14,7 & 32849 & 236 & 14588 & 227 & 0,0015 & 0,0648 & 0,0004 & 42,85 & 1,04 & 0,007 & 0,444 & ,0069 \\
\hline 18628 & 0,12 & 13697 & 19,2 & 42047 & 314 & 18725 & 252 & 0,0014 & 0,0762 & 0,0005 & 54,35 & 1,246 & 0,007 & 0,445 & 0,006 \\
\hline 18656 & 0,16 & 10553 & 16,2 & 36312 & 284 & 15155 & 198 & 0,0015 & 0,0818 & 0,0004 & 53,3 & 1,434 & 0,008 & 0,417 & 0,0055 \\
\hline 18683 & 0,15 & 11854 & 15,9 & 31822 & 237 & 16767 & 209 & 0,0013 & 0,0761 & 0,0005 & 56,72 & 1,134 & 0,007 & 0,527 & 0,0066 \\
\hline 18707 & 0,15 & 10213 & 15,7 & 36206 & 259 & 16684 & 192 & 0,0015 & 0,0818 & 0,0004 & 53,19 & 1,349 & 0,007 & 0,461 & 0,0053 \\
\hline 18730 & 0,19 & 10110 & 15,7 & 40777 & 284 & 17229 & 235 & 0,0016 & 0,0668 & 0,0004 & 43,02 & 1,209 & 0,007 & 423 & 0058 \\
\hline 18753 & 0,10 & 12158 & 16,9 & 40906 & 284 & 18358 & 252 & 0,0014 & 0,0671 & 0,0004 & 48,25 & 1,127 & 0,007 & 0,449 & 0,0062 \\
\hline 18775 & 0,13 & 11370 & 16,7 & 42233 & 302 & 19858 & 261 & 0,0015 & 0,064 & 0,0004 & 43,56 & 1,157 & 0,007 &, 47 & 0,0062 \\
\hline 18797 & 0,15 & 12642 & 17,3 & 41196 & 281 & 20279 & 255 & 0,0014 & 0,0678 & 0,0004 & 49,58 & 1,102 & 0,007 & 0,492 & 0,0062 \\
\hline 18821 & 0,16 & 10915 & 16,7 & 41410 & 294 & 18869 & 217 & 0,0015 & 0,077 & 0,0004 & 50,3 & 1,355 & 0,007 & 0,456 & 0,0052 \\
\hline 18846 & 0,11 & 10240 & 14,7 & 35925 & 249 & 16593 & 210 & 0,0014 & 0,07 & 0,0004 & 48,76 & 1,186 & 0,007 & 0,462 & 0,0058 \\
\hline 18874 & 0,15 & 9730 & 14,1 & 37186 & 247 & 15909 & 178 & 0,0014 & 0,0792 & 0,0004 & 54,66 & 1,388 & 0,007 & 0,428 & 0,0048 \\
\hline 18904 & 0,19 & 9050 & 15,1 & 43382 & 299 & 17283 & 216 & 0,0017 & 0,0699 & 0,0003 & 41,9 & 1,384 & 0,007 & 0,398 & 0,005 \\
\hline 18938 & 0,18 & 9693 & 14,7 & 43910 & 302 & 18274 & 214 & 0,0015 & 0,0687 & 0,0003 & 45,29 & 1,411 & 0,007 & 0,416 & 0,0049 \\
\hline 18975 & 0,23 & 12027 & 17,5 & 49687 & 337 & 19542 & 228 & 0,0015 & 0,0768 & 0,0004 & 52,75 & 1,478 & 0,007 & 0,393 & 0,0046 \\
\hline 19018 & 0,17 & 11873 & 17,6 & 42829 & 311 & 18784 & 259 & 0,0015 & 0,068 & 0,0004 & 45,84 & 1,201 & 0,007 & 0,439 & 0,006 \\
\hline 19065 & 0,16 & 8701 & 14,3 & 38272 & 267 & 15195 & 190 & 0,0016 & 0,0753 & 0,0004 & 45,79 & 1,405 & 0,007 & 0,397 & 0,005 \\
\hline 19118 & 0,19 & 12156 & 17,6 & 45461 & 311 & 19007 & 238 & 0,0014 & 0,0739 & 0,0004 & 51,08 & 1,307 & 0,007 & 0,418 & 0,0052 \\
\hline 19177 & 0,18 & 10569 & 15,9 & 45335 & 302 & 18825 & 203 & 0,0015 & 0,0783 & 0,0004 & 52,06 & 1,488 & 0,007 & 0,415 & 0,0045 \\
\hline 19244 & 0,16 & 10305 & 14,8 & 44167 & 277 & 17015 & 203 & 0,0014 & 0,0729 & 0,0003 & 50,76 & 1,365 & 0,006 & 0,385 & 0,0046 \\
\hline 19318 & 0,18 & 7937 & 13,9 & 40699 & 286 & 14634 & 220 & 0,0018 & 0,0632 & 0,0003 & 36,08 & 1,3 & 0,007 & 0,36 & 0,0054 \\
\hline 19400 & 0,18 & 11285 & 15,7 & 44209 & 267 & 18277 & 249 & 0,0014 & 0,0631 & 0,0004 & 45,32 & 1,072 & 0,006 & 0,413 & 0,0056 \\
\hline 19490 & 0,09 & 9610 & 14,7 & 49420 & 306 & 16685 & 229 & 0,0015 & 0,0642 & 0,0003 & 41,97 & 1,336 & 0,006 & 0,338 & 0,0046 \\
\hline 19590 & 0,13 & 8661 & 13,3 & 41511 & 263 & 14613 & 192 & 0,0015 & 0,0693 & 0,0003 & 45,11 & 1,37 & 0,006 & 0,352 & 0,0046 \\
\hline 19700 & 0,12 & 10802 & 16,4 & 51090 & 336 & 19008 & 242 & 0,0015 & 0,0678 & 0,0003 & 44,64 & 1,388 & 0,007 & 0,372 & 0,0047 \\
\hline 19820 & 0,15 & 10227 & 15,1 & 47317 & 308 & 17531 & 210 & 0,0015 & 0,0719 & 0,0003 & 48,7 & 1,467 & 0,007 & 0,371 & 0,0044 \\
\hline
\end{tabular}




\begin{tabular}{|c|c|c|c|c|c|c|c|c|c|c|c|c|c|c|c|c|c|c|c|c|}
\hline $\begin{array}{l}\text { Idade } \\
\text { (anos) }\end{array}$ & $\begin{array}{c}\text { T.S. } \\
\text { (mm.ky-1) }\end{array}$ & S.M. & $\delta^{13} \mathrm{C}$ & $\begin{array}{c}\text { Alq. } \\
\text { (ng.g-1) }\end{array}$ & $\begin{array}{l}\Sigma \text { n-alc. } \\
(\mu \mathbf{g} \cdot \mathbf{g}-1)\end{array}$ & IPC & Pri/Fit. & TAR & $\begin{array}{c}\text { TSM - USP } \\
\left({ }^{\circ} \mathrm{C}\right)\end{array}$ & $\begin{array}{c}\text { TSM - UAB } \\
\left({ }^{\circ} \mathrm{C}\right)\end{array}$ & $\begin{array}{l}\text { Clorin. } \\
408 \mathrm{~nm}\end{array}$ & $\begin{array}{l}\text { Clorin. } \\
662 \mathrm{~nm} \\
\end{array}$ & $\begin{array}{l}\text { Álc. } \\
\text { (P/L) }\end{array}$ & $\begin{array}{l}\text { Ác. } \\
\text { (P/L) }\end{array}$ & $C / N$ & $\begin{array}{c}\text { Alif. } \\
\text { L }\end{array}$ & $\begin{array}{c}\text { Alif. } \\
\mathbf{P}\end{array}$ & $\begin{array}{c}\mathrm{R}-\mathrm{OH} \\
\mathrm{L}\end{array}$ & $\begin{array}{c}\mathrm{R}-\mathrm{OH} \\
\mathrm{P}\end{array}$ & $\begin{array}{c}\text { R- } \\
\text { COOH } \\
L \\
\end{array}$ \\
\hline 19950 & 0,15 & 32,2 & $-20,5$ & 250,99 & 1,53 & 2,9 & 1,85 & 2,46 & 22,64 & 23,02 & 2584929 & 460431 & 1,49 & 0,26 & 7,95 & 0,28 & 0,32 & 0,36 & 0,39 & 0,53 \\
\hline 20091 & 0,14 & 30,5 & $-20,3$ & 164,84 & 4,49 & 1,07 & 2,25 & 1,14 & 22,27 & 22,1 & 3311556 & 627581 & 1,06 & 0,29 & 7,79 & 0,36 & 0,87 & 0,39 & 0,40 & 0,78 \\
\hline 20240 & 0,13 & 27 & $-20,5$ & 202,69 & 1,9 & 2,25 & 1,85 & 1,08 & 22,15 & 22,11 & 2908661 & 509136 & 1,02 & 0,18 & 7,62 & 0,35 & 0,38 & 0,39 & 0,39 & 0,84 \\
\hline 20400 & 0,12 & 26,1 & $-20,2$ & 239,87 & 1,92 & 2,21 & 2,18 & 1,3 & 22,1 & 22,25 & 2884533 & 485831 & 0,99 & 0,16 & 7,13 & 0,32 & 0,42 & 0,24 & 0,38 & 0,87 \\
\hline 20568 & 0,12 & 25,8 & $-20,4$ & 320,05 & 2,03 & 2,78 & 2 & 0,93 & 22,11 & 21,87 & 2622417 & 421451 & 1,56 & 0,16 & 7,49 & 0,37 & 0,35 & 0,26 & 0,34 & 0,50 \\
\hline 20745 & 0,11 & 25,8 & $-20,3$ & 167,15 & 1,74 & 2,12 & 2,11 & 0,73 & 22,32 & 21,73 & 2376336 & 343118 & 1,30 & 0,20 & 7,7 & 0,34 & 0,25 & 0,31 & 0,35 & 0,64 \\
\hline 20930 & 0,11 & 26 & $-20,3$ & 183,13 & 1,54 & 1,99 & 2,02 & 0,89 & 21,93 & 20,97 & 2516258 & 395347 & 1,11 & 0,25 & 7,64 & 0,31 & 0,27 & 0,44 & 0,38 & 0,42 \\
\hline 21123 & 0,1 & 25,9 & $-20,2$ & 170,69 & 1,6 & 1,69 & 2,38 & 0,8 & 21,27 & 22,13 & 2901884 & 470060 & 0,86 & 0,44 & 7,93 & 0,34 & 0,27 & 0,44 & 0,38 & 0,41 \\
\hline 21325 & 0,1 & 26 & $-20,4$ & 194,02 & 1,47 & 1,95 & 1,97 & 0,88 & 22,28 & 21,78 & 2490743 & 400718 & 0,86 & 0,45 & 8,2 & 0,28 & 0,24 & 0,23 & 0,30 & 1,01 \\
\hline 21534 & 0,09 & 26,2 & $-20,6$ & 126,6 & 1,95 & 1,32 & 2,37 & 1,01 & 21,89 & 21,77 & 2134851 & 313896 & 1,32 & 0,18 & 8,07 & 0,31 & 0,31 & 0,27 & 0,34 & 0,34 \\
\hline 21750 & 0,09 & 26,2 & $-20,5$ & 181,73 & 1,54 & 2,06 & 1,53 & 0,66 & 21,13 & 21,56 & 2273427 & 344427 & 1,23 & 0,25 & 8,22 & 0,32 & 0,21 & 0,25 & 0,32 & 0,43 \\
\hline 21974 & 0,09 & 26,2 & $-20,3$ & 135,37 & 1,79 & 1,77 & 2,01 & 1,07 & 23,07 & 22,36 & 2167698 & 349180 & 0,95 & 0,15 & 8,54 & 0,25 & 0,27 & 0,20 & 0,15 & 0,64 \\
\hline 22208 & 0,08 & 26,8 & $-20,1$ & 217,04 & 1,35 & 2,89 & 1,97 & 0,69 & 22,91 & 22,78 & 2280201 & 353218 & 0,74 & 0,11 & 8,31 & 0,33 & 0,23 & 0,31 & 0,36 & 0,40 \\
\hline 22456 & 0,08 & 27,8 & $-20,4$ & 249,91 & 2,28 & 2,15 & 2,19 & 1,34 & 22,02 & 21,58 & 2704506 & 450550 & 1,14 & 0,19 & 7,81 & 0,39 & 0,52 & 0,33 & 0,39 & 0,42 \\
\hline 22721 & 0,07 & 28 & $-20,5$ & 249,91 & 1,79 & 2,49 & 1,95 & 0,96 & 22,02 & 21,69 & 3051312 & 543110 & 1,18 & 0,22 & 8,34 & 0,32 & 0,31 & 0,43 & 0,37 & 0,65 \\
\hline 23007 & 0,07 & 28 & $-20,4$ & 188,73 & 1,6 & 2,4 & 2,06 & 0,77 & 22,46 & 21,94 & 2497889 & 383450 & 0,87 & 0,15 & 7,63 & 0,35 & 0,27 & 0,39 & 0,33 & 0,40 \\
\hline 23316 & 0,06 & 27,6 & $-20,5$ & 205,04 & 2,84 & 3,35 & 1,87 & 0,64 & 22,27 & 22,45 & 2220273 & 338375 & 0,85 & 0,22 & 8,46 & 0,38 & 0,24 & 0,40 & 0,29 & 0,64 \\
\hline 23653 & 0,06 & 26,8 & $-19,9$ & 292,12 & 1,36 & 3,22 & 1,96 & 0,82 & 21,77 & 22,49 & 2310306 & 347800 & 0,66 & 0,15 & 7,7 & 0,36 & 0,29 & 0,40 & 0,25 & 0,89 \\
\hline 24020 & 0,05 & 26,3 & $-20,5$ & 212,19 & 1,48 & 5,92 & 1,66 & 0,71 & 22,37 & 22,87 & 1041418 & 155131 & 0,63 & 0,11 & 8,04 & 0,34 & 0,24 & 0,35 & 0,17 & 0,48 \\
\hline 24421 & 0,05 & 25,5 & $-20,1$ & 212,23 & 2,09 & 1,75 & 1,85 & 0,85 & 21,21 & 21,52 & 2395914 & 358091 & 0,50 & 0,15 & 8,18 & 0,36 & 0,30 & 0,21 & 0,15 & 0,87 \\
\hline 24860 & 0,04 & 25,5 & $-20,2$ & 206,43 & 2,09 & 3,15 & 1,82 & 0,47 & 23,36 & 22,82 & 2500529 & 403627 & 0,69 & 0,11 & 8,86 & 0,28 & 0,13 & 0,08 & 0,20 & 0,04 \\
\hline 25338 & 0,04 & 25,1 & $-20,1$ & 219,07 & 1,68 & 2,28 & 1,85 & 0,49 & 22,71 & 22,84 & 1749938 & 245876 & 2,44 & 0,27 & 9,28 & 0,30 & 0,15 & 0,08 & 0,26 & 0,00 \\
\hline 25853 & 0,04 & 25,6 & $-20,2$ & 179,66 & 1,18 & 2,45 & 2,16 & 0,66 & 23,33 & 22,35 & 1767315 & 266230 & 3,45 & 33,33 & 9,26 & 0,27 & 0,18 & 0,09 & 0,22 & 0,01 \\
\hline 26401 & 0,04 & 26,3 & $-20,2$ & 166,95 & 1,16 & 2,33 & 2,04 & 0,5 & 22,65 & 22,56 & 2123245 & 316066 & 2,44 & 16,67 & 8,47 & 0,31 & 0,15 & 0,09 & 0,29 & 0,04 \\
\hline 26979 & 0,03 & 26,8 & $-20,4$ & 143,13 & 0,96 & 2,65 & 1,86 & 0,51 & 23,18 & 22,49 & 1947189 & 285191 & 3,13 & 0,46 & 8,92 & 0,24 & 0,12 & 0,07 & 0,28 & 0,02 \\
\hline 27581 & 0,03 & 26,8 & $-20,2$ & 219,92 & 1,17 & 5,27 & 1,83 & 0,36 & 22,54 & 23,31 & 1947189 & 285191 & 4,00 & 0,58 & 8,34 & 0,27 & 0,10 & 0,10 & 0,39 & 0,06 \\
\hline 28206 & 0,03 & 27,9 & $-20,3$ & 233,46 & 1,17 & 6,4 & 2,07 & 0,31 & 22,86 & 23,1 & 1624672 & 241506 & 3,70 & 1,22 & 7,79 & 0,30 & 0,09 & 0,11 & 0,33 & 0,06 \\
\hline 28848 & 0,03 & 28,7 & $-20,4$ & 216,48 & 1,68 & 1,6 & 2,34 & 0,84 & 21,75 & 21,91 & 1797224 & 275435 & 2,94 & 1,39 & 7,9 & 0,28 & 0,23 & 0,13 & 0,19 & 0,03 \\
\hline 29504 & 0,03 & 29,4 & $-20,4$ & 243,58 & 1,1 & 4,23 & 2,81 & 0,38 & 22,77 & 23,07 & 1574792 & 239146 & 1,49 & 0,65 & 8,35 & 0,24 & 0,09 & 0,14 & 0,28 & 0,04 \\
\hline 30171 & 0,03 & 29,1 & $-20,2$ & 200,85 & 1,26 & 2,38 & 2,35 & 0,55 & 22,48 & 23,02 & 1580808 & 234047 & 1,96 & 1,64 & 8,01 & 0,29 & 0,16 & 0,15 & 0,36 & 0,03 \\
\hline 30843 & 0,03 & 29,1 & $-20,2$ & 207,72 & 2,4 & 2,05 & 1,7 & 0,41 & 22 & 22,65 & 1607856 & 239582 & 2,38 & 9,09 & 8,94 & 0,31 & 0,13 & 0,11 & 0,19 & 0,03 \\
\hline 31519 & 03 & 2 & $-20,5$ & 66 & 1,86 & 1,47 & 1,99 & 0,85 & 21,84 & 22,18 & 1644653 & 6 & 79 & 0,53 & 8,85 & 0,30 & 25 & 0,09 & 0,20 & 02 \\
\hline
\end{tabular}




\begin{tabular}{|c|c|c|c|c|c|c|c|c|c|c|c|c|c|c|c|}
\hline $\begin{array}{l}\text { Idade } \\
\text { (anos) }\end{array}$ & $\begin{array}{c}\mathrm{R}-\mathrm{COOH} \\
\mathbf{P} \\
\end{array}$ & (Al) & (Ba) & $\begin{array}{c}\text { (Ca) } \\
\mu \mathrm{g} \cdot \mathrm{g}^{-1} \\
\end{array}$ & $(\mathrm{Sr})$ & $(\mathrm{Fe})$ & (Ti) & $\mathrm{Ba} / \mathrm{Al}$ & $\mathrm{Ba} / \mathrm{Ti}$ & $\mathrm{Ba} / \mathrm{Ca}$ & $\mathrm{Al} / \mathrm{Ti}$ & $\mathrm{Sr} / \mathrm{Ti}$ & $\mathrm{Sr} / \mathrm{Ca}$ & $\mathrm{Fe} / \mathrm{Ca}$ & $\mathrm{Ti} / \mathrm{Ca}$ \\
\hline 19950 & 0,16 & 9371 & 15,1 & 52335 & 239 & 18516 & 230 & 0,0016 & 0,0657 & 0,0003 & 40,74 & 1,039 & 0,005 & 0,354 & 0,0044 \\
\hline 20091 & 0,14 & 9367 & 14,1 & 44099 & 297 & 16265 & 181 & 0,0015 & 0,0779 & 0,0003 & 51,75 & 1,641 & 0,007 & 0,369 & 0,0041 \\
\hline 20240 & 0,14 & 12891 & 18,2 & 51730 & 349 & 21088 & 269 & 0,0014 & 0,0677 & 0,0004 & 47,92 & 1,297 & 0,007 & 0,408 & 0,0052 \\
\hline 20400 & 0,14 & 10815 & 15,6 & 43399 & 299 & 18107 & 242 & 0,0014 & 0,0645 & 0,0004 & 44,69 & 1,236 & 0,007 & 0,417 & 0,0056 \\
\hline 20568 & 0,10 & 10830 & 15,7 & 52980 & 355 & 19572 & 224 & 0,0014 & 0,0701 & 0,0003 & 48,35 & 1,585 & 0,007 & 0,369 & 0,0042 \\
\hline 20745 & 0,16 & 9250 & 14,9 & 49689 & 336 & 17361 & 247 & 0,0016 & 0,0603 & 0,0003 & 37,45 & 1,36 & 0,007 & 0,349 & 0,005 \\
\hline 20930 & 0,19 & 9234 & 14,3 & 45450 & 295 & 15852 & 231 & 0,0015 & 0,0619 & 0,0003 & 39,97 & 1,277 & 0,006 & 0,349 & 0,0051 \\
\hline 21123 & 0,19 & 9950 & 14,8 & 45060 & 304 & 17170 & 241 & 0,0015 & 0,0614 & 0,0003 & 41,29 & 1,261 & 0,007 & 0,381 & 0,0053 \\
\hline 21325 & 0,18 & 11393 & 15,6 & 44305 & 305 & 18700 & 246 & 0,0014 & 0,0634 & 0,0004 & 46,31 & 1,24 & 0,007 & 0,422 & 0,0056 \\
\hline 21534 & 0,08 & 8512 & 13,4 & 42972 & 292 & 15795 & 223 & 0,0016 & 0,0601 & 0,0003 & 38,17 & 1,309 & 0,007 & 0,368 & 0,0052 \\
\hline 21750 & 0,07 & 11171 & 15,6 & 47537 & 314 & 18744 & 231 & 0,0014 & 0,0675 & 0,0003 & 48,36 & 1,359 & 0,007 & 0,394 & 0,0049 \\
\hline 21974 & 0,07 & 11358 & 16,5 & 51695 & 345 & 19413 & 270 & 0,0015 & 0,0611 & 0,0003 & 42,07 & 1,278 & 0,007 & 0,376 & 0,0052 \\
\hline 22208 & 0,08 & 12486 & 17,2 & 56295 & 370 & 20606 & 295 & 0,0014 & 0,0583 & 0,0003 & 42,33 & 1,254 & 0,007 & 0,366 & 0,0052 \\
\hline 22456 & 0,09 & 9227 & 13,6 & 40851 & 269 & 15018 & 231 & 0,0015 & 0,0589 & 0,0003 & 39,94 & 1,165 & 0,007 & 0,368 & 0,0057 \\
\hline 22721 & 0,10 & 10354 & 14,8 & 48728 & 316 & 18174 & 225 & 0,0014 & 0,0658 & 0,0003 & 46,02 & 1,404 & 0,006 & 373 & 0,0046 \\
\hline 23007 & 0,09 & 9380 & 15 & 59455 & 387 & 16521 & 230 & 0,0016 & 0,0652 & 0,0003 & 40,78 & 1,683 & 0,007 & 0,278 & 0,0039 \\
\hline 23316 & 0,09 & 9474 & 14,6 & 66205 & 400 & 16515 & 229 & 0,0015 & 0,0638 & 0,0002 & 41,37 & 1,747 & 0,006 & 0,249 & 0,0035 \\
\hline 23653 & 0,09 & 7003 & 11,9 & 65275 & 382 & 12431 & 237 & 0,0017 & 0,0502 & 0,0002 & 29,55 & 1,612 & 0,006 & 0,19 & 0,0036 \\
\hline 24020 & 0,07 & 7101 & 11,3 & 77195 & 414 & 11134 & 208 & 0,0016 & 0,0543 & 0,0001 & 34,14 & 1,99 & 0,005 & 0,144 & 0,0027 \\
\hline 24421 & 0,10 & 7697 & 11,5 & 83395 & 403 & 12494 & 204 & 0,0015 & 0,0564 & 0,0001 & 37,73 & 1,975 & 0,005 & 0,15 & 0,0024 \\
\hline 24860 & 0,01 & 6421 & 10,6 & 79945 & 419 & 11496 & 197 & 0,0017 & 0,0538 & 0,0001 & 32,59 & 2,127 & 0,005 & 0,144 & 0,0025 \\
\hline 25338 & 0,02 & 6556 & 10,5 & 90080 & 450 & 11111 & 188 & 0,0016 & 0,0559 & 0,0001 & 34,87 & 2,394 & 0,005 & 0,123 & 0,0021 \\
\hline 25853 & 0,19 & 7428 & 11,2 & 81415 & 511 & 9968 & 221 & 0,0015 & 0,0507 & 0,0001 & 33,61 & 2,312 & 0,006 & 0,122 & 0,0027 \\
\hline 26401 & 0,02 & 5703 & 9,15 & 83465 & 400 & 10328 & 155 & 0,0016 & 0,059 & 0,0001 & 36,79 & 2,581 & 0,005 & 0,124 & 0,0019 \\
\hline 26979 & 0,01 & 4775 & 8,35 & 75080 & 370 & 9456 & 148 & 0,0017 & 0,0564 & 0,0001 & 32,26 & 2,5 & 0,005 & 0,126 & 0,002 \\
\hline 27581 & 0,07 & 6177 & 9,6 & 95000 & 448 & 11217 & 179 & 0,0016 & 0,0536 & 0,0001 & 34,51 & 2,503 & 0,005 & 0,118 & 0,0019 \\
\hline 28206 & 0,09 & 5936 & 9,65 & 83140 & 415 & 10110 & 176 & 0,0016 & 0,0548 & 0,0001 & 33,73 & 2,358 & 0,005 & 0,122 & 0,0021 \\
\hline 28848 & 0,02 & 5800 & 9,25 & 87125 & 414 & 10750 & 179 & 0,0016 & 0,0517 & 0,0001 & 32,4 & 2,313 & 0,005 & 0,123 & 0,0021 \\
\hline 29504 & 0,07 & 6488 & 10,3 & 85570 & 433 & 11094 & 189 & 0,0016 & 0,0545 & 0,0001 & 34,33 & 2,291 & 0,005 & 0,13 & 0,0022 \\
\hline 30171 & 0,28 & 5461 & 8,95 & 74275 & 371 & 9140 & 152 & 0,0016 & 0,0589 & 0,0001 & 35,93 & 2,441 & 0,005 & 0,123 & 0,002 \\
\hline 30843 & 0,01 & 5892 & 9,7 & 88960 & 446 & 10523 & 178 & 0,0016 & 0,0545 & 0,0001 & 33,1 & 2,506 & 0,005 & 0,118 & 0,002 \\
\hline 31519 & 0,02 & 4526 & 8,25 & 74100 & 339 & 8783 & 146 & 0,0018 & 0,0565 & 0,0001 & 31 & 2,322 & 0,005 & 0,119 & 0,002 \\
\hline
\end{tabular}




\begin{tabular}{|c|c|c|c|c|c|c|c|c|c|c|c|c|c|c|c|c|c|c|c|c|}
\hline $\begin{array}{l}\text { Idade } \\
\text { (anos) }\end{array}$ & $\begin{array}{c}\text { T.S. } \\
\text { (mm.ky-1) }\end{array}$ & S.M. & $\delta^{13} \mathrm{C}$ & $\begin{array}{c}\text { Alq. } \\
\text { (ng.g-1) }\end{array}$ & $\begin{array}{l}\Sigma \mathrm{n} \text {-alc. } \\
\mu \mathrm{g} \cdot \mathrm{g}^{-1}\end{array}$ & IPC & Pri/Fit. & TAR & $\begin{array}{c}\text { TSM - USP } \\
\left({ }^{\circ} \mathrm{C}\right)\end{array}$ & $\begin{array}{c}\text { TSM - UAB } \\
\left({ }^{\circ} \mathrm{C}\right)\end{array}$ & $\begin{array}{l}\text { Clorin. } \\
408 \mathrm{~nm}\end{array}$ & $\begin{array}{l}\text { Clorin. } \\
662 \mathrm{~nm}\end{array}$ & $\begin{array}{l}\text { Álc. } \\
\text { (P/L) }\end{array}$ & $\begin{array}{l}\text { Ác. } \\
\text { (P/L) }\end{array}$ & $\mathrm{C} / \mathrm{N}$ & $\begin{array}{c}\text { Alif. } \\
\text { L }\end{array}$ & $\begin{array}{c}\text { Alif. } \\
\text { P }\end{array}$ & $\begin{array}{c}\mathrm{R}-\mathrm{OH} \\
\mathrm{L}\end{array}$ & $\begin{array}{c}\text { R-OH } \\
\mathbf{P} \\
\end{array}$ & $\begin{array}{c}\mathrm{R}- \\
\mathrm{COOH} \\
\mathrm{L}\end{array}$ \\
\hline 32193 & 0,03 & 29,2 & $-20,2$ & 198,67 & 1 & 4,06 & 1,71 & 0,48 & 22,27 & 22,84 & 1642739 & 242177 & 2,17 & 0,97 & 8,72 & 0,25 & 0,12 & 0,09 & 0,36 & 0,03 \\
\hline 32862 & 0,03 & 28,2 & $-20,1$ & 214,68 & 1,65 & 1,58 & 2,12 & 0,53 & 23,51 & 22,71 & 1727252 & 254370 & 4,17 & 1,69 & 8,04 & 0,34 & 0,18 & 0,12 & 0,26 & 0,06 \\
\hline 33552 & 0,03 & 28 & $-20,4$ & 312,4 & 0,98 & 5,74 & 2,25 & 0,27 & 24,04 & 22,95 & 1643665 & 248606 & 2,17 & 3,23 & 9,09 & 0,29 & 0,08 & 0,09 & 0,25 & 0,07 \\
\hline 34169 & 0,03 & 28 & $-20,3$ & 188 & 1,74 & 1,44 & 2,43 & 0,54 & 22,68 & 23,08 & 1638543 & 241100 & 2,63 & 0,40 & 8,02 & 0,36 & 0,20 & 0,14 & 0,32 & 0,17 \\
\hline 34800 & 0,03 & 26,4 & $-20,5$ & 260,55 & 1,37 & 3,28 & 2,24 & 0,28 & 22,89 & 23,2 & 1744683 & 251903 & 2,33 & 5,88 & 9,31 & 0,38 & 0,11 & 0,14 & 0,32 & 0,17 \\
\hline
\end{tabular}




\begin{tabular}{|c|c|c|c|c|c|c|c|c|c|c|c|c|c|c|c|}
\hline $\begin{array}{l}\text { Idade } \\
\text { (anos) }\end{array}$ & $\begin{array}{c}\mathrm{R}-\mathrm{COOH} \\
\mathbf{P} \\
\end{array}$ & (AI) & (Ba) & $\begin{array}{c}\text { (Ca) } \\
\mu \mathrm{g} \cdot \mathrm{g}^{-1}\end{array}$ & $(\mathrm{Sr})$ & $(\mathrm{Fe})$ & (Ti) & $\mathrm{Ba} / \mathrm{Al}$ & $\mathrm{Ba} / \mathrm{Ti}$ & $\mathrm{Ba} / \mathrm{Ca}$ & $\mathrm{Al} / \mathrm{Ti}$ & $\mathrm{Sr} / \mathrm{Ti}$ & $\mathrm{Sr} / \mathrm{Ca}$ & $\mathrm{Fe} / \mathrm{Ca}$ & $\mathrm{Ti} / \mathrm{Ca}$ \\
\hline 32193 & 0,06 & 6056 & 10,1 & 85255 & 429 & 10419 & 170 & 0,0017 & 0,0594 & 0,0001 & 35,62 & 2,524 & 0,005 & 0,122 & 0,002 \\
\hline 32862 & 0,20 & 6050 & 10,2 & 94020 & 440 & 10604 & 187 & 0,0017 & 0,0545 & 0,0001 & 32,35 & 2,353 & 0,005 & 0,113 & 0,002 \\
\hline 33552 & 0,03 & 6093 & 9,45 & 74355 & 358 & 9709 & 171 & 0,0016 & 0,0553 & 0,0001 & 35,63 & 2,094 & 0,005 & 0,131 & 0,0023 \\
\hline 34169 & 0,98 & 6765 & 10,6 & 96465 & 472 & 11840 & 194 & 0,0016 & 0,0546 & 0,0001 & 34,87 & 2,433 & 0,005 & 0,123 & 0,002 \\
\hline 34800 & 0,98 & 6765 & 10,6 & 96465 & 472 & 11840 & 194 & 0,0016 & 0,0546 & 0,0001 & 34,87 & 2,433 & 0,005 & 0,123 & 0,002 \\
\hline
\end{tabular}


